University of Louisville

ThinkIR: The University of Louisville's Institutional Repository

Electronic Theses and Dissertations

$5-2020$

\title{
Materials-processing relationships for metal fused filament fabrication of Ti-6Al-4V alloy.
}

Paramjot Singh

University of Louisville

Follow this and additional works at: https://ir.library.louisville.edu/etd

Part of the Manufacturing Commons, and the Metallurgy Commons

\section{Recommended Citation}

Singh, Paramjot, "Materials-processing relationships for metal fused filament fabrication of Ti-6Al-4V alloy." (2020). Electronic Theses and Dissertations. Paper 3388.

https://doi.org/10.18297/etd/3388

This Doctoral Dissertation is brought to you for free and open access by ThinkIR: The University of Louisville's Institutional Repository. It has been accepted for inclusion in Electronic Theses and Dissertations by an authorized administrator of ThinkIR: The University of Louisville's Institutional Repository. This title appears here courtesy of the author, who has retained all other copyrights. For more information, please contact thinkir@louisville.edu. 


\title{
MATERIALS-PROCESSING RELATIONSHIPS FOR \\ METAL FUSED FILAMENT FABRICATION
}

OF Ti-6Al-4V ALLOY

\author{
By \\ Paramjot Singh \\ A Dissertation \\ Submitted to the Faculty of the \\ J.B. Speed School of Engineering of the University of Louisville \\ in Fulfillment of the Requirements \\ for the Degree of \\ Doctor of Philosophy \\ in Mechanical Engineering \\ Department of Mechanical Engineering \\ University of Louisville \\ Louisville, Kentucky, United States
}

May 2020 
Copyright 2020 by Paramjot Singh

All Rights Reserved 



\title{
MATERIALS-PROCESSING RELATIONSHIPS FOR METAL FUSED FILAMENT FABRICATION \\ OF Ti-6Al-4V ALLOY \\ By
}

\author{
Paramjot Singh
}

A Dissertation Approved on

April 6, 2020

by the following Dissertation Committee:

Dr. Kunal H. Kate

Dissertation Chair

Dr. Sundar V. Atre

Dissertation Member

Dr. Thomas A. Berfield

Dissertation Member

Dr. Jagannadh Satyavolu

Dissertation Member 


\section{DEDICATION}

This dissertation is dedicated to my parents Kultar Singh and Jaswant Kaur, and my late grandparents Dalip Singh and Harbans Kaur, who supported me through my endeavors in life with their love and encouragement. 


\section{ACKNOWLEDGEMENTS}

At first, I would like to thank my advisor, Dr. Kunal H. Kate, who has been a great mentor and a friend during the course of the study. I really appreciate him providing me the ground to think and execute with his unfailing patience and consistent motivation, this wouldn't have been possible without his support. His unprecedented vision and faith kept me motivated through my journey as a Ph.D. student.

I would also like to thank Dr. Sundar V. Atre, who was always there to provide his guidance and support, and I cherish every discussion we had over the past years. He has been a great role model with exceptional leadership and visionary. With Dr. Kunal H. Kate and Dr. Sundar V. Atre have both contributed to my growth as an individual and as a researcher by setting great example of professionalism.

I would extend my sincere gratitude and thanks to Dr. Vamsi K. Balla who has been a very crucial person in providing guidance and help during his 1-year visit to the University of Louisville and continues to support. I enjoyed all discussions and learning received from his experience. Also, I would thank Dr. Azim Gokce for sharing his expertise, guidance and friendship.

I also want to thank my committee members, Dr. Thomas A. Berfield and Dr. Jagannadh Satyavolu for taking time out of their busy schedule and providing constructive criticism for my research. I would like to extend my gratitude to Dr. Thomas A. Berfield to allow me to use his laboratory facility at times and providing necessary advice. I would like to 
thank Dr. Jacek Jasinski to provide me with the access to facilities at the Conn Center, and answering all of my questions.

I take the opportunity to thank each member of the NASA FABLAB team, Lawrence Hubner, Curtis Hill, Tracie Prater, Christopher Roberts, and others, for giving me the opportunity to work with them on a great project and hold insightful discussions in the review meetings. A very special thanks to Techshot team members Andy Kurk, Brian Gettler, Stephen Tuma, and others for the unparallel trust in my work and helping with all necessary furnace runs and other required testing. I would like to thank Stefan Joens and Bryan Sherman at DSH Technologies for providing insight and help in performing initial sintering experiments. I would also like to thank Andy Shives at Praxair Surface Technologies for meeting Ti-6Al-4V powder requirements. I would also thank Jim Adams from the Material Powder Industries Federation (MPIF) for his generosity and support that allowed me to present at the international conferences. This definitely has contributed to my professional growth and network. I would also like to thank Dr. Randall German for being a great support all the time, providing guidance and advise on the Ti-6Al-4V processing and challenges.

I also want to thank my lab mates and colleagues Dr. Subrata Deb Nath, Dr. Harish Irrinki, Qasim Shaikh, Kavish Sudan, Arul Arumugham, Changwoo Gal, Monica Martinez, Anthony Zalmanov, Dr. Anagh Deshpande, Dr. Alireza Tofangchi, Pu Han and Si Han for their help and support throughout my time at the University of Louisville.

I would like to thank my parents, Kultar Singh and Jaswant Kaur, for their love, support and encouragement. My elder sisters Babaldeep Kaur and her husband Jaspreet Aulakh, 
and Sukhdeep Kaur for their love and constant encouragement. I also want to thank my friends Saransh Gupta, Santosh Rauniyar, Vamsi Krishna, and Adwait Ghike for their support during the journey. 


\section{ABSTRACT \\ MATERIALS-PROCESSING RELATIONSHIPS FOR METAL FUSED FILAMENT FABRICATION \\ OF Ti-6Al-4V ALLOY \\ Paramjot Singh}

April 6, 2020

Additive manufacturing (AM) is at the mainstream to cater the needs for rapid tooling and small-scale part production. The metal AM of complex geometries is widely accepted and promoted in the industry. While several metal AM technologies exist and are matured to a level where expectation in terms of design and properties are possible to realize. But the metal AM suffers from the heavy expense to acquire equipment, isotropic property challenges, and potential hazards to work with loose reactive metal powder.

With this motivation, the dissertation aims to develop the fundamental aspects to print metal parts with bound Ti-6Al-4V powder filaments with the approach of metal fused filament fabrication $\left(\mathrm{MF}^{3}\right)$. Since fused filament fabrication (FFF) is the most accessible form of AM technology and combining with the conventional sintering process yields the advantage of producing net shape parts to the well-established standards. Ti-6Al-4V is the material of most interest in the aerospace, medical and automotive industry due to its high strength to weight ratio, great corrosion resistance, and bio-inert nature. In order to fabricate three-dimensional components from $\mathrm{Ti}-6 \mathrm{Al}-4 \mathrm{~V}$ using the $\mathrm{MF}^{3}$ process, it is 
critical to understand and address material, process, and design-related constraints to meet end properties. The goal of this dissertation is to establish a fundamental understanding of the $\mathrm{MF}^{3}$ process with Ti- $6 \mathrm{Al}-4 \mathrm{~V}$ alloy, to produce parts with comparable properties to the traditional process of metal injection molding (MIM). The effect of Ti-6Al-4V particle size distribution on material printability and the process productivity with $\mathrm{MF}^{3}$ is studied with modeling and experimental observations. It was inferred that bound filament viscosity and strength properties are crucial to its printability and processing rate limits. The Ti-6Al-4V particle size variations were also investigated after printing for the effect of sintering conditions to evaluate the resulting physical, mechanical and microstructural properties. It was found that maintaining a low oxygen concentration in the starting powder and throughout the processing, cycle is crucial to obtain useful mechanical properties with $\mathrm{MF}^{3}$ of Ti-6Al-4V.

When designing parts for $\mathrm{MF}^{3}$ (DfMF ${ }^{3}$ ), it is important to understand how the filament properties affect processability, part quality, and ensuing properties. But there doesn't exist any database containing powder-polymer material properties and generating data via experiments can be expensive and time taking. A part of the dissertation investigated models that can predict powder-polymer material properties which are required as input parameters for simulating the $\mathrm{MF}^{3}$ using the Digimat- $\mathrm{AM}^{\circledR}$ process design platform for fused filament fabrication. Here, Ti-6Al-4V powder-binder feedstock at powder loading from 56-60 vol.\% was used to predict properties such as density, specific heat, thermal conductivity, Young's modulus, viscosity, and specific volume. Thus, estimated material properties served as an input parameter to conduct $\mathrm{DfMF}^{3}$ simulations to understand material-processing-geometry interactions. 
TABLE OF CONTENTS

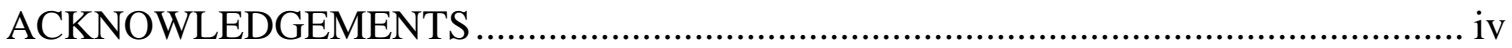

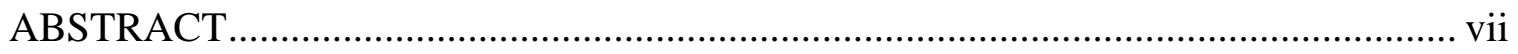

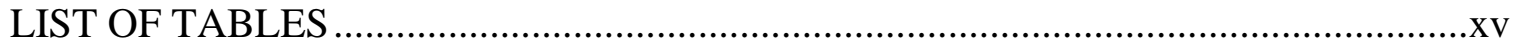

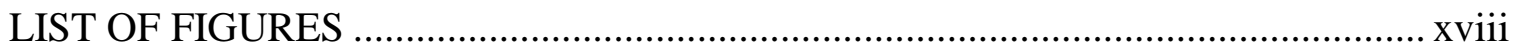

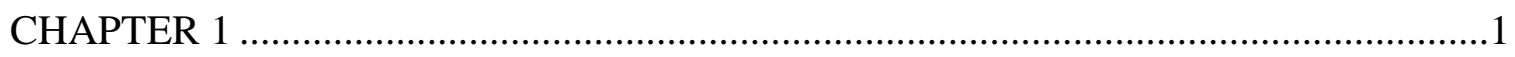

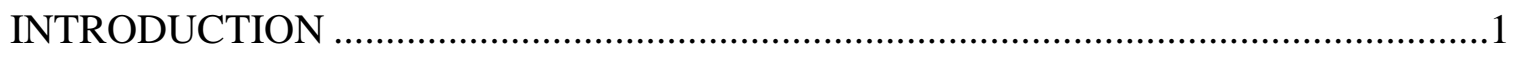

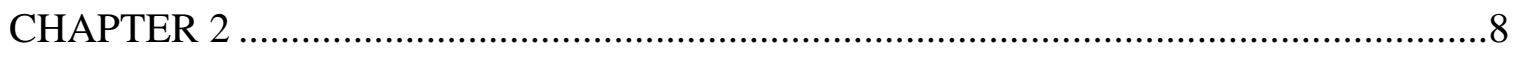

METAL FUSED FILAMENT FABRICATION $\left(\mathrm{MF}^{3}\right)$ OF Ti-6Al-4V .........................

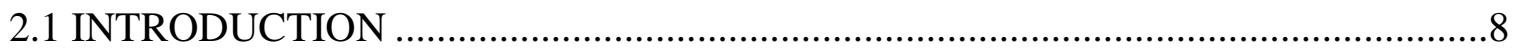

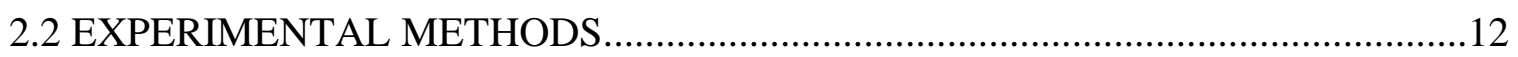

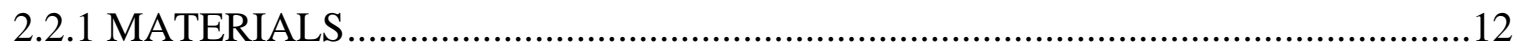

2.2.2 FEEDSTOCK PREPARATION AND CHARACTERIZATION ..........................13

2.2.3 FILAMENT EXTRUSION AND MF ${ }^{3}$ PRINTING ..........................................14

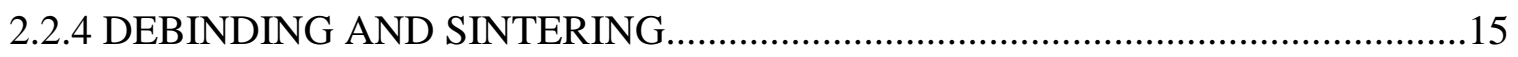

2.2.5 PHYSICAL, MECHANICAL AND MICROSTRUCTURAL

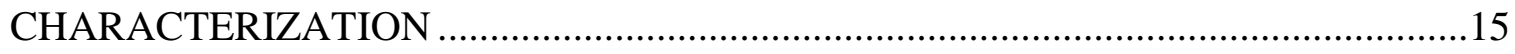

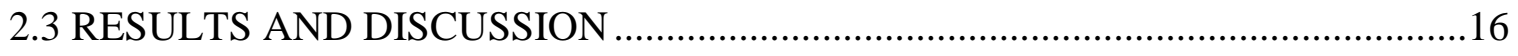


CHAPTER 3

PRINTABILITY STUDIES OF Ti-6Al-4V BY METAL FUSED FILAMENT

FABRICATION $\left(\mathrm{MF}^{3}\right)$

3.1 INTRODUCTION

3.2.1 FILAMENT PREPARATION AND CHARACTERIZATION 
CHAPTER 4

FACTORS AFFECTING DENSITY AND RELATED PROPERTIES OF Ti-6Al-4V ALLOY WITH METAL FUSED FILAMENT FABRICATION $\left(\mathrm{MF}^{3}\right)$..........................57

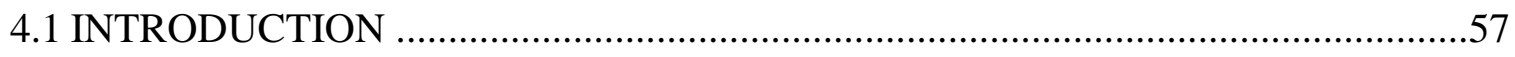

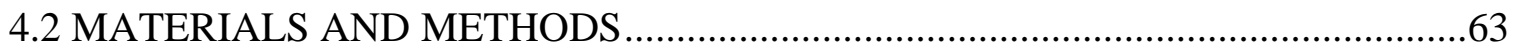

4.2.1 POWDER-BINDER FEEDSTOCK-FILAMENT DEVELOPMENT ......................63

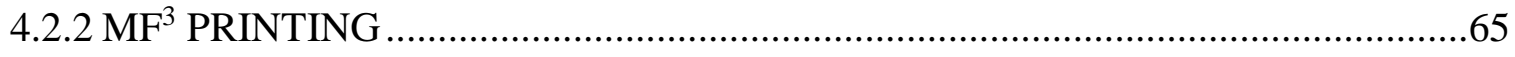

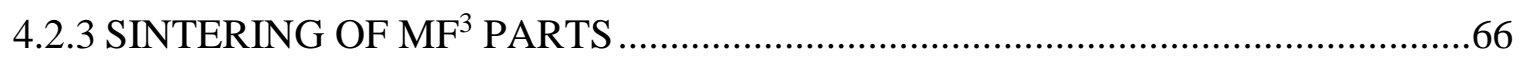

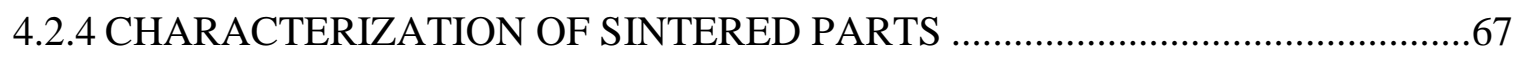

4.3 RESULTS AND DISCUSSIONS ……………………....................................68

4.3.1 FEEDSTOCK CHARACTERISTICS ………………….................................68

4.3.2 EFFECT OF EXTRUSION TEMPERATURE ON FILAMENT PROPERTIES ....70

4.3.3 EFFECT OF PRINT PARAMETERS ON PART QUALITY ………………….....73

4.3.4 EFFECT OF SINTERING CONDITIONS ON THE MF³ PART PROPERTIES ...78

4.3.5 EFFECT OF PARTICLE SIZE ON SINTERED PROPERTIES OF Ti-6Al-4V .....83

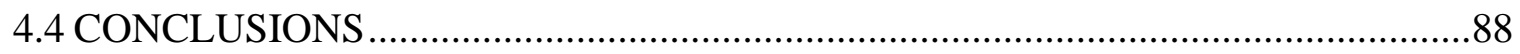

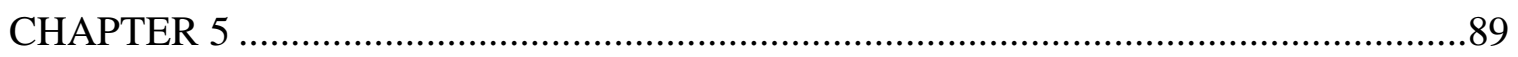

ESTIMATING POWDER-POLYMER MATERIAL PROPERTIES USED IN DESIGN FOR METAL FUSED FILAMENT FABRICATION $\left(\right.$ DFMF $\left.^{3}\right)$.......................................

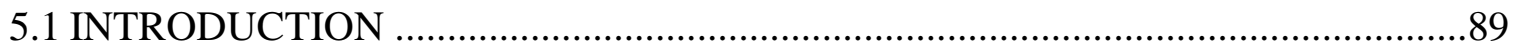


5.3 MATERIALS AND EXPERIMENTAL METHODS ………………….....................96

5.4 ESTIMATING PROPERTIES OF POWDER-POLYMER MIXTURES ....................98

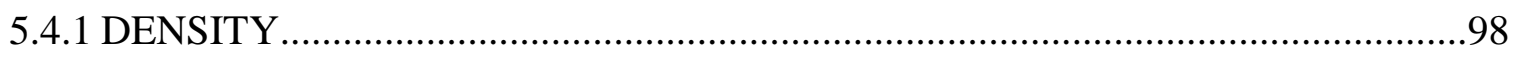

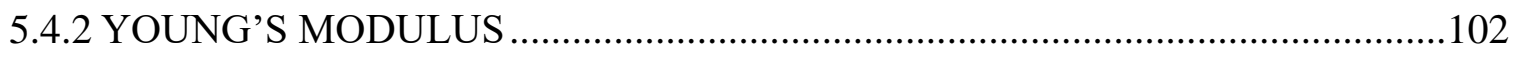

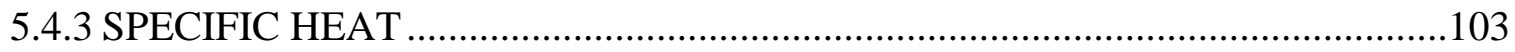

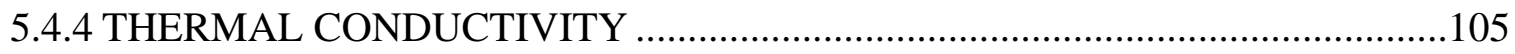

5.4.5 COEFICIENT OF THERMAL EXPANSION (CTE) ……………………............106

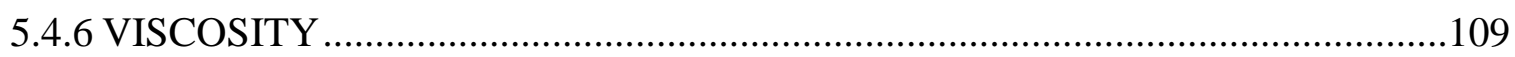

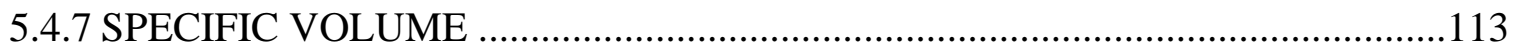

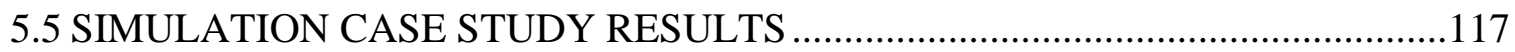

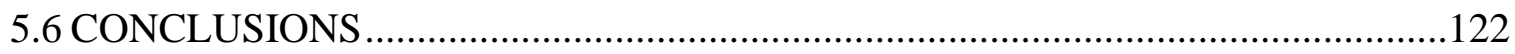

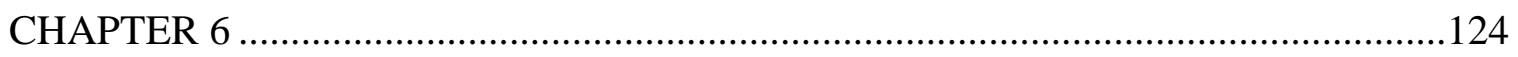

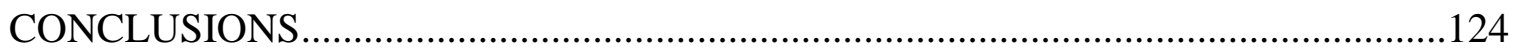

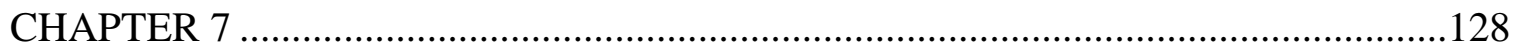

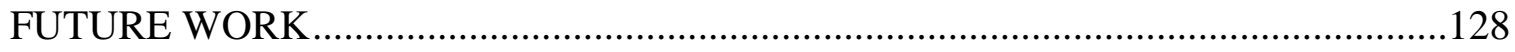

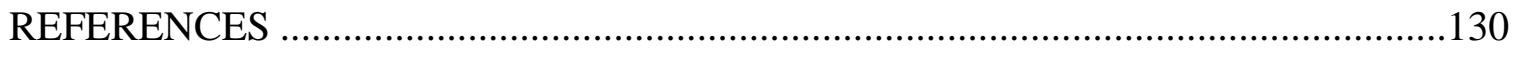

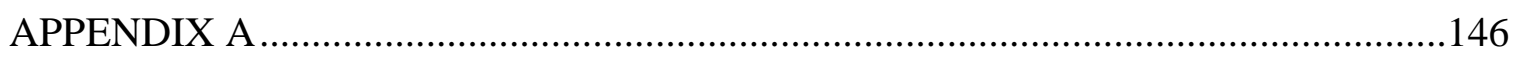

INFLUENCE OF POWDER CHARACTERISTICS ON THE PROPERTIES OF

LASER-POWDER BED FUSION PROCESSED Ti-6Al-4V .......................................146 


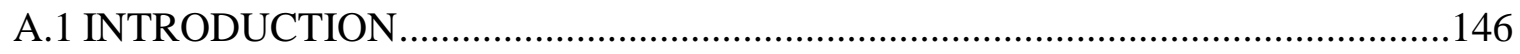

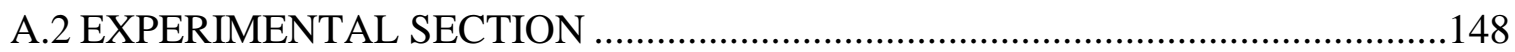

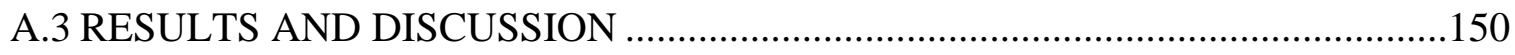

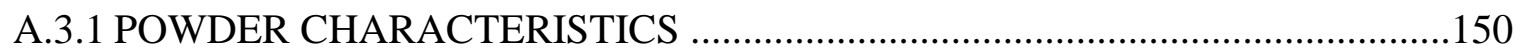

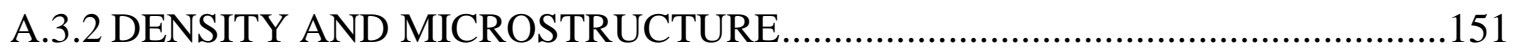

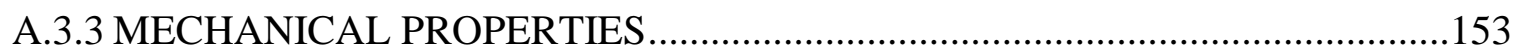

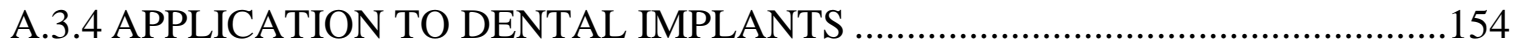

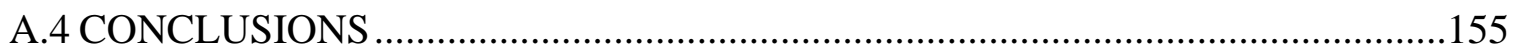

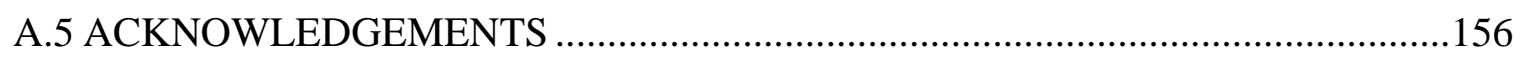

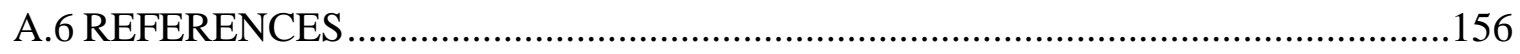

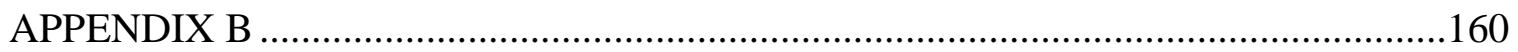

ESTIMATION OF EXTRUSION-BASED 3D PRINTING PROCESS WITH

VISCOSITY-SHEAR-RATE MEASUREMENTS FOR POWDER-FILLED

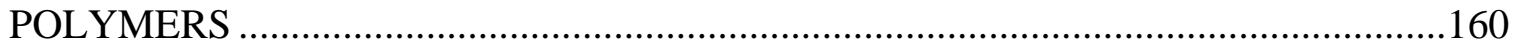

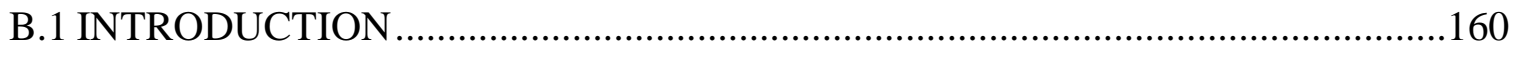

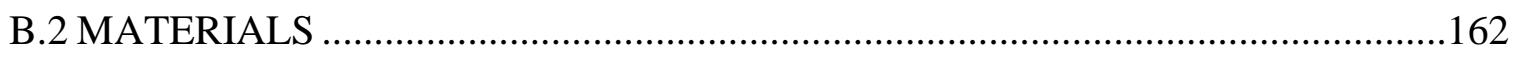

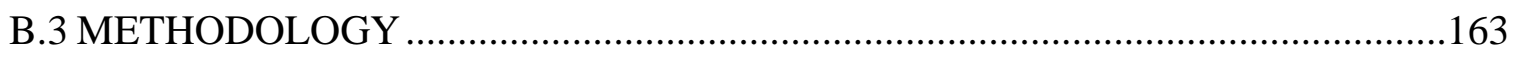

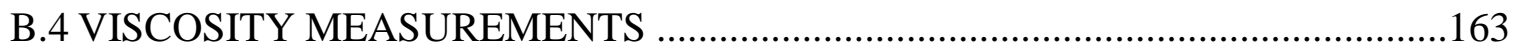

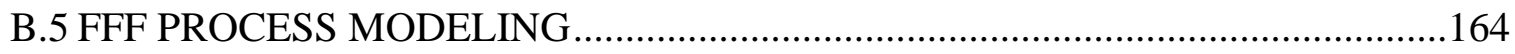

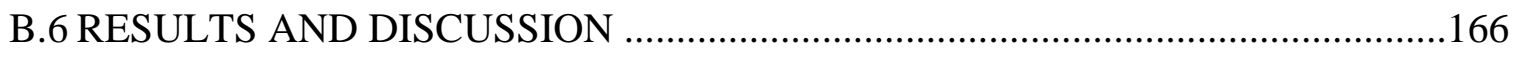


B.6.2 3D PRINTING

B.6.3 EFFECT OF EXTRUSION MASS FLOW RATE .170

B.6.4 EFFECT OF 3D PRINTING PROCESS TEMPERATURE .171

B.7 CONCLUSIONS .171

B.8 REFERENCES

APPENDIX C .173

NASA FABLAB REPORTS .173

C.1 INTRODUCTION...

CURRICULUM VITAE. .185 


\section{LIST OF TABLES}

Table 2.1. Properties of Ti-6Al-4V components fabricated using several manufacturing

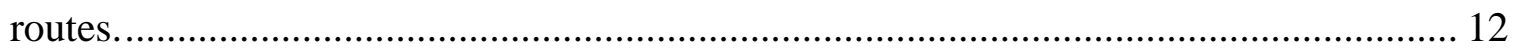

Table 2.2. Characteristics of Ti-6Al-4V alloy powder used in this investigation. ........... 18

Table 2.3. Dimensional tolerance of the printed parts for Ti-6Al-4V using the $\mathrm{MF}^{3}$ process.

Table 2.4. Physical and mechanical properties of sintered $\mathrm{MF}^{3}$ Ti-6Al-4V parts........... 26

Table 3.1. Ti-6Al-4V powder size distribution and density attributes. ......................... 38

Table 3.2. Mechanical properties of filaments with 59 vol.\% Ti-6Al-4V powder........... 47

Table 3.3. Viscosity and filament strength parameters obtained for ABS, B1, and B2, to

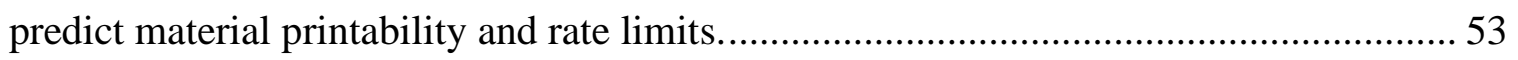

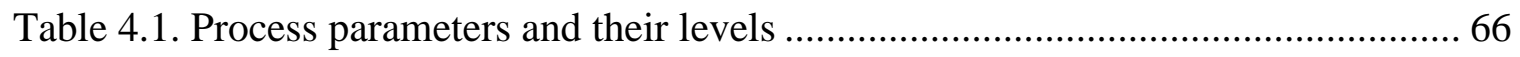

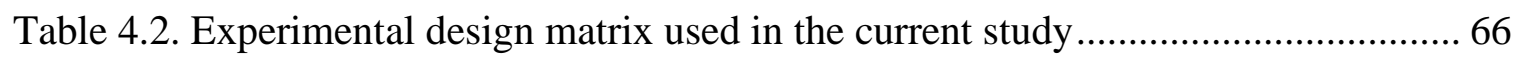

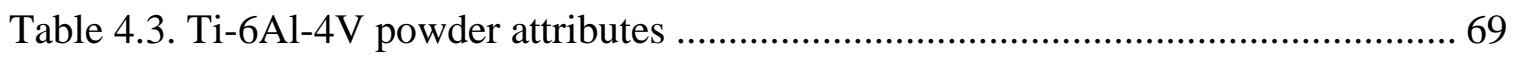

Table 4.4. ANOVA analysis for relative density (\%) of printed geometries.................. 76

Table 4.5. ANOVA analysis for dimensional change $(\%)$ between printed and CAD file

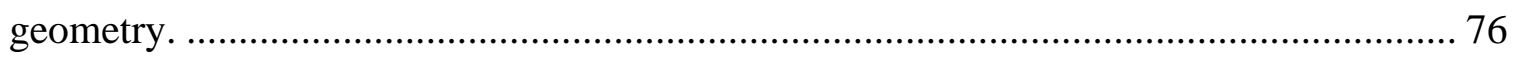

Table 5.1. Material properties of Ti-6Al-4V alloy at room temperature ........................ 95

Table 5.2. Experimental methods and respective ASTM standard for measuring the

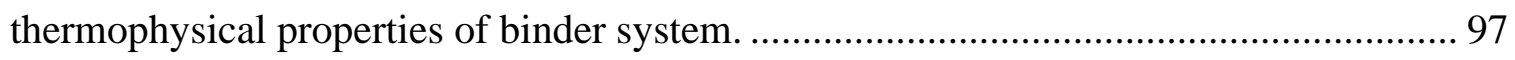


Table 5.3. Experimentally determined binder thermophysical properties. 101

Table 5.4. Estimated specific heat of Ti-6Al-4V powder-binder feedstock with different filler volume fractions for several temperatures. A volume fraction of 1 represents the specific heat of Ti-6Al-4V at different temperatures collected from literature sources. 104

Table 5.5. Estimated thermal conductivity of Ti-6Al-4V powder-binder feedstock with different filler volume fractions for several temperatures. A volume fraction of 1 represents the thermal conductivity of Ti-6Al-4V at different temperatures collected from literature sources 106

Table 5.6. Estimated viscosity of Ti-6Al-4V powder-binder feedstock with different filler volume fractions at different temperatures and shear rates. 111

Table 5.7. Estimated Cross-WLF constants to determine viscosity at varying shear-rates and temperatures for binder and 0.59 volume fraction $\mathrm{Ti}-6 \mathrm{Al}-4 \mathrm{~V}$ powder in the binder feedstock. 112

Table 5.8. Estimated specific volume of Ti-6Al-4V powder-binder feedstock with different filler volume fractions at different temperatures, and pressure of $0 \mathrm{MPa}$ and $50 \mathrm{MPa}$. 115

Table 5.9. Estimated dual-domain Tait constants for Ti-6Al-4V powder-binder feedstock at 0 and 0.59 volume fractions. 117

Table 5.10. Thermophysical properties of some metals used in $\mathrm{MF}^{3}$ : data taken from the reference [53]. 122

Table A.1. Literature to compare Ti-6Al-4V properties produced by powder with different production method (GA: gas atomized, PA: plasma atomized, NA: not available) ....... 148

Table A.2. Powder particle size and measured density. 151

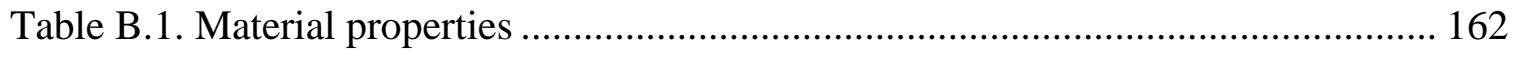

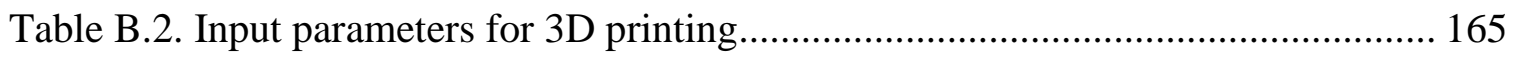

Table B.3. Process modeling for FFF of unfilled and metal filled systems.................. 169 
Table C.1. Pycnometer measured Ti-6Al-4V feedstock density compared to estimated

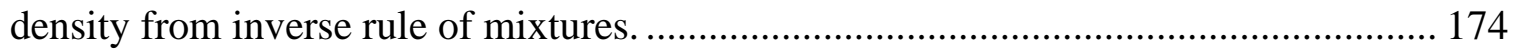




\section{LIST OF FIGURES}

Figure 2.1. Overview of the $\mathrm{MF}^{3}$ process used in the present study to fabricate Ti-6Al-4V parts.

Figure 2.2. X-ray diffraction pattern for Ti-6Al-4V powder consisting of primary $\alpha$ phase with an inset of the SEM image revealing the spherical morphology of particles.

Figure 2.3. a. Effect of solids loading on mixing torque, b. Influence of temperature and shear rate on the viscosity of Ti-6Al-4V feedstock (59 vol.\%) prepared in this work. .... 20

Figure 2.4. SEM images of the filament showing powder distribution, powder-polymer interface and filament surface morphology. 21

Figure 2.5. a. CAD file dimensions for tablet and tensile bar, b. (Top) Sliced file for MF3 process showing printing paths for infill and perimeter, (bottom) Typical MF3 printed tablet and tensile bar in green state, c. SEM of green part revealing uniform powder-

polymer distribution. 23

Figure 2.6. Thermogravimetric analysis of the Ti-6Al-4V to understand polymer decomposition. 26

Figure 2.7. a. Sintered tensile sample representing directional orientation along $\mathrm{X}-\mathrm{Y}-\mathrm{Z}$ axis exhibiting $\alpha$ and $\beta$ phases determined by XRD analysis, b. Sintered and polished part microstructure along XY-YZ-XZ plane, with high magnifications (right image) highlighting Widmanstatten microstructure, c. Fracture surface of the tensile tested samples showing the presence of fine dimples, consistent with ductile fracture 28

Figure 2.8. Various green and sintered parts with the MF3 process...... 29

Figure 3.1. Schematic of MF3 process for Ti-6Al-4V 32 
Figure 3.2. a. MF3 process mechanism with filament being fed into the liquefier, b. Ti6Al-4V-polymer filament under printing conditions without any failures, c. Ti-6Al-4Vpolymer filament failure under shear, d. Inconsistent extrusion due to Ti-6Al-4V-polymer filament slip between feeding rolls. 34

Figure 3.3. SEM of fine $\{\mathrm{D} 50(13 \mu \mathrm{m})\}$ and coarse $\{\mathrm{D} 50(30 \mu \mathrm{m})\}$ Ti-6Al-4V powders used in this study. 39

Figure 3.4. Momentum balance performed on the three sections of the nozzle geometry to determine the overall pressure drop. 41

Figure 3.5. Influence of shear rate on the feedstock viscosity for 59 vol.\% fine and coarse Ti-6Al-4V powder at $240{ }^{\circ} \mathrm{C}$.

Figure 3.6. a. Knurled wheel drive mechanism used to feed the filament into the liquefier representing tooth engagement onto the filament surface, b. Indentation marks on the filament surface used to calculate the shear area. 47

Figure 3.7. The force required to overcome the pressure drop for estimated and experimental cases. The horizontal line represents the maximum force the filament can sustain before failure. The vertical line shows the limiting feed rates for successful material extrusion and printing. a. Fine powder filament, b. Coarse powder filament. 48

Figure 3.8. Effect of feed rate on the, a. printed geometry. b. printed part weight (Dotted line indicates expected part weight of $1.5 \mathrm{~g}$ ). 51

Figure 3.9. a. Variation of viscosity with shear rate of ABS (black), B2 (green), and B1 (red) feedstocks at $240{ }^{\circ} \mathrm{C}$, b. Estimated force determined from pressure drop calculations evaluated against the horizontal line representing limiting force a filament sustain prior to failure. 54

Figure 4.1. Metal fused filament fabrication of Ti-6Al-4V process overview and achievable properties $\{$ literature reference for MIM [28, 30, 31, 74] \}. 59 
Figure 4.2. Critical effects of low-density filaments on green part density and the importance of printing parameters on the defects generated in the green parts which are carried forward to sintered parts produced using $\mathrm{MF}^{3}$ 61

Figure 4.3. a. Effect of filament extrusion temperature on the morphology and density of coarse powder Ti-6Al-4V feedstock at 59 vol.\%, b. effect of extrusion temperature on the diameter, c. effect of extrusion temperature on the surface roughness 72

Figure 4.4. Influence of printing parameters on the quality of MF3 parts. 74

Figure 4.5. Main effects plot for the effect of layer height, extrusion multiplier, and overlap, on a. density, b. dimensions. 77

Figure 4.6. A cross-sectional view of the parts with the lowest (left) and highest (right) density from the design of experiment results. 78

Figure 4.7. a. Effect of printed green part density on the sintered density for coarse Ti-6Al$4 \mathrm{~V}, \mathrm{~b}$. Effect of hold time and temperature on the sintered density of coarse Ti-6Al-4V.80

Figure 4.8. Effect of sintered density on the a. UTS, b. elongation, and the effect of oxygen content on the c. UTS, d. elongation. 82

Figure 4.9. a. Effect of sintering time and temperature on the density of fine and coarse powder MF3 parts, b. Effect of sintered density on the UTS of fine and coarse powder parts, c. Effect of sintered density on the elongation of fine and coarse powder parts..... 85

Figure 4.10. a. The microstructure of the etched MF3 sintered samples for fine Ti-6Al-4V powder, $b$. The microstructure of the etched MF3 sintered samples for coarse Ti-6Al-4V powder, c. Fracture surface analysis for MF3 samples with fine (left) and coarse (right) Ti$6 \mathrm{Al}-4 \mathrm{~V}$ powder. 87

Figure 5.1. a. Process overview for $\mathrm{MF}^{3}$ with examples of fabricated Ti-6Al-4V parts by our group and $b$. the present work for determining the input material parameters for conducting DfMF $^{3}$. 90 
Figure 5.2. Typical defects observed during MF3 process of Ti-6Al-4V alloy system fabricated by our group showing a. dark regions representing pores within a cut-cross section of a powder-polymer filament, b. gaps between layers within an MF3 fabricated green part, c. crack propagation observed after debinding and d. presence of pores present in the sintered $\mathrm{MF}^{3}$ part. 92

Figure 5.3. Estimated (a) density, and (b) Young's modulus for Ti-6Al-4V filler-binder feedstock at different volume fractions 100

Figure 5.4. Estimated thermal properties of composite Ti-6Al-4V powder-binder feedstock at different volume fractions for: a. specific heat as a function of temperature, and b) thermal conductivity as a function of temperature, and c. coefficient of thermal expansion. 108

Figure 5.5. Estimated viscosity of the Ti-6Al-4V powder-binder feedstock for a shear rate of $20-1600 \mathrm{~s}-1$ at (a) $413 \mathrm{~K}$ and (b) $423 \mathrm{~K}$ with different volume fractions. 109

Figure 5.6. Estimated specific volume of Ti-6Al-4V powder-binder feedstock at different filler volume fractions for (a) $0 \mathrm{MPa}$ and (b) $50 \mathrm{MPa}$. 114

Figure 5.7. Experimental and simulation result verifications using estimated values: a) CAD file for ASTM E8 tensile sample with dimensions, b) Simulation of the part using the estimated material properties for 59 vol.\% Ti-6Al-4V + binder feedstock c) Printed green parts with 0.59 vol. \% of Ti-6Al-4V + binder feedstock, d) Simulation of the ABS part using the available material database in Digimat-AM ${ }^{\circledR}$, e) Printed part with ABS material filament, f) Warpage analysis resulting from experiments and simulation for 59 vol.\% Ti$6 \mathrm{Al}-4 \mathrm{~V}+$ binder feedstock and ABS. 118

Figure 5.8. Dimensions for an ASTM E8 tensile sample obtained from simulations and experiments for 59 vol. \% solids loading Ti-6Al-4V feedstock and ABS. 120

Figure 5.9. Examples for Digimat-AM® simulations that show typical outputs such as (a) warpage, and (b) residual stress in case studies for parts an end-of-arm tool (top) and automotive brake lever (bottom). 121 
Figure A.1. ASTM E8 tensile bar geometry printed on the Concept Laser Mlab. 149

Figure A.2. (a) SEM of the Ti-6Al-4V powder, (b) XRD of the Ti-6Al-4V powder..... 151

Figure A.3. Micrographs of L-PBF printed Ti-6Al-4V parts along the build and scan directions are two magnifications; (a,c) along build direction revealing columnar grains at low magnification and the acicular $\alpha$ martensite at higher magnification, $(b, d)$ along the scan direction showing equiaxed grains at low magnification. 152

Figure A.4. Comparison of the mechanical properties of Ti-6Al-4V samples produced by textured powder in the current study, and literature on L-PBF of gas and plasma atomized powder, MIM and wrought properties. 154

Figure A.5. Dental implant prototypes with pore size of 100 and $400 \mu \mathrm{m}$ printed with LPBF (a) printed parts in actual scale and two times scaled up version, (b) threaded geometry on the implant, (c) pores on the implant surface measuring $400 \mu \mathrm{m}$. 155

Figure B.1. Hollow square $(30 \mathrm{~mm} \times 30 \mathrm{~mm})$ with $0.5 \mathrm{~mm}$ thickness 165

Figure B.2. Thermogravimetric Analysis to determine the homogeneous powder-binder distribution. 167

Figure B.3. (a) Electron microscopy image for the bronze powder, (b) filaments with 70 wt.\% \& 80 wt.\% bronze in the binder, (c) FFF process with metal filament 3D printing, (d) printed parts with $80 \mathrm{wt} . \%$ bronze. 168

Figure B.4. Viscosity measurements at varying shear rate for PLA, at $210^{\circ} \mathrm{C}$, and Bronze filled system at $210{ }^{\circ} \mathrm{C} \& 250{ }^{\circ} \mathrm{C}$.

Figure C.1. Viscosity measured at $140{ }^{\circ} \mathrm{C} \& 160{ }^{\circ} \mathrm{C}$ with a shear rate of $20-160 \mathrm{~s}^{-1}$ for Ti$6 \mathrm{Al}-4 \mathrm{~V}$ coarse powder at different loadings. 173

Figure C.2. Results from TGA relate the residual weight to the initial powder added to the binder. 174

Figure C.3. $\mathrm{MF}^{3}$ printed geometries and their dimensional analysis. 175 
Figure C.4. Taguchi design of experiments (DOE) to find the effect of solids loading (vol.\%), extrusion multiplier (FR\%), and melt temperature $\left({ }^{\circ} \mathrm{C}\right)$ on $\mathrm{MF}^{3}$ parts sintered at $1300^{\circ} \mathrm{C}$ for 3 hours.

Figure C.5. Green density and sintered density of the $\mathrm{MF}^{3}$ parts, with " $\mathrm{D}$ " signifying the experiment DOE number (reference Figure C.4). 176

Figure C.6. Linear shrinkage along $\mathrm{X}, \mathrm{Y}$, and $\mathrm{Z}$ axis for $\mathrm{MF}^{3}$ parts with numbers indicating the DOE condition. 176

Figure C.7. Surface roughness for $\mathrm{MF}^{3}$ sintered parts with numbers indicating the DOE condition. 177

Figure C.8. Sintered defects in $\mathrm{MF}^{3}$ parts along the $\mathrm{Z}$ plane (perpendicular to the build direction). 177

Figure C.9. Sintered defects in MF3 parts along the X-Y plane (parallel to the build direction). 178

Figure C.10. Viscosity measured at $140{ }^{\circ} \mathrm{C} \& 160{ }^{\circ} \mathrm{C}$ with a shear rate of $20-160 \mathrm{~s}^{-1}$ for Ti-6Al-4V coarse powder with a different binder composition (B1). 178

Figure C.11. Ti-6Al-4V MF${ }^{3}$ feedstock viscosity at a constant shear rate of $50 \mathrm{~s}^{-1}$ at 140 ${ }^{\circ} \mathrm{C}$, to enable homogeneity assessments. 179

Figure C.12. Sintering of filament samples at different temperatures. 179

Figure C.13.Complex geometries printed with $\mathrm{MF}^{3}$ using 59 vol.\% Ti-6Al-4V filament. 180

Figure C.14. $\mathrm{MF}^{3}$ sintered honeycomb structure. 180

Figure C.15. Effect of hot iso-static pressing (HIP) on $\mathrm{MF}^{3}$ part density for Ti-6Al-4V coarse and fine powder. 181

Figure C.16. Effect of hot iso-static pressing (HIP) on $\mathrm{MF}^{3}$ sample UTS for Ti-6Al-4V coarse and fine powder. 181 
Figure C.17. Effect of hot iso-static pressing (HIP) on $\mathrm{MF}^{3}$ sample elongation for Ti-6Al-

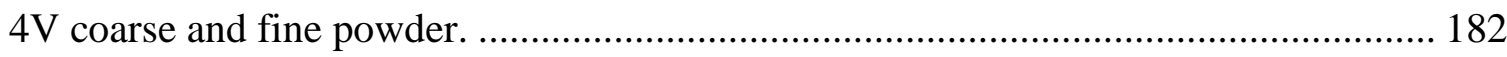

Figure C.18. Effect of hot iso-static pressing (HIP) on the coarse Ti-6Al-4V MF ${ }^{3}$ sample

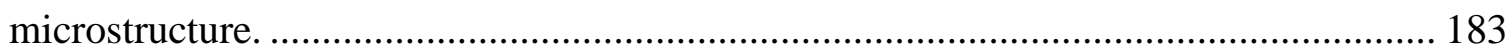

Figure C.19. Effect of hot iso-static pressing (HIP) on the fine Ti-6Al-4V MF ${ }^{3}$ sample

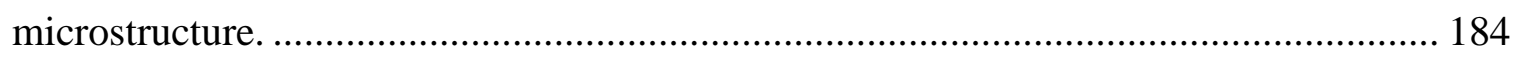




\section{CHAPTER 1}

\section{INTRODUCTION}

The process of producing net shape parts using layer-by-layer deposition named "additive manufacturing (AM)" has evolved to a stage where it is being effectively used to produce application-specific end-user parts. The implications of additive processes with both polymers and metals are wide in the aerospace, automotive, medical, and consumer product industries. Currently, a wide variety of metal AM technologies exists for metal part production that includes laser powder bed fusion (L-PBF), direct energy deposition (DED) and electron beam melting (EBM), and binder jetting. These processes involve very high initial capital investment and fabricating parts with such processes come with its unique challenges and safety concerns due to the involvement of direct working with loose reactive metal powder.

Powder bed-based AM processes that use high power laser/electron beam and melt the interacting metal particles, fusing them through the manipulations of process parameters are comparatively in the more advanced state when compared with fused filament fabrication-based AM to manufacture metal parts. However, these AM technologies still face certain challenges due to high thermal gradients, localized heat, and rapid cooling rates which induce residual stresses, non-equilibrium microstructures, and microstructural anisotropy leading to structural property differences $[1,2]$. On the other hand, binder jetting 
produces high-resolution parts but suffers complications arising from the powder bed density variations between inter and intra layers, limited material choices, binder-powder compatibility, de-powdering of green parts, low-density, etc. [3].

Alternatively, the fused filament fabrication $(\mathrm{FFF})$ is a well-studied process for polymers and commercially being widely used with printers costing from $\$ 200$ up to $\$ 500000$. This makes it the most accessible form of AM technology compared to other technologies. The current work presented in this dissertation developed a hybrid FFF process called Metal fused filament fabrication $\left(\mathrm{MF}^{3}\right)$ that can effectively fabricate metal parts and the process has been demonstrated to manufacture Ti-6Al-4V alloy parts. The $\mathrm{MF}^{3}$ process is a hybrid additive manufacturing technique which essentially combines FFF and Metal Injection Molding (MIM) processes. The process involves filled metal-polymer filament which is printed and subsequently thermally processed to remove polymer (debinding) and densifying (sintering) to produce mechanically strong metal components. $\mathrm{MF}^{3}$ offers potential benefits of eliminating loose powder health hazards and producing isotropic parts utilizing traditional knowledge from MIM. As a result, there is a growing interest in $\mathrm{MF}^{3}$ based processes. Currently, there are two commercial companies such as Markforged, and Desktop Metal that uses the $\mathrm{MF}^{3}$ process to fabricate metal components [4, 5]. However, in addition to the limited list of materials available on their portfolio which includes 17-4 PH stainless steel, 316 stainless steel, tool steel grades, copper, and Inconel 625, the fundamental understanding of the process is still lacking in the community. 
The current work, therefore, aims to use Ti-6Al-4V alloy as a basis to develop powderpolymer feedstock, filaments, parts, debinding and sintering processes for $\mathrm{MF}^{3}$ followed by evaluation of Ti-6Al-4V alloy components thus produced. Titanium and its alloys are great candidates for applications requiring high specific strength, biocompatibility, good corrosion resistance [6]. Typically, subtractive processing of titanium incurs heavy costs, and the aerospace terminology states titanium has a buy-to-fly ratio of 12:1 [7]. For example, the buy-to-fly ratio for the F-22 fighter jet is $12.2: 1$, meaning $82 \%$ of the material is scrapped [6]. Thus, AM became an attractive tool to process Ti-based alloys. Unalloyed titanium has two allotropic forms i.e., at low temperature it exists in $\alpha$ (hcp-hexagonal close-packed crystal structure) structure and above $882{ }^{\circ} \mathrm{C}$ it transforms into $\beta$ (bcc-body centered cubic crystal structure) structure. The addition of alloying elements can either stabilize the $\alpha$ phase by raising the transition temperature or stabilize $\beta$ phase by lowering the transition temperature. Ti- $6 \mathrm{Al}-4 \mathrm{~V}$ alloy is a $\alpha-\beta$ alloy, with $6 \mathrm{wt} \%$ aluminum as $\alpha$ stabilizer and $4 \mathrm{wt} . \%$ vanadium as $\beta$ stabilizer. The microstructure of the alloy at room temperature strongly depends on the cooling rates experienced by the alloy during processing. With slow cooling rates from the $\beta$-transition temperature $\left(995{ }^{\circ} \mathrm{C}\right)$, the $\beta$ transforms into globular $\alpha$ and with faster cooling rates the $\alpha$ nucleation starts leading to growth of $\alpha$ platelets in the prior- $\beta$ grains. The amount of these two phases, the grain size, and their aspect ratio are closely linked to the mechanical properties. As a result, microstructural control is extremely important to achieve desired mechanical properties in Ti-6Al-4V alloy. 
$\mathrm{MF}^{3}$ has been used to process some materials that include $316 \mathrm{~L}$ stainless steel $[8,9], 17-4$ PH stainless steel [4, 10], W-Cr [11], and WC-Co [12]. Until now there is no literature or no commercial work available on the processing of Ti-6Al-4V alloy using $\mathrm{MF}^{3}$. Further, the fundamental understanding of the process is still lacking in the community. The current dissertation investigates the material-process-property interrelationships of $\mathrm{MF}^{3}$ processed Ti-6Al-4V alloy. The focus of the work was to determine the process physics for material printability, physical, mechanical and microstructural properties with two different gas atomized Ti-6Al-4V powder size distributions.

CHAPTER 2 presents an introduction to the $\mathrm{MF}^{3}$ of Ti-6Al-4V process, followed by effective powder-binder feedstock preparation for the filament fabrication, printing to attain high green density parts, process optimization for complete binder removal and sintering to achieve desired mechanical and microstructural properties. The results from the study provide important insights on the $\mathrm{MF}^{3}$ process and its ability to produce parts with properties such as $875 \pm 15 \mathrm{MPa}$ with $17 \pm 3 \%$ elongation, at $94.1 \pm 0.1 \%$ relative density, which are comparable to traditional MIM processed parts. The results presented in CHAPTER 2 contribute towards a manuscript that is being submitted to the Materials Today journal.

CHAPTER 3 investigates the influence of filament-feedstock properties on successful extrusion and printing with metal filled filaments in $\mathrm{MF}^{3}$. An approach has been presented to estimate the pressure drop for a given liquefier-nozzle geometry utilizing data from 
viscosity measurements and other geometrical parameters of the liquefier channel. Then, the force required to overcome the pressure drop was determined and compared with the force sustained by the filament before the onset of its failure. Based on this the printability and printing rate limit criteria of filaments with 59 vol.\% (87 wt.\%) Ti-6Al-4V powder loaded in a polymer binder has been determined. The proposed model can predict how new material compositions and process conditions affect printed part quality and production speeds in $\mathrm{MF}^{3}$ process. CHAPTER 3 findings have been published in International Journal of Refractory Metals \& Hard Materials, 2020 (DOI: https://doi.org/10.1016/j.ijrmhm.2020.105249).

CHAPTER 4 presents some of the critical challenges associated with $\mathrm{MF}^{3}$ of metal parts, which must be addressed to obtain high-density green parts and the influence of sintering parameters on the $\mathrm{MF}^{3} \mathrm{Ti}-6 \mathrm{Al}-4 \mathrm{~V}$ properties. Printing parameters were evaluated using Taguchi analysis to achieve the highest green density and dimensional precision in the Ti6Al-4V parts made using $\mathrm{MF}^{3}$. The effect of sintering parameters on the density of $\mathrm{MF}^{3}$ fabricated Ti-6Al-4V parts was also investigated with two different powder compositions. The sintered parts were evaluated for their physical, mechanical, and microstructural properties and correlated with sintering conditions and interstitial concentration. The results highlighted the importance of optimal printing parameter selection to obtain green parts with high density having close dimensional tolerance to the CAD file. Also, the effect of powder size and chemical composition on the final part properties of sintered $\mathrm{MF}^{3} \mathrm{Ti}$ 6Al-4V has been discussed in detail. CHAPTER 4 is currently under internal review to be submitted to Additive Manufacturing Journal. 
CHAPTER 5 evaluates a design-based approach called design for metal fused filament fabrication $\left(\mathrm{DfMF}^{3}\right)$ to estimate material properties that can serve as input parameters for simulation platforms to predict warpage and dimensional changes for design with $\mathrm{MF}^{3}$. To identify the influence of varying powder content (solids loading, chemistry), properties were estimated for density, thermal conductivity, specific heat, modulus, coefficient of thermal expansion, viscosity as a function of shear rate and temperature, and specific volume as a function of pressure and temperature. The estimated material properties for Ti-6Al-4V powder-polymer were used to understand simulation outputs such as warpages and dimensions using the $\mathrm{DfMF}^{3}$ platform, Digimat- $\mathrm{AM}^{\circledR}$. Further, a comparison of warpage and dimensions between $\mathrm{DfMF}^{3}$ simulations and 3D printing experiments was performed for a 59 vol. \% solids loading Ti-6Al-4V powder-polymer material system. The output of the $\mathrm{DfMF}^{3}$ study was compared to FFF simulations and experiments of an unfilled acrylonitrile butadiene styrene (ABS) polymer. It is expected that the overall approach will significantly reduce the trial-and-error in designing new materials used to fabricate complex $\mathrm{MF}^{3}$ parts. These findings have been published in JOM, 2020 (DOI: https://doi.org/10.1007/s11837-019-03920-y).

Appendix A reports the investigation of the microstructure and mechanical properties of Ti-6Al-4V printed via laser powder bed fusion (L-PBF) as a function of the printing parameters and the characteristics of the powder. L-PBF was used to print tensile coupons and characterized for microstructure, density, hardness, tensile strength, and elongation. 
With the L-PBF approach, it opens the ability to explore Ti-6Al-4V powders which are available at a low cost compared to gas and plasma atomized powders and thereby further strengthening the scope for AM of Ti-6Al-4V alloys for innovative product development.

Appendix B reports on the challenge when working with the metal FFF 3D printing process. With an increase in metal powder loading in the polymer matrix, there is an increase in viscosity of the metal-filled polymer feedstock that obstructs the flow of material through the nozzle while extrusion 3D printing. The current work focuses on understanding the science behind the rheological properties of unfilled and metal powder filled polymers by correlating it with the extrusion process in FFF 3D printing to gain better control on feedstock flow behavior. This preliminary investigation was a steppingstone leading to developing the process model for printability and rate limits available in

\section{CHAPTER 2.}

Appendix $\mathbf{C}$ consists of some valuable data that was produced during the course of the work in understanding various powder-binder interactions in terms of printing and sintered related attributes. Also, reported is some work on post-processing of $\mathrm{MF}^{3}$ sintered part by hot isostatic pressing which is expected to become part of future investigations. 


\section{CHAPTER 2}

\section{METAL FUSED FILAMENT FABRICATION $\left(\mathrm{MF}^{3}\right)$ OF TI-6AL-4V}

\section{$2.1 \quad$ INTRODUCTION}

Metal fused filament fabrication $\left(\mathrm{MF}^{3}\right)$ is a novel hybrid additive manufacturing technique which essentially combines green part fabrication by fused filament fabrication (FFF) and thermal processing of metal injection molding (MIM). The overall $\mathrm{MF}^{3}$ process used in this study is presented in Figure 2.1. Here, feedstock filaments were made using powderbinder mixtures and printed on an FFF printer. Thermal processing by debinding followed by sintering were used to produce strong metal components.

$\mathrm{MF}^{3}$ can offer several advantages compared to existing AM processes such as laser powder bed fusion (L-PBF), direct energy deposition (DED) and electron beam melting (EBM). Some examples of potential benefits include: (i) significantly lower capital cost compared to other metal AM processes (ii) the absence of high rapid heating/cooling rates could possibly result in equiaxed grains and more isotropic microstructure and mechanical properties (iii) elimination of handling loose powder during printing (iv) improved powder recyclability during net-shaping due to lower process temperatures at the green state, (v) well-known debinding and sintering knowledge from metal injection molding (vi) potential 
to fabricate parts in space, where the use of other powder-bed based AM processes poses serious powder and bed stability concerns.

Several groups have recently reported variations of the $\mathrm{MF}^{3}$ process using polymer-metal feedstocks with solids loading between 50 to 60 vol.\% for direct material extrusion or produced into filaments to print geometries with/without subjecting them to thermal treatments [4, 5, 11-17]. Gonzalez-Gutierrez et al. [4] reported tensile properties of 17-4PH stainless steel printed with polymer-metal powder bound filaments, achieving sintered ultimate tensile strength of $695 \pm 35 \mathrm{MPa}$ with $3.8 \pm 1.9 \%$ elongation at break. Thompson et al. [9] performed fused filament fabrication of $316 \mathrm{~L}$ stainless steel to produce $95 \%$ dense sintered parts. Bose et al. [11] achieved 98.4\% density and hardness of $945 \pm 80 \mathrm{HV}$ in WCr alloy. Lengauer et al. [12] investigated polymer-WC-Co filaments for printing intricate geometries and reported sintered shrinkage of $21 \pm 1 \%$. However, the majority of these studies only provide a general overview on the feasibility of $\mathrm{MF}^{3}$ process to create metal parts.

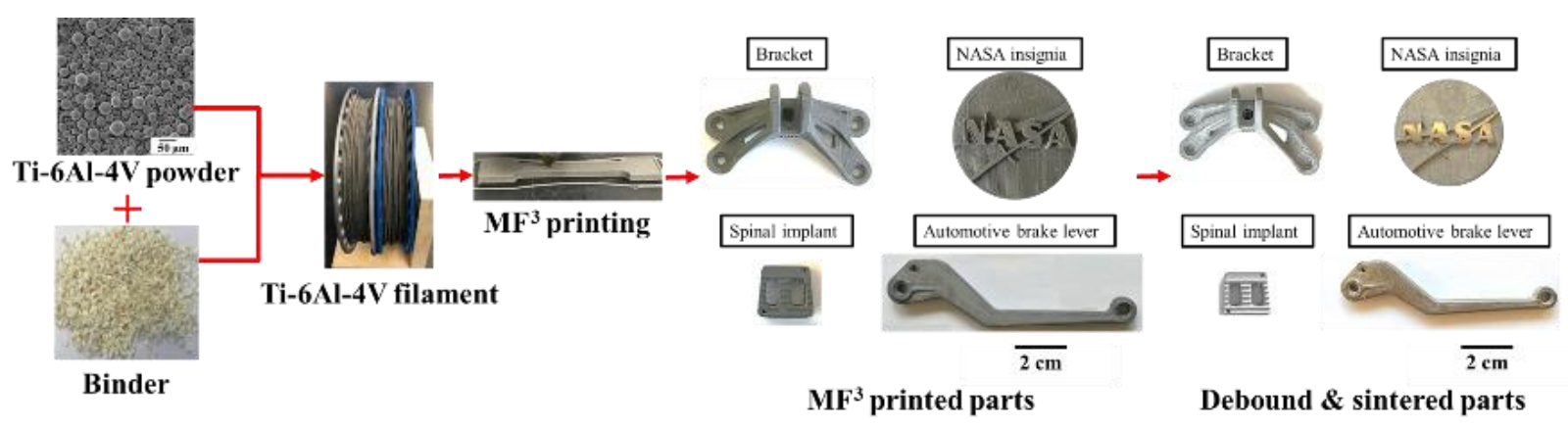

Figure 2.1. Overview of the $\mathrm{MF}^{3}$ process used in the present study to fabricate Ti-6Al-4V parts. 
In order to successfully design metal-polymer mixtures for use in $\mathrm{MF}^{3}$, several considerations must be taken into account such as high powder loading, homogeneous powder-binder distribution, sufficient filament stiffness, low viscosity during printing and no binder residue prior to sintering. Typically, a high powder loading (> 50 vol.\%) is expected to reduce slumping during debinding and shrinkage during sintering. On the other hand, a very high powder loading could result in inconsistent printing due to hindrance in feedstock flow through the printing nozzle. Similarly, a non-uniform powder dispersion in the polymer matrix can result in processing difficulties due to high fluctuations in the viscosity and associated pressure changes in the nozzle leading to inconsistent printing. In $\mathrm{MF}^{3}$, the filament is driven into the heated liquefier by a knurled roller and the filament acts as a plunger to force the material through the nozzle. Therefore, sufficient filament strength and stiffness are necessary to avoid filament breakage at the nozzle tip [18]. Further, improper selection of print extrusion parameters can lead to poor layer/bead adhesion and generate voids between printed beads, resulting in low green density and poor structural integrity of printed parts [19-21]. Moreover, the printing process is directly affected by material viscosity which not only changes with temperature and shear rate, but also with compositional and powder-binder ratio [13, 18, 22-24]. It is also desirable to have high density green parts, as the presence of large voids and related defects cannot be eliminated during sintering and eventually result in inferior mechanical properties [25]. Once the part is printed, any binder residue can retard densification and affect microstructures, thereby producing parts with inferior properties. The sintering process and environmental control are also equally important for control of microstructure, densification, distortion and properties. Proper control of the debinding and sintering 
processes are particularly challenging step in $\mathrm{MF}^{3}$ parts owing to their high geometric complexity. To our knowledge few prior reports have examined feedstock and filament characteristics, print parameters, and debinding and sintering outcomes critical for successful $\mathrm{MF}^{3}$ processing.

Ti-6Al-4V alloy has a combination of properties (such as high specific strength to weight ratio, biocompatibility, good corrosion resistance), that makes it an excellent material of choice for automotive, medical and aerospace applications. As a result, significant amounts of research has been done on AM of this alloy using processes including L-PBF, EBM and DED. The localized heating and extreme thermal gradients in these processes leads to high residual stresses which in turn govern the macrostructure and the microstructures of printed parts [26]. The inevitable defect formation and directional property anisotropy are still a constraint with these AM routes [1, 27]. Table 2.1 lists some of the common physical and mechanical properties of Ti-6Al-4V alloy produced with metal injection molding (MIM), laser-powder bed fusion (L-PBF) and wrought (Ti-6Al-4V annealed sheet acquired from McMaster-Carr).

To our knowledge, no scientific report has addressed the processing of Ti-6Al-4V using the $\mathrm{MF}^{3}$ process. In this work, we report Ti-6Al-4V parts fabricated using $\mathrm{MF}^{3}$ process following effective powder-binder feedstock preparation for filament fabrication, printing of parts to attain high green density, and binder removal and sintering to achieve properties and microstructures comparable to other processes. 
Table 2.1. Properties of Ti-6Al-4V components fabricated using several manufacturing routes.

\begin{tabular}{|c|c|c|c|c|c|}
\hline Process & $\begin{array}{c}\text { Relative } \\
\text { density } \\
\mathbf{( \% )}\end{array}$ & $\begin{array}{c}\text { Yield } \\
\text { strength } \\
\mathbf{( M P a )}\end{array}$ & $\begin{array}{c}\text { Ultimate } \\
\text { tensile } \\
\text { strength } \\
\mathbf{( M P a )}\end{array}$ & $\begin{array}{c}\text { Elongation } \\
\mathbf{( \% )}\end{array}$ & Source \\
\hline MIM & $97.3 \pm 1.2$ & $750 \pm 25$ & $860 \pm 40$ & $14 \pm 4$ & {$[28-32]$} \\
\hline L-PBF & $99.7 \pm 0.15$ & $\begin{array}{c}1150 \pm \\
80\end{array}$ & $1270 \pm 70$ & $6 \pm 2$ & {$[33-35]$} \\
\hline $\begin{array}{c}\text { Wrought } \\
\text { (Annealed) }\end{array}$ & 100 & $790 \pm 15$ & $1080 \pm 20$ & $18 \pm 2$ & $\begin{array}{c}\text { Current } \\
\text { work }\end{array}$ \\
\hline
\end{tabular}

\subsection{EXPERIMENTAL METHODS}

\subsubsection{MATERIALS}

In the current work, a commercially available Ti-6Al-4V alloy powder was used. The asreceived powder was characterized in terms of true, apparent and tap densities in order to assess flowability and packing density. The true density $(\rho)$ of powder was measured using a helium gas pycnometer (Micromeritics Accupyc II 1340). The tap density $\left(\rho_{t}\right)$ of powder was measured using a tap density volumeter (Aimsizer Scientific AS-100) as per ASTM B527-15. The apparent volume of powder (without any mechanical tapping) was measured in a cylinder and divided by its mass to obtain the apparent density $\left(\rho_{a}\right)$. The phases in the powder were identified analyzing X-ray diffraction (XRD) pattern (collected using Discovery D8 Bruker HR-XRD). A proprietary binder was used for this study for feedstock preparation. 


\subsubsection{FEEDSTOCK PREPARATION AND CHARACTERIZATION}

Solids loading is the ratio of the volume of metal powder to the total volume of the powder and binder in a feedstock and is expressed in vol.\%. The critical solids loading was determined in a torque rheometer (Brabender CWB, Intelli-Torque Plasti-Corder). An initial batch with 58 vol.\% of the powder-binder mixture was blended and introduced at $180{ }^{\circ} \mathrm{C}$ and mixed with a blade rotating speed of $100 \mathrm{rpm}$. The mixing torque was monitored until it stabilized, indicating homogeneous mixing. Additional powder was added in increments of 1 vol.\% each time until the torque stabilized. With each addition, the mixing torque was monitored until a discontinuous rise in torque and torque variation, from which, the critical solids loading was determined.

Based on the critical solids loading determined by torque rheometry, a solids loading of 59 vol.\% was selected for preparing the feedstock filaments for further $\mathrm{MF}^{3}$ printing using the mixing conditions reported above. The generated mixing torque was monitored to evaluate the mixture homogeneity of the feedstock until it became stable at 45 minutes of mixing. Viscosity measurements as a function of shear rate and temperature were also performed for this feedstock using a capillary rheometer (Goettfert Rheograph 20) with a tungsten carbide die (L/D ratio of 30:1). The feedstock viscosity was measured at $160{ }^{\circ} \mathrm{C}$ and 170 ${ }^{\circ} \mathrm{C}$ for shear rates between $20 \mathrm{~s}^{-1}$ and $800 \mathrm{~s}^{-1}$, to understand the shear-rate and temperature effects on feedstock viscosity. Feedstock homogeneity was determined from measuring time-dependent variations in viscosity at a constant shear rate and temperature [36]. In the

current study, a constant shear rate of $50 \mathrm{~s}^{-1}$ at $160{ }^{\circ} \mathrm{C}$ was used to evaluate the variations 
in feedstock viscosity to measure its homogeneity. Additionally, feedstock homogeneity was also evaluated by measuring the pycnometer density of the feedstock, while sampling the feedstock across random portions of the same batch to correlate with viscosity measurements.

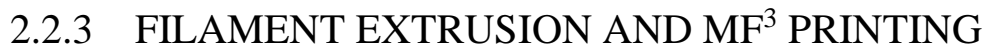

The 59 vol.\% Ti-6Al-4V feedstock was extruded into filaments with a consistent diameter of $1.75 \pm 0.05 \mathrm{~mm}$ using a capillary die with L/D ratio of $30 / 1.75 \mathrm{~mm}$ on a Goettfert Rheograph 20. The extrusion temperature was $105^{\circ} \mathrm{C}$ with a uniform extrusion speed of $0.1 \mathrm{~mm} / \mathrm{s}$ with pressure measured at the capillary entrance corresponding to $40 \pm 3 \mathrm{MPa}$. The stiffness of the filament was evaluated in terms of Young's modulus using tensile tests (Shimadzu EZ tensile testing machine). Our initial experiments showed that an extrusion temperature of $240{ }^{\circ} \mathrm{C}$ enabled consistent material flow due to optimal feedstock viscosity during printing. Similarly, a bed temperature of $65^{\circ} \mathrm{C}$ resulted in good adhesion of the part to the build platform during entire printing process. A layer height of $150 \mu \mathrm{m}$ with $100 \%$ infill selected to achieve close packing of printed beads leading to dense green parts. The selected bead deposition angle of alternating $0^{\circ}$ and $90^{\circ}$ resulted in sound and dense parts. While a print speed of $10 \mathrm{~mm} / \mathrm{s}$ resulted in good infill, consistent material flow (at extrusion multiplier of 115\%) and strong inter-bead and inter-layer bonding, this could not be achieved at higher printing speeds. The printed parts were characterized for green density using Archimedes principle and analyzed for pore distribution along the cross-section using scanning electron microscope. For relative density calculations, the pycnometer density of 
feedstock at 59 vol.\% $\left(3.01 \mathrm{~g} / \mathrm{cm}^{3}\right)$, and Ti-6Al-4V powder $\left(4.43 \mathrm{~g} / \mathrm{cm}^{3}\right)$ were used as a basis.

\subsubsection{DEBINDING AND SINTERING}

A two-step debinding procedure was used to reduce thermal debinding time and debindingrelated defects while completely removing the binder components. In this method, $\mathrm{MF}^{3}$ printed green parts were first solvent debound in heptane above $50^{\circ} \mathrm{C}$. Then the samples were dried in an oven at $80^{\circ} \mathrm{C}$ to remove residual solvent. The thermal debinding profile was developed using thermal degradation data of solvent debound samples generated using thermogravimetric analyzer (SDT Q600 by TA Instruments). Thermogravimetric analysis (TGA) experiments were performed with a heating rate of $2{ }^{\circ} \mathrm{C} / \mathrm{min}$ up to $550{ }^{\circ} \mathrm{C}$ in $\mathrm{N}_{2}$ atmosphere. Thermal debinding of the samples was carried out in partial vacuum of 600 mTorr with argon sweep (TM Furnaces) using a heating rate of $1{ }^{\circ} \mathrm{C} / \mathrm{min}$ and held for 3 10 hours below $600^{\circ} \mathrm{C}$. Thermally debound samples were sintered in the same vacuum furnace at temperatures from $1200-1400{ }^{\circ} \mathrm{C}$ for $1-4 \mathrm{~h}$ with argon as cover gas and a typical heating rate of $3^{\circ} \mathrm{C} / \mathrm{min}$.

\subsubsection{PHYSICAL, MECHANICAL AND MICROSTRUCTURAL}

\section{CHARACTERIZATION}

The density of sintered parts was characterized using the Archimedes principle. The mechanical properties of sintered tensile test coupons (ASTM E8) were determined using a tensile testing machine (MTS hydraulic tensile testing machine) with $100 \mathrm{kN}$ load cell at a strain rate $0.001 \mathrm{~s}^{-1}$ using an extensometer to measure the elongation in the gauge length. 
For microstructural analysis, sintered samples were polished using $\mathrm{SiC}$ papers in the sequence of $120 / 240 / 400 / 600 / 800 / 1200$ followed by $1 \mu \mathrm{m}$ diamond slurry and then colloidal silica slurry. The cross section of the sintered samples was etched using Kroll's reagent to reveal microstructural features and was observed under optical microscope (Olympus BX-51). Additional phase analysis was performed using an XRD analyzer, and the fracture surfaces were analyzed to correlate with the resulting properties, using a Scanning Electron Microscope (SEM).

\subsection{RESULTS AND DISCUSSION}

\subsubsection{METAL POWDER CHARACTERISTICS}

Figure 2.2 shows the Bragg's peaks detected by XRD primarily belonging to hexagonal close packed $\alpha$-Ti. No noticeable amounts of $\beta$-Ti peaks were identified. This is in agreement with published work in literature. The spherical morphology of the Ti-6Al-4V powder was determined by SEM and is shown as an inset in Figure 2.2. The powder morphology is comparable to Ti-6Al-4V powder used in some of the MIM studies [28, 30, $32,37]$. 


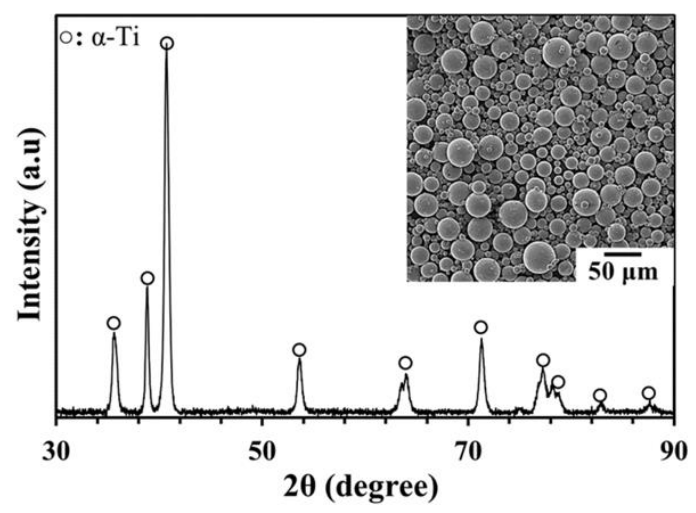

Figure 2.2. X-ray diffraction pattern for Ti-6Al-4V powder consisting of primary $\alpha$ phase with an inset of the SEM image revealing the spherical morphology of particles.

The packing attributes of the Ti-6Al-4V powder are summarized in Table 2.2. The spherical morphology of the powder results in improved flowability and high packing density. A higher powder packing density allows more powder addition into a feedstock mixture and reduces the overall sintering shrinkage. The powder packing fraction can be theoretically determined from the ratio of powder $\rho_{t}$ to $\rho$ [38], for the powder under investigation, it was found at 0.62 . The higher powder flowability is useful to lower the feedstock viscosity making printing easier at high solids loadings. The Hausner ratio of $\rho_{t}$ to $\rho_{a}$, and for current powder it was found to be 1.08 . A Hausner ratio $<1.2$ is taken to represent acceptable powder flowability. 
Table 2.2. Characteristics of Ti-6Al-4V alloy powder used in this investigation.

\begin{tabular}{|l|l|}
\hline Pycnometer density $\left(\mathrm{g} / \mathrm{cm}^{3}\right)$ & $4.43 \pm 0.002$ \\
\hline Apparent density $\left(\mathrm{g} / \mathrm{cm}^{3}\right)$ & $2.54 \pm 0.005$ \\
\hline Tap density $\left(\mathrm{g} / \mathrm{cm}^{3}\right)$ & $2.75 \pm 0.03$ \\
\hline
\end{tabular}

\subsubsection{METAL POWDER-POLYMER FEEDSTOCK CHARACTERISTICS}

Figure 2.3.a shows the effect of metal powder addition on the mixing torque during feedstock preparation. It can be seen that from 59 vol. $\%$ until 64 vol.\% the torque increased by increments of $0.4 \pm 0.2 \mathrm{~N} \cdot \mathrm{m}$ for every 1 vol. $\%$ increment in the powder addition. This trend is indicative of increased interparticle friction with increased solid loading in the powder-binder feedstock mixture [39]. However, the mixing torque abruptly increased > $2.4 \pm 0.2 \mathrm{~N} \cdot \mathrm{m}$ with increase in the solids loading beyond 64 vol. $\%$. This transition is indicative of a mixture with less binder available to homogeneously coat each particle, resulting in excessive inter-particle friction $[38,39]$. For the current powder binder system, the critical loading was determined to be 64 vol. $\%$ and the powder solids loading was selected at 59 vol.\% to ensure good feedstock flowability and viscosity during $\mathrm{MF}^{3}$ printing process, based on trial-and-error. The viscosity of 59 vol.\% Ti-6Al-4V feedstock was determined at $160{ }^{\circ} \mathrm{C}$ and $170{ }^{\circ} \mathrm{C}$ for shear rate range of $20 \mathrm{~s}^{-1}$ to $800 \mathrm{~s}^{-1}$. As shown in Figure 2.3.b, the viscosity decreased with increase in shear rate and temperature. On increasing the temperature from $160{ }^{\circ} \mathrm{C}$ to $170{ }^{\circ} \mathrm{C}$ the viscosity decreased from $355 \pm 5$ to $310 \pm 2 \mathrm{~Pa} \cdot \mathrm{s}$ at a shear rate of $160 \mathrm{~s}^{-1}$. Additionally, the effect of increasing shear rate from 
$20 \mathrm{~s}^{-1}$ to $800 \mathrm{~s}^{-1}$ showed a decrease in the viscosity from $635 \pm 35 \mathrm{~Pa}$ s to $190 \pm 5 \mathrm{~Pa}$ s for $160{ }^{\circ} \mathrm{C}$, and $540 \pm 5 \mathrm{~Pa}$ s to $165 \pm 1 \mathrm{~Pa}$ 's for $170{ }^{\circ} \mathrm{C}$.

In $\mathrm{MF}^{3}$, the viscosity and subsequent pressure drop in the heated nozzle is dependent on a number of factors such as the powder loading, binder composition, feed rate, temperature and heat transfer gradients (temperature drops) in the heated liquefier and nozzle sections. Anderegg et al. [18] experimentally verified the temperature drop at the exit of the heated liquefier leading to an increase in viscosity and a high pressure differential. Such a pressure drop can result in non-uniform material extrusion during the process leaving air gaps between deposited beads and bonded layers. The pressure drop is also dependent on the feedstock material homogeneity and powder loading. With the current Ti-6Al-4V feedstock at 59 vol.\% loading, a printing temperature of $240{ }^{\circ} \mathrm{C}$ was used to lower the feedstock viscosity. FFF systems typically operate at shear rates $<300 \mathrm{~s}^{-1}$ [40]. When the extrusion force exceeds the shear strength of the filament at the roller feeding mechanism, the filament fails at the entrance [41]. In practice, a printing speed $<10 \mathrm{~mm} / \mathrm{s}$ was used for the current Ti-6Al-4V filaments. Recent work by our group discussed in detail the effect of filament viscosity and strength properties on the material printability and rate limits specific to $\mathrm{MF}^{3}$ of Ti-6Al-4V [24].

In order to assess feedstock homogeneity, a constant shear rate of $50 \mathrm{~s}^{-1}$ at $160{ }^{\circ} \mathrm{C}$ was used to evaluate the variation in feedstock viscosity The feedstock viscosity measurement was repeated for eight data points and it was observed that feedstock viscosity remained at 730 Pa's with a standard deviation of $\pm 2 \mathrm{~Pa} \cdot \mathrm{s}$. This small deviation in feedstock viscosity and 
resulting coefficient of variation below $0.5 \%$ was taken to indicate that the feedstock had a high homogeneity. The viscosity variation assessment was consistent with the inferences from the variations in pycnometer density of the feedstock, $2.96 \pm 0.002 \mathrm{~g} / \mathrm{cm}^{3}$, which was in close agreement with the estimated density based on the inverse rule-of-mixtures $(\sim 3$ $\left.\mathrm{g} / \mathrm{cm}^{3}\right)[42]$
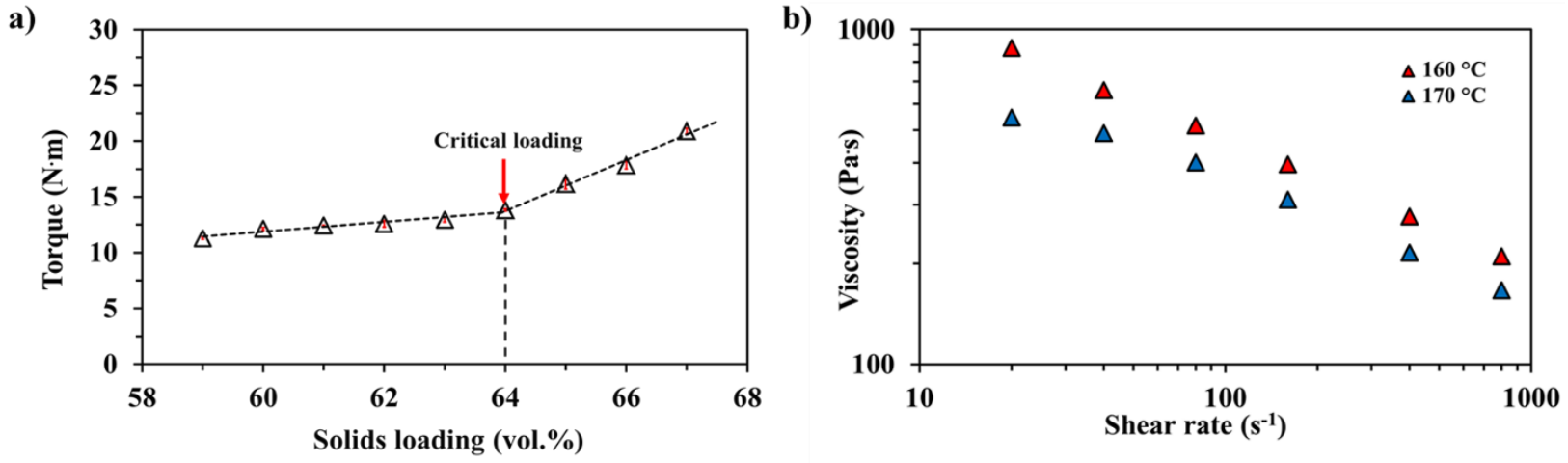

Figure 2.3. a. Effect of solids loading on mixing torque, b. Influence of temperature and shear rate on the viscosity of Ti-6Al-4V feedstock (59 vol.\%) prepared in this work.

\subsubsection{FILAMENT PROPERTIES}

The green filament produced from 59 vol.\% Ti-6Al-4V feedstock was characterized for density using the Archimedes principle and which was found to be $100 \%$ relative to the pycnometer density of the feedstock $\left(2.96 \pm 0.002 \mathrm{~g} / \mathrm{cm}^{3}\right)$. Having a high filament density enables uniform stiffness and reduces the chances of breaking during printing. Further, it enables easy and consistent extrusion of material by maintaining uniform pressure during deposition, and therefore high filament density translates into high green part density. The elastic modulus of current filament was found to be $170 \pm 20 \mathrm{MPa}$. 
Filament SEM images along the cross-section

a)

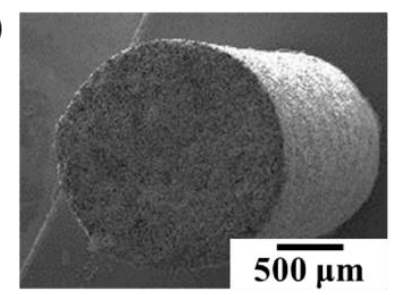

b)

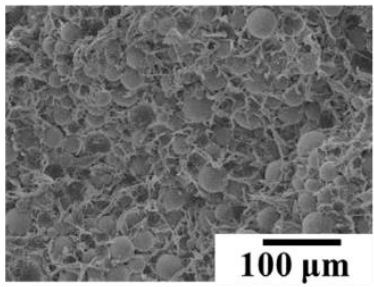

c)

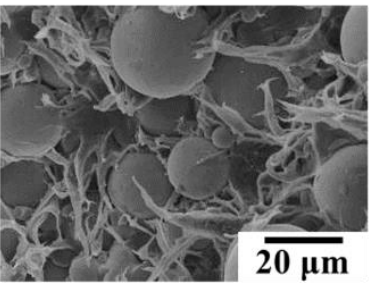

Filament SEM images along the outer face

d)

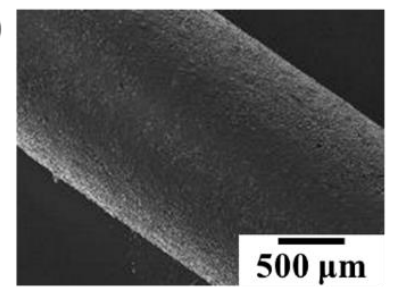

e)

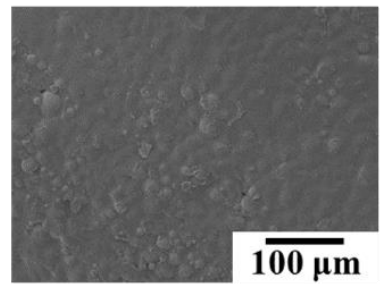

f)

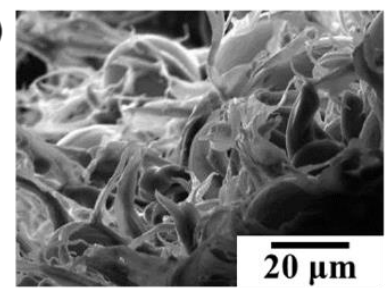

Figure 2.4. SEM images of the filament showing powder distribution, powder-polymer interface and filament surface morphology.

The filaments were also analyzed for defects and other inconsistencies using SEM along cross-section and outer surface. As shown in Figure 2.4.a \& Figure 2.4.b the powder was found to be homogeneously dispersed in the polymer matrix with no noticeable presence of voids. At higher magnification, a good powder-polymer interface with numerous adhesion/contact points on the powder can be clearly seen in Figure 2.4.c. This is expected to provide sufficient mechanical strength to the filaments and enable uniform flow. Figure 2.4.d \& Figure 2.4.e shows the outer surface of the filament. The surface was found to be smooth without any large defects, which can reduce strength of the filament. The surface also appears to be covered with polymer and some regions of exposed metal powder (Figure 2.4.e \& Figure 2.4.f), possibly contributing to the good filament flexibility that 
helps in improving resistance to surface damage during handling and feeding through the printer.

\subsection{4 $\mathrm{MF}^{3}$ PRINTING}

The printed parts were analyzed for their dimensions and compared to the actual CAD file dimensions to account for any resulting expansion or contraction post printing process. Figure 2.5.a shows a tablet and an ASTM tensile specimen with dimensions, and Figure 2.5.b (Top) shows the sliced file that directs the nozzle travel around the bed to create the entire 3D geometry. Figure 2.5.b (bottom) shows typical green parts printed using a Pulse FFF printer. Table 2.3 lists the difference in printed part and the actual CAD file dimensions, which was found to be within $0.5 \%$ of the actual geometry. The geometric tolerances of the parts depend on the motion controlled by the gantry system, selection of process parameters, and printed material properties. In the gantry system, step size of the stepper motor controls the accuracy and details to which a CAD model is translated into a build part. Along the XY plane, as shown in Table 2.3, the resulting difference was positive (parts larger than respective designs). Since the material coming though the nozzle flows laterally and also the die swelling phenomenon occurs as the melt leaves the printer nozzle, resulting in radial expansion of extrudate which affects dimensions and limits the resolution considerations of FFF parts [43]. The dimensions ( $\mathrm{X}$ and $\mathrm{Y}$ directions) were found to depend on process parameters such as the extrusion multiplier and printing speed. Similarly, the layer thickness, bead width and the feed rate were some of the other governing parameters that affected the final dimensions of the build geometry. Interestingly, the dimensional change was negative along printing direction ( $\mathrm{Z}$ direction). One of the possible reasons could be attributed to thermal contraction of the printed layers 
up on cooling. Printing material composition and its thermo-physical properties like viscosity, specific volume, thermal conductivity, and specific heat are expected to have strong influence on the final geometry [44]. Understanding material properties and its relation to the process parameters can further enable improvements in dimensional control and defect avoidance during printing.

a)

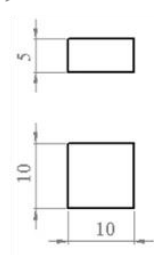

\section{CAD file dimensions}

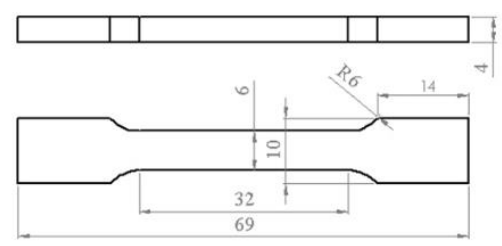

$\mathrm{MF}^{3}$ printed green part cross-sectional microscopic analysis

c)

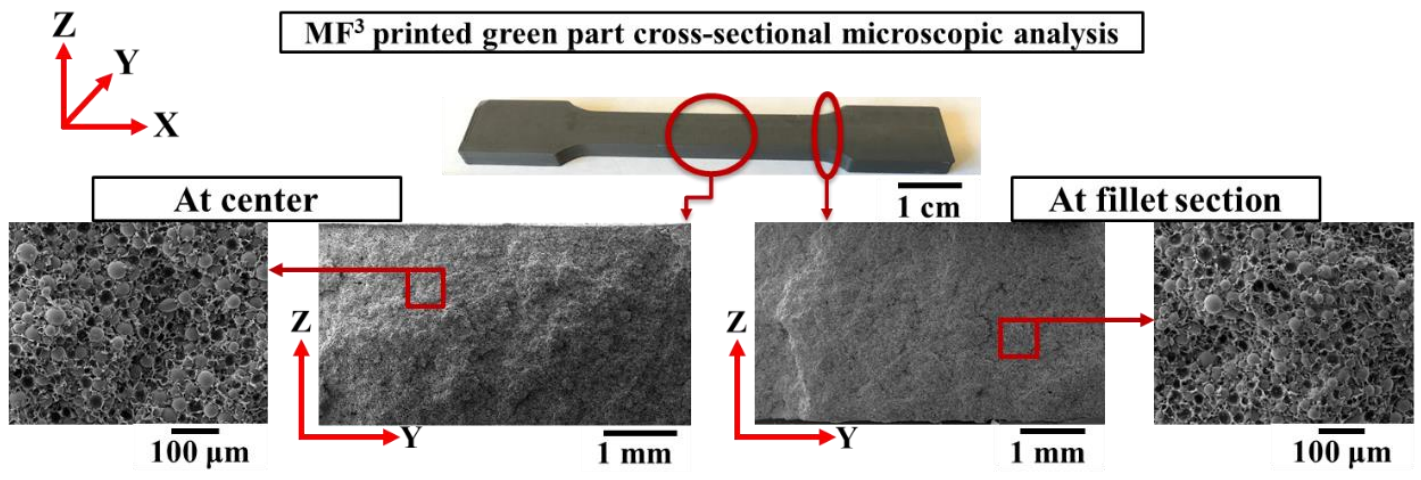

Figure 2.5. a. CAD file dimensions for tablet and tensile bar, b. (Top) Sliced file for MF3 process showing printing paths for infill and perimeter, (bottom) Typical MF3 printed tablet and tensile bar in green state, c. SEM of green part revealing uniform powderpolymer distribution. 
Table 2.3. Dimensional tolerance of the printed parts for Ti-6Al-4V using the $\mathrm{MF}^{3}$ process.

\begin{tabular}{|c|c|c|}
\hline \multirow{2}{*}{ Direction } & \multicolumn{2}{|c|}{$\begin{array}{c}\text { Difference in CAD file and printed } \\
\text { part dimensions }(\%)\end{array}$} \\
\cline { 2 - 3 } & Tablet & Tensile bar \\
\hline $\mathrm{X}$ & $0.4 \pm 0.3$ & $0.2 \pm 0.1$ \\
\hline $\mathrm{Y}$ & $0.1 \pm 0.1$ & $0.1 \pm 0.05$ \\
\hline $\mathrm{Z}$ & $-0.5 \pm 0.2$ & $-0.5 \pm 0.2$ \\
\hline
\end{tabular}

In addition to dimensional analysis, the density of the printed parts was also analyzed. It was found that all samples had green density of $98.5 \pm 0.6 \%$ relative to the density of the feedstock. Figure 2.5.c shows SEM images of a cross-sectioned green tensile bar along the YZ plane with no visible macroscale voids. The slightly lower density of $\sim 1 \%$ in the printed parts is believed to be internal pores generated during the printing process, as the green filament was found to be fully dense (100\%). Previous studies with unfilled polymer parts printed using FFF have suggested that these voids could be eliminated by adjusting a number of factors such as layer height, nozzle diameter, volumetric print speed and material extrusion temperature [45-47]. Typically, for the same extrusion and printing speed, a low layer height is expected to push more material laterally and reduce any voids. The nozzle diameter is selected based on the desired feature resolution, particle size of filler and the desired pressure drop to maintain uniform flow. Increasing volumetric print speed increases the amount of extrudate being driven out through the nozzle and therefore, can reduce existing voids. Increasing the printing temperature reduces viscosity and allows better flow of material. 
Magnified microstructures of green parts in different regions (at center and at the fillet section in Figure 2.5.c, revealed uniform dispersion of metal powder within the polymer binder throughout the part. All particles were found to be covered with the polymer binder which indicates uniform feedstock flow through the nozzle during $\mathrm{MF}^{3}$ printing. Further, such uniform distribution of metal powder and polymer binder in the printed green part could help in achieving enough green strength (for handling) and more uniform binder removal and shrinkage during debinding and sintering steps, respectively.

\subsubsection{DEBINDING AND SINTERING}

Following solvent debinding, the remaining binder was thermally removed using conditions determined from TGA. Figure 2.6 presents TGA of present feedstock, which revealed polymer binder breakdown in three stages (represented by zones $\mathbf{1 - 3}$ in Figure 2.6). The peaks from the weight loss rate denote the temperature at which maximum binder removal is reached. It can be seen that $20 \mathrm{wt} . \%$ of the binder was removed at $250{ }^{\circ} \mathrm{C} .20$ wt. $\%$ of the binder was also removed $330{ }^{\circ} \mathrm{C}$. The remaining $60 \mathrm{wt} . \%$ of the binder was removed at $440{ }^{\circ} \mathrm{C}$. Debinding was conducted below $660{ }^{\circ} \mathrm{C}$ for various time intervals to ensure that all the binder was entirely eliminated. Complete removal of binder is the most critical part of the entire process, any remaining impurities (typically carbon) can easily react with titanium to form carbides at elevated temperatures, thereby reducing ductility [48]. The debinding cycle was followed by sintering in the same furnace for temperatures between $1200-1400{ }^{\circ} \mathrm{C}$ for $1-4$ hours with partial vacuum and continuous argon flow to minimize oxidation. Table 2.4 shows part sintered properties, with current conditions achieved relative density of $94.2 \pm 0.1 \%$ with average shrinkage of $14.5 \pm 0.5 \%$ along three directions (X-Y-Z). 

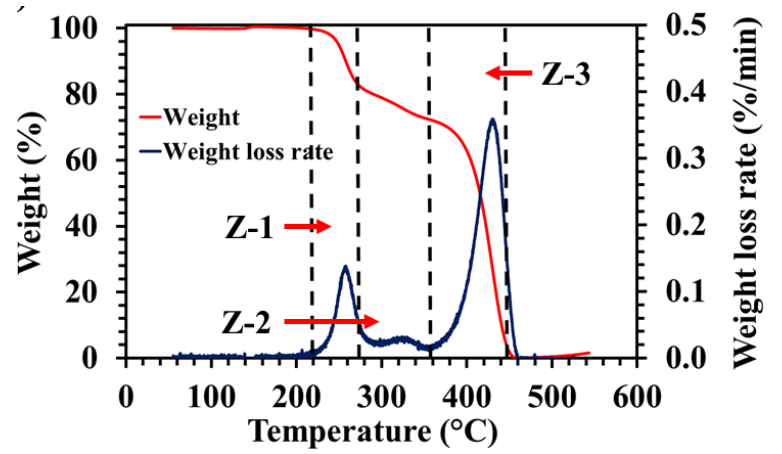

Figure 2.6. Thermogravimetric analysis of the Ti-6Al-4V to understand polymer decomposition.

Table 2.4. Physical and mechanical properties of sintered $\mathrm{MF}^{3}$ Ti-6Al-4V parts.

\begin{tabular}{|c|c|c|c|c|c|c|}
\hline \multirow{2}{*}{$\begin{array}{c}\text { Density } \\
(\%)\end{array}$} & \multicolumn{3}{|c|}{$\begin{array}{c}\text { Shrinkage } \\
(\%)\end{array}$} & \multirow{2}{*}{$\begin{array}{c}\text { Yield } \\
\text { strength } \\
\text { (MPa) }\end{array}$} & \multirow{2}{*}{$\begin{array}{l}\text { Ultimate tensile } \\
\text { strength } \\
\text { (MPa) }\end{array}$} & \multirow{2}{*}{$\begin{array}{c}\text { Elongation } \\
(\%)\end{array}$} \\
\hline & $\mathbf{X}$ & $\mathbf{Y}$ & $\mathbf{Z}$ & & & \\
\hline $\begin{array}{c}94.2 \pm \\
0.1\end{array}$ & $\begin{array}{c}14 \pm \\
0.5\end{array}$ & $\begin{array}{c}15 \pm \\
0.5\end{array}$ & $\begin{array}{l}15 \pm \\
0.5\end{array}$ & $745 \pm 10$ & $875 \pm 15$ & $17 \pm 3$ \\
\hline
\end{tabular}

\subsubsection{MECHANICAL PROPERTIES AND MICROSTRUCTURE}

The sintered Ti-6Al-4V parts produced by $\mathrm{MF}^{3}$ exhibited an ultimate tensile strength (UTS) of $875 \pm 15 \mathrm{MPa}$, yield strength of $745 \pm 10 \mathrm{MPa}$ with an elongation of $17 \pm 3 \%$. The resulting UTS of $\mathrm{MF}^{3}$ specimens was comparable to the properties listed in Table 2.1 for MIM Ti-6Al-4V alloy. The oxygen content was 0.2 wt. \% (ASTM standard $<0.2$ wt.\%) while the carbon content was 0.14 wt. \% (ASTM standard $<0.08$ wt.\%). Further studies are on-going to examine the effects of oxygen and carbon content on the properties of sintered Ti-6Al-4V produced by $\mathrm{MF}^{3}$ and will be reported elsewhere. 
Figure 2.7.a shows the XRD pattern for the phases present in the sintered Ti-6Al-4V alloy. Bragg's peaks pertaining to hexagonal close-packed $\alpha$-Ti, and body-centered cubic $\beta$-Ti peaks were identified. The microstructure of the sintered tensile bar along different planes were collected and shown in Figure 2.7.b. In all cross-sectioned planes, the microstructures consisted of typical $\alpha+\beta$ phases of Ti-6Al-4V alloy. The matrix is $\alpha$, with the presence of intergranular $\beta$ phase (prior $\beta$ ). The prior $\beta$ grain size was determined using the linear intercept method (ASTM E112-13) and found to be $150 \pm 5 \mu \mathrm{m}$. The higher magnification image reveals the Widmanstatten microstructure primarily consisting of $\alpha$ and $\beta$ lamellae [28]. No pores as a result of printing process were observed in the microstructure, correlating well with the high initial green density $\sim 99 \%$ to that of feedstock. The tensile fractured surfaces were characterized with SEM shown in Figure 2.7.c. The fracture surfaces highlight the presence of fine dimples throughout the sample surface supporting the ductile fracture [48, 49], as represented from obtained mechanical properties. Further studies of material properties and microstructure of sintered parts and its dependence on various $\mathrm{MF}^{3}$ process parameters is on-going and will be reported elsewhere. 
a)

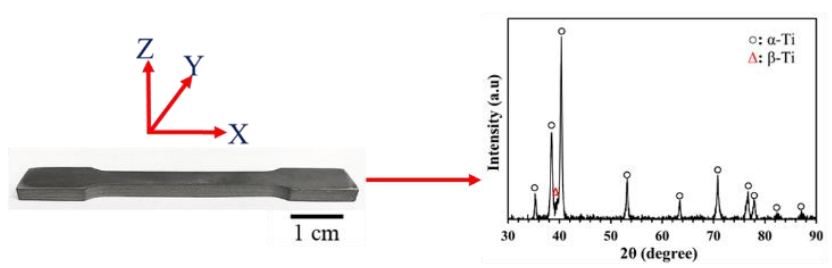

b)
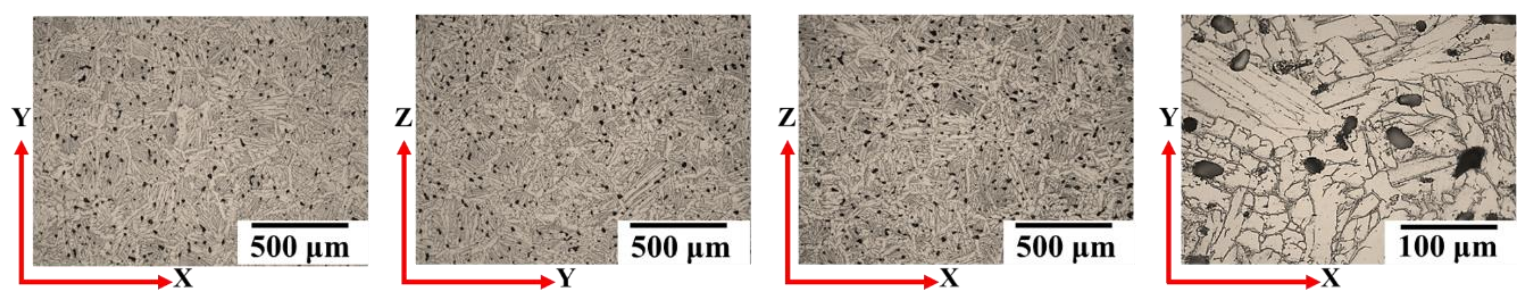

c)
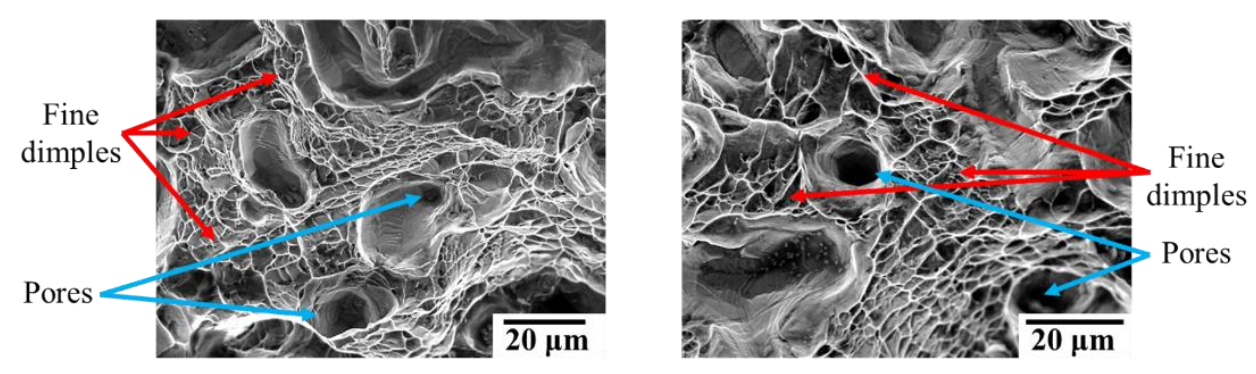

Figure 2.7. a. Sintered tensile sample representing directional orientation along $X-Y-Z$ axis exhibiting $\alpha$ and $\beta$ phases determined by XRD analysis, $b$. Sintered and polished part microstructure along XY-YZ-XZ plane, with high magnifications (right image) highlighting Widmanstatten microstructure, c. Fracture surface of the tensile tested samples showing the presence of fine dimples, consistent with ductile fracture. 


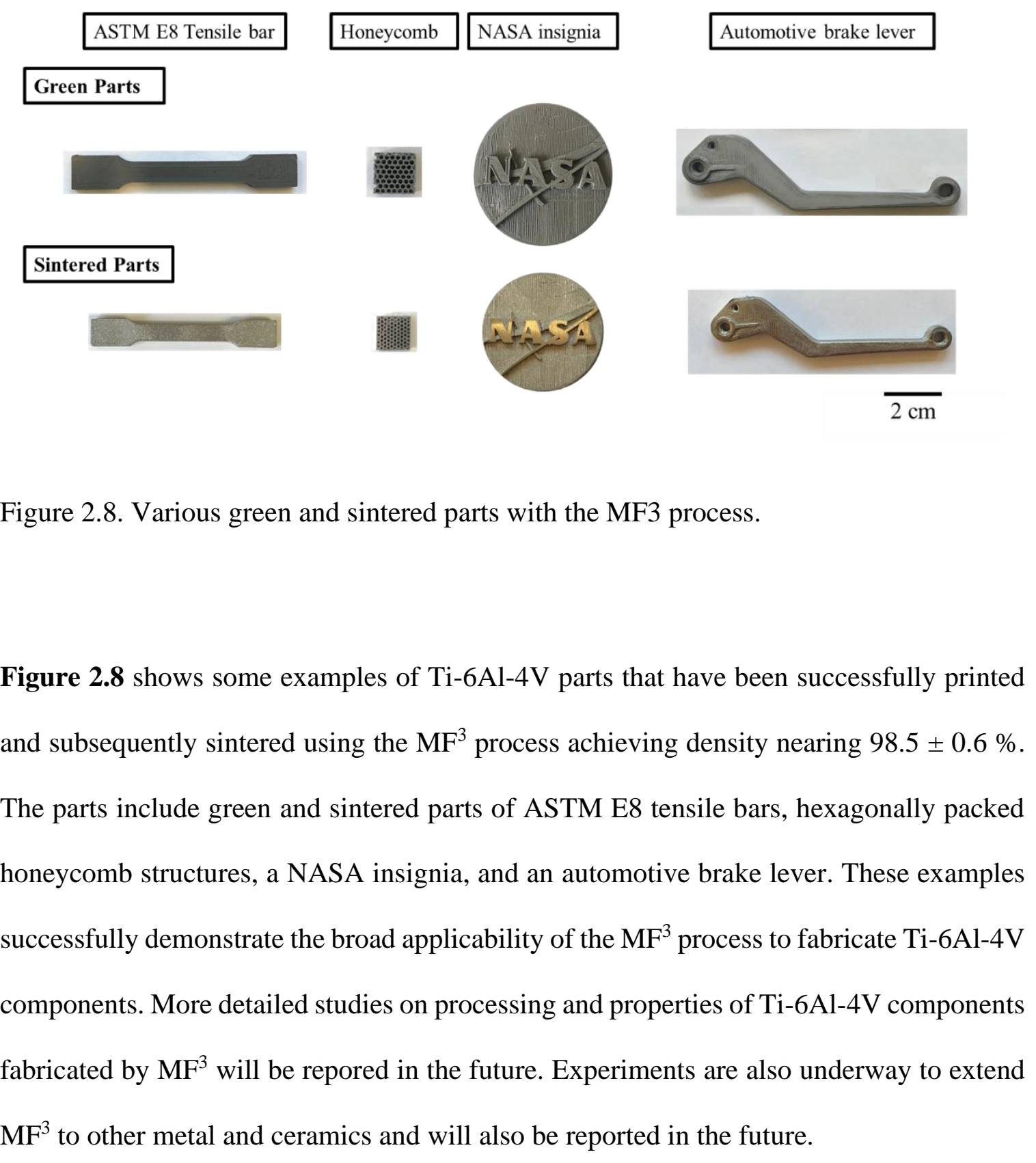




\subsection{CONCLUSIONS}

This study successfully demonstrated the preparation polymer-Ti-6Al4-V alloy feedstock and filaments that were 3D printed and thermally processed using the $\mathrm{MF}^{3}$ process. Polymer bound continuous filament with 59 vol.\% of Ti-6Al-4V powder was found to exhibit desirable mechanical and flow characteristics, enabling successful part printing with $\mathrm{MF}^{3}$. The dimensions of printed parts were found to be with $\pm 0.5 \%$ of part design. Green parts were printed with density of $98.5 \pm 0.6 \%$ relative to that of feedstock. The parts were sintered to $94.1 \pm 0.1 \%$ relative density of the bulk material with ultimate tensile strength of $875 \pm 15 \mathrm{MPa}$, yield strength of $745 \pm 10 \mathrm{MPa}$ and $17 \pm 3 \%$ elongation which compare favorably relative to metal injection molded Ti-6Al-4V. Our results clearly demonstrate the capability of $\mathrm{MF}^{3}$ process to fabricate complex Ti-6Al-4V parts with useful properties using metal-polymer based feedstock systems. 


\section{CHAPTER 3}

\section{PRINTABILITY STUDIES OF TI-6AL-4V BY METAL FUSED FILAMENT FABRICATION $\left(\mathrm{MF}^{3}\right)$}

\subsection{INTRODUCTION}

Additive manufacturing of metals using metal fused filament fabrication $\left(\mathrm{MF}^{3}\right)$ is based on highly-filled, metal powder-polymer filaments, where polymer binder helps to hold metal particles together in a feedstock and assist in material flow and deposition during extrusionbased printing $[9,11,12,17]$. As shown in Figure 3.1, the printing process in metal fused filament fabrication $\left(\mathrm{MF}^{3}\right)$ is similar to fused filament fabrication (FFF) with subsequent steps involving binder removal and sintering at elevated temperatures to densify the printed parts [50]. The powder loading in the metal powder-polymer bound filament typically varies between 50 and 65 vol.\% of the metal powder. For the $\mathrm{MF}^{3}$ process, low powder loading helps lower the viscosity of material feedstock for the ease of processability at the operating printing temperature and speed combinations. In contrast, as the $\mathrm{MF}^{3}$ process extends from metal injection molding (MIM), it is suggested that having sufficiently high powder loading can avoid the problem of slumping or high shrinkage during debindingsintering $[51,52]$. Prior work performed by our group looked at estimating feedstock material properties such as physical, thermal, rheological and mechanical for highly-filled powder-polymer systems to address challenges in processing and designing new powderpolymer formulations for metal injection molding and $\mathrm{MF}^{3}[50,53-55]$. Therefore, material 
sensitivity and process interactions are still a subject of interest to determine printability and rate limits for new material filament development for $\mathrm{MF}^{3}$ process $[43,56]$. Any compositional variations in filled/unfilled filaments can significantly influence their physical, thermal and mechanical properties, which subsequently dictates printability.

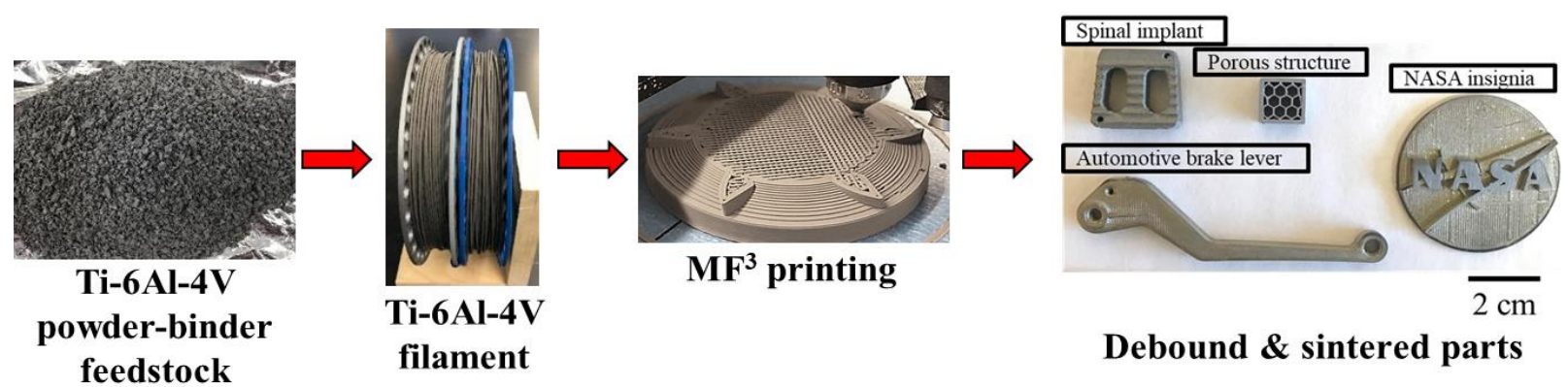

Figure 3.1. Schematic of MF3 process for Ti-6Al-4V.

Currently, the printability of a new material is assessed by performing iterative experiments with filaments at varying process conditions. A way to mitigate this time-consuming and expensive approach is to have a model that can predict and reduce the number of significant experiments. To this end, a critical variable to model is the operating pressure drop at the nozzle exit which governs the necessary force required to achieve successful printing. Further, the pressure drop determines the existing rate limits for faster and consistent printing to produce defect-free parts. The parameters that influence the pressure drop include feedstock/filament viscosity, extrusion speed (volumetric flow rate), as well as the liquefier (heater assembly) and nozzle geometry. In addition, the filament is used as a plunger to supply necessary force to overcome pressure drop at the nozzle. Consequently, 
the mechanical properties of the filament determine the ability to continuously extrude material during $\mathrm{MF}^{3}[57,58]$.

The importance of feedstock viscosity, nozzle geometry and feed rate on the pressure drop and printability are briefly discussed below:

Feedstock viscosity: The metal powder-polymer binder feedstock used to prepare filaments should exhibit appropriately low viscosity to enable continuous material extrusion at the operating printing temperature and feed rate [13]. Metal powder related attributes that affect feedstock viscosity are powder shape, size, packing, and solids loading [59]. Typically, spherical particles $<45 \mu \mathrm{m}$ are preferred due to their good flowability and filling characteristics to achieve high packing density along with low feedstock viscosity $[51,52]$. Similarly, low solids loading in the feedstock enables easy extrusion but poses sintering challenges such as high shrinkage, slumping and low dimensional tolerances. In contrast, excessively high solids loading can result in high extrusion forces, filament breakage, printing failure and poor extrusion due to high viscosity. Fine particles have been found to increase the feedstock viscosity due to increased interparticle friction but are preferred to achieve high sintered densities at relatively low sintering temperatures $[51,60]$. Increasing printing temperature can reduce feedstock viscosity but there exists a limit, which is dictated by polymer binder degradation temperature.

Nozzle geometry: The length/diameter ratio of the liquefier channel, converging angle and exit diameters of the nozzle play a vital role in influencing the pressure drop at the nozzle exit (refer Figure 3.2a The pressure drop is directly proportional to the liquefier channel 
length and inversely proportional to the nozzle diameter and its converging angle $[18,22$, 61]. The nozzle geometry also limits the particle size of the filler in the feedstock that is be extruded without powder-binder separation.

Feed rate: With an increase in the feed rate, the volumetric flow of the feedstock material increases through the nozzle. The increased flow also increases the pressure drop at the nozzle exit and thus requires a higher force to achieve continuous flow of material [62]. At high feed rates, filament strength limits can result in print failures due to filament slip or shear [63].

a)

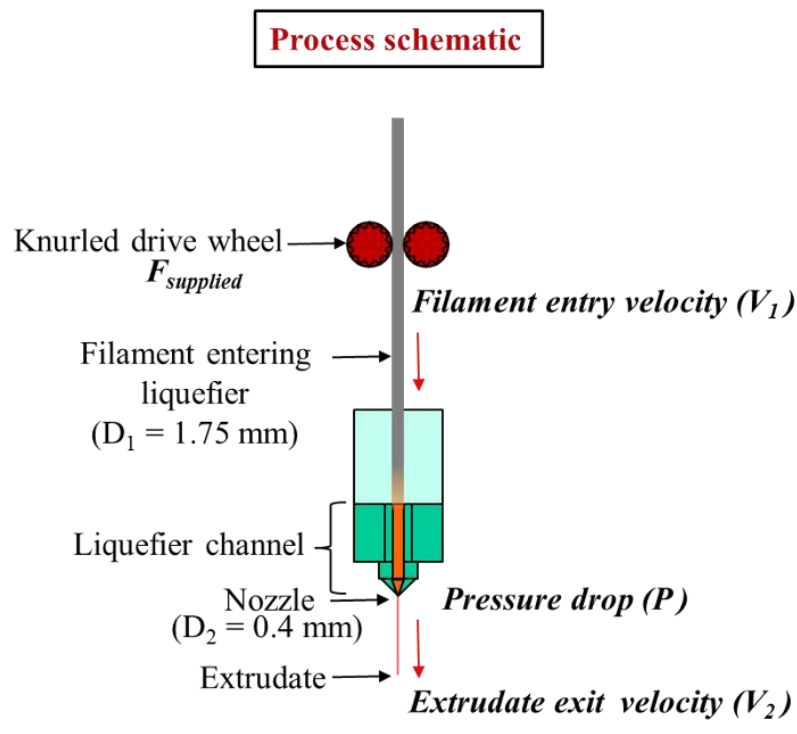

b)

Filament under nominal conditions

c)

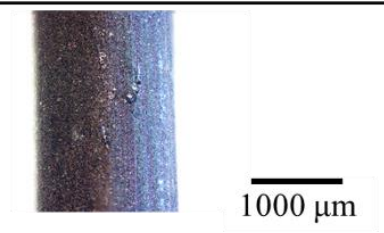

Filament failure under shear

d)
Inconsistent material extrusion

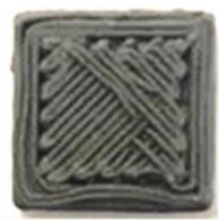

$2 \overline{\mathrm{mm}}$

Figure 3.2. a. MF3 process mechanism with filament being fed into the liquefier, b. Ti6Al-4V-polymer filament under printing conditions without any failures, c. Ti-6Al-4Vpolymer filament failure under shear, d. Inconsistent extrusion due to Ti-6Al-4V-polymer filament slip between feeding rolls. 
To overcome the overall pressure drop $(\mathrm{P})$ at the nozzle exit (schematically shown in Figure 3.2a), sufficient force must be exerted by the filament for continuous material deposition (Ti-6Al-4V-polymer filament used in this study is shown in Figure 3.2b). In majority of cases, the force transmitted by the pinch roller, of a typical $\mathrm{MF}^{3}$ feed mechanism, to the filament is sufficiently higher than the force supported by filament surface prior to failure. Go et al. [64] attributed the filament failure to the shear forces imposed by the grooved pinch roller which pushes the filament into the liquefier. Such shear failure of the Ti-6Al-4V-polymer filament, shown in Figure 3.2c, occurs when the exerted pinch roller force exceeds the maximum shear force that can be sustained by the filament surface. In other extreme situations, slipping of the Ti-6Al-4V-polymer filament at the pinch roller interface can occur and results in inconsistent material flow, which is presented in Figure 3.2d. For successful extrusion (Figure 3.2a), the force supplied $\left(\mathrm{F}_{\text {supplied }}\right)$ must be greater than the force required to overcome total pressure drop in the nozzle $(\mathrm{P})$, which depends on filament cross-sectional area $\left(\mathrm{A}_{\text {filament }}\right)$.

$$
F_{\text {supplied }}>P \times A_{\text {filament }}
$$

However, under specified printing conditions, if the $\mathrm{F}_{\text {supplied }}$ exceeds the force supported by the filament shear area $\left(\mathrm{A}_{\text {shear }}\right)$ and shear strength $\left[\tau_{\text {shear }}(\mathrm{v})\right]$, the filament failure occurs (Figure 3.2c).

$$
F_{\text {supplied }}>\tau_{\text {shear }}(v) \times A_{\text {shear }}
$$


Therefore, for successful and continuous material extrusion, the following requirement must be met:

$$
\tau_{\text {shear }}(v) \times A_{\text {shear }}>P \times A_{\text {filament }}
$$

Previous studies have reported the pressure drop at the nozzle exit, proposed filament failure criteria, and governing rate limits for printing [18, 20-28]. Anderegg et al. [5] performed in-situ pressure measurements during the FFF process and experimentally verified the model to predict pressure drop (75\% sensitivity) for ABS \{poly(acrylonitrilebutadiene-styrene) \} printing. Similarly, Ramanath et al. [65] and Bellini et al. [27] found comparative trends for the pressure drop analysis of the liquefier through modeling, experiments and FEA simulations. Gilmer et al. [26] used the relation proposed by Venkataraman et al. [66] (i.e., elastic modulus/viscosity ratio) as a criterion to assess filament failure in the FFF process, and determined a range over the expected shear rates in FFF process where successful printing can be executed. Rangarajan et al. [67] proposed the ratio of the pressure drop in the nozzle to the filament bucking stress must be $<1.1$ for successful melt flow in FFF. Serdeczny et al. [21] experimentally investigated filament feed force and proposed a model to estimate maximum feed rates. Go et al. [23] determined the equivalent extrusion force at filament failure from indentation marks imposed by the grooved drive wheel on the filament surface.

Although the pressure drop estimations have been well studied by modeling and experimental verifications and some criterion have been proposed to determine the filament 
failure, the reported work involves common thermoplastics, with only two studies reporting filament behavior for ceramic fused filament fabrication [27, 28]. Overall, there is a persistent gap in assessing the printing characteristics of highly filled materials used in $\mathrm{MF}^{3}$.

In our initial work [5], it was found that a low viscosity accompanied by good strength of the filament are critical to achieving continuous material flow for $\mathrm{MF}^{3}$. A feedstock exhibiting high homogeneity by itself promotes un-interrupted flow, and a good filament strength can act as a piston to drive the material through the nozzle overcoming the pressure drop at the end of the nozzle. The current work attempts to bridge the existing gap in determining the critical parameters to assess printability and printing rate limits for new filament developments for the $\mathrm{MF}^{3}$ process. An approach has been presented to estimate the pressure drop for given liquefier-nozzle geometry utilizing data from viscosity measurements and other geometrical parameters of the liquefier channel. Then the force required to overcome the pressure drop was determined and compared against the force sustained by filament at the failure, in order to develop printability and printing rate limit criteria of filaments with $59 \mathrm{vol} . \%$ Ti-6Al-4V powder loaded in a polymer binder.

\subsection{EXPERIMENTS AND MODELING}

\subsubsection{FILAMENT PREPARATION AND CHARACTERIZATION}


For filament preparation, Ti-6Al-4V powder (Praxair Surface Technologies, Indianapolis, IN) with two different particle size distributions was used as the filler with 59 vol. \% powder loading into a multi-component polymer binder. Ti-6Al-4V powder used in the study had a median particle size of $30 \mu \mathrm{m}$ and $13 \mu \mathrm{m}$, which were further categorized as coarse and fine respectively (Figure 3.3). The powder size distribution, pycnometer, apparent, and tap density are provided in Table 3.1.

Table 3.1. Ti-6Al-4V powder size distribution and density attributes.

\begin{tabular}{|c|c|c|}
\hline Powder & Coarse & Fine \\
\hline $\mathrm{D}_{10}(\mu \mathrm{m})$ & 2 & 7 \\
\hline $\mathrm{D}_{50}(\mu \mathrm{m})$ & 30 & 13 \\
\hline $\mathrm{D}_{90}(\mu \mathrm{m})$ & 44 & 21 \\
\hline Pycnometer density $\left(\mathrm{g} / \mathrm{cm}^{3}\right)$ & $4.43 \pm 0.002$ & $4.43 \pm 0.002$ \\
\hline Apparent density $\left(\mathrm{g} / \mathrm{cm}^{3}\right)$ & $2.54 \pm 0.002$ & $2.20 \pm 0.002$ \\
\hline Tap density $\left(\mathrm{g} / \mathrm{cm}^{3}\right)$ & $2.75 \pm 0.03$ & $2.73 \pm 0.01$ \\
\hline
\end{tabular}



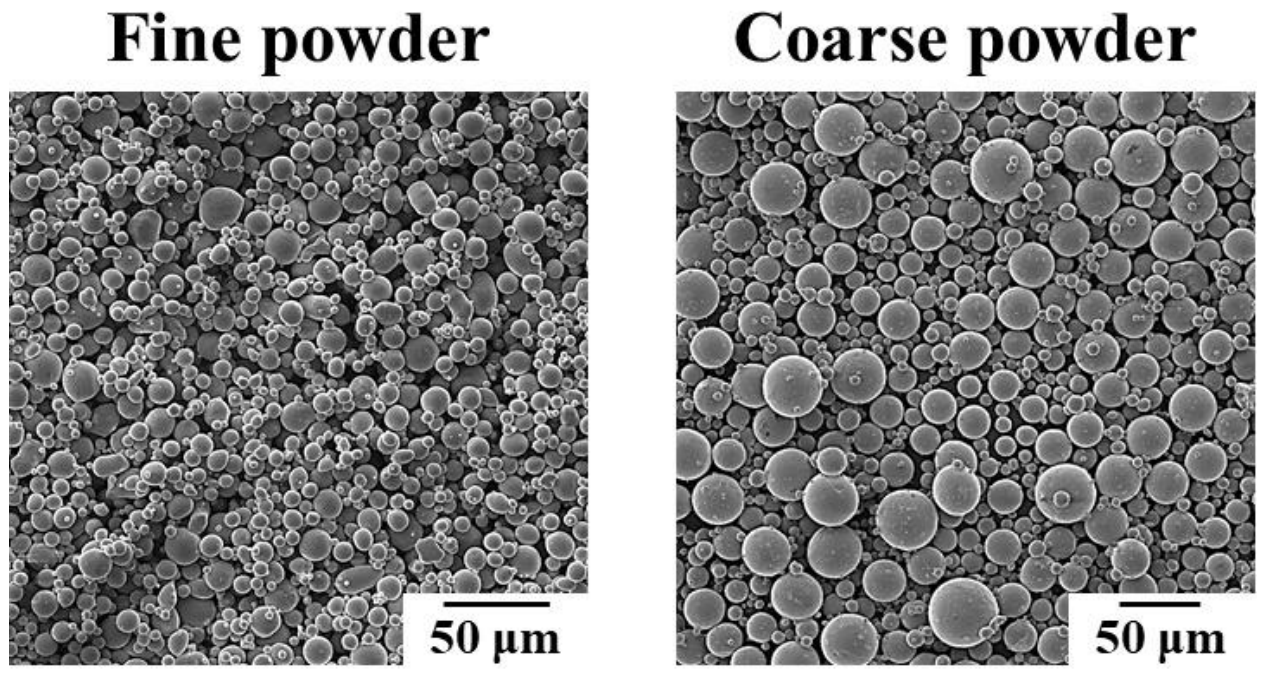

Figure 3.3. SEM of fine $\{\mathrm{D} 50(13 \mu \mathrm{m})\}$ and coarse $\{\mathrm{D} 50(30 \mu \mathrm{m})\}$ Ti-6Al-4V powders used in this study.

The current binder composition consists of several polymeric components that are proprietary. The key function of binder during the $\mathrm{MF}^{3}$ process is to feed the filament through the nozzle without buckling and hold the printed shape together for further processing. The binder components need to be removed without leaving behind any residue following debinding to maximize sinter densification and properties.

For both powder-binder feedstocks, the critical loading was determined using a torque rheometer, with mixing performed at $180{ }^{\circ} \mathrm{C}$ under a blade rotating speed of $100 \mathrm{rpm}$ (Brabender CWB, Intelli-Torque Plasti-Corder). For fine and coarse powder feedstocks, the critical loading was determined at 64 vol. $\%$ and 63 vol.\% respectively. The feedstocks for filament preparation were produced at a 59 vol. \% (87 wt.\%) with Ti-6Al-4V powder 
loaded into binder matrix for ease of processability during $\mathrm{MF}^{3}$. The 59 vol.\% Ti-6Al-4V feedstock with fine and coarse powder were extruded into filaments with a consistent diameter of $1.75 \pm 0.05 \mathrm{~mm}$ using a capillary die of $\square 1.75 \mathrm{~mm}$ (Gottfert Rheograph 20). The extrusion temperature was $105^{\circ} \mathrm{C}$ with a uniform extrusion speed of $0.1 \mathrm{~mm} / \mathrm{s}$.

Rheological testing was performed on both fine and coarse Ti-6Al-4V feedstock using a capillary rheometer (Goettfert Rheograph 20) with a tungsten carbide die (L/D ratio of 30:1). Viscosity was measured in the shear rate range of $20-800 \mathrm{~s}^{-1}$ at $240{ }^{\circ} \mathrm{C}$. A total of four tests were performed to ensure repeatability, average and standard deviation were computed from these set of measurements. The apparent shear rate obtained was corrected with Rabinowitsch correction to account for the actual shear rate at the wall [68]. Feedstock homogeneity was also assessed by measuring the viscosity variations at a fixed shear rate and temperature, and by measuring pycnometer feedstock density [36]. Typically, the $\mathrm{MF}^{3}$ feedstocks exhibit shear-thinning behavior i.e., viscosity decreases with increasing shear rate [5, 69]. Material flow properties were determined by applying the power law of Ostwald and de Waele for non-Newtonian fluids (shown in Equation 3.4) to the viscosity measurements. These flow parameters further enabled calculating the pressure drop at the nozzle exit.

$$
\dot{\gamma}=\phi \cdot \tau^{m}
$$

where, $\dot{\gamma}$ is shear rate, $\tau$ is the shear stress, $\phi$ is the material fluidity, and $\mathrm{m}$ describing material flow characteristic and its deviation from the Newtonian flow. 
The ultimate tensile strength ( $\left.\sigma_{U T S}\right)$ of the filament was determined from the stress-strain data generated using a tensile testing machine (Shimadzu EZ-test 500N). All tests were conducted at $20^{\circ} \mathrm{C}$, with a load cell of $500 \mathrm{~N}$ at a strain rate of $0.001 \mathrm{~s}-1$. Care was taken to ensure no filament slip occurred in the gripping section during the test. Filament assumed to be of consistent $1.75 \mathrm{~mm}$ in diameter to have a uniform cross-sectional area. A total of four measurements were performed for each filament type, and the average and standard deviation were determined to ensure repeatability. The ultimate tensile strength thus obtained was used to estimate the shear strength ( $\tau_{\text {shear }}$ ) of the filament using the Equation 5, which is an approximation using distortion energy theory, and sensitive to shear rate for considering thermoplastic viscoelastic behavior [23, 32].

$$
\tau_{\text {shear }}=\frac{\sigma_{U T S}}{\sqrt{3}}
$$

\subsubsection{ESTIMATING PRESSURE DROP AND FORCE REQUIREMENT}

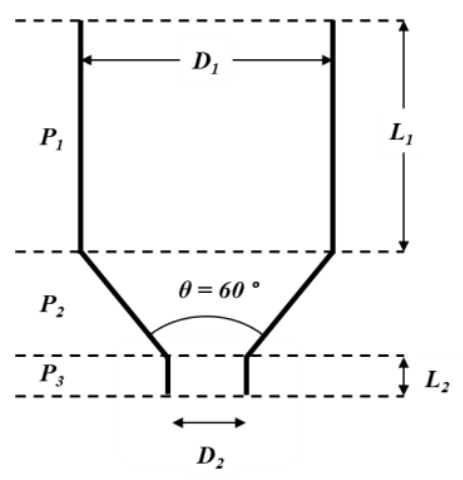

Figure 3.4. Momentum balance performed on the three sections of the nozzle geometry to determine the overall pressure drop. 
The pressure drop in the three sections of the liquefier (Figure 3.4), was estimated by performing momentum balance in conjunction with the power-law viscosity models [18, 22, 61, 70], Equation 3.6, Equation 3.7, Equation 3.8 and Equation 3.9. Some of the key assumptions in these models include melt in incompressible and isothermal, a no-slip boundary condition at the wall, flow is fully developed, steady-state, and laminar [61].

$$
\begin{gathered}
P_{1}=2 L_{1}\left[\frac{Q(m+3)}{\pi \phi\left(\frac{D_{1}}{2}\right)^{m+3}}\right]^{1 / m} \\
P_{2}=\frac{m}{3 \times \tan \left(\frac{\theta}{2}\right)} \times\left(\frac{1}{D_{2}^{3 / m}}-\frac{1}{\left.D_{1}^{3 / m}\right) \times\left[\frac{Q}{\pi \phi}(m+3) 2^{m+3}\right]^{1 / m}}\right. \\
P_{3}=2 L_{2}\left[\frac{Q(m+3)}{\left.\pi \phi\left(\frac{D_{2}}{2}\right)^{m+3}\right]^{1 / m}}\right. \\
P=P_{1}+P_{2}+P_{3}
\end{gathered}
$$

where $P$ is the total pressure drop with $P_{1}, P_{2}$, and $P_{3}$ are the pressure drops in the three different sections of the liquefier/nozzle region shown in Figure 3.4. $Q$ is the volumetric flow rate for the extrudate leaving the nozzle. $L_{l}$ and $D_{1}$ are the length and diameter at the entrance section, which is $10.5 \mathrm{~mm}$ and $1.75 \mathrm{~mm}$ respectively, and $L_{2}$ and $D_{2}$ are length 
and diameter at the exit section which is $0.6 \mathrm{~mm}$ and $0.4 \mathrm{~mm}$ respectively. And $\theta$ is the nozzle angle $\left(60^{\circ}\right)$

The volumetric flow $(Q)$ rate required for pressure drop calculations was determined in two different ways:

Estimated feed rate: In this case (Equation 3.10) the volumetric flow rate $(Q)$ was estimated following mass conservation (assuming the melt is incompressible), wherein the volume of material pushed into the liquefier is equal to the extrudate volume at the nozzle exit [71].

$$
Q\left(\mathrm{~cm}^{3} / \mathrm{s}\right)=A_{1} v_{1}=A_{2} v_{2}
$$

where, $A_{l}$ is the cross-sectional area of the filament having diameter $1.75 \mathrm{~mm}$, and $A_{2}$ is the cross-sectional area at the nozzle exit having a diameter $0.4 \mathrm{~mm} . v_{l}$ is the rate at which filament is pushed by pinch rollers into the liquefier and $v_{2}$ is the exit velocity of the extrudate as it leaves the nozzle. The feed rate $\left(v_{1}\right)$ was varied from $0.5 \mathrm{~mm} / \mathrm{s}$ to $16 \mathrm{~mm} / \mathrm{s}$, which directly influence the volumetric flow of the material thereby affecting the pressure drop.

Experimental feed rate: In this case, the actual volumetric flow rate $(Q)$ was determined by weighing the extrudate after extruding filament through the nozzle at $240{ }^{\circ} \mathrm{C}$ for $10 \mathrm{~s}$ at different feed rates $(0.5 \mathrm{~mm} / \mathrm{s}$ to $16 \mathrm{~mm} / \mathrm{s})$, without depositing the material on the substrate. 
For each feed rate condition, to ensure repeatability, the average volumetric flow rate and its standard deviation were determined from four measurements. The flow rate was calculated using Equation 3.11.

$$
Q\left(\mathrm{~cm}^{3} / \mathrm{s}\right)=\frac{\text { Measured extrudate mass }\left(\frac{\mathrm{g}}{\mathrm{s}}\right)}{\text { Material density }\left(\frac{\mathrm{g}}{\mathrm{cm}^{3}}\right)}
$$

The pressure drop estimations were performed for the liquefier nozzle geometry with varying flow rates corresponding to the filament feed rates between $0.5 \mathrm{~mm} / \mathrm{s}$ and $16 \mathrm{~mm} / \mathrm{s}$. The materials constants $m$ and $\Phi$ were determined from the experimentally measured viscosity data. To overcome the pressure drop $P$ in Equation 3.9, a force, $F$ is required to achieve successful material extrusion, which can be calculated with Equation 3.12.

$$
F=P \times A_{\text {filament }}
$$

where, $A_{\text {filament }}$ is the area of filament cross-section at entry.

\subsection{RESULTS AND DISCUSSION}

\subsubsection{FEEDSTOCK-FILAMENT PROPERTIES}

The feedstocks with 59 vol.\% Ti-6Al-4V fine and coarse powder loaded into binder matrix were characterized for viscosity as a function of shear rate at $240^{\circ} \mathrm{C}$. The viscosity of the feedstock material is sensitive to temperature, shear rate and the powder solids loading [51]. Figure 3.5 shows that, for both the coarse and fine powder filament feedstocks, the viscosity decreases with increasing shear rate. For fine powder feedstock, increasing the 
shear rate from $20 \mathrm{~s}^{-1}$ to $800 \mathrm{~s}^{-1}$ showed a decrease in the viscosity from $475 \pm 30 \mathrm{~Pa}$ s to $60 \pm 5$ Pa's. Similarly, for coarse powder feedstock the viscosity decreased from $410 \pm 20$ Pa's to $35 \pm 5 \mathrm{~Pa}$. At all the experimented shear rates, the finer powder exhibited a relatively higher viscosity than the coarse powder, which can be attributed to the higher surface area of small powder particles requiring higher binder amount for uniform wetting.

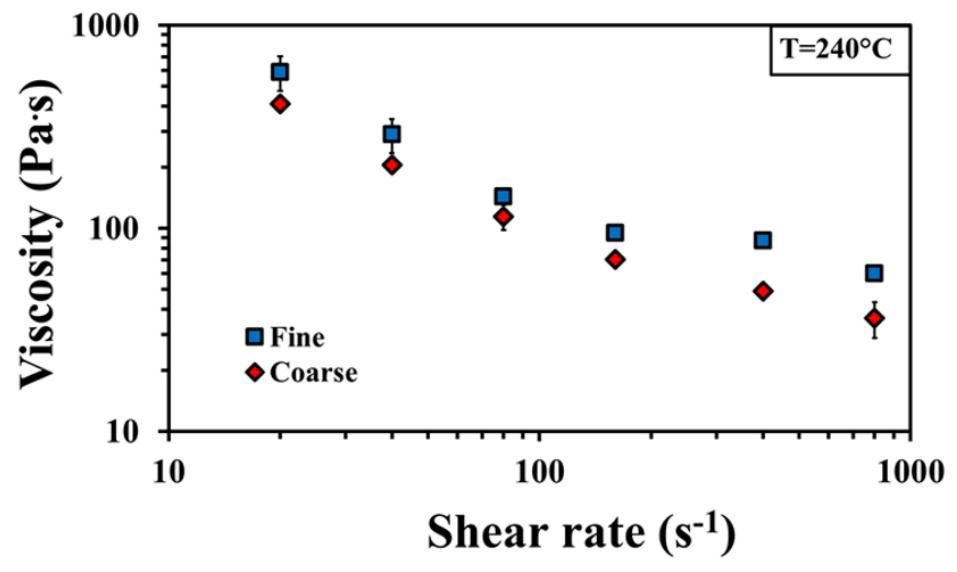

Figure 3.5. Influence of shear rate on the feedstock viscosity for 59 vol. $\%$ fine and coarse Ti-6Al-4V powder at $240{ }^{\circ} \mathrm{C}$.

The exponents $\phi$ and $m$ were determined (using Equation 3.4) for coarse and fine powder feedstock at $240{ }^{\circ} \mathrm{C}$ in the shear rate range of $160 \mathrm{~s}^{-1}$ to $800 \mathrm{~s}^{-1}$, as suggested by Hopmann and Michaeli [61] for acceptable accuracy. $\phi$ for fine and coarse powder feedstock was 7 x $10^{-8}$ and $2 \times 10^{-6}$ respectively, and $m$ for fine and coarse powder feedstock was 2.2454 and 2.093 respectively. $\phi$ represents fluidity, which for fine powder was lower by two orders of magnitude compared to the coarse powder, owing to comparably higher viscosity as seen in Figure 3.5. In the shear rate range of $10^{0}$ to $10^{4} \mathrm{~s}^{-1}$, the expected $m$ values are in the range of 2-4 for non-Newtonian fluids [61]. The parameter, $m$ is indicative of the 
material tendency towards non-Newtonian behavior. The parameter, $m$ was found to be $\sim 10 \%$ higher for the fine powder feedstock compared to the coarse powder feedstock, in agreement with the higher viscosity of fine powder. These parameters were substituted in Equations 3.6, Equation 3.7 and Equation 3.8 in order to estimate the pressure drop for the specific material.

Estimating the shear strength of the filament (from its tensile strength) is important to assess the failure probability of filament at the entry under different printing conditions. For this purpose, the shear contact area between the filament and the feed drive wheel was determined using surface indentations inscribed by the knurled drive wheel on the filament surface when the filament is being pushed into the liquefier, as shown in Figure 3.6a. The indentation marks on the filament surface, Figure 3.6b, were analyzed using an optical microscope (Olympus BX-51) and the contact area was measured. The area under the shear force exerted by the drive wheel on the filament thus determined for 4 filament samples was $1.45 \pm 0.08 \mathrm{~mm} 2$. The measured area and the subsequently obtained extrusion force are dependent on drive wheel tooth geometry (shape, size, depth, angle) and filament strength properties. Go et al. [23] experimentally determined the failure force and found a good agreement of nearly 85\% with the estimated shear force (determined from Equation 3.5). Table 3.2 shows the experimentally determined ultimate tensile strength ( $\left.\sigma_{U T S}\right)$ of the filament and the corresponding shear strength $\left(\tau_{\text {shear }}\right)$ estimated using Equation 3.5. Filaments produced with both the feedstocks had comparable UTS. Utilizing the values thus obtained, the maximum force $\left(\tau_{\text {shear }} \times A_{\text {shear }}\right)$ the filament can sustain before failure was determined to be $\sim 1 \mathrm{~N}$ for both fine and coarse powder filaments. The values thus 
obtained serve as the limiting force at which the filament fails either by slip/failure, thereby interrupting the print. The printing is expected to run smooth with continuous material flow as long the required force to overcome pressure drop at nozzle exit is lower than above determined limiting force for filament. Once the required force to overcome pressure drop exceeds this limiting value, failure is expected with stalling the printing operation.

a)

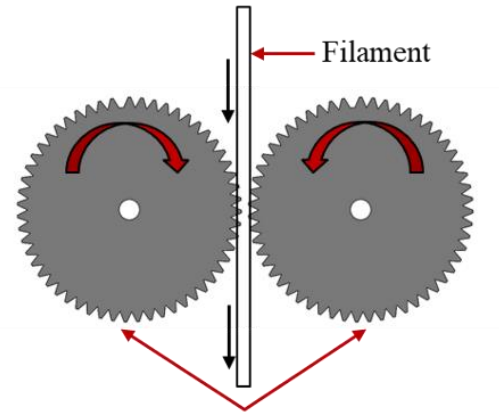

Knurled wheel mechanism b)

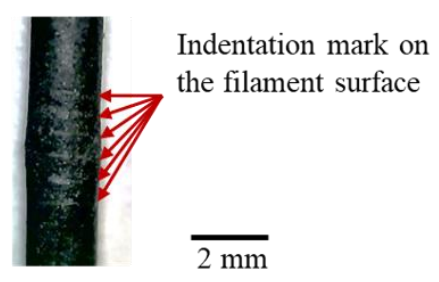

Figure 3.6. a. Knurled wheel drive mechanism used to feed the filament into the liquefier representing tooth engagement onto the filament surface, b. Indentation marks on the filament surface used to calculate the shear area.

Table 3.2. Mechanical properties of filaments with 59 vol.\% Ti-6Al-4V powder.

\begin{tabular}{|c|c|c|}
\hline Parameter & Fine powder filament & Coarse powder filament \\
\hline$\sigma_{\text {UTS }}(\mathrm{MPa})$ & $1.25 \pm 0.30$ & $1.15 \pm 0.15$ \\
\hline$\tau_{\text {shear }}(\mathrm{MPa})$ & $0.72 \pm 0.15$ & $0.67 \pm 0.10$ \\
\hline $\mathrm{F}_{\text {shear }}(\mathrm{N})$ & $1.02 \pm 0.20$ & $0.95 \pm 0.10$ \\
\hline
\end{tabular}




\subsubsection{PRESSURE DROP ESTIMATIONS AND THE FORCE REQUIREMENTS}

The pressure drop resulting from both the fine and coarse powder filament extrusion, under estimated and experimental cases were determined at different feed rates and the resulting force required to achieve successful material extrusion are presented in Figure 3.7.
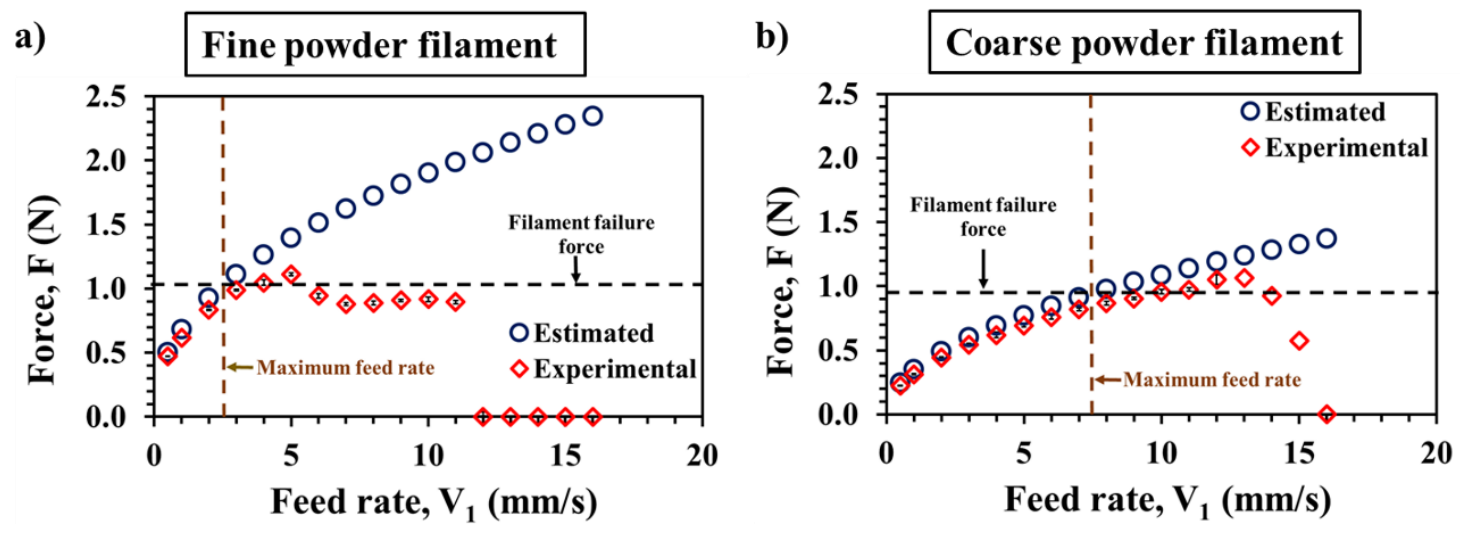

Figure 3.7. The force required to overcome the pressure drop for estimated and experimental cases. The horizontal line represents the maximum force the filament can sustain before failure. The vertical line shows the limiting feed rates for successful material extrusion and printing. a. Fine powder filament, b. Coarse powder filament.

For estimated feed rate, as shown in Figures 3.7a \& 3.7b, both filament types showed gradual increase in the extrusion force with increasing feed rate. At $0.5 \mathrm{~mm} / \mathrm{s}$ the required force to overcome pressure drop for fine powder filament is $0.5 \mathrm{~N}$, which at $16 \mathrm{~mm} / \mathrm{s}$ reaches $2.35 \mathrm{~N}$. Similarly, the extrusion force increased from $0.25 \mathrm{~N}$ to $1.4 \mathrm{~N}$ for coarse powder filaments. The higher force requirements for the fine powder are attributed to its high viscosity leading to a high-pressure differential at the nozzle end, and to enable continuous material flow the force required is higher. 
Distinguishable difference was observed for the influence of feed rate on extrusion forces for experimental feed rate. It can be seen that the extrusion force increased gradually up to a certain speed after which it dropped to zero. For fine powder filaments, a maximum force of $\sim 1 \mathrm{~N}$ was reached at $5 \mathrm{~mm} / \mathrm{s}$ and the force fluctuated at $\sim 0.90 \mathrm{~N}$ until $11 \mathrm{~mm} / \mathrm{s}$ and after that dropped to zero. However, the coarse powder filaments found to sustain relatively higher feed rates, up to $13 \mathrm{~mm} / \mathrm{s}$, before a drop in force requirement was observed. The maximum feed rate achieved for coarse powder filament was twice that of the fine powder filament, suggesting the possibility of higher throughput when printing a 3D geometry. The coarse powder filament had a comparable limiting force (Table 3.2) as that of the fine powder filament but a relatively lower viscosity (Figure 3.5) which enabled it to get printed at higher feed rates until the force reaches limiting value of $\sim 1 \mathrm{~N}$.

In estimated case, both filaments represent an ideal situation where it is assumed that the filament strength is sufficient enough to meet the necessary force requirements to overcome the existing nozzle pressure drop. The experimental case represents actual operating conditions during $\mathrm{MF}^{3}$ with filament strength restriction on its ability to provide the necessary force for continuous material flow as a function of increasing feed rate. Such behavior can be attributed to the limiting filament strength, where the force supported by the filament remains consistent or below $\sim 1 \mathrm{~N}$ for fine and coarse powder filaments. Successful material extrusion and printing are expected as long the force required to overcome the pressure drop is respective of the limiting strength of the filament, once the 
required force exceeds the shear force supported by filament surface, chances of print failure are inevitable.

The horizontal dashed line in Figures 3.7a $\&$ 3.7b represents the limiting force supported by the filament shear area. When a vertical line is drawn from the point of intersection between the limiting force and the required force to overcome the pressure drop (from experimental case), the maximum supported speed or rate limits can be estimated. From Figure 3.7a, for fine powder filament, the estimated feed rate limit was found to be 2.5 $\mathrm{mm} / \mathrm{s}$ and, from Figure 3.7b for coarse powder filament, the estimated feed rate limit was at $7.6 \mathrm{~mm} / \mathrm{s}$. Exceeding the extrusion rate limits typically would result in print-related issues and failures.

From Figures 3.7a \& 3.7b, it can be clearly seen that at low feed rates the force requirements remain almost the same for experimental and estimated cases. But with increasing feed rate the differences between experimental and estimated cases increases due to filament slip (as seen in Figure 3.7a for experimental case, within speed range of $5-11 \mathrm{~mm} / \mathrm{s}$ ) followed by complete shear failure with no material exiting from the nozzle. Experimental case provides the actual in-process overview of the phenomenon with events occurring during the process itself, and verification to the approach used with estimated case to determine material printability and rate limits. 


\subsubsection{PRINTABILITY ASSESSMENT}

The effect of feed rate on the printing process was experimentally evaluated for both the powder filament systems. For each feed rate, 4 samples $\left(10 \times 10 \times 5 \mathrm{~mm}^{3}\right)$ were printed (with Pulse 3D printer from Matterhackers), and with a filament density of $3 \mathrm{~g} / \mathrm{cm}^{3}$, the printed parts with $100 \%$ density were expected to weigh $1.5 \mathrm{~g}$. Figure 3.8a shows the parts in the as-printed condition, and Figure 3.8b shows the weight of respective parts with increasing feed rate.

a)

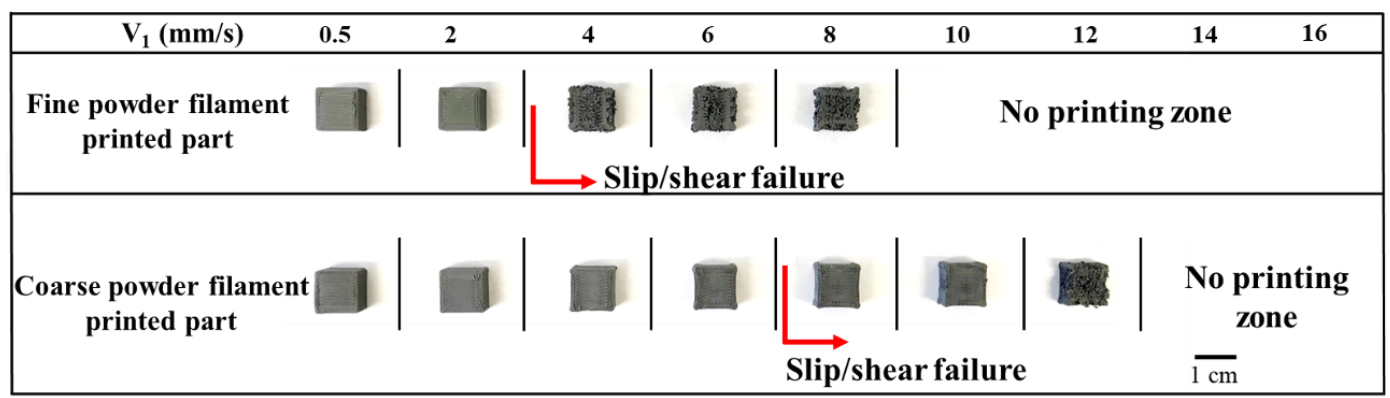

b)

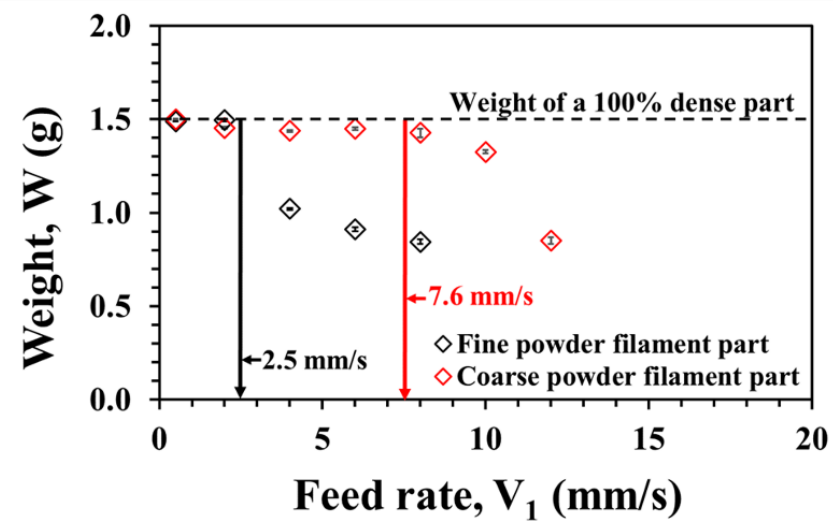

Figure 3.8. Effect of feed rate on the, a. printed geometry. b. printed part weight (Dotted line indicates expected part weight of $1.5 \mathrm{~g}$ ). 
Fine powder filaments exhibited good printability and weigh of $1.49 \pm 0.05 \mathrm{~g}$ up to feed rate of $2 \mathrm{~mm} / \mathrm{s}$ as seen from Figure 3.8. Further, an increase in the feed rate from 4 to 8 $\mathrm{mm} / \mathrm{s}$ resulted in nonuniform material deposition with wide gaps throughout the structure (Figure 3.8a), and part weight dropped to $0.9 \pm 0.1 \mathrm{~g}$. No parts could be printed with feed rate of $10 \mathrm{~mm} / \mathrm{s}$ and beyond. These printing results correlate very well with the findings from the estimations shown in Figure 3.7a for estimated case, where $2.5 \mathrm{~mm} / \mathrm{s}$ was found as the limiting feed rate for finer powder filaments. Also, experimental case (Figure 3.7a), represented feed rate above $5 \mathrm{~mm} / \mathrm{s}$ and until $11 \mathrm{~mm} / \mathrm{s}$ causing failure due to slip with intermittent flow of material, which was evident in the printed parts with structural gaps and reduced weight in Figure 3.8. During printing operation with feed rate of $10 \mathrm{~mm} / \mathrm{s}$ and above, printing was not realized due to shear failure of the filament. On the other hand, the coarse powder filaments exhibited good printability (with weights of $1.46 \pm 0.08 \mathrm{~g}$ ) until feed rate of $6 \mathrm{~mm} / \mathrm{s}$, as seen from Figure 3.8, and with increasing feed rate from 8 to12 $\mathrm{mm} / \mathrm{s}$ the printed parts had nonuniform material deposition leading to wide gaps in the parts (Figure 3.8a). A feed rate of $14 \mathrm{~mm} / \mathrm{s}$ and beyond resulted in no printing. These printing results also corroborate the findings shown in Figure 3.7b for estimated case, where $7.6 \mathrm{~mm} / \mathrm{s}$ was found as the limiting feed rate, beyond which failure is expected. Similarly, experimental case (Figure 3.7b) represented speed above $13 \mathrm{~mm} / \mathrm{s}$ causing failure due to slip resulting in inconsistent material deposition and ultimately reaching condition of no printing. 


\subsubsection{APPLICABILITY AND TESTING TO OTHER FILAMENTS}

The above approach from estimated case in conjunction with the force sustained by filament at failure was used to evaluate three different filament systems. ABS (commercially available from SainSmart), two filaments with 59 vol.\% loaded Ti-6Al-4V with each having different binder systems were used as a case study to evaluate printability and rate limits. The filament feedstock was characterized for viscosity in the shear rate range of $160-800 \mathrm{~s}^{-1}$ at $240{ }^{\circ} \mathrm{C}$ to determine $m$ and $\phi$ values used as input variables to determine pressure drop (Equation 3.9). The filament mechanical strength was determined, and from there the force at filament shear was evaluated (Equation 3.5). The obtained viscosity and strength related parameters are available in Table $\mathbf{3 . 3}$ for all 3 filament systems.

Table 3.3. Viscosity and filament strength parameters obtained for ABS, B1, and B2, to predict material printability and rate limits.

\begin{tabular}{|c|c|c|c|c|c|}
\hline Material & $\mathbf{m}$ & $\begin{array}{c}\Phi \\
\left(\mathbf{P a}^{-1} \mathbf{s}^{-\mathbf{1}}\right)\end{array}$ & $\begin{array}{c}\boldsymbol{\sigma}_{\text {UTS }} \\
(\mathbf{M P a})\end{array}$ & $\begin{array}{c}\boldsymbol{\tau}_{\text {shear }} \\
(\mathbf{M P a})\end{array}$ & $\begin{array}{c}\boldsymbol{F}_{\text {shear }} \\
(\mathbf{N})\end{array}$ \\
\hline $\mathrm{ABS}$ & 2.4585 & $1 \times 10^{-10}$ & $16.5 \pm 1.10$ & $9.5 \pm 0.5$ & $13.6 \pm 0.7$ \\
\hline $\mathrm{B} 1$ & 2.1268 & $2 \times 10^{-7}$ & $0.24 \pm 0.04$ & $0.14 \pm 0.02$ & $0.2 \pm 0.03$ \\
\hline $\mathrm{B} 2$ & 1.5666 & $1 \times 10^{-5}$ & $1.4 \pm 0.40$ & $0.80 \pm 0.2$ & $1.15 \pm 0.25$ \\
\hline
\end{tabular}


a)

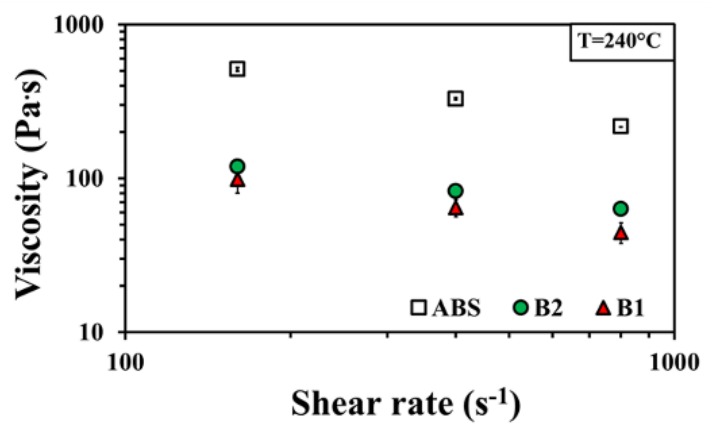

b)

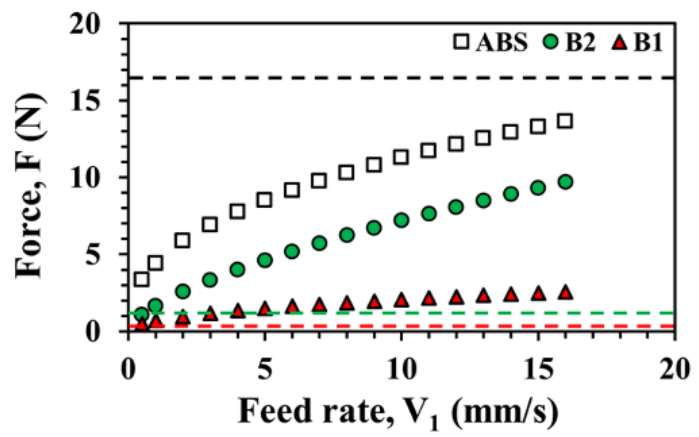

Figure 3.9. a. Variation of viscosity with shear rate of ABS (black), B2 (green), and B1 (red) feedstocks at $240{ }^{\circ} \mathrm{C}$, b. Estimated force determined from pressure drop calculations evaluated against the horizontal line representing limiting force a filament sustain prior to failure.

Figure 3.9a shows the viscosity of all three systems at the shear rate range of $160-800 \mathrm{~s}^{-1}$, with ABS having the highest viscosity followed by B2 and then B1. At 400s ${ }^{-1}$, ABS had a viscosity of $325 \pm 5 \mathrm{~Pa} \cdot \mathrm{s}, \mathrm{B} 2$ had a viscosity of $80 \pm 1 \mathrm{~Pa}$ s, and B1 had the lowest value of $65 \pm 5$ Pas. Figure 3.9b shows the resulting force (Equation 3.12), required to overcome the pressure drop (Equations 3.6-3.9) for continuous material extrusion for all three systems. ABS required a force of $3.3 \mathrm{~N}$ to enable extrusion starting at a feed rate of 0.5 $\mathrm{mm} / \mathrm{s}$, and reached $13.6 \mathrm{~N}$ at a feed rate of $16 \mathrm{~mm} / \mathrm{s}$. The force estimated for the shear failure of $\mathrm{ABS}$ was $16.5 \pm 1 \mathrm{~N}$ which was above the required force for feeding the material, thereby allowing for smooth material printability at all explored speeds. Feedstock B2 required a force of $\sim 1 \mathrm{~N}$ to enable extrusion starting at a feed rate of $0.5 \mathrm{~mm} / \mathrm{s}$ and reached 9.7 $\mathrm{N}$ for a feed rate of $16 \mathrm{~mm} / \mathrm{s}$. However, the estimated force at shear failure was $\sim 1.1$ $\mathrm{N}$ which was relatively close to the required force at the lowest feed rate. Consequently, 
printing was not possible owing to problems related to inconsistent material flow as seen for experimental case in Figure 3.7a. Feedstock B1 required a force of $\sim 0.5 \mathrm{~N}$ to enable extrusion starting at a feed rate of $0.5 \mathrm{~mm} / \mathrm{s}$, which at $16 \mathrm{~mm} / \mathrm{s}$ reaches $2.5 \mathrm{~N}$. Since the estimated force at shear is found to be $0.2 \mathrm{~N}$ the printing failed. With printing experiments at $0.5 \mathrm{~mm} / \mathrm{s}$ it was confirmed that feedstock B1 was not printable at all, and feedstock B2 showed inconsistent material flow and later failed at the roller grip. In contrast, the ABS filament printed without failure under the printing speeds evaluated. Accordingly, the predictions of the printability model were consistent with the printability experiments with the 3 materials.

\subsection{CONCLUSIONS}

The printability and printing rate limits for a Ti-6Al-4V filament can be determined by estimating the force required to overcome the nozzle pressure drop and comparing it to the maximum force the filament can sustain prior to failure. An increase in feed rate from 0.5 $\mathrm{mm} / \mathrm{s}$ to $16 \mathrm{~mm} / \mathrm{s}$ for Ti-6Al-4V filaments resulted in an increase in the force required to overcome the pressure drop from $0.5 \mathrm{~N}$ to $2.35 \mathrm{~N}$ and $0.25 \mathrm{~N}$ to $1.4 \mathrm{~N}$, for fine and coarse powder filaments, respectively. The maximum force that a Ti-6Al-4V filament can sustain was found to be $\sim 1 \mathrm{~N}$ for fine and coarse powder filaments. Successful $\mathrm{MF}^{3}$ printing could be achieved as long the force required to overcome the pressure drop remained below the strength of the filament. Based on this, the maximum feed rates were found to be $2.5 \mathrm{~mm} / \mathrm{s}$ and $7.6 \mathrm{~mm} / \mathrm{s}$ respectively for fine and coarse filaments, which was consistent with the viscosity differences between the 2 feedstocks. The printing results indicated that the 
printing was disrupted beyond $2 \mathrm{~mm} / \mathrm{s}$ and $6 \mathrm{~mm} / \mathrm{s}$ for fine and coarse powder filaments, respectively. The printability of a commercially available ABS and two other Ti-6Al-4V powder binder formulations were evaluated to further confirm the applicability of the model. A good fit for was observed between prediction and experimentally observed performance, suggesting a strong potential for the proposed model to be extended to designing new materials for the $\mathrm{MF}^{3}$ process. 


\section{CHAPTER 4}

\section{FACTORS AFFECTING DENSITY AND RELATED PROPERTIES OF TI-6AL-4V}

ALLOY PARTS MADE USING METAL FUSED FILAMENT FABRICATION (MF3)

\subsection{INTRODUCTION}

Producing net shape functional parts with metals is at the forefront of additive manufacturing (AM), where metal fused filament fabrication $\left(\mathrm{MF}^{3}\right)$ stands as a potentially fast advancing technology. The $\mathrm{MF}^{3}$ process utilizes continuous filament made with polymer filled metal particles as the feedstock material. These filaments can be used on any commercially available Fused Filament Fabrication (FFF) printers to produce 3D geometries, which are subsequently post-processed to remove the polymer binder followed by densification. The entire process involves several steps: homogeneous feedstock preparation, producing filaments and then printing fully dense green parts, solvent/thermal debinding, and sintering parts at elevated temperatures for densification. The feasibility to produce metal parts using this technique has been demonstrated by several researchers and is gaining significant interest in the past five years $[4,5,8-12,72,73]$. The $\mathrm{MF}^{3}$ process presents multiple advantages in the face of AM to eliminate the material-specific constraints that limit common metal AM technologies (laser powder bed fusion, direct energy deposition). Since any powder feedstock can be produced into filaments and therefore printed and subsequently sintered utilizing the established sintering knowledge. $\mathrm{MF}^{3}$ shares lot of similarities with Metal Injection Molding (MIM) in terms of feedstock 
development, binder removal and sintering. Since the densification of the part is achieved by classical sintering, the parts with isotropic properties can be manufactured using $\mathrm{MF}^{3}$.

Some of the previous work by our group demonstrated that estimating thermophysical material properties for powder-filled polymer mixtures, including Ti-6Al-4V alloy, is extremely critical to address process-related challenges in the development of new powderpolymer formulations for $\mathrm{MF}^{3}$ and $\mathrm{MIM}$ [54, 55, 72]. Additionally, our recent work addressed the material related challenges which need to be sufficed to have an uninterrupted printing process for $\mathrm{MF}^{3}$ [[13]]. It was found that filament viscosity and its strength in conjunction with the liquefier geometry are the governing factors to determine material printability and its rate of printing. Since the build rates for AM processes are typically low, optimizing the processing speed offers the advantage to realize the potentials of the technology. The filament development, printing, and sintering involve several critical parameters, which requires a careful investigation to maximize the process performance. Therefore, understanding the processing variables and their effect is very critical to achieve high sintered density and property consistency in the parts made using $\mathrm{MF}^{3}$. Figure 4.1 shows the $\mathrm{MF}^{3}$ process overview with powder-binder mixtures produced into filaments, once printed into parts, it goes through sintering to achieve final properties comparable to those of the traditional processes. 


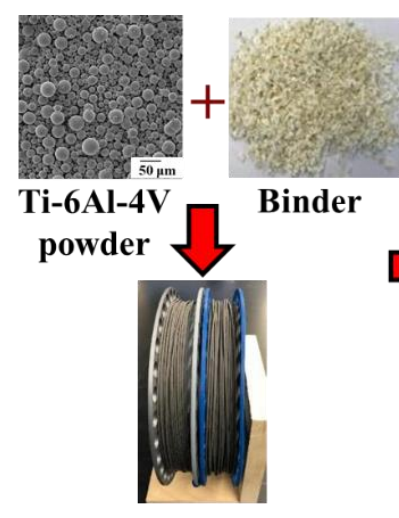

Ti-6Al-4V filament

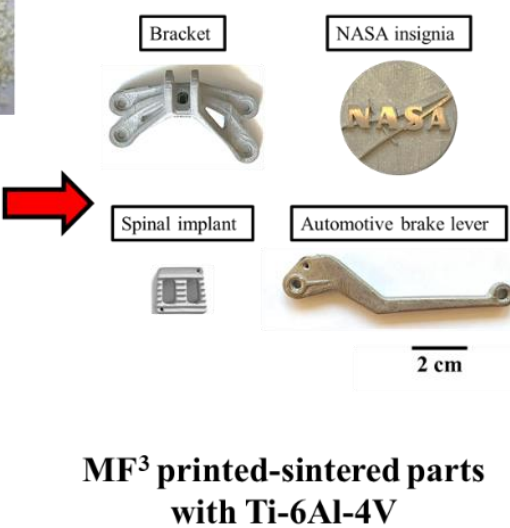

with Ti-6Al-4V

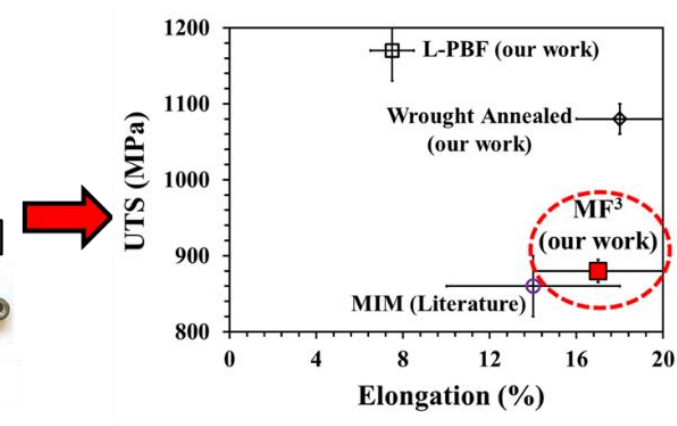

Mechanical properties of Ti-6Al-4V by $\mathrm{MF}^{3}$ and other processes

Figure 4.1. Metal fused filament fabrication of Ti-6Al-4V process overview and achievable properties $\{$ literature reference for MIM $[28,30,31,74]\}$.

Since the $\mathrm{MF}^{3}$ is a multi-step process, it is an ultimate necessity to control each processing step cautiously to achieve desired properties in the sintered parts. For example, our experiments during the processing of Ti-6Al-4V alloy with $\mathrm{MF}^{3}$ showed different defects originating at each individual step, which can be detrimental to the mechanical properties of the parts. Figure 4.2 shows microscale pores in the filament and macroscale pores resulting from the printing defects, altogether these defects compromise the properties at each stage and thus final sintered part. As shown in Figure 4.2, a low-density filament with voids scattered throughout the cross-section, when printed into a geometry, adds up to the low density of the printed part. Furthermore, the defects can arise due to incorrect print parameter selection, leading to wide macroscale pores, further reducing the part density. When these low-density printed parts are subjected to sintering, the condition exacerbates to produce final structures with inherent voids representing a low sintered density. 
Poor filament density along with diameter inconsistency can affect its strength and flow properties, and further resulting in inconsistent material flow when printing. Also, diameter reduction can decrease the volumetric flow of material from the expected value at the optimum print condition, creating print defects. The print parameters are very specific to the material flow and strength properties, since viscosity increases with the addition of metal particles or other forms of fillers, and feed rate is limited by filament strength. For every new composition of material development, the print parameters must be tailored specifically to material-process interactions to eliminate print defects. The final step is the debinding-sintering of metals which requires an optimal control of time, temperature and process environment conditions. A part with too many distributed internal voids has higher chances of slumping during the solvent/thermal extraction of the polymer. The problem of low-density sintered part elevates further from the metal susceptibility to existing impurities, which results in poor mechanical properties. 


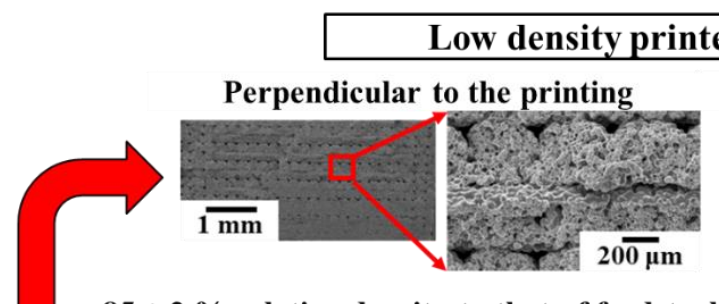

$85 \pm 2 \%$ relative density to that of feedstock density at 59 vol. $\%$ Ti-6Al-4V

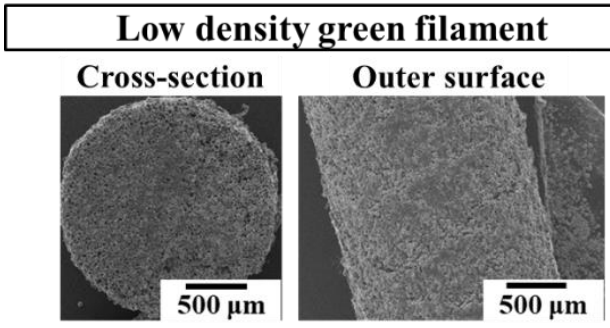

$90 \pm 1 \%$ relative density to that of feedstock density at 59 vol.\% Ti-6Al-4V

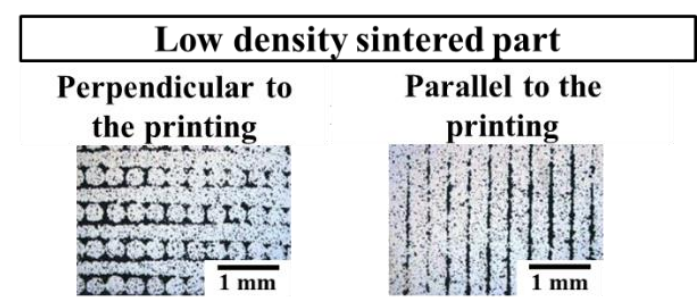

$84 \pm 2 \%$ relative density to that of bulk Ti-6Al-4V powder density

Figure 4.2. Critical effects of low-density filaments on green part density and the importance of printing parameters on the defects generated in the green parts, which are carried forward to sintered parts produced using $\mathrm{MF}^{3}$.

The defects/voids resulting from the FFF printing parameters on the mechanical properties has been well investigated for common thermoplastic materials including Polylactic Acid (PLA), Acrylonitrile butadiene (ABS) and Polycarbonate [75, 76]. Some of the commonly investigated print parameters for thermoplastic materials include layer thickness, extrusion temperature, infill percentage and pattern, bead (road) width, and print speed $[10,56,75-$ 84]. The majority of these studies found a good agreement between low layer height and associated improvement in the strength and dimension stability of thermoplastic parts [7780]. Other significant parameters included high infill percentage and bead width to eliminate the voids. To our knowledge, there is no open literature available in terms of the filament development for the $\mathrm{MF}^{3}$ process or even filled polymer composite filaments. 
Only a recent study investigated print parameter optimization for the $\mathrm{MF}^{3}$ process with 17$4 \mathrm{PH}$ stainless steel and found the extrusion multiplier as a major influencing factor to improve the green part tensile strength [10]. As mentioned earlier, process parameters need revision for any new material compositions due to the variations in the viscosity and strength characteristics of different materials used to make filaments.

Ti-6Al-4V is the ultimate material of choice for the aerospace industry for its attractive high strength to weight ratio, and its bioinert nature makes it a great candidate for the medical device industry $[6,85]$. Conventionally, MIM has been a widely adopted process to produce titanium alloy parts, with a recent shift is made towards AM technologies owing to the freedom of customization. $\mathrm{MF}^{3}$ offers a combination of $\mathrm{AM}$ (from the perspective of customization), and MIM (able to produce isotropic properties throughout the part volume). However, sintering Ti-6Al-4V requires adequate control of processing technique to achieve the targeted results and meet the ASTM requirements with the minimal pickup of interstitials [86]. Common problems from oxygen and carbon impurities on mechanical properties have widely been reported in the published studies [87, 88]. There exists a very narrow window for the maximum concentration of the interstitials which considered in the safe range to obtain repeatable properties for Ti-6Al-4V. Even a slight increase can result in a drastic compromise in properties, particularly elongation to fracture $[48,88]$.

In this work we report the critical aspects of filament development to achieve high density and dimensional stability using Ti-6Al-4V powder binder feedstock. Furthermore, the 
effects of print parameters were systematically evaluated using Taguchi design of experiments to fabricate Ti-6Al-4V alloy parts with highest possible density and dimensional precision using $\mathrm{MF}^{3}$. The effect of sintering parameters on the density and mechanical properties of $\mathrm{MF}^{3} \mathrm{Ti}-6 \mathrm{Al}-4 \mathrm{~V}$ was investigated and correlated with residual interstitials in these parts.

\subsection{MATERIALS AND METHODS}

\subsubsection{POWDER-BINDER FEEDSTOCK-FILAMENT DEVELOPMENT}

In the current study, spherical Ti-6Al-4V powder (Praxair Surface Technologies, Indianapolis, IN) with two-particle size variations, having a median size of $30 \mu \mathrm{m}$ and 13 $\mu \mathrm{m}$ were used, which were further categorized as coarse and fine, respectively. Both powders were characterized for pycnometer density (Micromeritics Accupyc II 1340) as per ASTM B923-16, apparent density and tap density (Aimsizer Scientific AS-100) as per ASTM D7481-18. The Hausner ratio (tap density/apparent density) was used as an index to determine the material flowability typically a value below 1.25 represents good powder flow [89]. The binder consisted of a multi-component polymer system which is proprietary. The key binder attributes are to lower the material viscosity to ease flow while printing and providing strength to the part while it is being thermally processed. Powder critical loading was experimentally determined using a torque rheometer (Brabender CWB, Intelli-Torque Plasti-Corder) with a mixing speed of $100 \mathrm{rpm}$ at $180{ }^{\circ} \mathrm{C}$. The critical loading represents the condition of maximum powder that can be safely infused into the binder matrix, 
exceeding which leads to increased interparticle friction and affects the flow during printing.

For the filament-feedstock preparations, the powder loading was selected at 59 vol.\% (1\% lower than the critical loading) to achieve consistent and uniform flow during printing. The feedstock mixing was carried out in a torque rheometer with prep mixer (Brabender CWB, Intelli-Torque Plasti-Corder) at a mixing speed of $100 \mathrm{rpm}$ at $180{ }^{\circ} \mathrm{C}$ for 45 minutes until the torque reached a stable plateau. The feedstock with coarse and fine Ti-6Al-4V powder at 59 vol.\% loading was characterized for homogeneity and powder loading consistency using a capillary rheometer (Goettfert Rheograph 20) and helium gas pycnometer (Micromeritics Accupyc II 1340), respectively. The time-dependent viscosity fluctuations were monitored at a constant shear rate of $50 \mathrm{~s}^{-1}$ at $160{ }^{\circ} \mathrm{C}$ to assess homogeneity. The feedstock pycnometer density measurements allowed direct comparison to the density estimated using the inverse rule of mixtures for the initial powder-binder fractions. The feedstock thermal properties were evaluated using Thermogravimetric Analysis, TGA (SDT Q600 TA Instruments) and Differential Scanning Calorimetry, DSC (Q20 TA Instruments), to determine the mixing, extrusion, and printing temperature conditions without causing polymer burnout.

The filament with coarse powder feedstock was extruded on a capillary rheometer (Goettfert Rheograph 20) using a capillary die with an L/D ratio of 30/1.75mm. The extrusion temperature was varied from $105{ }^{\circ} \mathrm{C}$ to $145{ }^{\circ} \mathrm{C}$ with each increment of $10{ }^{\circ} \mathrm{C}$ to 
examine its effect on the filament density relative to the feedstock, its diameter variations, and surface roughness. The green density measurements were performed using the Archimedes method, the diameter was determined using a digital caliper, and surface roughness analyzed using surface profilometer (Surftest SJ-210).

\subsection{2 $\mathrm{MF}^{3}$ PRINTING}

Three important printing parameters namely layer thickness, extrusion multiplier, and overlap, were identified from the literature and our preliminary experiments, to investigate their effect on the part density and dimensional variations. Other parameters were kept constant include extrusion and bed temperature at $240{ }^{\circ} \mathrm{C}$ and $65^{\circ} \mathrm{C}$, respectively, infill at $100 \%$, a print speed of $10 \mathrm{~mm} / \mathrm{s}$. The printer was equipped with a nozzle of $400 \mu \mathrm{m}$ diameter. The printing experiments were designed using the Taguchi optimization, which has been effectively implemented in FFF process parameter control. Table 4.1 shows the variables and levels selected for the current study. A design matrix, an L9 orthogonal array was selected to account for the factors and their level, available in Table 4.2. The printing was performed on an FFF printer (Pulse from MatterHackers fitted with a Bondtech extruder). For repeatability, four samples were printed at each condition to obtain the average and standard deviation. 
Table 4.1. Process parameters and their levels

\begin{tabular}{|c|c|c|c|}
\hline Process parameter & Level 1 & Level 2 & Level 3 \\
\hline Layer height $(\mu \mathrm{m})$ & 150 & 225 & 300 \\
\hline Extrusion multiplier (a.u) & 0.90 & 1.05 & 1.20 \\
\hline Overlap (\%) & 30 & 40 & 50 \\
\hline
\end{tabular}

Table 4.2. Experimental design matrix used in the current study

\begin{tabular}{|c|c|c|c|}
\hline Experiment number & $\begin{array}{c}\text { Layer height } \\
(\boldsymbol{\mu m})\end{array}$ & $\begin{array}{c}\text { Extrusion multiplier } \\
(\mathbf{a . u})\end{array}$ & $\begin{array}{c}\text { Overlap } \\
(\mathbf{\%})\end{array}$ \\
\hline 1 & 150 & 0.90 & 30 \\
\hline 2 & 150 & 1.05 & 40 \\
\hline 3 & 150 & 1.2 & 50 \\
\hline 4 & 225 & 0.90 & 40 \\
\hline 5 & 225 & 1.05 & 50 \\
\hline 6 & 225 & 1.2 & 30 \\
\hline 7 & 300 & 0.90 & 30 \\
\hline 8 & 300 & 1.05 & 40 \\
\hline 9 & 300 & 1.2 & \\
\hline
\end{tabular}

The results for density and dimensions were analyzed using ANOVA analysis to determine the significant factors.

\subsubsection{SINTERING OF $\mathrm{MF}^{3}$ PARTS}

The printed parts were subjected to debinding for binder removal. The binder removal was carried out in 2 steps: initially with solvent extraction to remove $40 \%$ of the total binder 
and remainder $60 \%$ was thermally decomposed. The solvent debinding was carried out in n-heptane at $64{ }^{\circ} \mathrm{C}$ for $4 \mathrm{~h}$. The data from thermogravimetric analysis (SDT Q600 TA Instruments) was used to design the heating profile which included 4 hold temperatures at $250{ }^{\circ} \mathrm{C}, 330{ }^{\circ} \mathrm{C}, 440{ }^{\circ} \mathrm{C}$, and $550{ }^{\circ} \mathrm{C}$, with incorporated hold times of $3 \mathrm{~h}, 3 \mathrm{~h}, 4 \mathrm{~h}$, and $4 \mathrm{~h}$, respectively. For thermal debinding, the heating rate was $1^{\circ} \mathrm{C}$ with processing atmosphere maintained at 600 millitorrs with intermittent argon gas sweep to drive away the burnt gases from polymer decomposition. The thermal binder removal was followed by sintering in the same furnace (TM super-series vacuum furnace). Sintering temperature was varied from $1200{ }^{\circ} \mathrm{C}$ to $1350{ }^{\circ} \mathrm{C}$ with a hold time of $2 \mathrm{hr}$ and $4 \mathrm{hr}$, using a partial vacuum of 150 millitorrs. Initially, the coarse Ti-6Al-4V powder was studied for the effect of sintering conditions on its density and mechanical properties. Further the effect of particle size and interstitial concentration were evaluated for both coarse and fine Ti-6Al-4V powders.

\subsubsection{CHARACTERIZATION OF SINTERED PARTS}

The effect of powder particle size at different time-temperature combinations on densification, mechanical properties, and interstitial content was analyzed. Sintered part density was measured using the Archimedes method as per ASTM B962-14. Mechanical testing of the samples (ASTM E8-16a) was conducted on a tensile testing machine (MTS hydraulic tensile testing machine) with a $100 \mathrm{kN}$ load cell at a strain rate $0.001 \mathrm{~s}-1 \mathrm{using}$ an extensometer. Oxygen and nitrogen interstitial content in the sintered samples was determined as per ASTM E1409-13 (Laboratory Testing Inc., PA). Carbon content in the sintered samples was analyzed as per ASTM E1941-10 (Laboratory Testing Inc., PA). 
Sintered samples were polished using $\mathrm{SiC}$ papers for microstructure examinations, in the sequence of $120 / 240 / 400 / 600 / 800 / 1200$ followed by $1 \mu \mathrm{m}$ diamond slurry and then colloidal silica slurry. The cross-sections were treated with Kroll's reagent to analyze the microstructural features using an optical microscope (Olympus BX-51). The grain size was determined using the linear intercept method with an image analysis tool (Image $\mathrm{J}$ ) as per ASTM E112-13. Further, the fracture surface was analyzed under a scanning electron microscope, SEM (TESCAN Vega 3) to investigate the failure mode.

\subsection{RESULTS AND DISCUSSIONS}

\subsubsection{FEEDSTOCK CHARACTERISTICS}

The powder attributes, including size distribution, density, critical loading, Hausner ratio, and interstitial content, are provided in Table 4.3. For coarse and fine powder, $90 \%$ of the particles were below $44 \mu \mathrm{m}$ and $21 \mu \mathrm{m}$, respectively, and both represented comparable pycnometer density. The Hausner ratio for coarse powder was 3.7\% lower than the fine powder, with both powders presenting excellent flowability, which can reduce feedstock viscosity to ease printing at high powder loadings. Higher tap density to pycnometer density ratio represents good powder packing behavior which was 0.62 and 0.61 for coarse and fine powder, respectively. The oxygen, carbon, and nitrogen content in the pre-alloyed powder were within the ASTM B988-18 prescribed limits for Ti-6Al-4V alloy. The powder was spherical in shape as shown in Table 4.3. 
Table 4.3. Ti-6Al-4V powder attributes

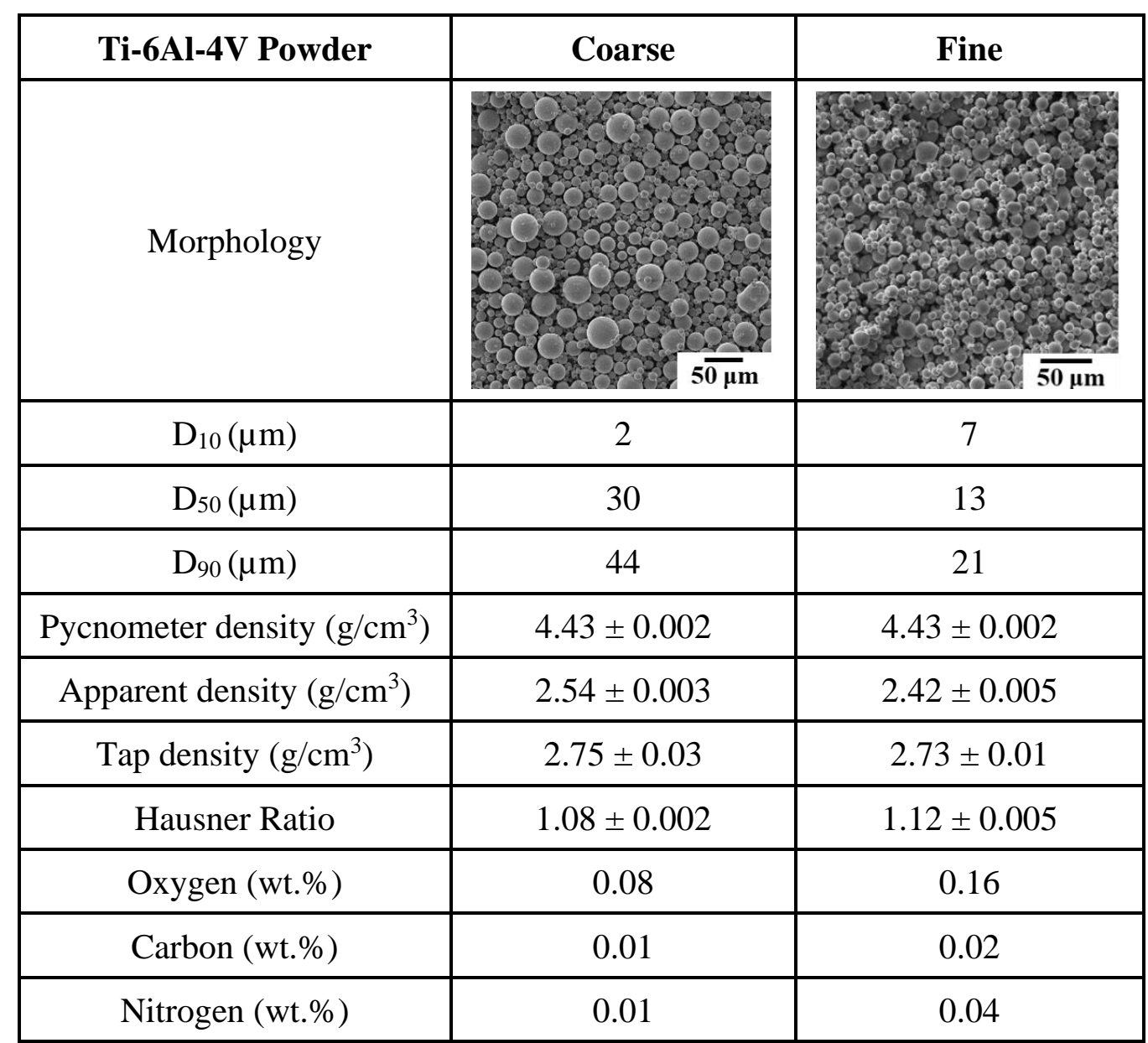

The powder critical loading for coarse and fine determined by torque rheometer was at 64 vol.\% and 63 vol.\%, respectively. A high powder loading is beneficial to achieve high densification and low shrinkage post sintering at the expense of increased feedstock viscosity causing printing issues. On the other hand, a low powder loading would enable easy printing as a result of low viscosity, but increases the chances of part slumping during debinding. Therefore, the powder loading for feedstock development was appropriately selected $\sim 5 \%$ lower than the experimentally obtained critical loading. At 59 vol. $\%$ powder 
loading, the feedstock consisting coarse and fine Ti-6Al-4V powder was prepared on the prep mixer.

The feedstock viscosity was evaluated at a constant shear rate of $50 \mathrm{~s}^{-1}$ at $160{ }^{\circ} \mathrm{C}$, to assess its variations, which can be correlated feedstock homogeneity. For coarse and fine powder feedstocks, the average viscosity remained at $730 \pm 2 \mathrm{~Pa}$ s and $1050 \pm 10 \mathrm{~Pa}$ s, respectively. The resulting low coefficient of variation below $\sim 1 \%$ indicated high mixture homogeneity. Further, the feedstock pycnometer density was found to be $2.96 \pm 0.002 \mathrm{~g} / \mathrm{cm}^{3}$ and $2.95 \pm$ $0.005 \mathrm{~g} / \mathrm{cm}^{3}$ for coarse and fine powder, respectively. These values are in good agreement with the feedstock density of $3 \mathrm{~g} / \mathrm{cm}^{3}$, estimated using the inverse rule of mixtures. More on the feedstock-filament attributes necessary for successful printability are available in our published work, where we demonstrated the effect of filament rheological and strength properties on printability and the speed limits [24].

\subsubsection{EFFECT OF EXTRUSION TEMPERATURE ON FILAMENT PROPERTIES}

The filament extrusion experiments were performed for the coarse Ti-6Al-4V powder at 59 vol.\% solids loading at different temperatures. Figure 4.3a shows the influence of extrusion temperature on the surface and sectional quality of the filaments. Correspondingly, the density measurements were also performed for the filament samples at the respective temperatures. The density was expressed relative to the feedstock pycnometer density for 59 vol. $\%$ powder loaded Ti-6Al-4V $\left(2.96 \pm 0.002 \mathrm{~g} / \mathrm{cm}^{3}\right)$. The results show that with increasing temperature from $105^{\circ} \mathrm{C}$ to $135^{\circ} \mathrm{C}$, the filament density 
decreased linearly from $99.8 \pm 0.2 \%$ to $91.2 \pm 0.2 \%$, while at $145^{\circ} \mathrm{C}$ the density increased to $99.9 \pm 0.1 \%$. Shown in Figure 4.3b, the filament diameter at $105^{\circ} \mathrm{C}$ was at $1.76 \pm 0.08$ mm which until $135{ }^{\circ} \mathrm{C}$ was $1.74 \pm 0.007$, remaining within $1 \%$ of the desired diameter of $1.75 \mathrm{~mm}$. At $145{ }^{\circ} \mathrm{C}$, the diameter rapidly dropped to $1.59 \pm 0.09 \mathrm{~mm}$. The effect of temperature was also prominent (Figure 4.3c) on the filament surface roughness, at 105 ${ }^{\circ} \mathrm{C}$ it was it $2.4 \pm 0.04 \mu \mathrm{m}$, and increased to $6.7 \pm 0.7 \mu \mathrm{m}$ at $145^{\circ} \mathrm{C}$. The measured density and surface roughness variations as a function of extrusion temperature corroborates the topographical observations shown in Figure 4.3a. 
a)

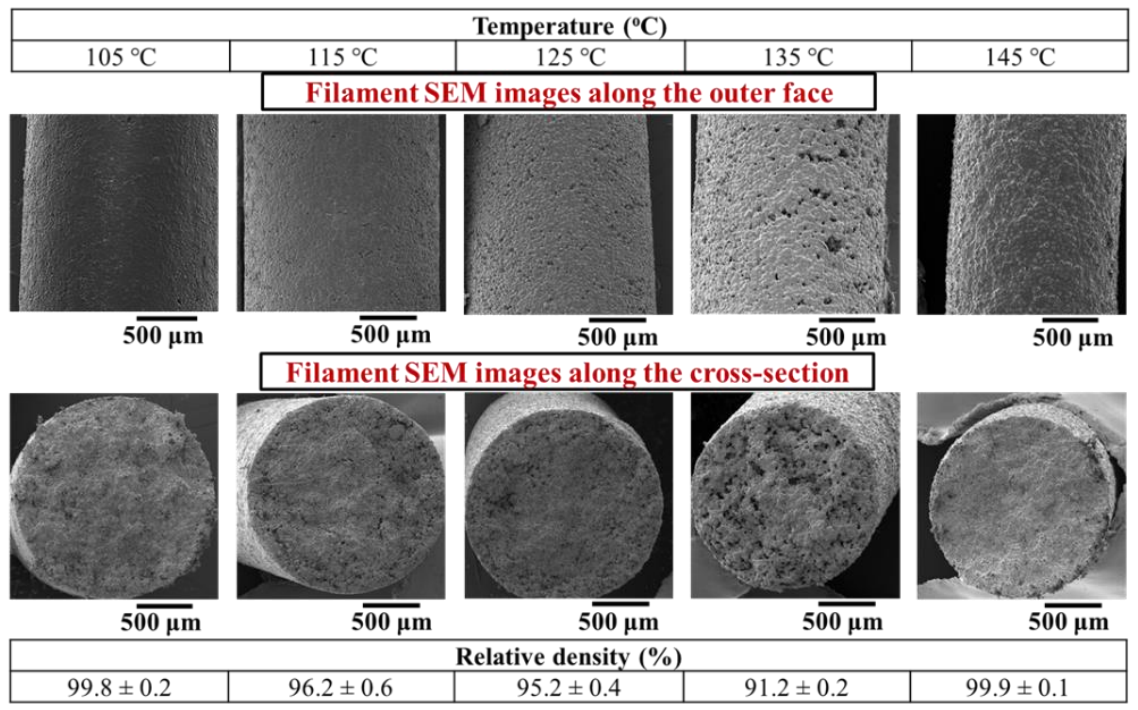

b)

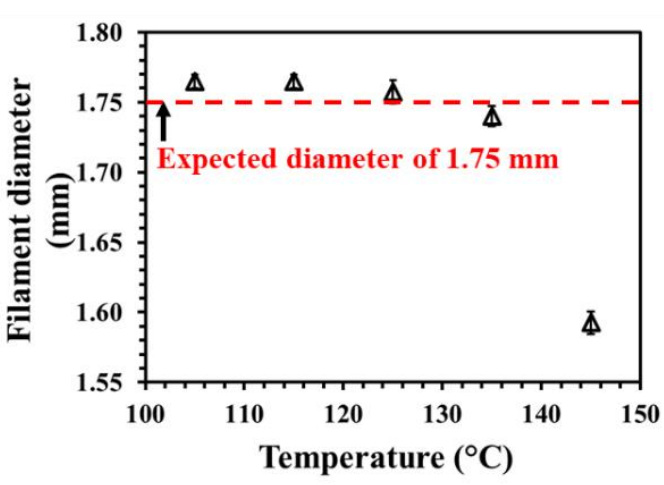

c)

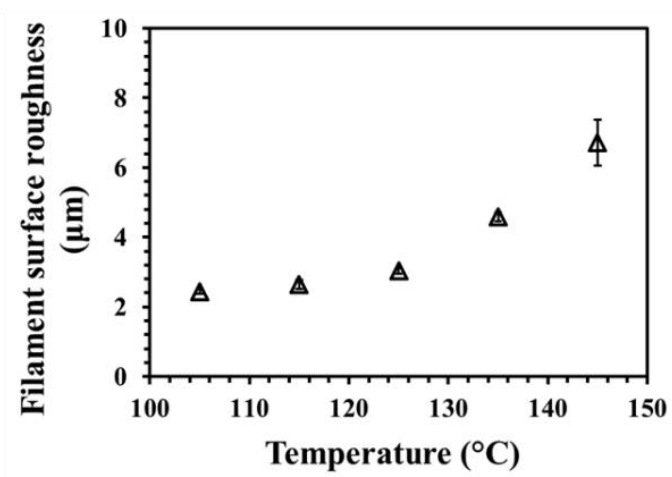

Figure 4.3. a. Effect of filament extrusion temperature on the morphology and density of coarse powder Ti-6Al-4V feedstock at 59 vol. $\%$, b. effect of extrusion temperature on the diameter, c. effect of extrusion temperature on the surface roughness.

The 59 vol.\% Ti-6Al-4V feedstock material was characterized by DSC to analyze the thermal properties. From the DSC, the glass transition $\left(\mathrm{T}_{\mathrm{g}}\right)$ was found to start at $85{ }^{\circ} \mathrm{C}$, and the melting temperature $\left(\mathrm{T}_{\mathrm{m}}\right)$ of the feedstock was found to be $140{ }^{\circ} \mathrm{C} . \mathrm{T}_{\mathrm{g}}$ represents the condition above which the amorphous molecules of the semi-crystalline polymer achieve mobility from their initial glassy state. $\mathrm{T}_{\mathrm{m}}$ represents the melting point for the crystalline 
part where the polymer chains alienate from the orderly arrangement and achieve the highest mobility. Comparing these values to the extrusion temperature conditions used in this investigation shows that the temperatures between $T_{g}$ and $T_{m}$ are favorable to achieve high density, consistent diameter, and low surface roughness.

At $105^{\circ} \mathrm{C}$, since the amorphous part of the feedstock has overcome the $\mathrm{T}_{\mathrm{g}}$, and shows some mobility, with the application of sufficient force, allows the chains to slide past each other easing the flow for extrusion. Simultaneously, with an increase in temperature the polymer viscosity decreases and compressibility increases, which creates pores volumes while extruding the filament. The same applies to the current experiments where the lowest explored temperature was $105^{\circ} \mathrm{C}$ that achieved the highest density and consistent diameter with the application of $7.77 \pm 0.14 \mathrm{kN}$ of force. When increasing temperature towards the $\mathrm{T}_{\mathrm{m}}$, the polymer viscosity drops, and the melt compressibility increases further, thereby allowing the filament to be extruded at low forces. At $135^{\circ} \mathrm{C}$, the filament extrusion force was $1.74 \pm 0.02 \mathrm{kN}$ and results in a density of $91.2 \pm 0.2 \%$. At low compaction forces, the packing of the powder-binder feedstock is expected to get affected (as seen in Figure 4.3). Once the temperature crosses the $\mathrm{T}_{\mathrm{m}}$, the polymer melt has very low viscosity with a higher concentration of the liquid media to aid flow in extrusion that leads to high density $(99.9 \pm$ $0.1 \%$.) at the expense of reduced diameter $(1.59 \pm 0.09 \mathrm{~mm})$.

\subsubsection{EFFECT OF PRINT PARAMETERS ON PART QUALITY}


The $\mathrm{MF}^{3}$ printing parameters studied in this investigation are layer height, extrusion multiplier, and overlap. Figure 4.4 illustrates each of the parameters, and their role on printing is as follows:

- Layer height $(\mu \mathrm{m})$ : Height of each layer being deposited on the build platform. Proper selection of layer height is essential to have each layer cohesively pressed onto the subsequent layer. The effect of particle size needs to be considered when selecting layer height.

- Extrusion multiplier (a.u): Controls the volume flow rate of the material, therefore increasing the extrusion multiplier increases the lateral spread of deposited material.

- Overlap (\%): It is the overlap between the infill pattern and the outer perimeter. An increase or decrease in overlap significantly determines the resulting gap between infill and outer perimeter.

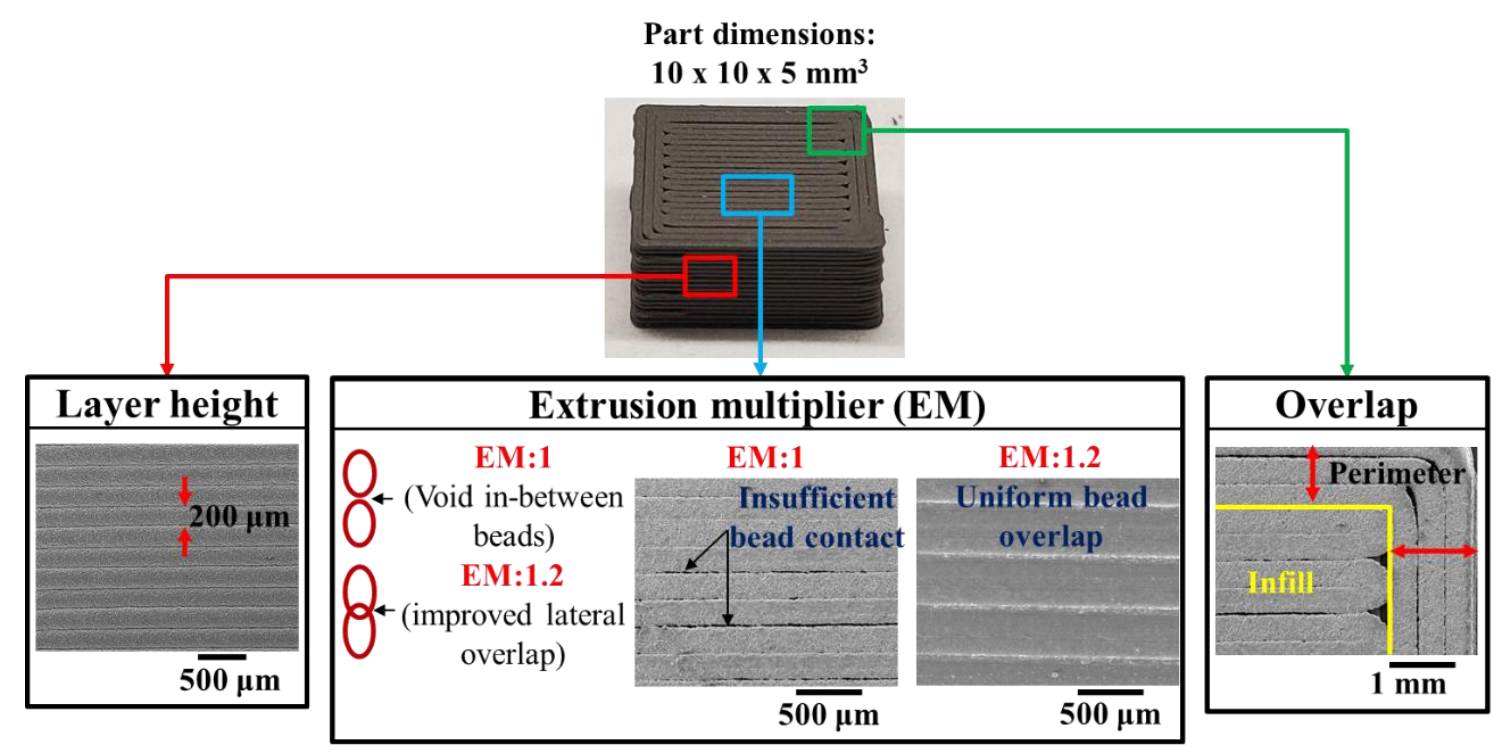

Figure 4.4. Influence of printing parameters on the quality of MF3 parts. 
The printed geometries from the experimental matrix (Table 4.2), were characterized for density and dimensions. The results thus obtained were analyzed using ANOVA analysis (Minitab 18) to determine critical printing parameters to achieve high density and dimensional stability in the green parts. The green density was expressed relative to the pycnometer density for 59 vol. $\%$ Ti-6Al-4V feedstock, which is $2.96 \pm 0.002 \mathrm{~g} / \mathrm{cm}^{3}$. The ANOVA analysis, Table 4, clearly shows that the extrusion multiplier has a significant effect on increasing the part density $(\mathrm{P}=0.02)$ with a $95.6 \%$ contribution compared to other parameters. The same was observed in the main effects plot (Figure 4.5a) where high extrusion multiplier yielded nearly $100 \%$ green part density. Increasing the extrusion multiplier from 0.9 to 1.05 , the density also increased from $90 \%$ to $99.2 \%$, and at 1.20 , the density was $99.8 \%$. The effect of layer height and overlap was found to be not the prominent factor in density improvement. Increasing layer height from $150 \mu \mathrm{m}$ to $300 \mu \mathrm{m}$, increased density by $0.9 \%$ only. Similarly, increasing overlap from $30 \%$ to $50 \%$ showed density improvement by $1.3 \%$. The dimensional changes were expressed as the percentage difference between the average of part dimension along $\mathrm{X}, \mathrm{Y}$, and $\mathrm{Z}$ plane and the CAD file dimensions. The ANOVA analysis, shown in Table 4.5, clearly indicates no significant effect of these printing parameters on the dimensional change (from the CAD model) of the printed parts, with $\mathrm{P}$ value $>0.05$. Figure 4.5b, shows a layer height of $150 \mu \mathrm{m}$, extrusion multiplier of 1.05 , and an overlap of $40 \%$ can produce parts within $0.6 \%$ of the dimensional tolerance. The contribution of the interactions between layer height and extrusion multiplier, and overlap and extrusion multiplier, were found to be negligible and were hence not accounted in the discussions. 
Table 4.4. ANOVA analysis for relative density (\%) of printed geometries.

\begin{tabular}{|c|c|c|c|c|c|c|}
\hline Factors & $\begin{array}{c}\text { Degrees of } \\
\text { freedom, d }\end{array}$ & $\begin{array}{c}\text { Sum of } \\
\text { squares, } \\
\text { SS }\end{array}$ & $\begin{array}{c}\text { Adjusted } \\
\text { mean } \\
\text { squares, Adj } \\
\text { MS }\end{array}$ & $\begin{array}{c}\text { F } \\
\text { value }\end{array}$ & $\begin{array}{c}\text { P } \\
\text { value }\end{array}$ & $\begin{array}{c}\% \\
\text { Contribution }\end{array}$ \\
\hline $\begin{array}{c}\text { Layer } \\
\text { height }\end{array}$ & 2 & 1.25 & 0.65 & 0.40 & 0.70 & 0.7 \\
\hline $\begin{array}{c}\text { Extrusion } \\
\text { multiplier }\end{array}$ & 2 & 167.40 & 83.70 & 51.10 & 0.02 & 95.6 \\
\hline Overlap & 2 & 3.35 & 1.70 & 1.00 & 0.50 & 1.9 \\
\hline Error & 2 & 3.30 & 1.65 & - & - & 1.8 \\
\hline Total & 8 & 175.25 & - & - & - & 100 \\
\hline
\end{tabular}

Table 4.5. ANOVA analysis for dimensional change $(\%)$ between printed and CAD file geometry.

\begin{tabular}{|c|c|c|c|c|c|c|}
\hline Factors & $\begin{array}{c}\text { Degrees of } \\
\text { freedom, d }\end{array}$ & $\begin{array}{c}\text { Sum of } \\
\text { squares, } \\
\text { SS }\end{array}$ & $\begin{array}{c}\text { Adjusted } \\
\text { mean } \\
\text { squares, } \\
\text { Adj MS }\end{array}$ & $\begin{array}{c}\text { F } \\
\text { value }\end{array}$ & $\begin{array}{c}\text { P } \\
\text { value }\end{array}$ & $\begin{array}{c}\% \\
\text { Contribution }\end{array}$ \\
\hline Layer height & 2 & 5.50 & 2.75 & 8.55 & 0.10 & 47.35 \\
\hline $\begin{array}{c}\text { Extrusion } \\
\text { multiplier }\end{array}$ & 2 & 5.30 & 2.65 & 8.30 & 0.10 & 45.65 \\
\hline Overlap & 2 & 0.18 & 0.10 & 0.30 & 0.80 & 1.5 \\
\hline Error & 2 & 0.65 & 0.30 & - & - & 5.5 \\
\hline Total & 8 & 11.60 & - & - & - & 100 \\
\hline
\end{tabular}


a)

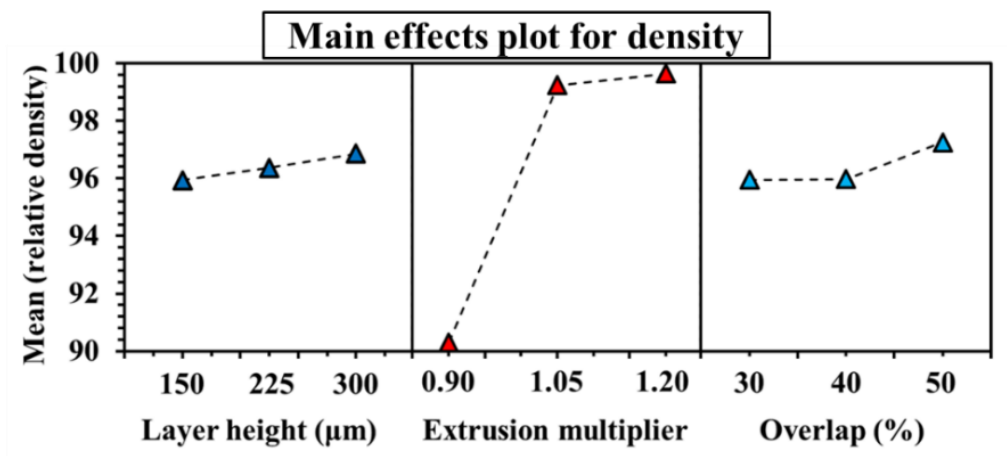

b)

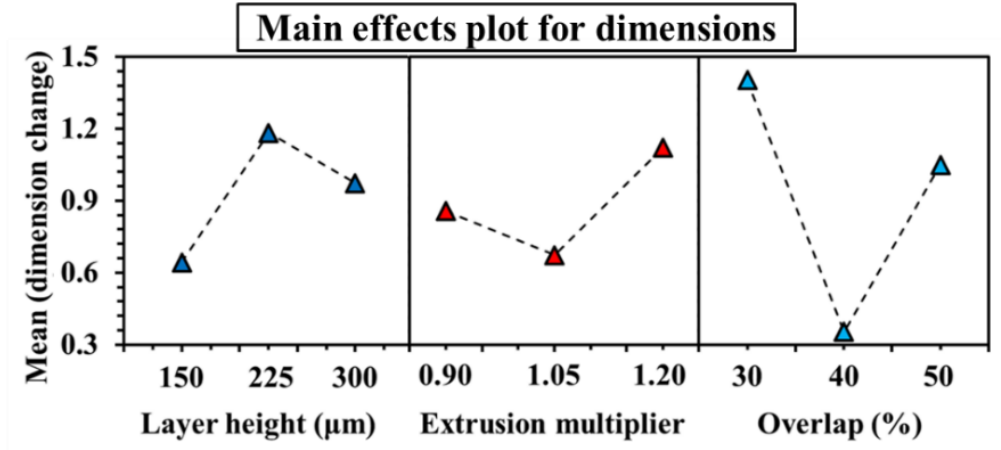

Figure 4.5. Main effects plot for the effect of layer height, extrusion multiplier, and overlap, on a. density, b. dimensions.

The parts from the experimental matrix with the lowest and highest density were sectioned for microscopic analysis with SEM (Figure 4.6). The part with a relative density of $89.8 \pm$ $0.2 \%$ corresponding to a layer height of $150 \mu \mathrm{m}$, extrusion multiplier of 0.9 , and overlap of $30 \%$ showed insufficient bonding between adjacent printed beads, and poor bonding between infill and outer perimeter, along the plane of deposition (top view). These defects in each layer were embedded throughout the part along the build direction, thus resulted in air gaps which are visible in the cross-sectional view of these parts, Figure 4.6 left (perpendicular to the plane of deposition). Part with a relative density of $99.8 \pm 0.1 \%$ corresponding to a layer height of $300 \mu \mathrm{m}$, extrusion multiplier of 1.2 , and overlap of $40 \%$, 
showed uniform bonding between adjacent printed beads, and good overlap between infill and outer perimeter. Having high density, the cross-section represented dense structure without any pores/airgaps (Figure 4.6 right).

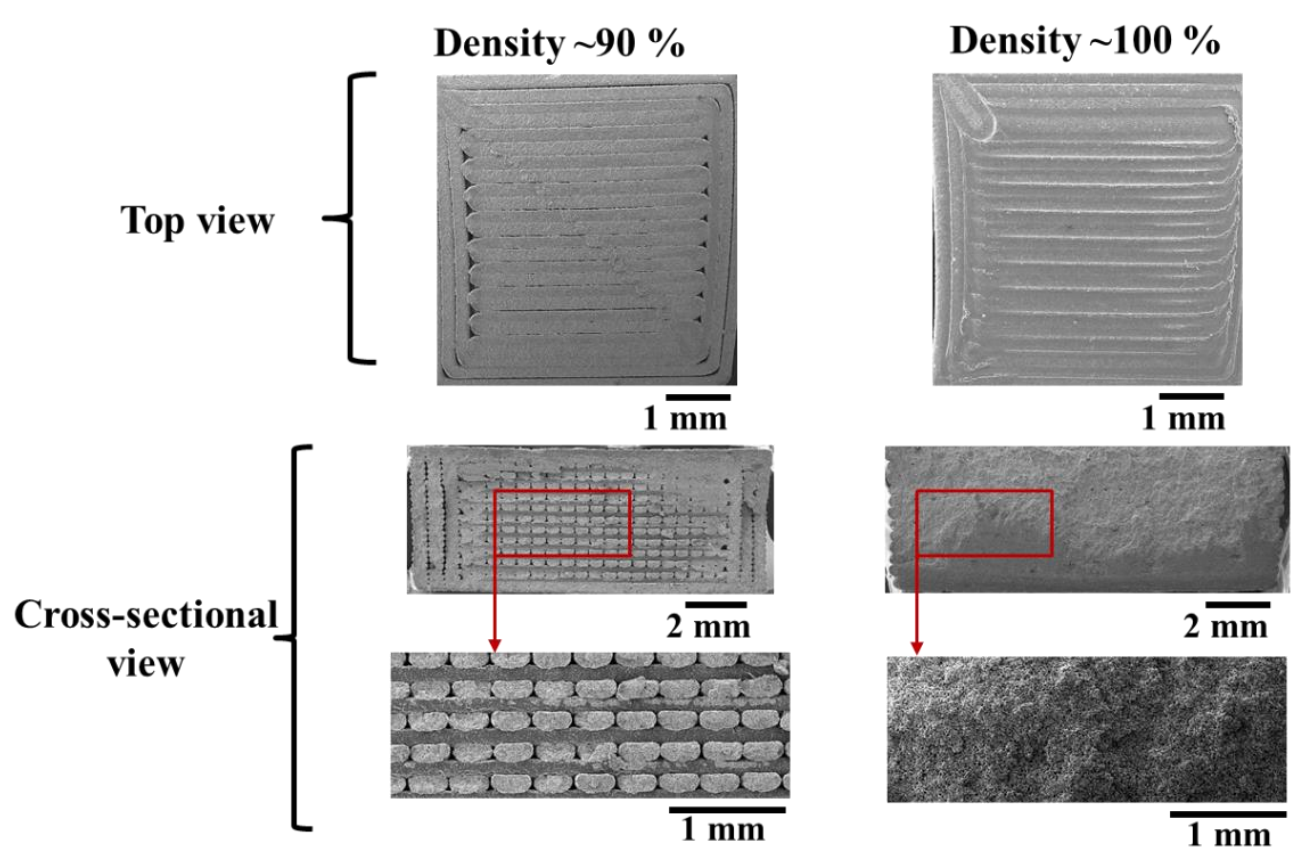

Figure 4.6. A cross-sectional view of the parts with the lowest (left) and highest (right) density from the design of experiment results.

\subsubsection{EFFECT OF SINTERING CONDITIONS ON THE MF ${ }^{3}$ PART PROPERTIES}

It is important to print parts with a high green density, as the presence of internal voids in the part geometry are further carried on to the sintering stage. When a part with internal voids goes through the sintering cycle, the expectation to obtain high final sintered density is compromised, and the resulting physical and mechanical properties are eventually affected. In the current study, the effect of green part density on the sintered density was 
investigated. Figure 4.7a shows the influence of green density on the sintered density of $\mathrm{MF}^{3}$ printed Ti-6Al-4V parts. Sintered density expressed as $\%$ of Ti-6Al-4V powder pycnometer density $\left(4.43 \mathrm{~g} / \mathrm{cm}^{3}\right)$ and green density expressed relative to the pycnometer density for 59 vol. $\%$ Ti- $6 \mathrm{Al}-4 \mathrm{~V}$ feedstock $\left(2.96 \pm 0.002 \mathrm{~g} / \mathrm{cm}^{3}\right)$. A part with a green density of $72 \pm 1 \%$ yielded a sintered density of $70 \pm 2.2 \%$, whereas a part with $99.8 \pm 0.1 \%$ of green density produced sintered density of $94.2 \pm 0.1 \%$. Therefore, having high green density in printed part shows high potential of translating into sintered density, which further controls the resulting physical and mechanical properties. Sintered density is dependent on time, temperature and environmental conditions. Also, any variation with particle size can affect sintered density by $\pm 3-5 \%$. Since sintering is a surface energydependent phenomenon, the existence of high or low surface area would yield slightly different results [25]. But an initial low-density green part with internal voids cannot achieve high sintered density.

Since the sintering temperature and time are known to have a strong influence on the sintered density and properties, the effects of sintering hold time and temperature were also investigated for the coarse powder printed green parts with $99.8 \pm 0.1 \%$ density. Two hold times $2 \mathrm{~h}$ and $4 \mathrm{~h}$, and three temperatures $1200{ }^{\circ} \mathrm{C}, 1250{ }^{\circ} \mathrm{C}$, and $1350{ }^{\circ} \mathrm{C}$ were explored, and their effect on the density is shown in Figure 4.7b. At $2 \mathrm{~h}$ hold time with an increase in the temperature from $1200{ }^{\circ} \mathrm{C}$ to $1350{ }^{\circ} \mathrm{C}$, increased the density from $92 \pm 0.4 \%$ to 95.2 $\pm 0.1 \%$. Further, increasing the hold time to $4 \mathrm{~h}$ at $1350{ }^{\circ} \mathrm{C}$, increased the density to 95.7 $\pm 0.1 \%$. Increasing temperature seemed to have prominent effect on the sintered density. And increasing hold time for the coarse powder at low temperatures showed $2 \%$ 
improvement in density, while at $1350^{\circ} \mathrm{C}$ the effect was non-significant. The sintering process is considered asymptotic and it slows as the time progresses nearing $100 \%$ density [52]. Sintered density is an important parameter which further controls material strengthrelated properties. With increased sinter time and temperature, the problem of grain growth enumerates, and from Hall-Petch relation, we understand the compromise between strength and the grain size for a particular material. Therefore, the selection of optimum timetemperature conditions is crucial in achieving the desired end properties.

a)

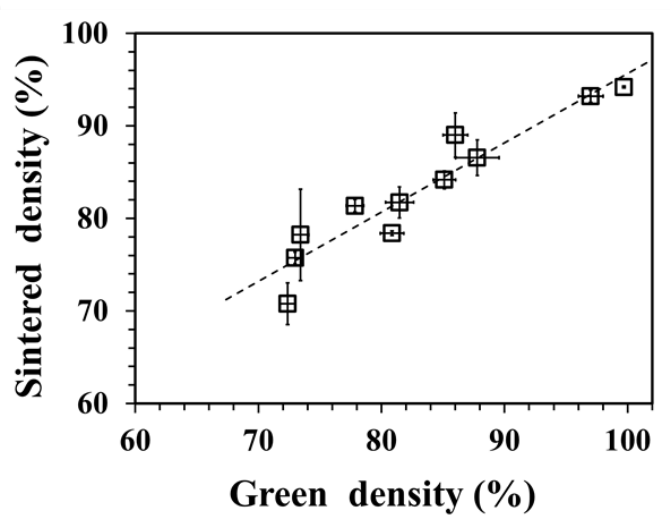

b)

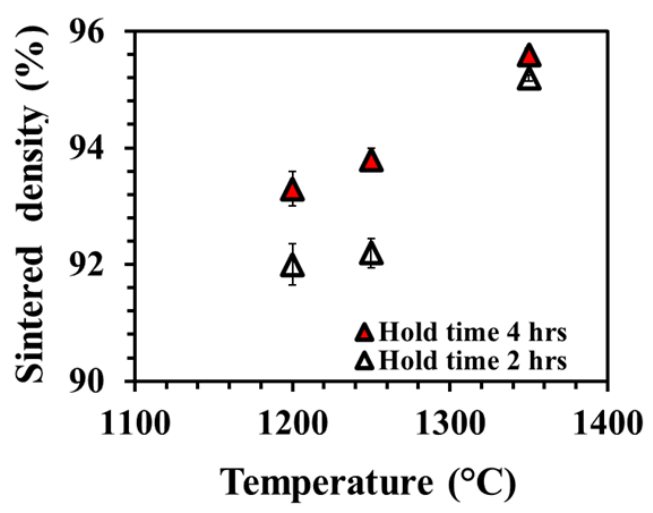

Figure 4.7. a. Effect of printed green part density on the sintered density for coarse Ti-6Al$4 \mathrm{~V}, \mathrm{~b}$. Effect of hold time and temperature on the sintered density of coarse Ti-6Al-4V.

Typically, a low sintered density would impart low strength to a part and a low elongation at fracture. A similar trend can be observed in Figure 4.8a and Figure 4.8b. The UTS in Figure 4.8a showed a gradual increase from $200 \pm 5 \mathrm{MPa}$ to $880 \pm 15 \mathrm{MPa}$ with increasing sintered density from $71 \pm 0.5 \%$ to $94.2 \pm 0.1 \%$. While at the same sintered density as shown in Figure 4.8b the elongation increased from $0.7 \pm 0.5 \%$ to $17 \pm 3 \%$. But surprisingly even at a high sintered density of Ti-6Al-4V, the mechanical properties 
including ultimate tensile strength (UTS) and elongation were found to represent wide fluctuation in properties. The tensile strength above $90 \%$ sintered density was found to vary in the range of 600-890 MPa. While elongation presented a steep range from $1 \%$ up to $17 \%$. To understand this sudden behavior, the interstitial concentration in the sintered samples was analyzed. Titanium is one of the highly reactive metals and complete isolation of the Ti-6Al-4V from oxygen during the sintering process is unavoidable [48, 90, 91]. Though sintering was conducted under inert atmospheric conditions, oxygen picked from the existing impurity from the furnace chamber and even the carrier gas exists as some of the concerns for Ti-6Al-4V alloy [90]. Also, the carbon impurities resulting from the binder burnout in the $\mathrm{MF}^{3}$ process can be the reason for compromise on properties. As reported in MIM a similar process to $\mathrm{MF}^{3}$, it is expected the carbon levels post sintering will be higher than from initial carbon in the Ti-6Al-4V powder. 
a)

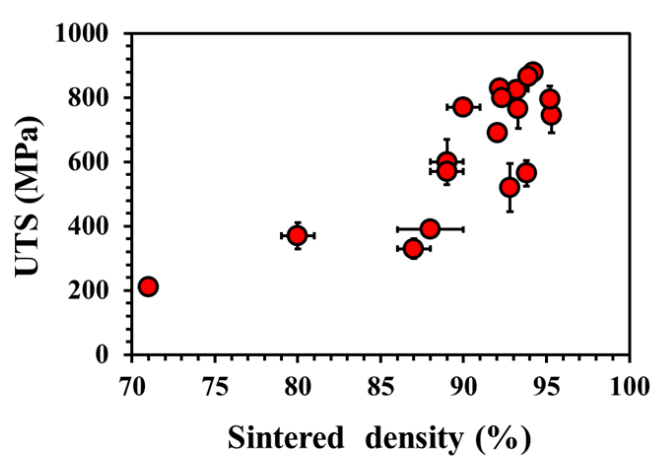

c)

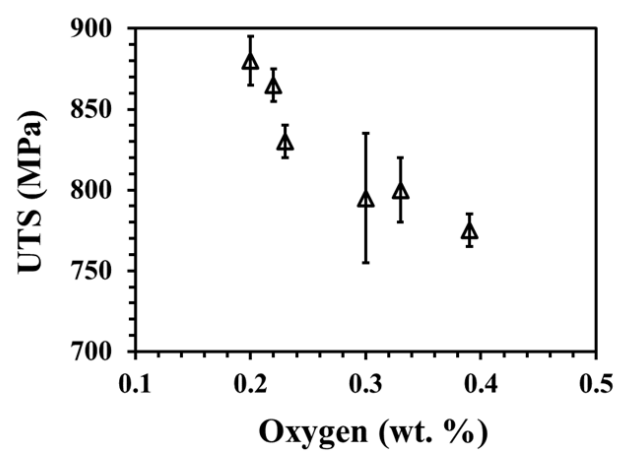

b)

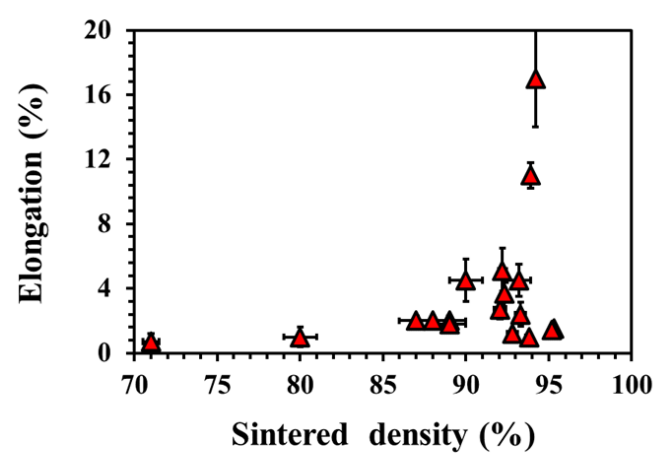

d)

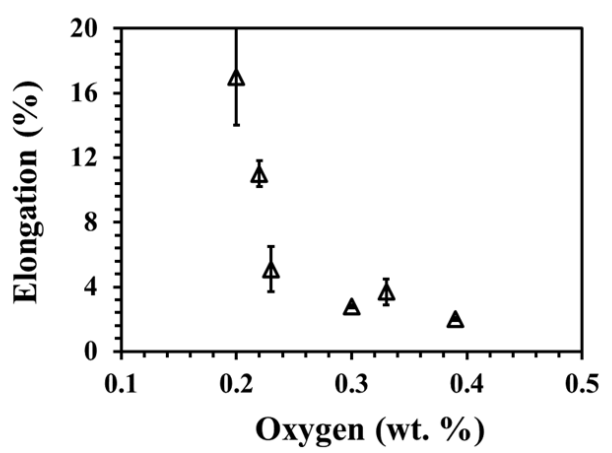

Figure 4.8. Effect of sintered density on the a. UTS, b. elongation, and the effect of oxygen content on the c. UTS, d. elongation

ASTM F2885-17 for MIM of Ti-6Al-4V components require oxygen, carbon and nitrogen levels to be below 0.20 wt. $\%, 0.08$ wt. $\%$, and 0.05 wt.\%, respectively. Selected samples sintered at hold time of $4 \mathrm{~h}$ in the temperature regime of $1200^{\circ} \mathrm{C}-1350^{\circ} \mathrm{C}$ were analyzed for their interstitial concentration (oxygen, carbon, and nitrogen), which was correlated with respective mechanical properties. Figure 4.8c shows the effect of oxygen on the UTS, which at 0.2 wt. $\%$ resulted in UTS of $875 \pm 15 \mathrm{MPa}$, and with increasing oxygen concentration to 0.39 wt.\% the UTS dropped to $775 \pm 10 \mathrm{MPa}$. Similarly, oxygen concentrations close to $0.2 \mathrm{wt} \%$ resulted in $17 \pm 3 \%$ elongation and higher concentration found to have serious effect on the elongation, which dropped to $2 \pm 1 \%$ as shown in 
Figure 4.8d. The carbon concentration in the present sintered samples was an average of $0.12 \pm 0.02 \mathrm{wt} . \%$. The nitrogen level in the sintered part was found to be $0.025 \pm 0.005$ wt.\%, well within the requirements of $<0.05 \mathrm{wt} . \%$. The oxygen equivalent is defined as, $\mathrm{O}_{\text {eq }}=\mathrm{O}+2 \mathrm{~N}+0.75 \mathrm{C}$, where $\mathrm{O}$ is the oxygen, $\mathrm{N}$ is the nitrogen, and $\mathrm{C}$ is the carbon. The $\mathrm{O}_{\text {eq }}$ considers all three interstitials to have a similar effect at different potency, which follows the order of $\mathrm{N}, \mathrm{O}$ and then $\mathrm{C}$. A value of $\mathrm{O}_{\mathrm{eq}}>0.4 \mathrm{wt} . \%$ is considered detrimental to the elongation. A similar trend was observed for the current experiments where at $\mathrm{O}_{\mathrm{eq}}$ 0.34 wt. $\%$, elongation was at $17 \pm 3 \%$, and when $\mathrm{O}_{\mathrm{eq}}$ reached 0.53 wt. $\%$, the elongation dropped to $2 \pm 1 \%$. Therefore, proper arrangements need to be made to sinter the Ti-6Al4V alloy to achieve consistent properties.

\subsubsection{EFFECT OF PARTICLE SIZE ON SINTERED PROPERTIES OF TI-6AL-4V}

Typically, a decrease in particle size is expected to provide high resolution in the $\mathrm{MF}^{3}$ printed parts. Both fine and coarse Ti-6Al-4V powder filaments were printed with $\mathrm{MF}^{3}$ and sintered for hold times of $2 \mathrm{hrs}$ and $4 \mathrm{hrs}$, at three temperatures $1200^{\circ} \mathrm{C}, 1250{ }^{\circ} \mathrm{C}$, and 1350 ${ }^{\circ} \mathrm{C}$. Sintered parts were analyzed for physical and mechanical properties and interstitial concentration. Figure 4.9a shows the effect of sintering time and temperature on the sintered density. It was found the parts made using finer powder exhibits $\sim 2-4 \%$ higher sintered density than the coarse powder parts. At $1200{ }^{\circ} \mathrm{C}$ for $2 \mathrm{hrs}$, fine powder part sintered to $95.4 \pm 0.2 \%$ density, while the coarse powder part had a density of $92 \pm 0.4 \%$. Increasing the sintering temperature to $1350{ }^{\circ} \mathrm{C}$ at $2 \mathrm{hrs}$, resulted in $97.4 \pm 0.7 \%$ density in fine powder parts and the coarse powder part showed a density of $95.2 \pm 0.1 \%$. The 
effect of hold time was also prominent for both powder types and at $1350{ }^{\circ} \mathrm{C}$ for 4 hrs the sintered density for fine and coarse powder was at $99.1 \pm 0.1 \%$ and $95.6 \pm 0.1 \%$, respectively. The time and temperature effects on sintering of fine powder was found to improve the sintered density, while increasing hold time for coarse powder at $1350^{\circ} \mathrm{C}$ didn't seem be favorable. Also, fine powder owing to its higher surface area offered better sinter-ability at low temperatures compared to a coarse powder.

$\mathrm{MF}^{3}$ parts sintered parts at $1250{ }^{\circ} \mathrm{C}$ for $4 \mathrm{hrs}$ with fine and coarse powder were characterized for UTS and elongation. At the given sintering conditions, the fine powder parts exhibited UTS of $960 \pm 20 \mathrm{MPa}$ and elongation of $4.4 \pm 0.7 \%$, while the coarse powder exhibited UTS of $880 \pm 15 \mathrm{MPa}$ and elongation $17 \pm 3 \%$ (Figure 4.9b and Figure 4.9c). For fine powder, post sintering oxygen content was at 0.3 wt. $\%$, an increase of 0.14 wt.\% from the starting powder concentration of 0.16 wt.\% (Table 4.1). Similarly, the oxygen content in coarse powder post sintering was 0.2 wt.\%, an increase of 0.12 wt.\% from the starting powder oxygen concentration of 0.08 wt.\% (available in Table 4.1). Although both powders show similar oxygen pickup post sintering, the fine powder had $0.02 \mathrm{wt} . \%$ higher than the coarse powder due to its high surface area available for oxidation at sintering temperature. The reason for the high UTS and low elongation for the fine powder was majorly due to the oxygen concentration in the sintered samples. As we have seen from the previous discussions in conjunction with Figure 4.8d where the effect of increasing oxygen concentration leads to a reduction in part elongation. 
a)

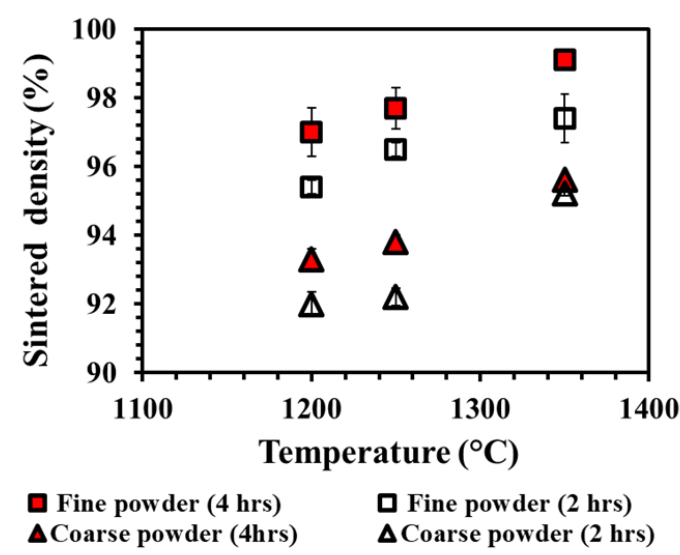

b)

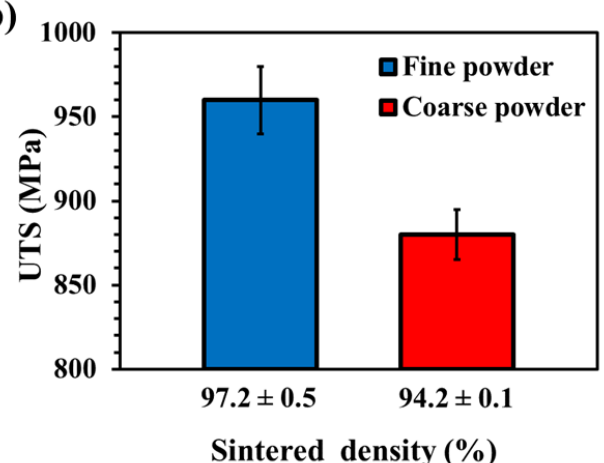

c)

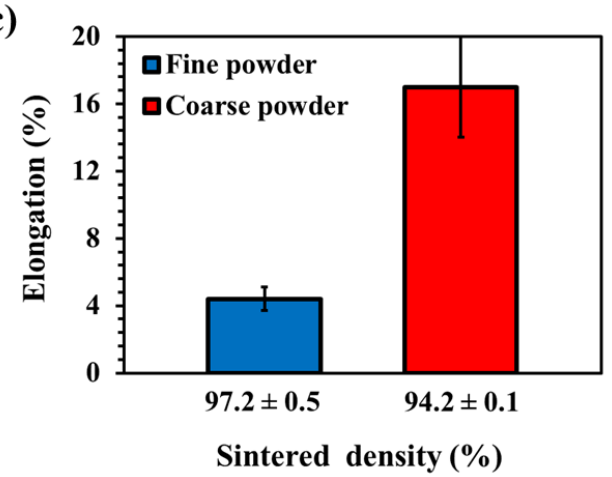

Figure 4.9. a. Effect of sintering time and temperature on the density of fine and coarse powder MF3 parts, b. Effect of sintered density on the UTS of fine and coarse powder parts, c. Effect of sintered density on the elongation of fine and coarse powder parts.

Further, the sintered samples were characterized for the microstructure, parallel to the print direction $(\mathrm{XY})$ and perpendicular to the print direction $(\mathrm{ZY})$. Figure 4.10a and Figure 4.10b show the microstructure for the $\mathrm{MF}^{3}$ sintered fine and coarse powder samples, respectively. The microstructure represents equiaxed grains consisting of prior $\beta$ along the grain boundaries and the $\alpha-\beta$ phase (shown in Figure 4.10a). The size of prior $\beta$ was determined using the linear intercept method and was found to be $280 \pm 40 \mu \mathrm{m}$ and $235 \pm$ 
$20 \mu \mathrm{m}$ for fine and coarse powder $\mathrm{MF}^{3}$ samples, respectively. During the final stage of sintering, as the densification approaches towards $100 \%$, if time-temperature conditions are not optimal grain coarsening is inevitable. Here, the density increases at the expense of grain size (Ostwald ripening). Such was the case for the fine powder which at $1250{ }^{\circ} \mathrm{C}$ for 4 hrs showed a relative density of $97.2 \pm 0.5 \%$ and $16 \%$ higher grain size compared to a coarse powder having a density of $94.2 \pm 0.1 \%$.

The fracture surface of the tensile test samples was analyzed using SEM. Figure 4.10c shows the fracture pattern for the fine and coarse powder $\mathrm{MF}^{3}$ samples. Fine powder sintered $\mathrm{MF}^{3}$ parts show a mixture of ductile and brittle fracture features, evidenced by the presence of cleavage facets acting as the site for brittle behavior and slight fine dimples indicative of the ductility. Whereas, the coarse powder $\mathrm{MF}^{3}$ parts represent complete ductile fracture with large area predominated by the fine dimples with the presence of small pores dispersed in the microstructure $[49,92]$. These fracture behavior analyses further signify the difference to the elongation obtained for fine and coarse powder samples. 
a)

\section{Fine powder $\mathrm{MF}^{3}$ sintered samples}

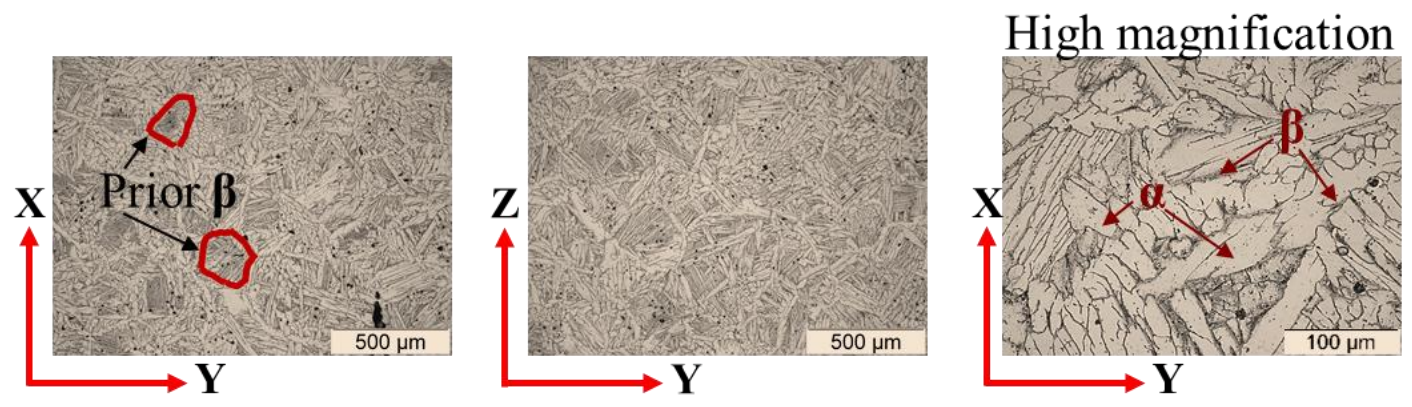

b)

\section{Coarse powder $\mathrm{MF}^{3}$ sintered samples}
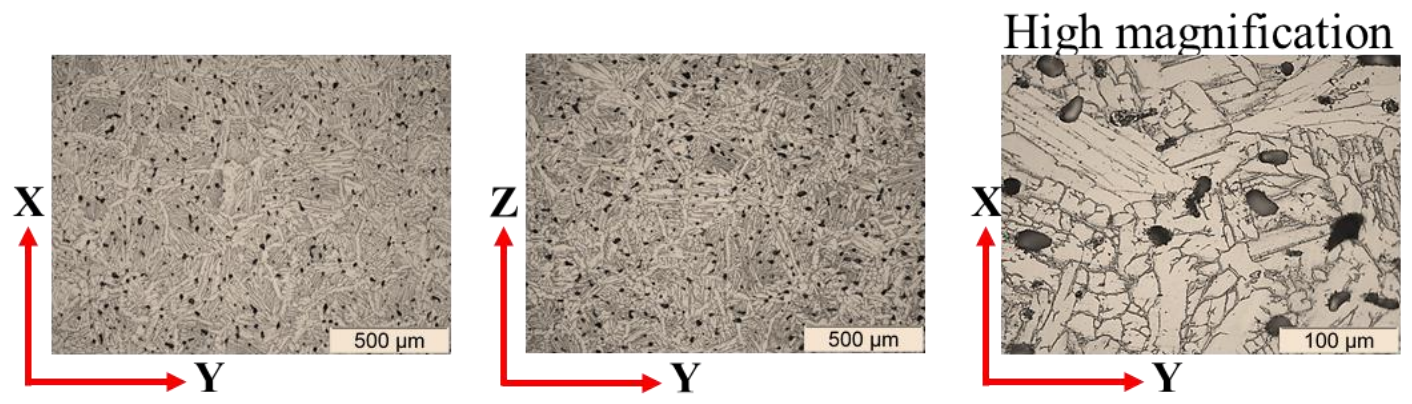

\section{c) Fracture surface analysis of $\mathrm{MF}^{3}$ sintered samples}
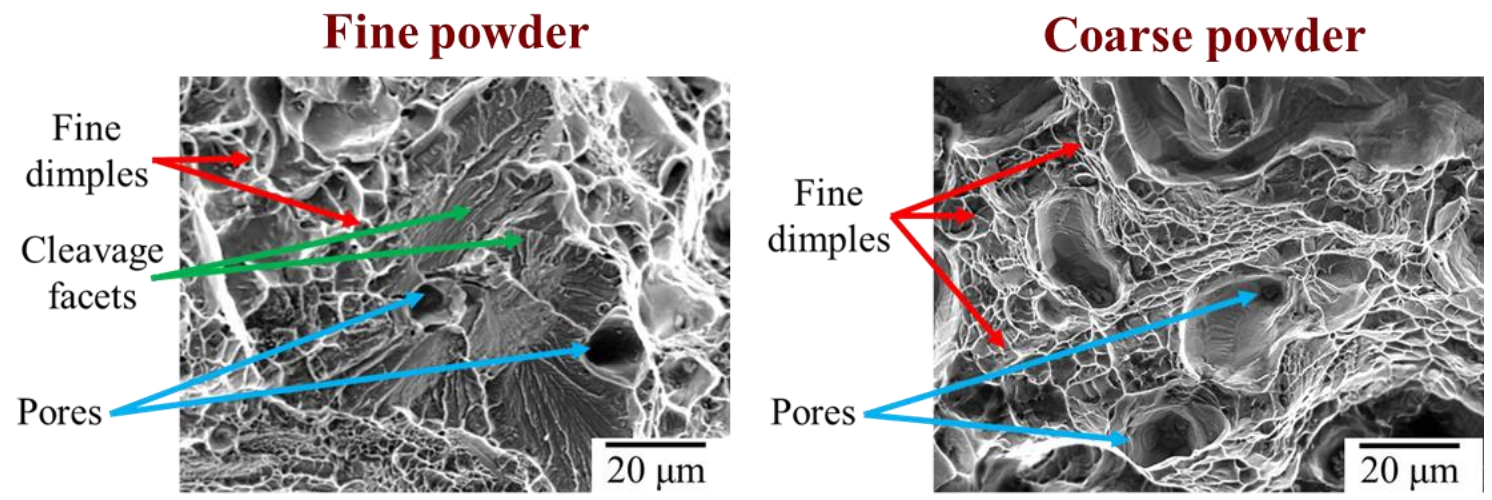

Figure 4.10. a. The microstructure of the etched MF3 sintered samples for fine Ti-6Al-4V powder, b. The microstructure of the etched MF3 sintered samples for coarse Ti-6Al-4V powder, c. Fracture surface analysis for MF3 samples with fine (left) and coarse (right) Ti$6 \mathrm{Al}-4 \mathrm{~V}$ powder. 


\subsection{CONCLUSIONS}

Our work demonstrates a successful approach to develop filaments and print parts which are near $100 \%$ of the feedstock density (59 vol.\% loaded Ti-6Al-4V powder). A careful selection of filament extrusion temperature enabled consistent filament with a high green density of $99.8 \pm 2 \%$, dimensional stability at $1.76 \pm 0.08 \mathrm{~mm}$, and low surface roughness of $2.4 \pm 0.04 \mu \mathrm{m}$. The experimental design was evaluated using Taguchi orthogonal matrix and ANOVA analysis helped determine significant parameters to achieve $99.8 \pm 0.1 \%$ of relative density in printed parts. Powder effects were investigated to determine the influence of particle size on the density, and oxygen content in the starting powder and post sintering on mechanical properties. Utilizing fine powder resulted in a density of $97.2 \pm$ $0.5 \%$, compared to a coarse powder with a density of $94.2 \pm 0.1 \%$ at $1250{ }^{\circ} \mathrm{C}$ for $4 \mathrm{hrs}$. The fine powder had $0.16 \mathrm{wt} . \%$ oxygen in the staring that post sintering increased to 0.30 wt. $\%$ and produced elongation of $4.4 \pm 0.7 \%$. Conversely, the coarse powder had 0.08 wt. $\%$ oxygen in the beginning that post sintering increased to $0.20 \mathrm{wt} . \%$ and produced elongation of $17 \pm 3 \%$. Although the UTS remained in the range of $700-960 \mathrm{MPa}$, a strong dependence of oxygen concentration was evident from the obtained results. 


\section{CHAPTER 5}

\section{ESTIMATING POWDER-POLYMER MATERIAL PROPERTIES USED IN DESIGN FOR METAL FUSED FILAMENT FABRICATION (DFMF $\left.{ }^{3}\right)$}

\section{$5.1 \quad$ INTRODUCTION}

Metal fused filament fabrication $\left(\mathrm{MF}^{3}\right)$ is a hybrid 3D printing process used to fabricate custom $3 \mathrm{D}$ metal components. $\mathrm{MF}^{3}$ provides an alternative to other energy-intensive metal additive manufacturing (AM) processes such as laser-powder bed fusion, selective laser sintering, and direct energy deposition. $\mathrm{MF}^{3}$ is a multi-step process that involves: a) mixing and extrusion of a powder-polymer mixture into filaments, b) 3D printing of a green part, c) polymer removal from the $3 \mathrm{D}$ printed green part by debinding to get a brown part, and d) densifying the brown part to achieve dense metal parts by sintering. Expected benefits of $\mathrm{MF}^{3}$ include greatly expanding the property window of parts fabricated using the established fused filament fabrication (FFF) process, printing with mixed and multimaterial systems, minimizing powder exposure at the printing stage, and expanding the range of materials that are available to current designers and users on the most widely used FFF platform [1].

Figure 5.1a shows a typical process overview for $\mathrm{MF}^{3}$ that has been demonstrated by our group to fabricate Ti-6Al-4V alloy components. The powder-polymer mixtures used in $\mathrm{MF}^{3}$ are adapted from metal injection molding (MIM) and are processed by modifying FFF 
that typically fabricate polymeric parts $[5,51]$. Although, materials design rules are known for processing powder-polymer mixtures using MIM they cannot be directly applied to formulate new $\mathrm{MF}^{3}$ materials owing to differences in physical phenomena involved in the two processes. Moreover, processing with polymers using FFF is well-known, but very limited literature exists on the processing of polymer systems with high solid loadings $(>50$ vol. \%) typically used for $\operatorname{MF}^{3}[5,12,14,15,17,69]$.

a)

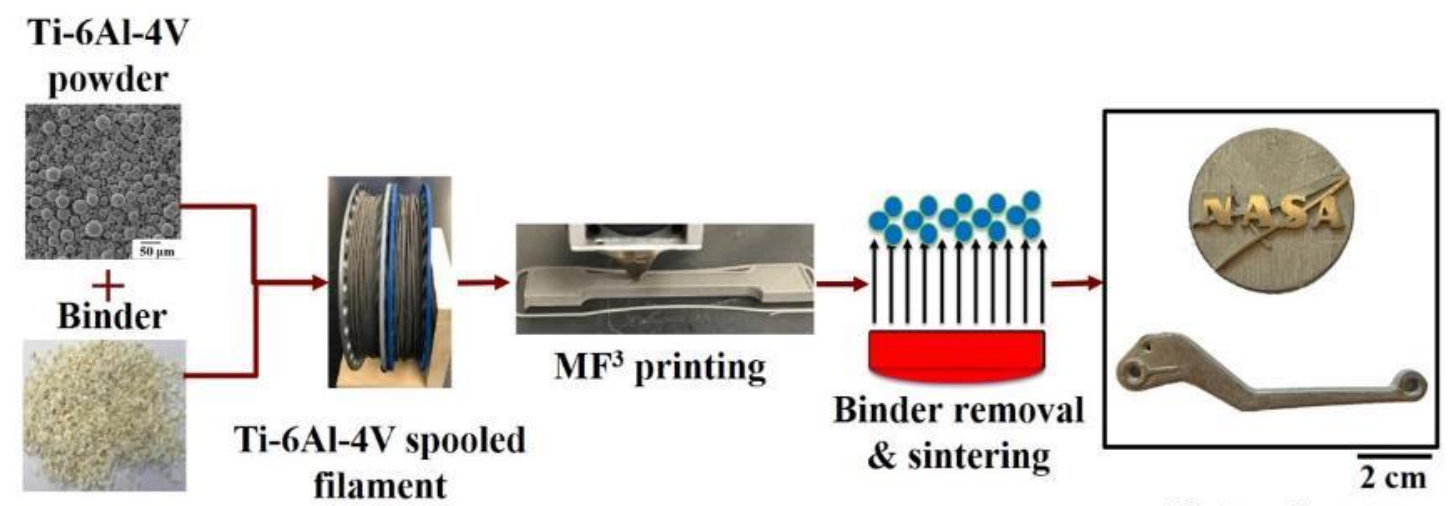

b)

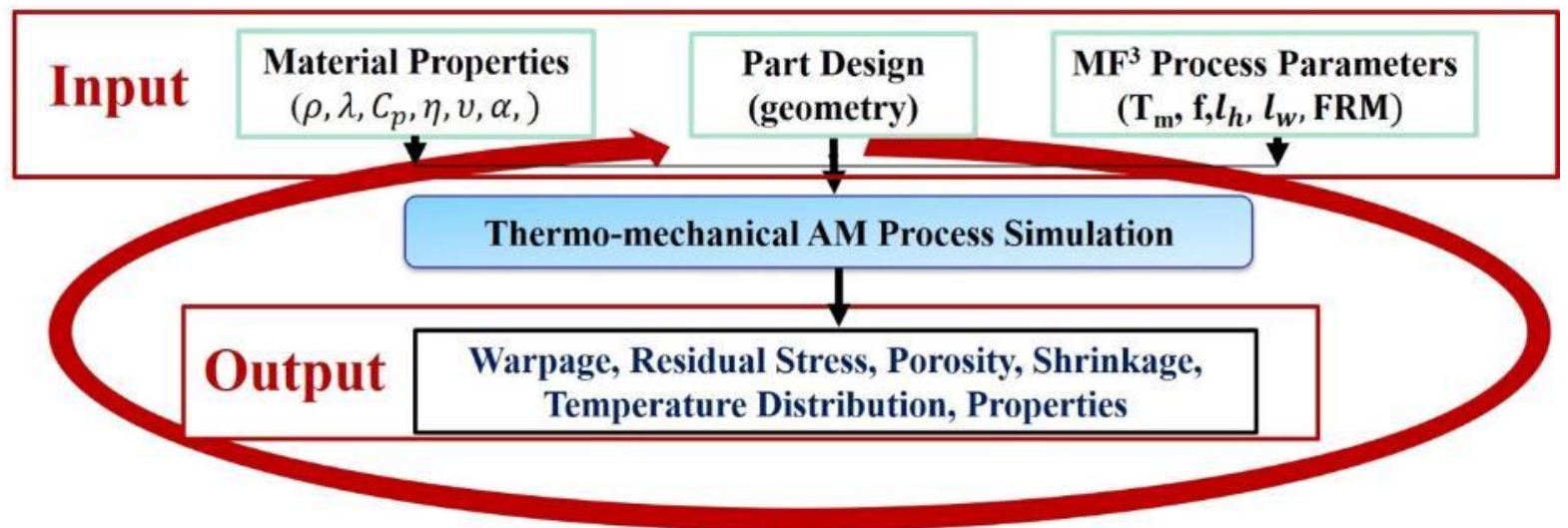

Figure 5.1. a. Process overview for $\mathrm{MF}^{3}$ with examples of fabricated Ti-6Al-4V parts by our group and $\mathrm{b}$. the present work for determining the input material parameters for conducting DfMF ${ }^{3}$. 
For example, in MIM, powder-polymer feedstocks are melt-processed at high shear-rates in the range of $10^{2}$ to $10^{5} \mathrm{~s}^{-1}[51]$. However, the FFF processing of a polymer is typically done at shear-rate in the range of $10-300 \mathrm{~s}^{-1}$ [18]. These differences pose significant processing challenges for powder-polymer mixtures that display shear-thinning behavior. Further, other properties such as density, thermal, mechanical and equation-of-state parameters (PVT) change with variation in powder-polymer concentrations. Any variations in powder-polymer composition can consequently affect filament properties, filament processing, 3D printing, debinding, and sintering. Accordingly, material compositional variations can affect the design of not only component geometrical attributes but also overhangs and support structures in the printed part. Figure 5.1b represents our present approach for capturing material influences on processing and part attributes using a designfor-metal-fused-filament-fabrication $\left(\mathrm{DfMF}^{3}\right)$ platform.

Our current work on processing Ti-6Al-4V powder-polymer mixtures with $\mathrm{MF}^{3}$ has examined several defects at different stages of $\mathrm{MF}^{3}$ processing owing to compositional variations and their impact on processing and geometry (Figure 5.2). Figures 5.2 a \& b were imaged using scanning electron microscopy (TESCAN Vega 3) and Figures 5.2c \& d were imaged using optical microscopy (Olympus BX-51). Figure 5.2a shows the presence of pores in the filament, leading to lower filament densities. These filaments were also found to buckle and crack under pressures exerted by the pinch roller during 3D printing owing to a lower strength. Figure 5.2b shows printing defects, such as gaps across layers within a cross-section resulting in low green density in $\mathrm{MF}^{3}$ parts, which can magnify post-sintering. Typical cracks occurring during debinding presumably due to the 
internal stresses in a part are presented in Figure 5.2c. Finally, Figure 5.2d shows the distribution of porosity within and between printing tracks and the gap between layers following sintering.

a)

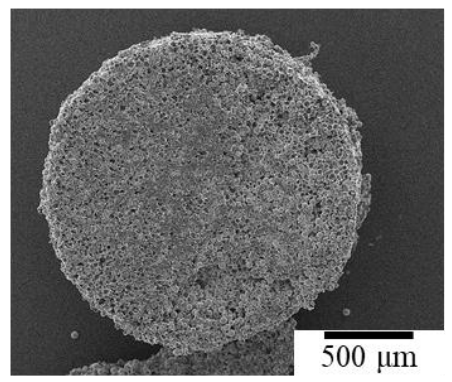

c)

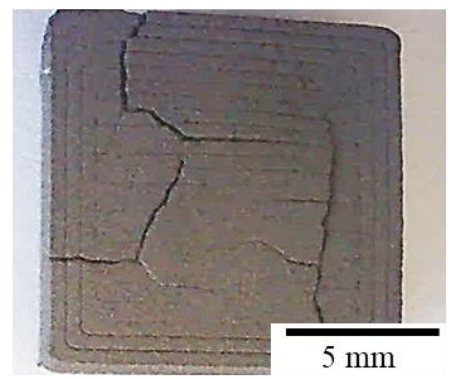

b)

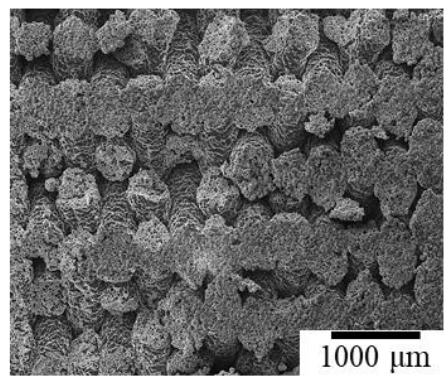

d)

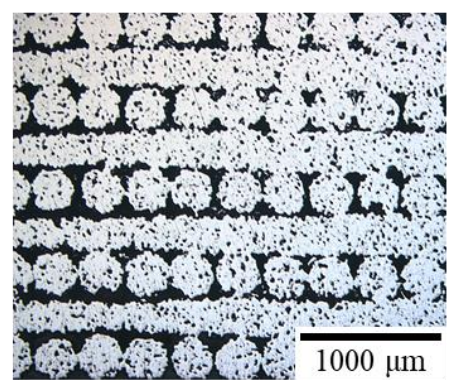

Figure 5.2. Typical defects observed during MF3 process of Ti-6Al-4V alloy system fabricated by our group showing a. dark regions representing pores within a cut-cross section of a powder-polymer filament, b. gaps between layers within an MF3 fabricated green part, c. crack propagation observed after debinding and d. presence of pores present in the sintered $\mathrm{MF}^{3}$ part.

Understanding defect evolution during $\mathrm{MF}^{3}$ processing will be crucial to achieve desired material properties and part functionality. Specifically, simulation tools to correctly identify appropriate material compositions and process parameters for designing parts suitable for $\mathrm{MF}^{3}$ can help reduce the trial-and-error involved in producing defect-free parts. As the density and thermal properties for metal-polymer systems are much higher than for 
an unfilled polymer, correct design protocols for parts with overhangs and support structures need to be identified with $\mathrm{MF}^{3}$. The potential of $\mathrm{MF}^{3}$ process in fabricating metal parts has been shown in some of the published work for 17-4 PH stainless steel, copper, WC-10Co, W-Cr and Cu-10Sn materials [4, 5, 11-13, 16, 17, 93]. However, the use of design tools to perform material and process simulations in $\mathrm{MF}^{3}$ has not yet been explored, thereby limiting the widespread use of $\mathrm{MF}^{3}$ process to manufacture parts with different materials for a variety of applications [93].

A number of FFF simulation platforms such as Digimat-AM ${ }^{\circledR}$ (MSC Software), GENOA ${ }^{\circledR}$ (AlphaSTAR), and GENESIS ${ }^{\circledR}$ (Vanderplaats R\&D), are commercially available that are currently being evaluated and adapted by us to conduct $\mathrm{DfMF}^{3}$ simulations. Common to these simulation platforms is the need for a range of powder-polymer mixture material properties such as physical, thermal, mechanical, rheological and equation-of-state parameters (PVT) as input parameters [94-96]. Compared to properties of more than 5000 different grades of plastics commonly used in injection molding simulation platforms, less than ten polymeric material systems are available in the database of FFF simulation platforms and none for $\mathrm{MF}^{3}$ materials. Any variations in powder concentrations or change in powder-polymer mixture material properties will require new experimental measurements to be performed, which can be time-consuming and expensive.

The current work addresses the important gap in the availability of powder-polymer properties for $\mathrm{DfMF}^{3}$ by selecting material models that predict properties using metal properties available in the literature in conjunction with experimentally measured polymer 
matrix properties. To identify the influence of varying powder content (solids loading, chemistry), properties were estimated for density, thermal conductivity, specific heat, modulus, coefficient of thermal expansion, viscosity as a function of shear-rate and temperature, and specific volume as a function of pressure and temperature. The estimated material properties for Ti-6Al-4V powder-polymer were used to understand simulation outputs such as warpages and dimensions using the DfMF $^{3}$ platform, Digimat-AM ${ }^{\circledR}$. Further, a comparison of warpage and dimensions between $\mathrm{DfMF}^{3}$ simulations and 3D printing experiments was performed for a 59 vol.\% solids loading Ti-6Al-4V powderpolymer material system. The output of the $\mathrm{DfMF}^{3}$ study was compared to FFF simulations and experiments of an unfilled acrylonitrile butadiene styrene (ABS) polymer. It is expected that the overall approach will significantly reduce the trial-and-error in designing new materials used to fabricate complex $\mathrm{MF}^{3}$ parts.

\subsection{MODELS FOR POWDER-POLYMER MATERIAL PROPERTIES}

There are various models that can predict material thermophysical properties for powderpolymer mixtures [53-55, 97-105]. Our recent work compared various models used to predict density, modulus, thermal conductivity, specific heat, viscosity, and specific volume and identified models that provided the best fit to experimental measurements of powder-polymer properties $[53,54,106]$. From the set of models screened for predicting material properties, models that provided the best fit (coefficient of regression $\mathrm{R}^{2}$ fit of 0.87-0.99) with experimental measurements in prior work were selected for subsequent material property estimations for conducting simulations for powder injection molding. In the current work, a protocol was developed to use existing literature filler (powder) 
properties and experimentally measured binder properties in conjunction with the selected models to estimate powder-polymer properties that are required to perform DfMF $^{3}$ simulations. Material properties include density, thermal conductivity, specific heat, modulus, coefficient of thermal expansion, viscosity as a function of shear-rate and temperature, and specific volume as a function of pressure and temperature. As a representative, yet high-impact material, Ti-6Al-4V alloy was used as the filler phase while experimentally measured properties of a wax-polymer binder were used as a matrix phase.

Table 5.1 lists thermomechanical properties at room temperature, of Ti-6Al-4V alloy collected from literature sources [31-40].

Table 5.1. Material properties of Ti-6Al-4V alloy at room temperature

\begin{tabular}{|c|c|c|}
\hline Property & Value & Reference \\
\hline Density $\left(\mathrm{kg} / \mathrm{m}^{3}\right)$ & $4.42 \pm 0.06$ & {$[28,30,31,37,107-110]$} \\
\hline Specific heat, $(\mathrm{J} / \mathrm{kg} \cdot \mathrm{K})$ & $560 \pm 30$ & {$[108,110-113]$} \\
\hline Thermal conductivity $(\mathrm{W} / \mathrm{m} \cdot \mathrm{K})$ & $6.5 \pm 0.4$ & {$[108-113]$} \\
\hline $\begin{array}{c}\text { Coefficient of thermal expansion } \\
\left(\mathrm{x} 10^{-6} \mathrm{~K}^{-1}\right)\end{array}$ & $8.8 \pm 0.4$ & {$[108-110,112,114,115]$} \\
\hline Modulus $(\mathrm{GPa})$ & $110 \pm 3$ & {$[108-112,116,117]$} \\
\hline
\end{tabular}




\subsection{MATERIALS AND EXPERIMENTAL METHODS}

Ti-6Al-4V powder has been selected as the filler phase to perform material property estimations. The effects of powder particle size distribution, shape, and packing behavior are not considered within the scope of the present work and will be addressed in future studies by our group. The binder used in this work comprised of paraffin wax, low-density polyethylene, polypropylene, and stearic acid.

Binder thermomechanical property measurements including density, modulus, specific heat, thermal conductivity, coefficient of thermal expansion, viscosity and specific volume were conducted at Datapoint Labs (Ithaca, NY) and previously reported by us [28]. These measurements were performed according to the ASTM standards listed in the Table 5.2. Solid density measurements were made for the binder using the Archimedes principle as laid out in ASTM standard D792. A Perkin Elmer differential scanning calorimetry (DSC) was used to measure specific heats for the binder in accordance with ASTM E1269 standard. Thermal conductivity measurements for the binder were made using a K-System II thermal conductivity system in accordance with ASTM standard D5930. Viscosity for the binder was measured according to ASTM D3835 using a Goettfert Rheograph capillary rheometer. Pressure-volume-temperature (PVT) measurements for the binder were made with a Gnomix PVT apparatus in accordance with ASTM D792. The feedstock properties for the composite with Ti-6Al-4V as filler with polymer binder were estimated using models discussed in the following sections. 
Table 5.2. Experimental methods and respective ASTM standard for measuring the thermophysical properties of binder system.

\begin{tabular}{|c|c|c|}
\hline Property & Instrument & Standard \\
\hline Density & Gas pycnometer & ASTM B923 \\
\hline Young's modulus & Universal testing machine & ASTM D638 \\
\hline Specific heat & Differential scanning calorimetry & ASTM E1269 \\
\hline Thermal conductivity & Line source method & ASTM D5930 \\
\hline Coefficient of thermal expansion & Thermomechanical analyzer & ASTM E831 \\
\hline Viscosity & Capillary rheometer & ASTM D3835 \\
\hline Specific volume & High-pressure dilatometry & ASTM D792 \\
\hline
\end{tabular}

For 3D printing experiments, four ASTM E8 tensile samples were printed on an FFF machine (Pulse 3D printer by Matterhackers) with 59 vol.\% Ti-6Al-4V powder-polymer feedstock filaments. The preparation of $\mathrm{MF}^{3}$ filaments was adapted for Ti-6Al-4V based on previous studies that have been reported elsewhere [12]. The print parameters consisted of a layer height of $150 \mu \mathrm{m}$, bead width of $550 \mu \mathrm{m}$, extrusion temperature of $240{ }^{\circ} \mathrm{C}$, bed temperature of $65^{\circ} \mathrm{C}$, nozzle diameter of $400 \mu \mathrm{m}$, and a constant print speed of $10 \mathrm{~mm} / \mathrm{s}$. For comparison, ABS, a common polymer for FFF printing was used for 3D printing tensile bar geometries and comparing the attributes of the part with simulations using material properties available in the Digimat-AM material database. 


\subsection{ESTIMATING PROPERTIES OF POWDER-POLYMER MIXTURES}

The experimentally measured values of polymer binder and literature Ti-6Al-4V filler properties were used to estimate feedstock properties of Ti-6Al-4V powder-polymer composite containing 56 to $60 \mathrm{vol} . \%$ solids loading.

\subsubsection{DENSITY}

The density of a filler-binder mixture is important in $\mathrm{MF}^{3}$ for calculating thermal stresses, shrinkage, and overhang and support structure design and can be estimated using various available models $[97,98]$. In this paper, an inverse rule-of-mixtures was used to estimate the composite feedstock density, given in Equation 5.1. This model has previously been verified in published work from our group by comparing it with experimental measurements for various fillers $[54,106]$.

$$
\frac{1}{\rho_{c}}=\frac{X_{f}}{\rho_{f}}+\frac{X_{b}}{\rho_{b}}
$$

where, $\rho$ is the density, $X$ is the mass fraction and the subscripts $c, b$ and $f$ stand for the composite, binder, and filler respectively.

Although the feedstock formulation is represented by weight fractions, for preparing powder-polymer mixtures, volumetric comparisons are more useful to compare powders of differing densities. Therefore, the volume fractions of powder and binder were estimated from the mass fractions using Equations 5.2 and 5.3, respectively: 


$$
\begin{gathered}
\phi_{f}=\frac{\frac{X_{f}}{\rho_{f}}}{\frac{X_{f}}{\rho_{f}}+\frac{X_{b}}{\rho_{b}}} \\
\phi_{b}=1-\phi_{f}
\end{gathered}
$$

where, $\phi_{f}$ and $\phi_{b}$ are the volume fractions of the filler and binder, respectively.

The experimentally obtained solid density for the binder system $\left(\rho_{b}\right)$ (provided in Table 5.3) and the filler properties compiled from the literature (provided in Table 5.1), were used to estimate the solid density of Ti-6Al-4V-binder mixtures as a function of volume fraction using Equation 5.1 and shown in Figure 5.3a. It was observed that for a change from 0.56 to 0.60 volume fraction of Ti-6Al-4V, the composite solid density increased from 2860 to $3000 \mathrm{~kg} / \mathrm{m}^{3}$. Further applicability of the model was verified by experimental density measurements for Ti-6Al-4V powder-binder feedstock at 0.59 volume fraction, which was found to be $2950 \mathrm{~kg} / \mathrm{m}^{3}$, representing a deviation $<0.6 \%$ from the estimated value of $2965 \mathrm{~kg} / \mathrm{m}^{3}$. For further verification, estimates of the model to experimental data on a PTFE- $\mathrm{TiO}_{2}$ system showed a coefficient of determination $\left(\mathrm{R}^{2}\right)$ of 0.98 , confirming good applicability to make density estimations [26]. 
a)

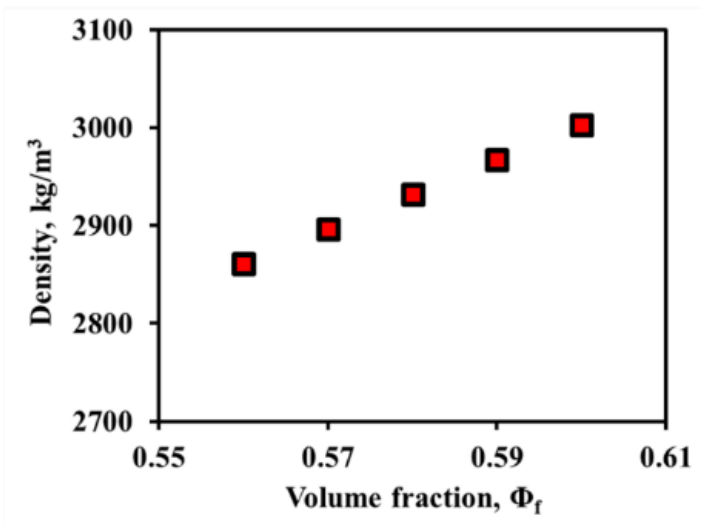

b)

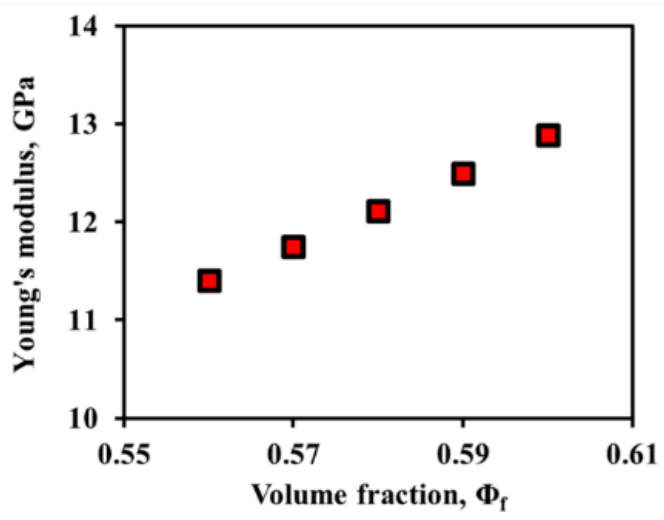

Figure 5.3. Estimated (a) density, and (b) Young's modulus for Ti-6Al-4V filler-binder feedstock at different volume fractions. 
Table 5.3. Experimentally determined binder thermophysical properties.

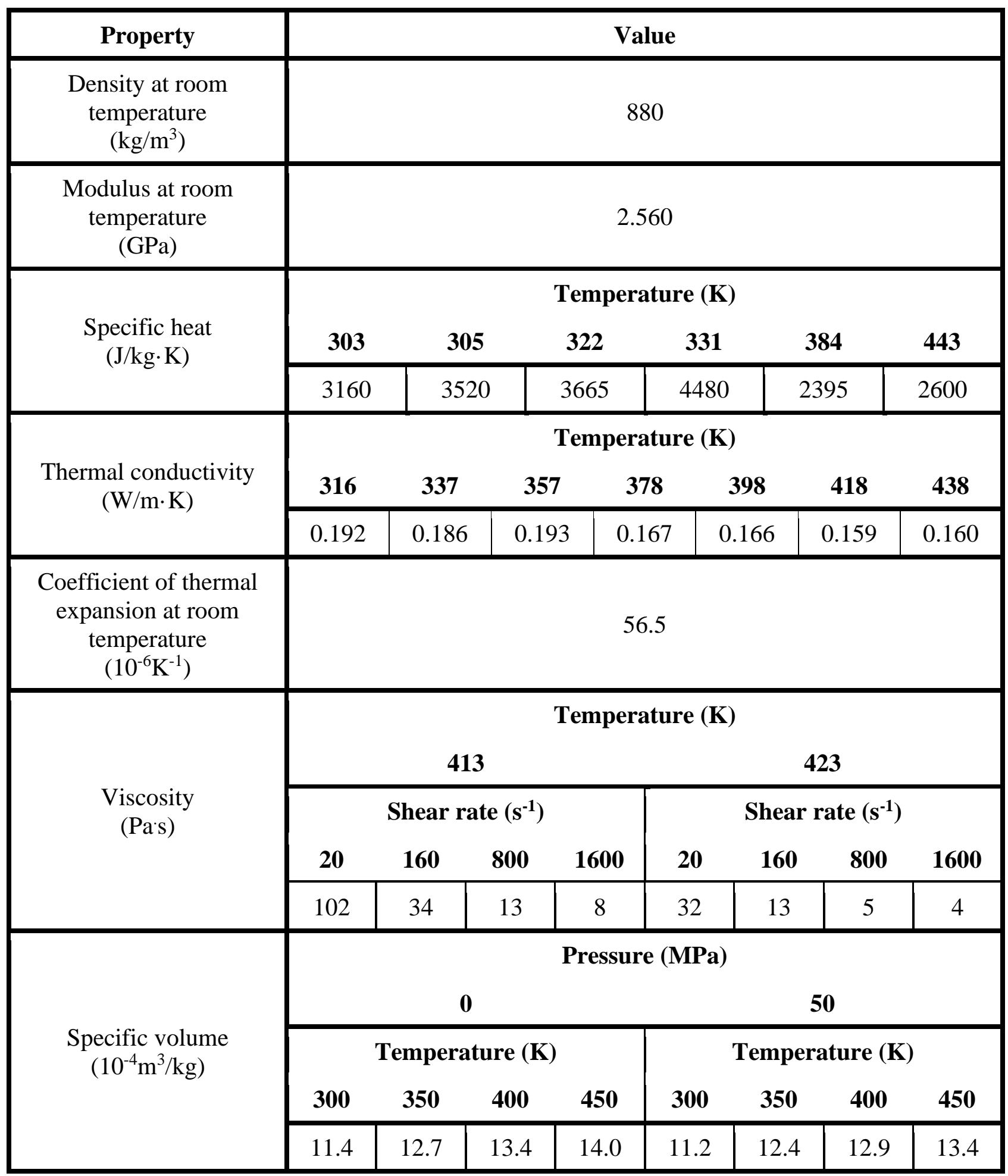




\subsubsection{YOUNG'S MODULUS}

The Young's modulus of the feedstock has a direct influence on the strength and distortion of parts fabricated by $\mathrm{MF}^{3}$. Good adhesion between metal particles and the polymer is very essential to achieve a high Young's modulus. Furthermore, solids loading, binder compositions, and temperature strongly influence Young's modulus. Among various models available [99-101] to predict Young's modulus of a filler-polymer mixture, Halpin and Tsai [99] developed a widely accepted model that takes into account the filler shape and loading direction. It has been widely used in studies in predicting the modulus and its estimates have been verified by experimental data for various filled polymer systems $[118$, 119]. This model is shown in Equation 5.4:

$$
\frac{E_{c}}{E_{b}}=\frac{1+\xi \eta \phi_{f}}{1-\eta \phi_{f}}
$$

where, $\mathrm{E}$ is the elastic modulus, $\xi$ is a shape parameter dependent on the geometry and loading direction, $\phi$ is volume fraction, subscripts $c, b$ and $f$ stand for the composite, binder, and filler respectively.

The parameter $\eta$ is given by Equation 5.5:

$$
\eta=\frac{E_{f} / E_{b}-1}{E_{f} / E_{b}+\xi}
$$

The parameter, $\xi$ can be approximated to 2 for spherical particles [99]. The Young's modulus for binder $\left(E_{b}\right)$ was determined experimentally at room temperature (available in Table 5.3) and reported in our prior work [28]. The Ti-6Al-4V filler properties were 
collected from the literature as shown in Table 5.1. The Young's modulus for intermediate volume fractions were estimated using Equation 5.4 and 5.5. As seen in Figure 5.3b, the modulus changed from $11.4 \mathrm{GPa}$ to $12.8 \mathrm{GPa}$ with the change in volume fraction from 0.56 to 0.60 . For verification, estimates of the model to experimental data on an epoxy-glass mixture above 0.4 volume fraction filler, showed a coefficient of determination $\left(\mathrm{R}^{2}\right)$ of 0.88, confirming good applicability to predict Young's modulus [26].

\subsubsection{SPECIFIC HEAT}

For polymers and metal powder feedstocks, the heat capacity is dependent on the processing temperature. The polymer melting results in phase change and further changes the heat capacity. For $\mathrm{MF}^{3}$, it is critical to understand the cooling trends that occur in the entire range of processing temperatures. In the current work, a modified rule-of-mixtures was used [102] as given in Equation 5.6 to determine the specific heat of the filler-polymer mixture. This equation has been successfully applied to mixtures with high volume fraction fillers. In our previous work $[53-55,106]$, the predicted values from this model have been evaluated against experimental specific heat measurements and it has produced a high coefficient of determination $\left(\mathrm{R}^{2}\right)$ of 0.97 , suggesting good applicability.

$$
C_{p_{c}}=\left[C_{p_{b}} X_{b}+C_{p_{f}} X_{f}\right] *\left[1+A * X_{b} X_{f}\right]
$$

where, $A$ is a correction factor assumed to be 0.2 for spherical particles. $C_{p}$ is the specific heat, $X$ is the mass fraction, and subscripts $c, b$, and $f$ stand for the composite, binder, and filler respectively. 
The specific heat for the binder system $\left(C_{p_{b}}\right)$ was experimentally obtained at different temperatures (provided in Table 5.3) as previously reported [28], and the filler properties were found from literature (Table 5.1 and Table 5.4 for each temperature). The values were used to estimate the specific heat capacity over a range of filler volume fractions using Equation 5.6 and are plotted in Figure 5.4a. From Figure 5.4a, it can be observed that for a change from 0.56 to 0.60 volume fraction of Ti- $6 \mathrm{Al}-4 \mathrm{~V}$ powder at $303 \mathrm{~K}$, the specific heat decreased from 983 to $926 \mathrm{~J} / \mathrm{kg} \cdot \mathrm{K}$. With increase in temperature, the specific heat first increased from $983 \mathrm{~J} / \mathrm{kg} \cdot \mathrm{K}$ at $303 \mathrm{~K}$ to $1173 \mathrm{~J} / \mathrm{kg} \cdot \mathrm{K}$ at $322 \mathrm{~K}$ and then decreased to $855 \mathrm{~J} / \mathrm{kg} \cdot \mathrm{K}$ at $443 \mathrm{~K}$. Additional data for specific heat for each volume fraction and temperature are provided in Table 5.4. For verification, estimates of the model to experimental data on a paraffin wax-iron mixture at 0.6 volume fraction filler, showed a coefficient of determination $\left(\mathrm{R}^{2}\right)$ of 0.99 , confirming excellent applicability to predict specific heat [26].

Table 5.4. Estimated specific heat of Ti-6Al-4V powder-binder feedstock with different filler volume fractions for several temperatures. A volume fraction of 1 represents the specific heat of Ti-6Al-4V at different temperatures collected from literature sources.

\begin{tabular}{|c|c|c|c|c|c|c|}
\hline \multirow{2}{*}{ Volume fraction of filler, $\Phi_{\mathbf{f}}$} & \multicolumn{6}{|c|}{ Temperature (K) } \\
\cline { 2 - 7 } & $\mathbf{3 0 3}$ & $\mathbf{3 0 5}$ & $\mathbf{3 2 2}$ & $\mathbf{3 3 1}$ & $\mathbf{3 8 4}$ & $\mathbf{4 4 3}$ \\
\cline { 2 - 7 } & \multicolumn{5}{|c|}{ Specific heat $\mathbf{C}_{\mathbf{p}}, \mathbf{J} / \mathbf{k g} \cdot \mathbf{K}$} \\
\hline 0.56 & 980 & 1000 & 1170 & 1120 & 830 & 860 \\
\hline 0.57 & 970 & 990 & 1150 & 1100 & 820 & 850 \\
\hline 0.58 & 950 & 970 & 1130 & 1080 & 810 & 840 \\
\hline 0.59 & 940 & 960 & 1110 & 1060 & 800 & 830 \\
\hline 0.60 & 930 & 940 & 1090 & 1040 & 790 & 820 \\
\hline 1 (for Ti6Al-4V) & $\mathbf{5 6 5}$ & $\mathbf{5 6 5}$ & $\mathbf{5 6 5}$ & $\mathbf{5 6 5}$ & $\mathbf{5 6 5}$ & $\mathbf{5 7 0}$ \\
\hline
\end{tabular}




\subsubsection{THERMAL CONDUCTIVITY}

The addition of metal particles in the polymer matrix increases the thermal conductivity of $\mathrm{MF}^{3}$ feedstocks due to the higher thermal conductivity of the metal. In $\mathrm{MF}^{3}$, the feedstock thermal conductivity is useful in the selection of extrusion and build platform temperatures that ensure high density and layer-to-layer bonding. The Bruggeman model shown in Equation 5.7, was used to estimate the thermal conductivity of powder-polymer mixture:

$$
1-\phi_{f}=\left(\frac{\lambda_{f}-\lambda_{c}}{\lambda_{f}-\lambda_{b}}\right)\left(\frac{\lambda_{b}}{\lambda_{c}}\right)^{1 / 3}
$$

where, $\lambda$ is the thermal conductivity, $\phi$ is the volume fraction of powder and the subscripts $c, b$ and $f$ stand for the composite, binder, and filler respectively. Equation $\mathbf{5 . 7}$ has been previously reported to predict the thermal conductivity of filled-polymer feedstock systems in reasonable agreement with experimental measurements [53-55, 102, 120].

The binder thermal conductivity $\left(\lambda_{b}\right)$ was experimentally determined (provided in Table 5.3) as previously reported [28], and the filler properties were taken from the literature (Table 5.1), intermediate volume fractions were estimated using Equation 5.7 (available in Table 5.5). It can be inferred from Figure 5.4b that for a change in volume fraction from 0.56 to 0.60 for Ti- $6 \mathrm{Al}-4 \mathrm{~V}$ powder at $316 \mathrm{~K}$, the thermal conductivity increased from 1.3 to $1.5 \mathrm{~W} / \mathrm{m} \cdot \mathrm{K}$. With increase in temperature from $316 \mathrm{~K}$ to $438 \mathrm{~K}$ at 0.59 volume fraction, the thermal conductivity first increased from 1.47 to $1.50 \mathrm{~W} / \mathrm{m} \cdot \mathrm{K}$ at $357 \mathrm{~K}$ and then decreased to $1.41 \mathrm{~W} / \mathrm{m} \cdot \mathrm{K}$ at $438 \mathrm{~K}$. The trend was similar for other volume fractions of Ti-6Al-4V feedstocks. The trend of the curve for composite feedstock is dominated by 
the thermal conductivity of the matrix/binder material. The typical crest and trough observed in the curve are due to the changes in the binder state from solid to liquid while heated to a definitive temperature. For verification, estimates of the model to experimental data on PLA-aluminum mixture above 0.5 volume fraction filler, showed a coefficient of determination $\left(\mathrm{R}^{2}\right)$ of $\sim 0.9$, confirming good applicability to predict thermal conductivity [26].

Table 5.5. Estimated thermal conductivity of Ti-6Al-4V powder-binder feedstock with different filler volume fractions for several temperatures. A volume fraction of 1 represents the thermal conductivity of Ti-6Al-4V at different temperatures collected from literature sources.

\begin{tabular}{|c|c|c|c|c|c|c|c|c|}
\hline \multirow{2}{*}{ Volume fraction of filler, $\boldsymbol{\Phi}_{\mathbf{f}}$} & \multicolumn{7}{|c|}{ Temperature $(\mathbf{K})$} \\
\cline { 2 - 7 } & $\mathbf{3 1 6}$ & $\mathbf{3 3 7}$ & $\mathbf{3 5 7}$ & $\mathbf{3 7 8}$ & $\mathbf{3 9 8}$ & $\mathbf{4 1 8}$ & $\mathbf{4 3 8}$ \\
\cline { 2 - 7 } & \multicolumn{7}{|c|}{ Thermal conductivity $\boldsymbol{\lambda}, \mathbf{W} / \mathbf{m} \cdot \mathbf{K}$} \\
\hline 0.56 & 1.30 & 1.29 & 1.33 & 1.23 & 1.24 & 1.22 & 1.24 \\
\hline 0.57 & 1.35 & 1.34 & 1.39 & 1.280 & 1.293 & 1.272 & 1.29 \\
\hline 0.58 & 1.40 & 1.40 & 1.44 & 1.34 & 1.35 & 1.33 & 1.35 \\
\hline 0.59 & 1.47 & 1.46 & 1.50 & 1.40 & 1.41 & 1.39 & 1.41 \\
\hline 0.60 & 1.53 & 1.52 & 1.57 & 1.46 & 1.48 & 1.46 & 1.48 \\
\hline $\mathbf{1}$ (for Ti6Al-4V powder) & $\mathbf{6 . 8 2}$ & $\mathbf{7 . 0 2}$ & $\mathbf{7 . 2 1}$ & $\mathbf{7 . 4 9}$ & $\mathbf{7 . 8 1}$ & $\mathbf{8 . 1 3}$ & $\mathbf{8 . 4 2}$ \\
\hline
\end{tabular}

\subsubsection{COEFFICIENT OF THERMAL EXPANSION (CTE)}

3D printed components expand and shrink during the heating and cooling stages of the process. Uneven temperature distributions can cause warping in parts due to the buildup of residual thermal stresses while cooling. Thermal stresses are proportional to the CTE of powder-polymer mixtures which can be calculated by several models [53-55, 104, 105]. 
The general rule-of-mixtures shown in Equation 5.8 requires fewer empirical constants compared to other models.

$$
\alpha_{c}=\phi_{f} \alpha_{f}+\alpha_{b}\left(1-\phi_{f}\right)
$$

where, $\alpha$ is the thermal expansion coefficient, $\phi$ is the volume fraction and the subscripts $c, f$, and $b$ stands for composite, filler, and binder respectively. In our previous work [54] when evaluated against experimental values it yields a regression coefficient of determination $\left(\mathrm{R}^{2}\right)$ in the range of $0.87-0.97$, indicating a good fit.

The CTE for binder $\left(\alpha_{b}\right)$ was experimentally obtained (can be found in Table 5.3) and the filler properties were found from literature provided in Table $\mathbf{5 . 1}$ while the values for intermediate volume fractions were estimated using Equation 5.8. In Figure 5.4c, for a change in volume fraction from 0.56 to 0.60 , the CTE decreased from $29.7 \times 10^{-6}$ to $27.8 \times 10^{-}$ ${ }^{6} \mathrm{~K}^{-1}$. For verification, estimates of the model to experimental data on an epoxy-alumina mixture at 0.5 volume fraction filler, showed a coefficient of determination $\left(\mathrm{R}^{2}\right)$ of $\sim 0.9$, confirming good applicability to predict CTE [26]. 
a)

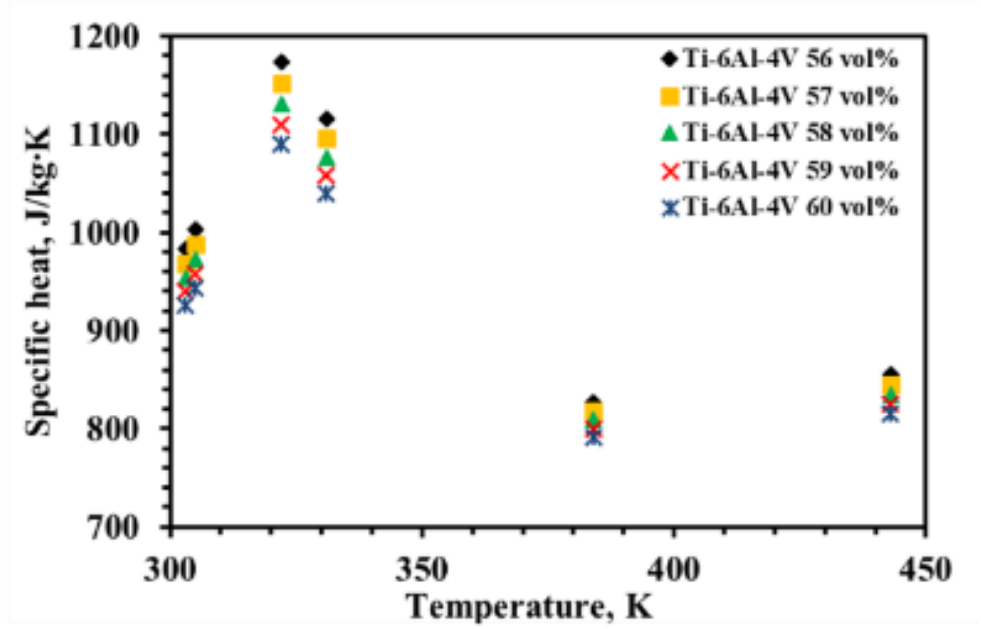

b)

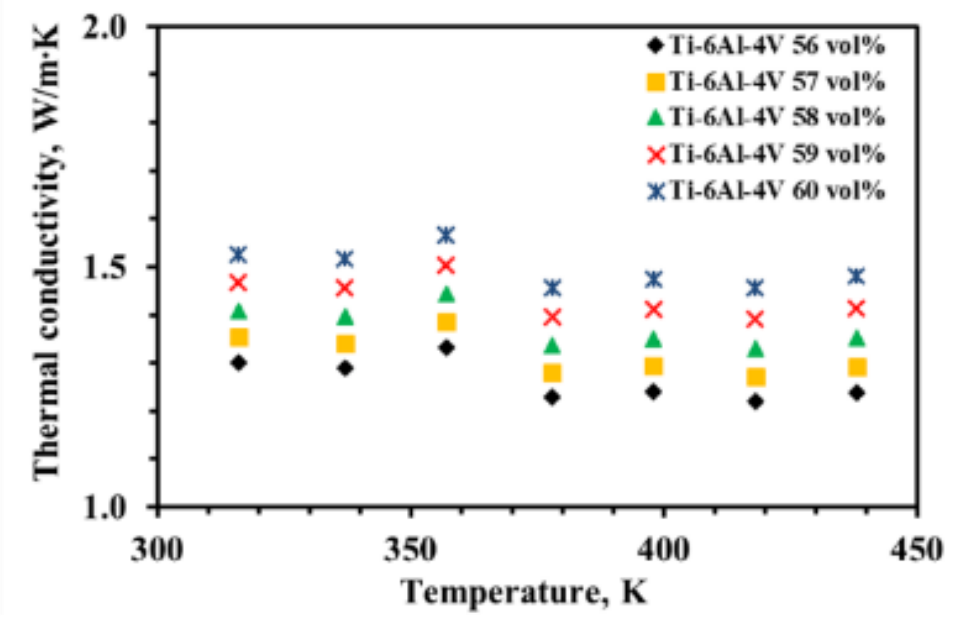

c)

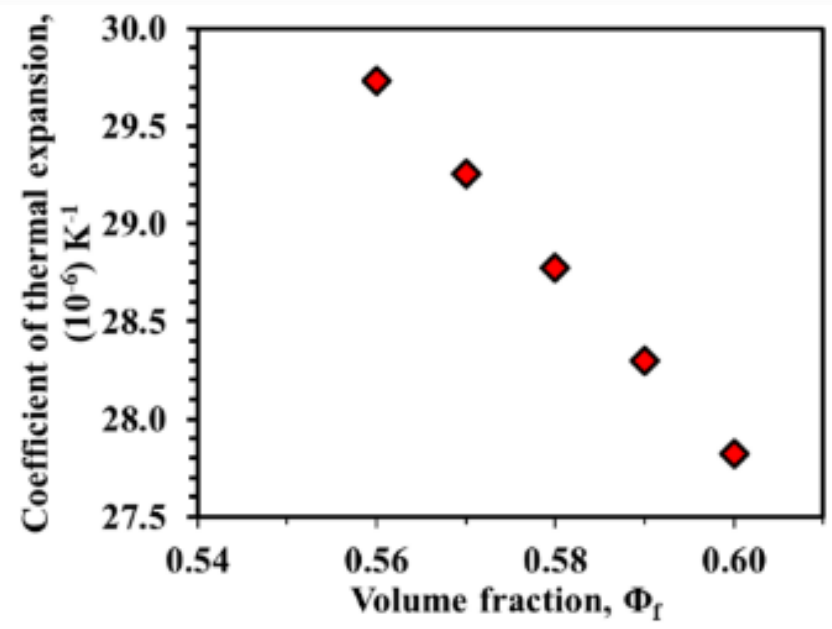

Figure 5.4. Estimated thermal properties of composite Ti-6Al-4V powder-binder feedstock at different volume fractions for: a. specific heat as a function of temperature, and b) thermal conductivity as a function of temperature, and c. coefficient of thermal expansion. 


\subsubsection{VISCOSITY}

In $\mathrm{MF}^{3}$, the molten feedstock material flows through the nozzle to form the desired geometry. The rheological understanding of powder-polymer mixtures is crucial since at higher powder loadings the feedstock viscosity increases. The typical filler content ranges between 50-65 vol.\%, and the viscosity varies as the inverse of powder particle size. Rheological characteristics provide clear understanding related to flow instabilities while printing and thereby the influence of powder loading, shear rate and temperature on the material flow properties.

a)

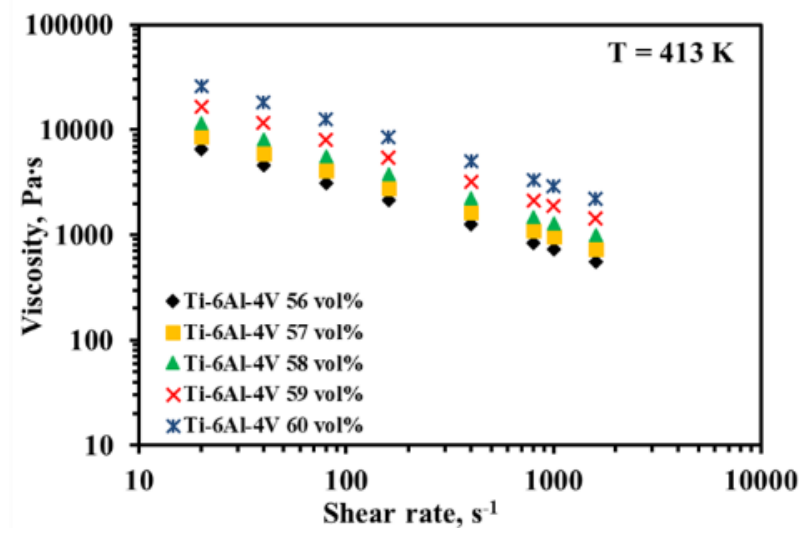

b)

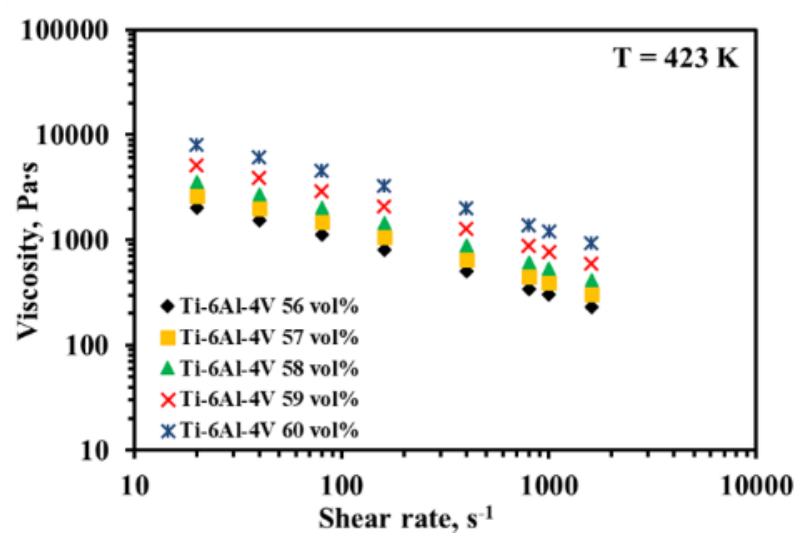

Figure 5.5. Estimated viscosity of the Ti-6Al-4V powder-binder feedstock for a shear rate of $20-1600 \mathrm{~s}-1$ at (a) $413 \mathrm{~K}$ and (b) $423 \mathrm{~K}$ with different volume fractions.

The Krieger-Dougherty model $[53-55,121]$ has been found to be suitable for predicting viscosity values for highly-filled powder-polymer mixtures from our previous work, generating coefficient of determination $\left(\mathrm{R}^{2}\right)$ ranging $0.94-0.99$ when compared to 
experimental viscosity measurements. A simplified form of the model is given in Equation

\section{9:}

$$
\eta_{c}=\frac{\eta_{b}}{\left[1-\frac{\phi_{f}}{\phi_{m}}\right]^{2}}
$$

where, $\eta$ is the viscosity. Subscripts $c$ and $b$ stand for composite and binder respectively. $\phi_{m}$ stands for the maximum packing fraction of the filler and is approximated to be 0.64 for randomly packed spheres [122], and $\phi_{f}$ is the filler volume fraction.

Figure 5.5 shows the variation in viscosity as a function of powder volume fraction, shear rate and temperature (tabulated data provided in Table 5.6). At $413 \mathrm{~K}$ and a shear rate of $800 \mathrm{~s}^{-1}$, increasing the volume fraction of powder from 0.56 to 0.60 increases the viscosity from 840 to 3350 Pas. For example, a volume fraction of 0.59 at $423 \mathrm{~K}$ with an increasing shear rate from 20 to $1600 \mathrm{~s}^{-1}$, the viscosity decreases one order of magnitude from 5130 to 590 Pas. Similarly, with increasing temperature from 413 to $423 \mathrm{~K}$, decreases the viscosity from 2140 to $840 \mathrm{~Pa}$ s for 0.59 volume fraction at $800 \mathrm{~s}^{-1}$. For processes operating under low shear rates, it is highly important to have low feedstock viscosity for successful flowability, especially for the $\mathrm{MF}^{3}$ process where the filament strength properties provide enough force for a continuous flow through the nozzle and successful printing operation. Experimental viscosity measurements for 0.59 volume fraction Ti-6Al-4V powder-binder feedstock at $423 \mathrm{~K}$ and $160 \mathrm{~s}^{-1}$, which was found to be $600 \mathrm{~Pa}$ s, representing a, overestimated value of $2070 \mathrm{~Pa}$ s. The differences in the particle packing behavior of Ti-6Al- 
$4 \mathrm{~V}$ powder may result in $\phi_{m}>0.64$ for the viscosity prediction of randomly packed, monosized spheres, resulting in overestimation compared to experimental data. For additional verification, estimates of the model to experimental data on an LDPE-alumina mixture at 0.6 volume fraction filler, showed a coefficient of determination $\left(\mathrm{R}^{2}\right)$ of $\sim 0.95$, confirming good applicability to predict viscosity for the system [26].

Table 5.6. Estimated viscosity of Ti-6Al-4V powder-binder feedstock with different filler volume fractions at different temperatures and shear rates.

\begin{tabular}{|c|c|c|c|c|c|c|c|c|}
\hline \multirow{5}{*}{$\begin{array}{l}\text { Volume fraction of } \\
\text { filler, } \Phi_{\mathrm{f}}\end{array}$} & \multicolumn{8}{|c|}{ Temperature (K) } \\
\hline & \multicolumn{4}{|c|}{413} & \multicolumn{4}{|c|}{423} \\
\hline & \multicolumn{4}{|c|}{ Shear rate $\left(s^{-1}\right)$} & \multicolumn{4}{|c|}{ Shear rate $\left(s^{-1}\right)$} \\
\hline & 20 & 160 & 800 & 1600 & 20 & 160 & 800 & 1600 \\
\hline & \multicolumn{8}{|c|}{ Viscosity (Pas) } \\
\hline 0.56 & 6520 & 2130 & 840 & 560 & 2000 & 810 & 340 & 230 \\
\hline 0.57 & 8520 & 2780 & 1100 & 730 & 2620 & 1060 & 450 & 300 \\
\hline 0.58 & 11600 & 3780 & 1490 & 990 & 3560 & 1440 & 610 & 410 \\
\hline 0.59 & 16700 & 5450 & 2140 & 1430 & 5130 & 2070 & 880 & 590 \\
\hline 0.60 & 26100 & 8500 & 3350 & 2230 & 8010 & 3290 & 1370 & 930 \\
\hline
\end{tabular}

Viscosity is sensitive to shear-rate and temperature. At low temperatures, the mixture viscosity is high, making it difficult to print. At high temperatures, the binder could break down or powder-binder separation could result during extrusion. Therefore, a bounded range of conditions are likely to exist across which successful printing is best achieved. The Cross-WLF equation can be used to numerically capture the shear-rate and temperature changes in viscosity [123], as shown in Equation 5.10: 


$$
\eta=\frac{\eta_{o}}{1+\left(\frac{\eta_{o} \dot{\gamma}}{\tau^{*}}\right)^{1-n}}
$$

where, $\eta$ is the melt viscosity (Pa's), $\eta_{o}$ is the zero shear viscosity (Pa's), $\dot{\gamma}$ is the shear rate $\left(\mathrm{s}^{-1}\right), \tau^{*}$ is the critical stress level at the transition to shear thinning $(\mathrm{Pa})$, which is determined by curve fitting, and $n$ is the power-law index in the high shear rate regime, also determined by curve fitting.

The viscosity of a filled polymer mixture and its temperature dependence can be calculated using Equation 5.11:

$$
\eta_{0}=D_{1} \exp \left[-\frac{A_{1}\left(T-T^{*}\right)}{A_{2}+\left(T-T^{*}\right)}\right]
$$

where $T$ is the temperature $(\mathrm{K}), T^{*}, D_{1}$, and $A_{1}$ are curve fitted coefficients, $A_{2}$ (assumed as $51.6 \mathrm{~K})$ is the WLF constant. The values of these coefficients can be obtained by curvefitting the estimated viscosity for different volume fractions of powder at various shear rates and temperatures. Representative extracted Cross WLF constants for a 59 vol. \% solids loading Ti-6Al-4V feedstock are provided in Table 5.7.

Table 5.7. Estimated Cross-WLF constants to determine viscosity at varying shear-rates and temperatures for binder and 0.59 volume fraction $\mathrm{Ti}-6 \mathrm{Al}-4 \mathrm{~V}$ powder in the binder feedstock. 


\begin{tabular}{|c|c|c|}
\hline \multirow{2}{*}{ Cross WLF constants } & \multicolumn{2}{|c|}{ volume fraction, $\boldsymbol{\Phi}_{\boldsymbol{f}}$} \\
\cline { 2 - 3 } & $\mathbf{0}$ & $\mathbf{0 . 5 9}$ \\
\hline $\mathrm{n}$ & 0.4 & 0.40 \\
\hline$\tau, \mathrm{Pa}$ & 793.46 & 203324.34 \\
\hline $\mathrm{D}_{1}, \mathrm{~Pa} \cdot \mathrm{s}$ & $4.29 \times 10^{23}$ & $1.67 \times 10^{15}$ \\
\hline $\mathrm{T}^{*}, \mathrm{~K}$ & 333 & 364 \\
\hline $\mathrm{A}_{1}$ & 78.13 & 46.37 \\
\hline $\mathrm{A}_{2}, \mathrm{~K}$ & 51.6 & 51.6 \\
\hline
\end{tabular}

\subsubsection{SPECIFIC VOLUME}

Warpage and non-uniform shrinkage during cooling have been some of the reported issues in the polymer FFF process which are equally important in $\mathrm{MF}^{3}$. The variation in specific volume as a function of temperature and pressure could help provide substantial information in mitigating dimensional variations during shrinkage of $\mathrm{MF}^{3}$ parts. The specific volume also depends on filler volume fraction and was calculated using the ruleof-mixtures [97] shown in Equation 5.12. The rule-of-mixtures has been found to be a reliable method in predicting the specific volume of polymer filled systems, with our previous work [54] produced a high coefficient of determination $\left(\mathrm{R}^{2}\right)$ of 0.99 when compared to experimental results.

$$
v_{c}=X_{f} v_{f}+v_{b}\left(1-X_{f}\right)
$$

where, $v$ is the specific volume, $X$ is the mass fraction, and the subscripts $c, f$, and $b$ refer to the composite, filler, and binder respectively. 
a)

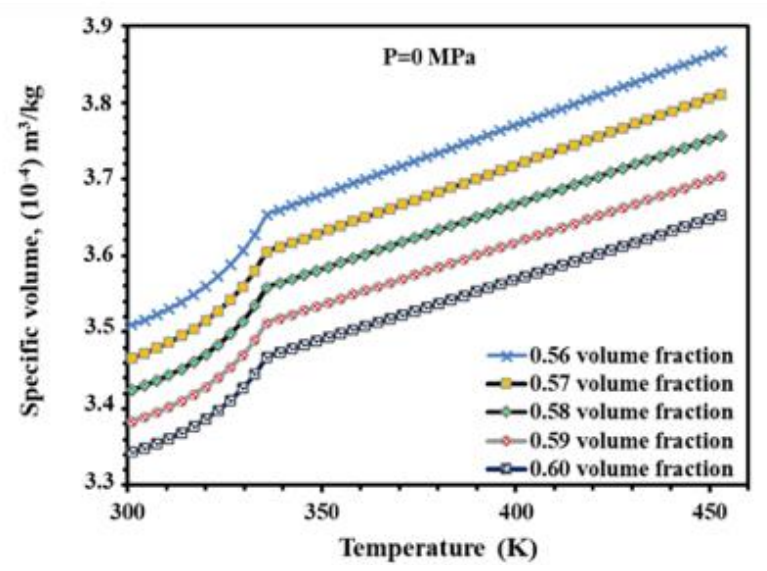

b)

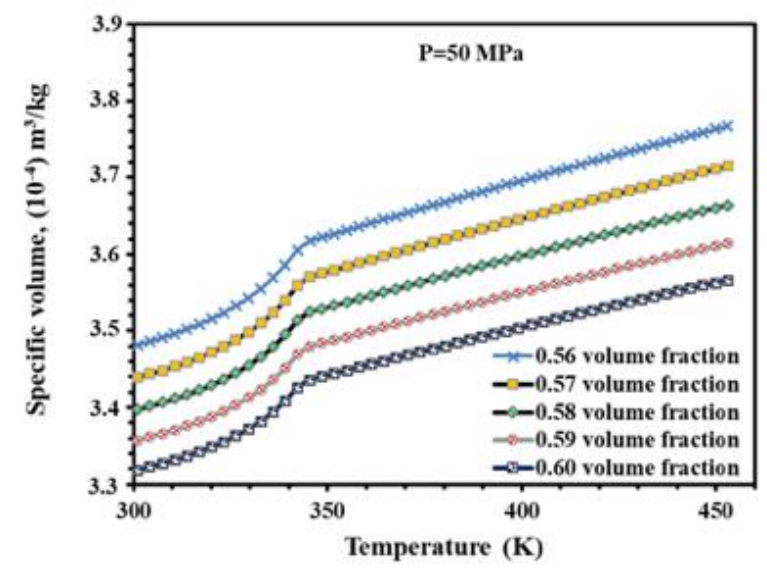

Figure 5.6. Estimated specific volume of Ti-6Al-4V powder-binder feedstock at different filler volume fractions for (a) $0 \mathrm{MPa}$ and (b) $50 \mathrm{MPa}$.

Figure 5.6 shows the variation of specific volume on temperature, pressure and powder volume fraction (data available in Table 5.8). Increasing the volume fraction from 0.56 to 0.60 at $0 \mathrm{MPa}$ decreased the specific volume from $3.51 \times 10^{-4}$ to $3.34 \times 10^{-4} \mathrm{~m}^{3} / \mathrm{kg}$ at 300 $\mathrm{K}$. When the temperature was increased from 300 to $450 \mathrm{~K}$ at $0 \mathrm{MPa}$, the specific volume increased from $3.51 \times 10^{-4}$ to $3.87 \times 10^{-4} \mathrm{~m}^{3} / \mathrm{kg}$ for feedstock with 0.56 volume fraction of Ti-6Al-4V powder. However, with increasing pressure from 0 to $50 \mathrm{MPa}$ (at $300 \mathrm{~K}$ and 0.56 volume fraction), the specific volume was found to decrease from $3.51 \times 10^{-4}$ to 3.48 $\times 10^{-4} \mathrm{~m}^{3} / \mathrm{kg}$. For additional verification, estimates of the model to experimental data on a PP-aluminum mixture at 0.5 volume fraction filler, showed a coefficient of determination $\left(\mathrm{R}^{2}\right)$ of 0.99 , confirming good applicability to predict specific volume for the system [26]. 
Table 5.8. Estimated specific volume of Ti-6Al-4V powder-binder feedstock with different filler volume fractions at different temperatures, and pressure of $0 \mathrm{MPa}$ and $50 \mathrm{MPa}$.

\begin{tabular}{|c|c|c|c|c|c|c|c|c|}
\hline \multirow{2}{*}{$\begin{array}{c}\text { Volume fraction } \\
\text { of filler, } \Phi_{f}\end{array}$} & \multicolumn{7}{|c|}{ Temperature (K) } & \multicolumn{5}{c|}{ Temperature (K) } \\
\cline { 2 - 9 } & $\mathbf{3 0 0}$ & $\mathbf{3 5 0}$ & $\mathbf{4 0 0}$ & $\mathbf{4 5 0}$ & $\mathbf{3 0 0}$ & $\mathbf{3 5 0}$ & $\mathbf{4 0 0}$ & $\mathbf{4 5 0}$ \\
\cline { 2 - 9 } & \multicolumn{8}{|c|}{ Specific volume (10 $\left.\mathbf{m}^{\mathbf{3}} / \mathbf{k g}\right)$} \\
\hline 0.56 & 3.51 & 3.68 & 3.77 & 3.86 & 3.48 & 3.63 & 3.70 & 3.76 \\
\hline 0.57 & 3.47 & 3.63 & 3.72 & 3.81 & 3.44 & 3.58 & 3.65 & 3.71 \\
\hline 0.58 & 3.42 & 3.59 & 3.67 & 3.75 & 3.40 & 3.53 & 3.60 & 3.66 \\
\hline 0.59 & 3.38 & 3.54 & 3.62 & 3.70 & 3.36 & 3.49 & 3.55 & 3.61 \\
\hline 0.60 & 3.34 & 3.49 & 3.57 & 3.65 & 3.32 & 3.44 & 3.50 & 3.56 \\
\hline
\end{tabular}

A two-domain Tait [123] model (Equation 5.13) can be used for generating specific volume data as a function of temperature and pressure pertaining to the $\mathrm{MF}^{3}$ processing conditions:

$$
v(T, p)=v_{o}(T)\left[1-C \ln \left(1+\frac{p}{B(T)}\right)+v_{t}(T, p)\right]
$$

where, $v(T, p)$ is the specific volume at a given temperature and pressure, $v_{o}(T)$ is the specific volume at zero gauge pressure, $T$ is the temperature in $\mathrm{K}, p$ is pressure in $\mathrm{Pa}$, and $C$ is a constant assumed to be 0.0894 for two-domain Tait model. The parameter $B(T)$, accounts for the pressure sensitivity of the material and is separately defined for the solid 
and melt regions. For the upper bound [123] when $T>T_{t}$ (volumetric transition temperature), $v_{o}, B$, and $v_{t}(T, p)$ are given by Equation 5.14, 5.15 and 5.16 respectively:

$$
\begin{gathered}
v_{o}=b_{1 m}+b_{2 m}\left(T-b_{5}\right) \\
B(T)=b_{3 m} e^{\left[-b_{4 m}\left(T-b_{5}\right)\right]} \\
v_{t}(T, p)=0
\end{gathered}
$$

where, $b_{1 m}, b_{2 m}, b_{3 m}, b_{4 m}$, and $b_{5}$ are curve-fitted coefficients. For the lower bound [123], when $T<T_{t}$, the parameter, $v_{o}, B$, and $v_{t}(T, p)$ are given by Equation 5.17, 5.18 and 5.19 respectively:

$$
\begin{gathered}
v_{o}=b_{1 s}+b_{2 s}\left(T-b_{5}\right) \\
B(T)=b_{3 s} e^{\left[-b_{4 s}\left(T-b_{5}\right]\right.} \\
v_{t}(T, p)=b_{7} e^{\left[b_{8}\left(T-b_{5}\right)-\left(b_{9} p\right)\right]}
\end{gathered}
$$


where, $b_{1 s}, b_{2 s}, b_{3 s}, b_{4 s}, b_{5}, b_{7}, b_{8}$, and $b_{9}$ are curve-fitted coefficients. The dependence of the volumetric transition temperature, $T_{t}$ on pressure can be given by Equation 5.20:

$$
T_{t}(p)=b_{5}+b_{6}(p)
$$

Representative extracted dual-domain Tait constants for 59 vol.\% solids loading Ti-6Al4V feedstock are provided in supplementary Table 5.9.

Table 5.9. Estimated dual-domain Tait constants for Ti-6Al-4V powder-binder feedstock at 0 and 0.59 volume fractions.

\begin{tabular}{|c|c|c|}
\hline \multirow{2}{*}{$\begin{array}{c}\text { Dual-domain Tait } \\
\text { constants }\end{array}$} & \multicolumn{2}{|c|}{ volume fraction, $\phi_{f}$} \\
\cline { 2 - 3 } & $\mathbf{0}$ & $\mathbf{0 . 5 9}$ \\
\hline $\mathrm{b}_{5}, \mathbf{K}$ & 336.15 & 321 \\
\hline $\mathrm{b}_{6}, \mathbf{K} / \mathbf{P a}$ & $1.47 \times 10^{-7}$ & $1.14 \times 10^{-6}$ \\
\hline $\mathrm{b}_{1 \mathrm{~m}}, \mathbf{m}^{\mathbf{3}} / \mathbf{k g}$ & $1.25 \times 10^{-3}$ & $3.47 \times 10^{-4}$ \\
\hline $\mathrm{b}_{2 \mathrm{~m}}, \mathbf{m}^{\mathbf{3}} / \mathbf{k g} \cdot \mathbf{K}$ & $1.34 \times 10^{-6}$ & $1.30 \times 10^{-7}$ \\
\hline $\mathrm{b}_{3 \mathrm{~m}}, \mathbf{P a}$ & $1.26 \times 10^{8}$ & $9.36 \times 10^{8}$ \\
\hline $\mathrm{b}_{4 \mathrm{~m}}, \mathbf{K}^{-1}$ & $5.86 \times 10^{-3}$ & $4.53 \times 10^{-3}$ \\
\hline $\mathrm{b}_{1 \mathrm{~s}}, \mathbf{m}^{\mathbf{3}} / \mathbf{k g}$ & $1.17 \times 10^{-3}$ & $3.40 \times 10^{-4}$ \\
\hline $\mathrm{b}_{2 \mathrm{~s}}, \mathbf{m}^{\mathbf{3}} / \mathbf{k g} \cdot \mathbf{K}$ & $8.57 \times 10^{-7}$ & $1.48 \times 10^{-7}$ \\
\hline $\mathrm{b}_{3 \mathrm{~s}}, \mathbf{P a}$ & $2.40 \times 10^{8}$ & $6.57 \times 10^{8}$ \\
\hline $\mathrm{b}_{4 \mathrm{~s}}, \mathbf{K}^{-\mathbf{1}}$ & $4.15 \times 10^{-3}$ & $3.94 \times 10^{-6}$ \\
\hline $\mathrm{b}_{7}, \mathbf{m}^{\mathbf{3}} \mathbf{k g}$ & $8.46 \times 10^{-5}$ & $3.23 \times 10^{-5}$ \\
\hline $\mathrm{b}_{8}, \mathbf{K}^{-\mathbf{1}}$ & $6.68 \times 10^{-2}$ & $9.12 \times 10^{-2}$ \\
\hline $\mathrm{b}_{9}, \mathbf{P a}^{-\mathbf{1}}$ & $1.39 \times 10^{-8}$ & $2.05 \times 10^{-8}$ \\
\hline & \multicolumn{2}{|c}{} \\
\hline
\end{tabular}

\subsection{SIMULATION CASE STUDY RESULTS}


In the current study, Digimat- $\mathrm{AM}^{\circledR}$ was used as a simulation tool which takes material thermophysical properties as the input parameters. Here, material properties for the 59 vol.\% Ti-6Al-4V powder-polymer feedstock system estimated using the models presented in Section 4 were used as input parameters to predict warpage/dimensional changes for a tensile bar printed with $\mathrm{MF}^{3}$.

a)
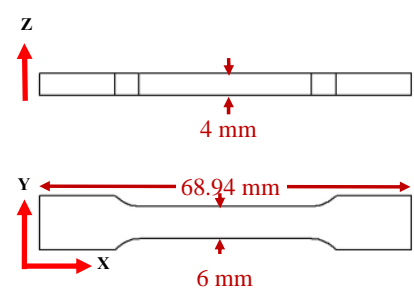

d)

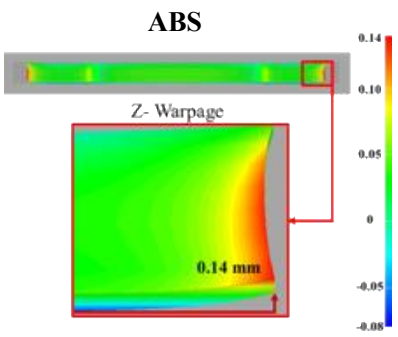

b)

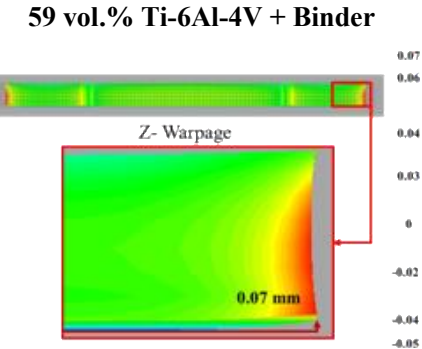

e)

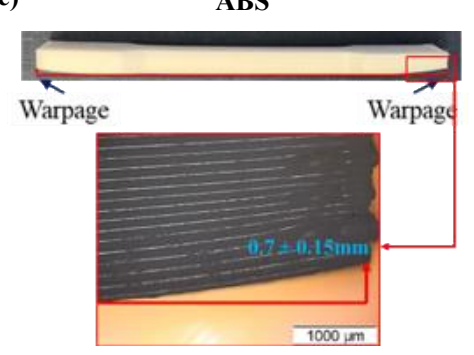

c) 59 vol.\% Ti-6Al-4V + Binder

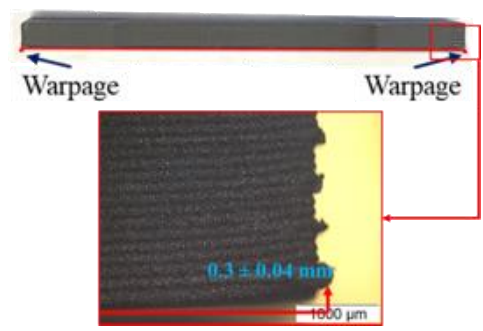

f)

Experiment and simulation warpage

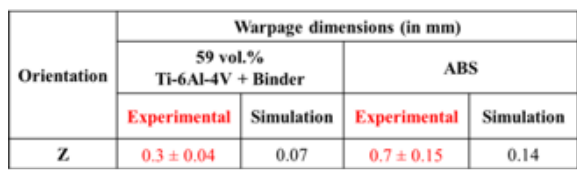

Figure 5.7. Experimental and simulation result verifications using estimated values: a)

CAD file for ASTM E8 tensile sample with dimensions, b) Simulation of the part using the estimated material properties for 59 vol.\% Ti-6Al-4V + binder feedstock c) Printed green parts with 0.59 vol. $\%$ of Ti-6Al-4V + binder feedstock, d) Simulation of the ABS part using the available material database in Digimat- $\mathrm{AM}^{\circledR}$, e) Printed part with $\mathrm{ABS}$ material filament, f) Warpage analysis resulting from experiments and simulation for 59 vol.\% Ti$6 \mathrm{Al}-4 \mathrm{~V}+$ binder feedstock and ABS. 
Figure 5.7a shows the CAD file with dimensions for an ASTM E8 tensile sample. The part dimensions of this geometry obtained from simulations and $\mathrm{MF}^{3}$ experiments were in excellent agreement (data provided in Figure 5.8). Warpage analysis of simulated and fabricated samples of 59 vol.\% Ti-6Al-4V MF${ }^{3}$ samples are shown in Figures 5.7b and 5.7c, respectively. Simulation results predicted the maximum warpage to be located at the edge of the tensile bar and the magnitude of warpage at this location along the $\mathrm{Z}$ direction to be $0.07 \mathrm{~mm}$. In close agreement to simulations, the $\mathrm{MF}^{3}$ experiments with the green parts verified that the location of maximum warpage was identical. However, the magnitude of warpage at this location in the $\mathrm{Z}$ direction was slightly higher at $0.3 \pm 0.04$ mm. In order to further, assess the differences between $\mathrm{MF}^{3}$ and FFF results, simulations and experiments were also conducted on a standard ABS polymer for the same tensile bar specimen and are represented in Figures 5.7d and 5.7e. For ABS parts from simulations, the location of maximum warpage was identical to the $\mathrm{MF}^{3}$ simulation result. However, the magnitude of warpage at this location in the $\mathrm{Z}$ direction was comparatively higher at $0.14 \mathrm{~mm}$. In FFF experiments with ABS, the location of maximum warpage correlated with the ABS simulation. However, the magnitude measured in the $\mathrm{Z}$ direction was also slightly higher $0.7 \pm 0.15 \mathrm{~mm}$. The warpage results obtained from simulations as well as experiments are summarized in Figure 5.7f. These results indicate that the location of maximum warpage is accurately predicted for both material systems. However, the magnitude of warpage is under-estimated by the Digimat- $\mathrm{AM}^{\circledR}$ simulation platform for both the systems and needs further analysis and refinement in the future. Typically, uneven heat distribution creates internal stresses within a part, resulting in warpage [43, 124]. Several material properties are known to contribute to the overall warpage. However, the 
CTE value of the 59 vol. \% Ti-6Al-4V powder-binder system $\left(2.8 \times 10^{-5} \mathrm{~K}^{-1}\right)$ is lower than that for $\mathrm{ABS}\left(9 \times 10^{-5} \mathrm{~K}^{-1}\right)$ and is concluded to be the major reason for the differences in the extent of warpage in the two material systems.

a)
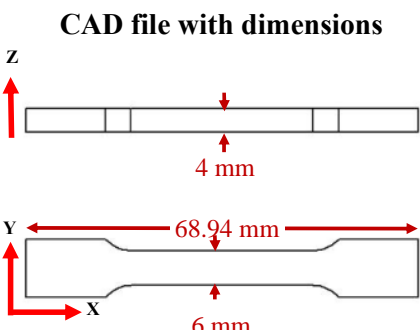

d)

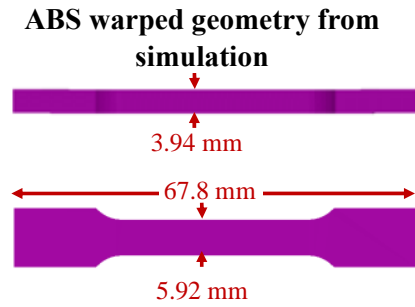

b)

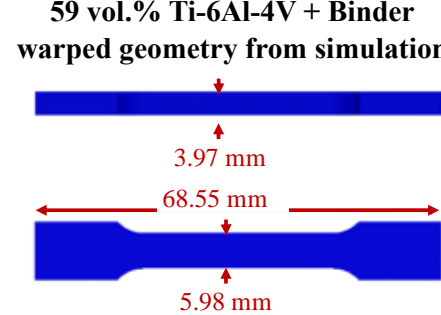

e)

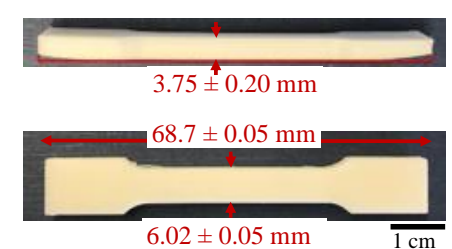

c) 59 vol. $\%$ Ti-6Al-4V + Binder printed geometry
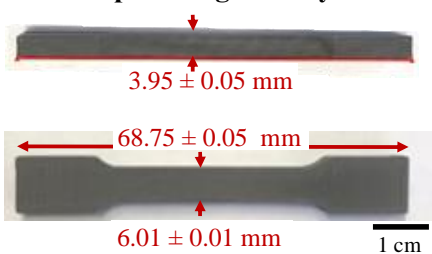

f) Dimensional differences for printed and

\begin{tabular}{|c|c|c|c|c|}
\hline \multirow{4}{*}{ Orientation } & \multicolumn{3}{|c|}{ Dimensions (in mm) } \\
\cline { 2 - 5 } & $\begin{array}{c}\mathbf{5 9} \text { vol.\% } \\
\text { Ti-6Al-4V + Binder }\end{array}$ & \multicolumn{2}{c|}{ ABS } \\
\cline { 2 - 5 } & Experimental & Simulation & Experimental & Simulation \\
\hline $\mathbf{X}$ & $68.75 \pm 0.05$ & 68.55 & $68.7 \pm 0.05$ & 67.8 \\
\hline $\mathbf{Y}$ & $6.00 \pm 0.01$ & 5.98 & $6.00 \pm 0.05$ & 5.92 \\
\hline $\mathbf{Z}$ & $3.95 \pm 0.05$ & 3.97 & $3.75 \pm 0.20$ & 3.94 \\
\hline
\end{tabular}

Figure 5.8. Dimensions for an ASTM E8 tensile sample obtained from simulations and experiments for 59 vol. \% solids loading Ti-6Al-4V feedstock and ABS.

The above results suggest the potential for using the material property estimation protocol for analyzing complex geometries using other output parameters of the $\mathrm{MF}^{3}$ process including warpage, residual stresses, porosity, and distortion. Preliminary results to demonstrate the geometry capability of the are shown in Figure 5.9. These studies are currently underway in our group and will be reported in the future. Table 5.10 provides material properties for other most commonly used metals that can be used to estimate input material properties for other $\mathrm{MF}^{3}$ systems based on the protocols presented in the present 
study. These studies are also currently underway in our group and will be reported in future publications.

a)

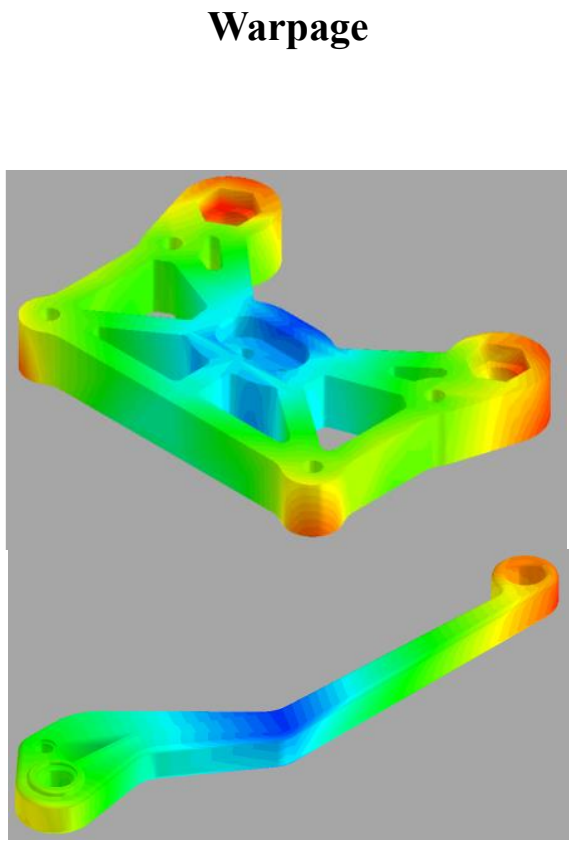

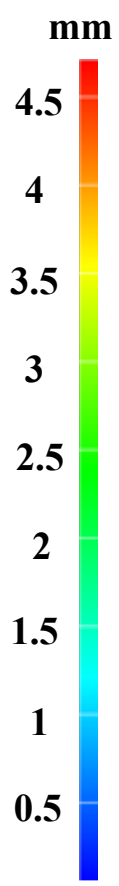

b)

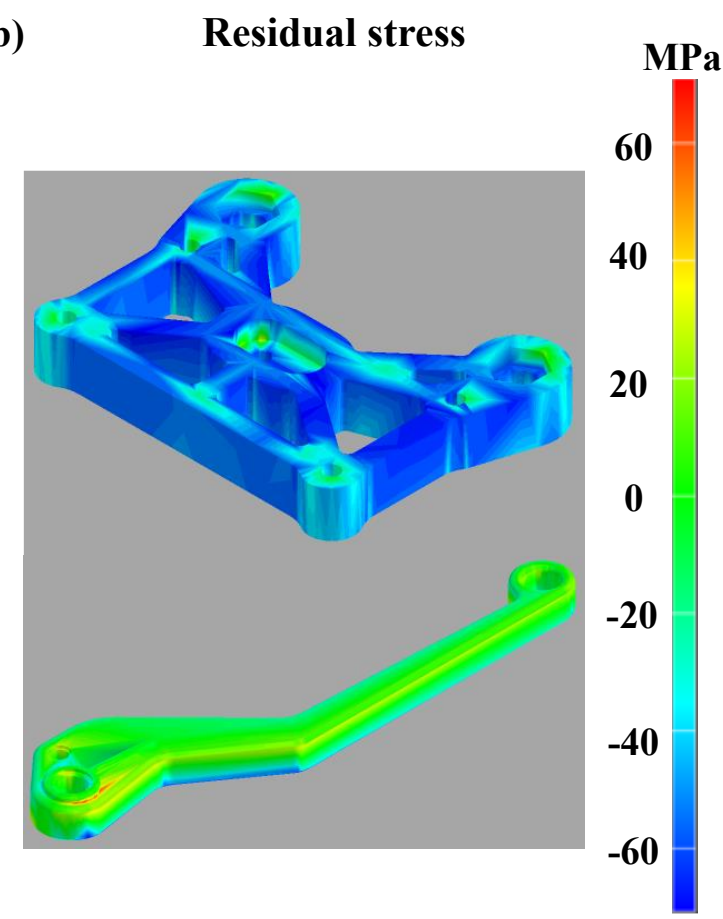

Figure 5.9. Examples for Digimat-AM® simulations that show typical outputs such as (a) warpage, and (b) residual stress in case studies for parts an end-of-arm tool (top) and automotive brake lever (bottom). 
Table 5.10. Thermophysical properties of some metals used in $\mathrm{MF}^{3}$ : data taken from the reference [53].

\begin{tabular}{|c|c|c|c|c|c|}
\hline Material & $\begin{array}{c}\text { Density } \\
\mathrm{kg} / \mathrm{m}^{3}\end{array}$ & $\begin{array}{c}\text { Specific } \\
\text { heat } \\
\text { J/kg.K }\end{array}$ & $\begin{array}{c}\text { Thermal } \\
\text { conductivity } \\
\text { W/m·K }\end{array}$ & $\begin{array}{c}\text { Coefficient of } \\
\text { thermal } \\
\text { expansion } \\
10^{-6} / K^{-1}\end{array}$ & $\begin{array}{c}\text { Elastic } \\
\text { modulus } \\
\text { GPa }\end{array}$ \\
\hline Aluminum & 2700 & 900 & 180 & 23 & 70 \\
\hline Copper & 8750 & 385 & 360 & 13 & 130 \\
\hline $\mathrm{W}-\mathbf{1 0 C u}$ & 17000 & 160 & 209 & 6 & 340 \\
\hline $\mathrm{Co}-28 \mathrm{Cr}-4 \mathrm{~W}-3 \mathrm{Ni}$ & 8800 & -- & 14.7 & 12.8 & 235 \\
\hline Inconel 718 & 8230 & -- & 11.4 & 12.8 & 200 \\
\hline 17-4PH stainless steel & 7810 & 460 & 14 & 10.8 & 190 \\
\hline 316L stainless steel & 8010 & 500 & 15.9 & 17 & 190 \\
\hline 420 stainless steel & 7860 & 460 & 24.9 & 12.2 & 190 \\
\hline
\end{tabular}

\subsection{CONCLUSIONS}

Based on the estimated metal-polymer mixture properties and their use in process simulations, the following conclusions can be drawn:

-The variation of material properties related to dimensional changes as a function of filler attributes and filler volume fraction can be estimated for Ti-6Al-4V powder-polymer mixtures. The properties estimated using various models enable the evaluation of component-level attributes fabricated by $\mathrm{MF}^{3}$ using $\mathrm{DfMF}^{3}$ platforms. The componentlevel attributes included here are the final dimensions and warpage. 
- The overall approach enables the understanding of the dependence of $\mathrm{MF}^{3}$ processing of complex Ti-6Al-4V components on the material composition.

- The experimental protocols for verifying the estimated material properties presented in this work can help in further refining the models and analyzing their influence on successfully predicting $\mathrm{MF}^{3}$ outcomes.

- It is expected that the overall approach will help reduce significant trial-and-error in designing new materials that can be used to fabricate complex geometries using $\mathrm{MF}^{3}$. 


\section{CHAPTER 6}

\section{CONCLUSIONS}

The dissertation presents first-of-its-kind attempt to address the material-process-property interactions observed in the processing Ti-6Al-4V alloy parts using metal fused filament fabrication $\left(\mathrm{MF}^{3}\right)$ process. The conclusions for the presented work are summarized below:

- It has been successfully demonstrated that a Ti-6Al-4V powder-polymer feedstock with 59 vol.\% solids loading can be compounded and extruded into filaments for $\mathrm{MF}^{3} 3 \mathrm{D}$ printing. Additionally, the fabrication of various complex geometries with overhang features was also demonstrated with the $\mathrm{MF}^{3}$ process. The printed part dimensions were found to be within $\pm 0.5 \%$ of the CAD design. Since the metal particles are bound in the polymer matrix, it eliminates the risk of health and safety hazards otherwise posed by loose powder handling during other additive manufacturing (AM) processes. Additionally, subsequent processing steps of debinding and sintering resulted in successfully retaining part geometry and mechanical properties.

- $\mathrm{MF}^{3}$ sintered parts exhibited an ultimate tensile strength of $875 \pm 15 \mathrm{MPa}$ with 17 $\pm 3 \%$ elongation, at $94.1 \pm 0.1 \%$ relative density which are comparable to metal injection molded (MIM) parts. The microstructures in different directions of the sintered parts were found to be isotropic throughout and are comparable to MIM microstructures. 
- A process model was developed and evaluated to determine the printing criterion with highly loaded Ti-6Al-4V powder (59 vol.\%) into the polymer matrix. Material printability and rate limits were determined by estimating the force required for material extrusion through the nozzle and comparing it to the filament failure force. The filament strength was found to be the limiting factor for the maximum force sustained by the filament before its failure during printing.

- The filament viscosity was found to be the dominant factor in controlling the pressure drop at the nozzle exit, and hence the force required to achieve continuous material flow. Coarse powder filaments with low viscosity enabled printing speeds up to $8 \mathrm{~mm} / \mathrm{s}$, suggesting high production capabilities. The fine powder filaments with relatively high viscosity could achieve feed-rates of $\sim 2 \mathrm{~mm} / \mathrm{s}$, beyond which the filaments failed.

- The above process model when extended for different compositions and commercially available material (ABS- acrylonitrile-butadiene-styrene), showed a reasonable fit between the predictions and experimental observations. This suggests a strong potential of the model to predict material and process interactions to understand print quality and speeds.

- Taguchi design of experiments was used to determine the influential print parameters that enable high green density and dimensional tolerances of the parts made using $\mathrm{MF}^{3}$. ANOVA analysis indicated that the extrusion multiplier as the most significant parameter to achieve $99.8 \pm 0.1 \%$ of relative density. Further, a layer height of $150 \mu \mathrm{m}$, extrusion multiplier of 1.05 , and an overlap of $40 \%$ were found to produce parts with high dimensional accuracy ( $0.6 \%$ CAD model). 
- The effect of Ti-6Al-4V powder size and its interstitial content was investigated with the sintering of $\mathrm{MF}^{3}$ produced parts. Powder with $\mathrm{d}_{50}=13 \mu \mathrm{m}$ resulted in a sintered density of $97.2 \pm 0.5 \%$, compared to a powder with $\mathrm{d}_{50}=30 \mu \mathrm{m}$ having a density of $94.2 \pm 0.1 \%$ at $1250{ }^{\circ} \mathrm{C}$ for 4 hrs. The oxygen concentration of fine powder $\left(\mathrm{d}_{50}=13 \mu \mathrm{m}\right)$ increased from $0.16 \mathrm{wt} . \%$ to $0.30 \mathrm{wt} . \%$ in the sintered parts which exhibited an elongation of $4.4 \pm 0.7 \%$. However, the coarse powder $\left(\mathrm{d}_{50}=30 \mu \mathrm{m}\right)$ had $0.08 \mathrm{wt} . \%$ oxygen which increased to $0.20 \mathrm{wt} . \%$ and produced an elongation of $17 \pm 3 \%$ in the sintered parts. This clearly demonstrates the strong influence of particle size and oxygen content on the sintered part density and elongation.

- Design for the metal fused filament fabrication $\left(\mathrm{DfMF}^{3}\right)$ platform was successfully implemented. Selected models were utilized to estimate material properties (density, modulus, thermal conductivity, specific heat, viscosity, and specific volume) with variation in powder-polymer concentrations for Ti-6Al-4V $\mathrm{MF}^{3}$ feedstock. These properties were used as input parameters to perform $\mathrm{MF}^{3}$ process simulation with Digimat AM software which currently has limited material properties available in its database. Additionally, simulations performed on test geometries revealed that part dimensions and warpages results were comparable to experimental results. It is expected that such a $\mathrm{DfMF}^{3}$ method can be prescribed to evaluate component level attributes such as dimensions and warpage of $\mathrm{MF}^{3}$ printed parts and identify appropriate process conditions for printing.

- The $\mathrm{DfMF}^{3}$ approach is expected to provide an understanding of material compositions and its effect on the processing of complex Ti-6Al-4V geometries by 
$\mathrm{MF}^{3}$. The future scope of the work can be extended for any material compositions involving filler particles in the polymer matrix. 


\section{CHAPTER 7}

\section{FUTURE WORK}

The work in the dissertation addressed some of the key challenges from the perspective of powder-polymer filament printability with the $\mathrm{MF}^{3}$ process, and how effective processing (filament-printing-debinding-sintering) of $\mathrm{MF}^{3} \mathrm{Ti}-6 \mathrm{Al}-4 \mathrm{~V}$ parts can be performed to obtain desired properties. The study also opens the scope for further scientific developments to expand its capability and understanding to other material systems. Some of the avenues which can be built off from the current work include:

- This dissertation was funded by NASA for the FABLAB project, which underlines the extended application of $\mathrm{MF}^{3}$ for in-space microgravity conditions. The effect of printing and sintering on the part dimensions, defects, and properties have been studied on earth and can be scaled to microgravity environments, which need further careful experimentations and material modeling. This aspect would form the novelty of the process to work with multi-materials as science expands beyond earth to establish manufacturing capabilities in adverse environments.

- The material properties have been investigated in the as-sintered condition only. Therefore a lot of microstructure, mechanical, and physical property enhancements and manipulations can be achieved by using different heat treatment cycles and hotisostatic pressing operations. This understanding will further enable establishing 
the effect of post-processing on microstructure-mechanical properties evolution in $\mathrm{MF}^{3}$ fabricated Ti-6Al-4V alloy parts.

- Design-related constraints and challenges with the $\mathrm{MF}^{3}$ remain to be investigated. For example, the influence of overhangs and complexities of the part design needs to be studied experimentally through mathematical modeling and simulations. This would allow undertaking design-related constraints in producing parts with $\mathrm{MF}^{3}$ and the related necessity to use support materials.

- Currently, the $\mathrm{MF}^{3}$ process has been demonstrated for Ti-6Al-4V alloy, but the capacity to be extended to multi-metals, ceramics, and composites remains wide open and requires definitive parameters and processes to be developed. 


\section{REFERENCES}

[1] Y. Kok, X.P. Tan, P. Wang, M. Nai, N.H. Loh, E. Liu, S.B. Tor, Anisotropy and heterogeneity of microstructure and mechanical properties in metal additive manufacturing: A critical review, Materials \& Design 139 (2018) 565-586.

[2] J.J. Lewandowski, M. Seifi, Metal additive manufacturing: a review of mechanical properties, Annual Review of Materials Research 46 (2016) 151-186.

[3] M. Ziaee, N.B. Crane, Binder jetting: A review of process, materials, and methods, Additive Manufacturing (2019).

[4] J. Gonzalez-Gutierrez, F. Arbeiter, T. Schlauf, C. Kukla, C. Holzer, Tensile properties of sintered 17-4PH stainless steel fabricated by material extrusion additive manufacturing, Materials Letters 248 (2019) 165-168.

[5] J. Gonzalez-Gutierrez, S. Cano, S. Schuschnigg, C. Kukla, J. Sapkota, C. Holzer, Additive manufacturing of metallic and ceramic components by the material extrusion of highly-filled polymers: A review and future perspectives, Materials 11(5) (2018) 840.

[6] Z.Z. Fang, J.D. Paramore, P. Sun, K.R. Chandran, Y. Zhang, Y. Xia, F. Cao, M. Koopman, M. Free, Powder metallurgy of titanium-past, present, and future, International Materials Reviews 63(7) (2018) 407-459.

[7] S. Seong, O. Younossi, B.W. Goldsmith, Titanium: industrial base, price trends, and technology initiatives, Rand Corporation2009. 
[8] J. Damon, S. Dietrich, S. Gorantla, U. Popp, B. Okolo, V. Schulze, Process porosity and mechanical performance of fused filament fabricated 316L stainless steel, Rapid Prototyping Journal (2019).

[9] Y. Thompson, J. Gonzalez-Gutierrez, C. Kukla, P. Felfer, Fused filament fabrication, debinding and sintering as a low cost additive manufacturing method of 316L stainless steel, Additive Manufacturing 30 (2019) 100861.

[10] D. Godec, S. Cano, C. Holzer, J. Gonzalez-Gutierrez, Optimization of the 3D Printing Parameters for Tensile Properties of Specimens Produced by Fused Filament Fabrication of 17-4PH Stainless Steel, Materials 13(3) (2020) 774.

[11] A. Bose, C.A. Schuh, J.C. Tobia, N. Tuncer, N.M. Mykulowycz, A. Preston, A.C. Barbati, B. Kernan, M.A. Gibson, D. Krause, Traditional and additive manufacturing of a new Tungsten heavy alloy alternative, International Journal of Refractory Metals and Hard Materials 73 (2018) 22-28.

[12] W. Lengauer, I. Duretek, M. Fürst, V. Schwarz, J. Gonzalez-Gutierrez, S. Schuschnigg, C. Kukla, M. Kitzmantel, E. Neubauer, C. Lieberwirth, Fabrication and properties of extrusion-based 3D-printed hardmetal and cermet components, International Journal of Refractory Metals and Hard Materials 82 (2019) 141-149.

[13] M.K. Agarwala, V.R. Jamalabad, N.A. Langrana, A. Safari, P.J. Whalen, S.C. Danforth, Structural quality of parts processed by fused deposition, Rapid Prototyping Journal 2(4) (1996) 4-19.

[14] S. Masood, W. Song, Development of new metal/polymer materials for rapid tooling using fused deposition modelling, Materials \& design 25(7) (2004) 587-594. 
[15] M. Nikzad, S. Masood, I. Sbarski, Thermo-mechanical properties of a highly filled polymeric composites for fused deposition modeling, Materials \& Design 32(6) (2011) 3448-3456.

[16] L. Ren, X. Zhou, Z. Song, C. Zhao, Q. Liu, J. Xue, X. Li, Process parameter optimization of extrusion-based 3D metal printing utilizing PW-LDPE-SA binder system, Materials 10(3) (2017) 305.

[17] G. Wu, N.A. Langrana, R. Sadanji, S. Danforth, Solid freeform fabrication of metal components using fused deposition of metals, Materials \& Design 23(1) (2002) 97-105.

[18] D.A. Anderegg, H.A. Bryant, D.C. Ruffin, S.M. Skrip Jr, J.J. Fallon, E.L. Gilmer, M.J. Bortner, In-situ monitoring of polymer flow temperature and pressure in extrusion based additive manufacturing, Additive Manufacturing 26 (2019) 76-83.

[19] J. Wang, H. Xie, Z. Weng, T. Senthil, L. Wu, A novel approach to improve mechanical properties of parts fabricated by fused deposition modeling, Materials \& Design 105 (2016) 152-159.

[20] H.W. Guan, M.M. Savalani, I. Gibson, O. Diegel, Influence of fill gap on flexural strength of parts fabricated by curved layer fused deposition modeling, Procedia Technology 20 (2015) 243-248.

[21] S. Ziemian, M. Okwara, C.W. Ziemian, Tensile and fatigue behavior of layered acrylonitrile butadiene styrene, Rapid Prototyping Journal 21(3) (2015) 270-278.

[22] H. Ramanath, C. Chua, K. Leong, K. Shah, Melt flow behaviour of poly-ecaprolactone in fused deposition modelling, Journal of Materials Science: Materials in Medicine 19(7) (2008) 2541-2550. 
[23] P.K. Gurrala, S.P. Regalla, Part strength evolution with bonding between filaments in fused deposition modelling: This paper studies how coalescence of filaments contributes to the strength of final FDM part, Virtual and Physical Prototyping 9(3) (2014) 141-149.

[24] P. Singh, V.K. Balla, A. Tofangchi, S.V. Atre, K.H. Kate, Printability studies of Ti6Al-4 V by metal fused filament fabrication (MF3), International Journal of Refractory Metals and Hard Materials (2020) 105249.

[25] R. German, Sintering: from empirical observations to scientific principles, Butterworth-Heinemann2014.

[26] S. Liu, Y.C. Shin, Additive manufacturing of Ti6Al4V alloy: A review, Materials \& Design 164 (2019) 107552.

[27] T. DebRoy, H. Wei, J. Zuback, T. Mukherjee, J. Elmer, J. Milewski, A.M. Beese, A. Wilson-Heid, A. De, W. Zhang, Additive manufacturing of metallic components-process, structure and properties, Progress in Materials Science 92 (2018) 112-224.

[28] E. Ergül, H. Özkan Gülsoy, V. Günay, Effect of sintering parameters on mechanical properties of injection moulded Ti-6Al-4V alloys, Powder Metallurgy 52(1) (2009) 6571.

[29] N.M. Nor, N. Muhamad, A.M. Ihsan, K. Jamaludin, Sintering parameter optimization of Ti-6Al-4V metal injection molding for highest strength using palm stearin binder, Procedia Engineering 68 (2013) 359-364.

[30] G. Obasi, O. Ferri, T. Ebel, R. Bormann, Influence of processing parameters on mechanical properties of Ti-6Al-4V alloy fabricated by MIM, Materials Science and Engineering: A 527(16-17) (2010) 3929-3935. 
[31] G. Shibo, Q. Xuanhui, H. Xinbo, Z. Ting, D. Bohua, Powder injection molding of Ti6Al-4V alloy, Journal of Materials Processing Technology 173(3) (2006) 310-314.

[32] A. Sidambe, I. Figueroa, H. Hamilton, I. Todd, Metal injection moulding of Ti-64 components using a water soluble binder, PIM International 4(4) (2010) 56-62.

[33] C. Qiu, N.J. Adkins, M.M. Attallah, Microstructure and tensile properties of selectively laser-melted and of HIPed laser-melted Ti-6Al-4V, Materials Science and Engineering: A 578 (2013) 230-239.

[34] H. Rafi, N. Karthik, H. Gong, T.L. Starr, B.E. Stucker, Microstructures and mechanical properties of Ti6Al4V parts fabricated by selective laser melting and electron beam melting, Journal of materials engineering and performance 22(12) (2013) 3872-3883. [35] B. Vrancken, L. Thijs, J.-P. Kruth, J. Van Humbeeck, Heat treatment of Ti6Al4V produced by Selective Laser Melting: Microstructure and mechanical properties, Journal of Alloys and Compounds 541 (2012) 177-185.

[36] R. Zauner, C. Binet, D. Heaney, J. Piemme, Variability of feedstock viscosity and its correlation with dimensional variability of green powder injection moulded components, Powder Metallurgy 47(2) (2004) 150-155.

[37] H.Ö. Gülsoy, N. Gülsoy, R. Calışıcı, Particle morphology influence on mechanical and biocompatibility properties of injection molded $\mathrm{Ti}$ alloy powder, Bio-medical materials and engineering 24(5) (2014) 1861-1873.

[38] J. Contreras, A. Jimenez-Morales, J. Torralba, Experimental and theoretical methods for optimal solids loading calculation in MIM feedstocks fabricated from powders with different particle characteristics, Powder metallurgy 53(1) (2010) 34-40. 
[39] R.M. German, A. Bose, Injection Molding of Metals and Ceramics, Metal Powder Industries Federation1997.

[40] E.L. Gilmer, D. Miller, C.A. Chatham, C. Zawaski, J.J. Fallon, A. Pekkanen, T.E. Long, C.B. Williams, M.J. Bortner, Model analysis of feedstock behavior in fused filament fabrication: Enabling rapid materials screening, Polymer 152 (2018) 51-61.

[41] J. Go, A.J. Hart, Fast desktop-scale extrusion additive manufacturing, Additive Manufacturing 18 (2017) 276-284.

[42] R. Supati, N. Loh, K. Khor, S. Tor, Mixing and characterization of feedstock for powder injection molding, Materials Letters 46(2-3) (2000) 109-114.

[43] B.N. Turner, S.A. Gold, A review of melt extrusion additive manufacturing processes: II. Materials, dimensional accuracy, and surface roughness, Rapid Prototyping Journal $21(3)(2015)$ 250-261.

[44] P. Singh, Q. Shaikh, V.K. Balla, S.V. Atre, K.H. Kate, Estimating Powder-Polymer Material Properties Used in Design for Metal Fused Filament Fabrication (DfMF3), JOM 72(1) (2020) 485-495.

[45] A. Abbott, G. Tandon, R. Bradford, H. Koerner, J. Baur, Process-structure-property effects on ABS bond strength in fused filament fabrication, Additive Manufacturing 19 (2018) 29-38.

[46] V. Kuznetsov, A. Solonin, O. Urzhumtsev, R. Schilling, A. Tavitov, Strength of PLA components fabricated with fused deposition technology using a desktop 3D printer as a function of geometrical parameters of the process, Polymers 10(3) (2018) 313. 
[47] Q. Sun, G. Rizvi, C. Bellehumeur, P. Gu, Effect of processing conditions on the bonding quality of FDM polymer filaments, Rapid Prototyping Journal 14(2) (2008) 7280.

[48] T. Ebel, O.M. Ferri, W. Limberg, F.-P. Schimansky, Metal injection moulding of advanced titanium alloys, Advances in Powder Metallurgy \& Particulate Materials 1 (2011) 45-57.

[49] Y. Cao, F. Zeng, B. Liu, Y. Liu, J. Lu, Z. Gan, H. Tang, Characterization of fatigue properties of powder metallurgy titanium alloy, Materials Science and Engineering: A 654 (2016) 418-425.

[50] P. Singh, Q. Shaikh, V.K. Balla, S.V. Atre, K.H. Kate, Estimating Powder-Polymer Material Properties Used in Design for Metal Fused Filament Fabrication (DfMF3), JOM (2019).

[51] R.M. German, Injection molding of metals and ceramics, Metal powder industries federation 3 (1997).

[52] D.F. Heaney, Handbook of metal injection molding, Woodhead Publishing2018.

[53] K.H. Kate, R.K. Enneti, V.P. Onbattuvelli, S.V. Atre, Feedstock properties and injection molding simulations of bimodal mixtures of nanoscale and microscale aluminum nitride, Ceramics International 39(6) (2013) 6887-6897.

[54] K.H. Kate, R.K. Enneti, S.-J. Park, R.M. German, S.V. Atre, Predicting powderpolymer mixture properties for PIM design, Critical reviews in solid state and materials sciences 39(3) (2014) 197-214. 
[55] K.H. Kate, V.P. Onbattuvelli, R.K. Enneti, S.W. Lee, S.-J. Park, S.V. Atre, Measurements of powder-polymer mixture properties and their use in powder injection molding simulations for aluminum nitride, JOM 64(9) (2012) 1048-1058.

[56] M. Harris, J. Potgieter, R. Archer, K.M. Arif, Effect of material and process specific factors on the strength of printed parts in fused filament fabrication: A review of recent developments, Materials 12(10) (2019) 1664.

[57] I. Gibson, D.W. Rosen, B. Stucker, Design for additive manufacturing, Additive manufacturing technologies, Springer2010, pp. 299-332.

[58] M.H. Khaliq, R. Gomes, C. Fernandes, J. Nóbrega, O.S. Carneiro, L.L. Ferrás, On the use of high viscosity polymers in the fused filament fabrication process, Rapid Prototyping Journal 23(4) (2017) 727-735.

[59] B. Hausnerova, B.N. Mukund, D. Sanetrnik, Rheological properties of gas and water atomized 17-4PH stainless steel MIM feedstocks: Effect of powder shape and size, Powder technology 312 (2017) 152-158.

[60] M. Seerane, P. Ndlangamandla, R. Machaka, The influence of particle size distribution on the properties of metal-injection-moulded 17-4 PH stainless steel, Journal of the Southern African Institute of Mining and Metallurgy 116(10) (2016) 935-940.

[61] C. Hopmann, W. Michaeli, Extrusion Dies for Plastics and Rubber: Design and Engineering Computations, Carl Hanser Verlag GmbH Co KG2016.

[62] M.P. Serdeczny, R. Comminal, D.B. Pedersen, J. Spangenberg, Experimental and analytical study of the polymer melt flow through the hot-end in material extrusion additive manufacturing, Additive Manufacturing (2019) 100997. 
[63] T.A. Osswald, J. Puentes, J. Kattinger, Fused filament fabrication melting model, Additive Manufacturing 22 (2018) 51-59.

[64] J. Go, S.N. Schiffres, A.G. Stevens, A.J. Hart, Rate limits of additive manufacturing by fused filament fabrication and guidelines for high-throughput system design, Additive Manufacturing 16 (2017) 1-11.

[65] B. Inc. https://www.basf.com/documents/de/about-us/Companies/new-businessgmbh/publications/3d-printing/TDS_BASF_Ultrafuse-316LX.pdf. (Accessed 15th August 2019).

[66] S. Tunchel, A. Blay, R. Kolerman, E. Mijiritsky, J.A. Shibli, 3D printing/additive manufacturing single titanium dental implants: a prospective multicenter study with 3 years of follow-up, International journal of dentistry 2016 (2016).

[67] W. Xu, M. Brandt, S. Sun, J. Elambasseril, Q. Liu, K. Latham, K. Xia, M. Qian, Additive manufacturing of strong and ductile $\mathrm{Ti}-6 \mathrm{Al}-4 \mathrm{~V}$ by selective laser melting via in situ martensite decomposition, Acta Materialia 85 (2015) 74-84.

[68] T. Osswald, N. Rudolph, Polymer rheology, Carl Hanser, München (2015).

[69] S. Rangarajan, G. Qi, N. Venkataraman, A. Safari, S.C. Danforth, Powder processing, rheology, and mechanical properties of feedstock for fused deposition of Si3N4 ceramics, Journal of the American Ceramic Society 83(7) (2000) 1663-1669.

[70] A. Bellini, S.u. Gu“ c, eri, M. Bertoldi, Liquefier dynamics in fused deposition, J. Manuf. Sci. Eng. 126(2) (2004) 237-246.

[71] P. Geng, J. Zhao, W. Wu, W. Ye, Y. Wang, S. Wang, S. Zhang, Effects of extrusion speed and printing speed on the 3D printing stability of extruded PEEK filament, Journal of Manufacturing Processes 37 (2019) 266-273. 
[72] P. Singh, Q. Shaikh, V.K. Balla, S.V. Atre, K.H. Kate, Estimating Powder-Polymer Material Properties Used in Design for Metal Fused Filament Fabrication (DfMF 3), JOM 72(1) (2020) 485-495.

[73] A. Korotchenko, D. Khilkov, M. Tverskoy, A. Khilkova, Use of additive technologies for metal injection molding, Engineering Solid Mechanics 8(2) (2020) 143-150.

[74] N.M. Nor, N. Muhamad, A. Ihsan, K. Jamaludin, Sintering parameter optimization of Ti-6Al-4V metal injection molding for highest strength using palm stearin binder, Procedia Engineering 68 (2013) 359-364.

[75] O.A. Mohamed, S.H. Masood, J.L. Bhowmik, Optimization of fused deposition modeling process parameters: a review of current research and future prospects, Advances in Manufacturing 3(1) (2015) 42-53.

[76] D. Popescu, A. Zapciu, C. Amza, F. Baciu, R. Marinescu, FDM process parameters influence over the mechanical properties of polymer specimens: A review, Polymer Testing 69 (2018) 157-166.

[77] C.C. Wang, T.W. Lin, S.S. Hu, Optimizing the rapid prototyping process by integrating the Taguchi method with the Gray relational analysis, Rapid prototyping journal (2007).

[78] S.H. Ahn, M. Montero, D. Odell, S. Roundy, P.K. Wright, Anisotropic material properties of fused deposition modeling ABS, Rapid prototyping journal (2002).

[79] R. Anitha, S. Arunachalam, P. Radhakrishnan, Critical parameters influencing the quality of prototypes in fused deposition modelling, Journal of Materials Processing Technology 118(1-3) (2001) 385-388. 
[80] D. Horvath, R. Noorani, M. Mendelson, Improvement of surface roughness on ABS 400 polymer using design of experiments (DOE), Materials Science Forum, Trans Tech Publ, 2007, pp. 2389-2392.

[81] M. Fernandez-Vicente, W. Calle, S. Ferrandiz, A. Conejero, Effect of infill parameters on tensile mechanical behavior in desktop 3D printing, 3D printing and additive manufacturing 3(3) (2016) 183-192.

[82] G. Gomez-Gras, R. Jerez-Mesa, J.A. Travieso-Rodriguez, J. Lluma-Fuentes, Fatigue performance of fused filament fabrication PLA specimens, Materials \& Design 140 (2018) $278-285$.

[83] C. Koch, L. Van Hulle, N. Rudolph, Investigation of mechanical anisotropy of the fused filament fabrication process via customized tool path generation, Additive Manufacturing 16 (2017) 138-145.

[84] U.K. uz Zaman, E. Boesch, A. Siadat, M. Rivette, A.A. Baqai, Impact of fused deposition modeling (FDM) process parameters on strength of built parts using Taguchi's design of experiments, The International Journal of Advanced Manufacturing Technology 101(5-8) (2019) 1215-1226.

[85] F. Froes, D. Eylon, Powder metallurgy of titanium alloys, International Materials Reviews 35(1) (1990) 162-184.

[86] R.M. German, Progress in titanium metal powder injection molding, Materials 6(8) (2013) 3641-3662.

[87] R. German, Titanium powder injection moulding: a review of the current status of materials, processing, properties and applications, PIM International 3(4) (2009) 21-37. 
[88] H. Miura, Y. Itoh, T. Ueamtsu, K. Sato, The influence of density and oxygen content on the mechanical properties of injection molded Ti-6Al-4V alloys, Advances in Powder Metallurgy and Particulate Materials 1 (2010) 46-53.

[89] M.E. Aulton, Powder flow, Aulton's Pharmaceutics, The design and manufacture of medicines, 4thedn edn. Churchill Livingstone, China (2013) 187-199.

[90] A. Dehghan-Manshadi, M. Bermingham, M. Dargusch, D. StJohn, M. Qian, Metal injection moulding of titanium and titanium alloys: Challenges and recent development, Powder Technology 319 (2017) 289-301.

[91] H. Wang, Z.Z. Fang, P. Sun, A critical review of mechanical properties of powder metallurgy titanium, International journal of powder metallurgy 46(5) (2010) 45-57.

[92] O. Ferri, T. Ebel, R. Bormann, Influence of surface quality and porosity on fatigue behaviour of Ti-6Al-4V components processed by MIM, Materials Science and Engineering: A 527(7-8) (2010) 1800-1805.

[93] B. Barmore, Fused Filament Fabrication of Filled Polymers for Metal Additive Manufacturing, (2016).

[94] e-xstream, Digimat-FE. https://www.e-xstream.com/products/tools/digimat-fe. (Accessed July 30 2019).

[95] Alphastar, Genoa. http://www.alphastarcorp.com/products/genoa-3dp-simulation/. (Accessed July 30 2019).

[96] Vanderplaats, Genesis. http://www.vrand.com/products/genesis/. (Accessed July 30 2019).

[97] L.E. Nielsen, Predicting the properties of mixtures, M. Dekker1978. 
[98] S. McGee, R. McGullough, Combining rules for predicting the thermoelastic properties of particulate filled polymers, polymers, polyblends, and foams, Polymer Composites 2(4) (1981) 149-161.

[99] W. Wu, K. Sadeghipour, K. Boberick, G. Baran, Predictive modeling of elastic properties of particulate-reinforced composites, Materials Science and Engineering: A 332(1-2) (2002) 362-370.

[100] T.J. Wooster, S. Abrol, J.M. Hey, D.R. MacFarlane, Thermal, mechanical, and conductivity properties of cyanate ester composites, Composites Part A: Applied science and manufacturing 35(1) (2004) 75-82.

[101] I. Balać, M. Milovančević, C.-y. Tang, P.S. Uskoković, D.P. Uskoković, Estimation of elastic properties of a particulate polymer composite using a face-centered cubic FE model, Materials letters 58(19) (2004) 2437-2441.

[102] Y.P. Mamunya, V. Davydenko, P. Pissis, E. Lebedev, Electrical and thermal conductivity of polymers filled with metal powders, European polymer journal 38(9) (2002) 1887-1897.

[103] L. Kowalski, J. Duszczyk, L. Katgerman, Thermal conductivity of metal powderpolymer feedstock for powder injection moulding, Journal of materials science 34(1) (1999) 1-5.

[114] A. Boudenne, L. Ibos, M. Fois, E. Gehin, J.C. Majeste, Thermophysical properties of polypropylene/aluminum composites, Journal of Polymer Science Part B: Polymer Physics 42(4) (2004) 722-732. 
[55] T. Zhang, J. Evans, K. Dutta, Thermal properties of ceramic injection moulding suspensions in the liquid and solid states, Journal of the European Ceramic Society 5(5) (1989) 303-309.

[106] K.H. Kate, R.K. Enneti, T. McCabe, S.V. Atre, Simulations and injection molding experiments for aluminum nitride feedstock, Ceramics International 42(1) (2016) 194-203. [107] N.M. Nor, N. Muhamad, M. Ibrahim, M. Ruzi, K. Jamaludin, Optimization of injection molding parameter of Ti-6Al-4V powder mix with palm stearin and polyethylene for the highest green strength by using Taguchi method, International Journal of Mechanical and Materials Engineering 6(1) (2011) 126-132.

[108] K.C. Mills, Recommended values of thermophysical properties for selected commercial alloys, Woodhead Publishing2002.

[109] G. Welsch, R. Boyer, E. Collings, Materials properties handbook: titanium alloys, ASM international1993.

[110] R. Enneti, V. Onbattuvelli, O. Gulsoy, K. Kate, S. Atre, Powder-binder formulation and compound manufacture in metal injection molding (MIM), Handbook of metal injection molding, Elsevier2019, pp. 57-88.

[111] G. Chen, C. Ren, X. Yang, X. Jin, T. Guo, Finite element simulation of high-speed machining of titanium alloy (Ti-6Al-4V) based on ductile failure model, The International Journal of Advanced Manufacturing Technology 56(9-12) (2011) 1027-1038.

[112] C.J. Smithells, Metals reference book, Elsevier2013.

[113] V. Wagner, M. Baili, G. Dessein, D. Lallement, Experimental characterization of behavior laws for titanium alloys: application to Ti5553, Key Engineering Materials, Trans Tech Publ, 2010, pp. 147-155. 
[114] J. Elmer, T. Palmer, S. Babu, E. Specht, In situ observations of lattice expansion and transformation rates of $\alpha$ and $\beta$ phases in Ti-6Al-4V, Materials Science and Engineering: A 391(1-2) (2005) 104-113.

[115] R. Rai, J. Elmer, T. Palmer, T. DebRoy, Heat transfer and fluid flow during keyhole mode laser welding of tantalum, Ti-6Al-4V, 304L stainless steel and vanadium, Journal of physics D: Applied physics 40(18) (2007) 5753.

[116] M. Niinomi, Mechanical properties of biomedical titanium alloys, Materials Science and Engineering: A 243(1-2) (1998) 231-236.

[117] Y. Lee, G. Welsch, Young's modulus and damping of $\mathrm{Ti} \cdot 6 \mathrm{Al} \cdot 4 \mathrm{~V}$ alloy as a function of heat treatment and oxygen concentration, Materials Science and Engineering: A 128(1) (1990) 77-89.

[118] Y.-P. Wu, Q.-X. Jia, D.-S. Yu, L.-Q. Zhang, Modeling Young's modulus of rubberclay nanocomposites using composite theories, Polymer Testing 23(8) (2004) 903-909.

[119] C.L. Tucker III, E. Liang, Stiffness predictions for unidirectional short-fiber composites: review and evaluation, Composites science and technology 59(5) (1999) 655671.

[120] C. Wong, R.S. Bollampally, Thermal conductivity, elastic modulus, and coefficient of thermal expansion of polymer composites filled with ceramic particles for electronic packaging, Journal of applied polymer science 74(14) (1999) 3396-3403.

[121] A. Metzner, Rheology of suspensions in polymeric liquids, Journal of rheology 29(6) (1985) 739-775.

[122] R.M. German, Homogeneity effects on feedstock viscosity in powder injection molding, Journal of the American Ceramic Society 77(1) (1994) 283-285. 
[123] H. Chiang, C. Hieber, K. Wang, A unified simulation of the filling and postfilling stages in injection molding. Part I: Formulation, Polymer Engineering \& Science 31(2) (1991) 116-124.

[124] A.H. Peng, Research on the interlayer stress and warpage deformation in FDM, Advanced Materials Research, Trans Tech Publ, 2012, pp. 1564-1567.

[125] L. Murr, S. Quinones, S. Gaytan, M. Lopez, A. Rodela, E. Martinez, D. Hernandez, E. Martinez, F. Medina, R. Wicker, Microstructure and mechanical behavior of Ti-6Al$4 \mathrm{~V}$ produced by rapid-layer manufacturing, for biomedical applications, Journal of the mechanical behavior of biomedical materials 2(1) (2009) 20-32.

[126] C. Qiu, N.J.E. Adkins, M.M. Attallah, Microstructure and tensile properties of selectively laser-melted and of HIPed laser-melted Ti-6Al-4V, Materials Science and Engineering: A 578 (2013) 230-239.

[127] B. Vandenbroucke, J.-P. Kruth, Selective laser melting of biocompatible metals for rapid manufacturing of medical parts, Rapid Prototyping Journal 13(4) (2007) 196-203.

[128] J. Mezzetta, Process-property relationships of Ti6Al4V fabricated through selective laser melting, McGill University Libraries, 2017. 


\section{APPENDIX A}

\section{INFLUENCE OF POWDER CHARACTERISTICS ON THE PROPERTIES OF LASER-POWDER BED FUSION PROCESSED TI-6AL-4V}

\section{A.1 INTRODUCTION}

Metal Additive Manufacturing (AM), a process of building 3-dimensional parts from a CAD file with a layer upon layer deposition has recently gained attention due to its versatility in manufacturing $3 \mathrm{D}$ prototypes with complex shape at shorter lead times to fabricating production grade specimens. Over the past few years, the technology has matured for better adoption and there is a rapid rise in the sales of metal AM systems [66]. Various types of AM processes are currently available and utilize raw starting materials in from of powder, wire, or powder-polymer mixture as feedstock. In current work, laser powder bed fusion (L-PBF) was investigated to investigate the influence of starting powder characteristics on the printed part properties. The specific process characteristic of L-PBF is that a high energy laser beam selectively melts a layer of powder according to the $2 \mathrm{D}$ slice model; subsequently another powder layer is applied wherein the laser metal powder fusion process is repeated until completion. Prior work on the L-PBF process has explored understanding the effect of powder characteristics such as irregular and spherical shape powders on the printed parts for $17-4 \mathrm{PH}$ stainless steel but there is limited study for understanding the effect of Ti-6Al-4V alloy powder characteristics and its morphology on the microstructure and mechanical properties of the parts produced by L-PBF [66]. 
Ti-6Al-4V alloy has been vastly explored in the context of AM owing to the cost advantages compared to conventional machining process. The Ti-6Al-4V powder used in the L-PBF process is usually spherical in shape and produced by either gas atomization or plasma atomization. The process operates at high temperature gradients due to the rapid solidification generating complex macrostructure and microstructure [5]. The macrostructure thus produced is composed of both columnar and equiaxed grains. The microstructure predominates the presence of fine and fully $\alpha^{\prime}$ martensite in as-printed condition which consequently results in high yield and tensile strength and a low ductility [4-6]. Table A.1 highlights previous work on L-PBF of Ti-6Al-4V using either gas or plasma atomized powder. From Table A.1 it can be observed that the typical mean particle size used in most studies was close to $35 \mu \mathrm{m}$ and the resulting reported average ultimate tensile strength (UTS) was around $1275 \mathrm{MPa}$ while the average yield strength was 1150 MPa. Additionally, it can be observed that the L-PBF produced parts had 34\% greater UTS while $21 \%$ greater yield strengths than wrought parts but the corresponding difference in L-PBF parts \% elongation (average 5.9\%) was 58\% lower than the wrought values. Moreover, the L-PBF printed parts showed high variance in the elongation value which range anywhere from 3 to $8 \%$. Overall, the samples in the as printed state have high strength compared to wrought and metal injection produced parts but reduced elongation. 
Table A.1. Literature to compare Ti-6Al-4V properties produced by powder with different production method (GA: gas atomized, PA: plasma atomized, NA: not available)

\begin{tabular}{|c|c|c|c|c|c|c|c|}
\hline Process & $\begin{array}{l}\text { Powder } \\
\text { production } \\
\text { method }\end{array}$ & $\begin{array}{c}\text { Mean } \\
\text { particle } \\
\text { size } \\
(\mu \mathrm{m})\end{array}$ & $\begin{array}{c}\text { Yield } \\
\text { strength } \\
(\mathrm{MPa})\end{array}$ & $\begin{array}{l}\text { UTS } \\
(\mathrm{MPa})\end{array}$ & $\begin{array}{l}\text { Young's } \\
\text { modulus } \\
(\mathrm{GPa})\end{array}$ & $\begin{array}{c}\text { Elongation } \\
(\%)\end{array}$ & $\begin{array}{c}\text { Referenc } \\
\mathrm{e}\end{array}$ \\
\hline \multirow{6}{*}{$\begin{array}{l}\text { L-PBF } \\
\quad \text { as } \\
\text { printed }\end{array}$} & PA & 36 & $\begin{array}{c}1195 \pm \\
20\end{array}$ & $\begin{array}{c}1270 \pm \\
10\end{array}$ & NA & $5 \pm 0.5$ & Rafi [34] \\
\hline & GA & 35 & $\begin{array}{c}1110 \pm \\
2\end{array}$ & 1250 & NA & 8 & $\mathrm{Xu}$ [67] \\
\hline & GA & 21 & 1300 & 1400 & NA & $3.5 \pm 1$ & $\begin{array}{l}\text { Murr } \\
{[125]}\end{array}$ \\
\hline & GA & 35 & $\begin{array}{c}1080 \pm \\
20\end{array}$ & $\begin{array}{c}1220 \pm \\
30\end{array}$ & NA & $6 \pm 1.5$ & Qiu [126] \\
\hline & PA & - & $\begin{array}{c}1110 \pm \\
10\end{array}$ & $1270 \pm 5$ & $110 \pm 2$ & $7.3 \pm 1.10$ & $\begin{array}{c}\text { Vrancken } \\
{[35]}\end{array}$ \\
\hline & GA & 35 & $\begin{array}{c}1125 \pm \\
75\end{array}$ & $\begin{array}{c}1250 \pm \\
50\end{array}$ & $93 \pm 3$ & $6 \pm 0.3$ & $\begin{array}{l}\text { Vandenbrou } \\
\text { cke [127] }\end{array}$ \\
\hline $\begin{array}{l}\text { L-PBF } \\
\text { stress } \\
\text { relieved }\end{array}$ & GA & 35 & $\begin{array}{c}1315 \pm \\
5\end{array}$ & $\begin{array}{c}1420 \pm \\
10\end{array}$ & NA & $3.5 \pm 1$ & $\begin{array}{c}\text { Mazzette } \\
{[128]}\end{array}$ \\
\hline $\begin{array}{c}\text { MIM } \\
\text { (sintere } \\
\text { d) }\end{array}$ & GA & 32 & NA & $700 \pm 10$ & NA & $6 \pm 0.5$ & Ergul [28] \\
\hline $\begin{array}{c}\text { Wroug } \\
\text { ht }\end{array}$ & - & _ & $\begin{array}{c}850 \pm \\
20\end{array}$ & $910 \pm 20$ & $112 \pm 2$ & $14 \pm 2$ & $\begin{array}{c}\text { Niinomi } \\
{[116]}\end{array}$ \\
\hline
\end{tabular}

\section{A.2 EXPERIMENTAL SECTION}

The Ti-6Al-4V powder used in the study is spherical with textured surface and the particle size ranging from $20-50 \mu \mathrm{m}$. Powder characteristics such as pycnometer density was measured using a Micrometrics Accupyc helium pycnometer, and tap density was 
measured using AS-100 tap density volumeter by Aimsizer Scientific. A Concept Laser Mlab Cusing system which employs a Nd:YAG laser of $100 \mathrm{~W}$ was used to print parts for microstructural characterization and mechanical testing. The print parameters selected for printing tensile bars include laser power (P) of $96 \mathrm{~W}$, scanning speed (V) of $900 \mathrm{~mm} / \mathrm{s}$, layer height (t) of $20 \mu \mathrm{m}$, and hatch spacing (h) (i.e the distance between two neighboring scan vectors) of $111 \mu \mathrm{m}$. The resulting energy density (E) was calculated using Equation A.1.

$$
E=\frac{P}{V h t}
$$

With the above set of process parameters, the calculated energy density from Equation 1 was $48 \mathrm{~J} / \mathrm{mm} 3$. The geometry of the tensile bar has been provided in the Figure A.1, which is according to the ASTM E8 standard for tensile testing of metals. All the samples were printed along the XY plane or parallel to the layer deposition process in L-PBF.

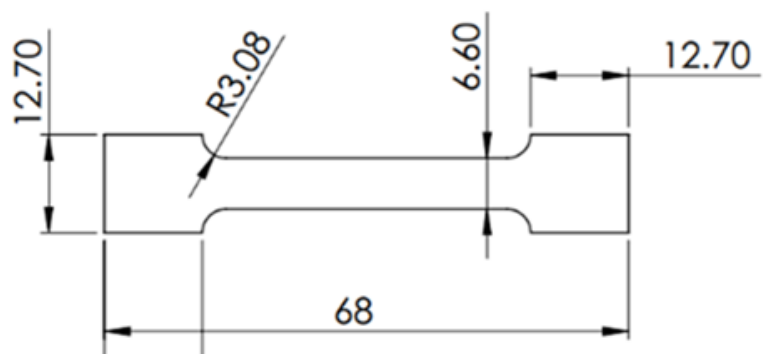

Figure A.1. ASTM E8 tensile bar geometry printed on the Concept Laser Mlab.

Th printed samples were characterized for density using the Archimedes method. The tensile test was conducted on a MTS hydraulic machine with $100 \mathrm{kN}$ of load cell at a strain 
rate of $0.001 \mathrm{~s}^{-1}$ at room temperature using an extensometer to obtain elongation in the gauge length. The hardness of the printed samples was measured using a Rockwell hardness tester. Further characterization was performed using an optical microscope to analyze the existing phases on the etched microstructure.

\section{A.3 RESULTS AND DISCUSSION}

\section{A.3.1 POWDER CHARACTERISTICS}

Figure A.2 shows the SEM image of the Ti-6Al-4V powder particles which has a slightly textured surface rather than being completely smooth. Table 2 provides details on powder attributes including particle size distribution, pycnometer density, apparent density and tap density, these properties provide a major insight in understanding the flowability and packing behavior of the powder in the L-PBF process. The mean particle diameter of the current powder was $31 \mu \mathrm{m}$ with true density corresponding to the pycnometer density of $4.44 \pm 0.002 \mathrm{~g} / \mathrm{cm} 3$. The XRD analysis indicates the presence of $\alpha$ and $\beta$ phase along with the presence of $\mathrm{Ti}_{3} \mathrm{Al}$. The $\mathrm{Ti}_{3} \mathrm{Al}$ phase is considered to be a result of the reduction step utilized in the powder manufacturing process, although previous work reported on the use of this powder indicates that the $\mathrm{Ti}_{3} \mathrm{Al}$ phase after L-PBF processing transforms into $\alpha$ as the excess aluminum in $\mathrm{Ti}_{3} \mathrm{Al}$ diffuses into other existing phases at elevated temperature. 
a)

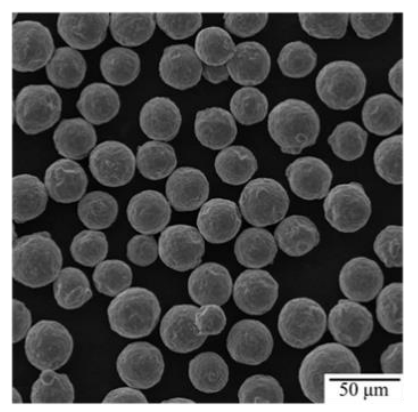

b)

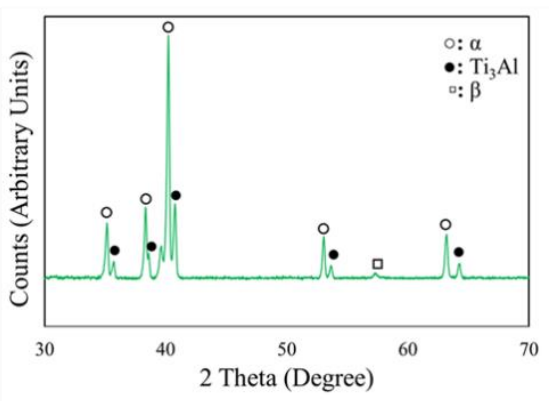

Figure A.2. (a) SEM of the Ti-6Al-4V powder, (b) XRD of the Ti-6Al-4V powder.

Table A.2. Powder particle size and measured density.

\begin{tabular}{|c|c|}
\hline $\mathrm{D}_{10}(\mu \mathrm{m})$ & 22 \\
\hline $\mathrm{D}_{50}(\mu \mathrm{m})$ & 31 \\
\hline $\mathrm{D}_{90}(\mu \mathrm{m})$ & 42 \\
\hline Pycnometer density $\left(\mathrm{g} / \mathrm{cm}^{3}\right)$ & $4.44 \pm 0.002$ \\
\hline Tap density $\left(\mathrm{g} / \mathrm{cm}^{3}\right)$ & $2.5 \pm 0.03$ \\
\hline
\end{tabular}

\section{A.3.2 DENSITY AND MICROSTRUCTURE}

The parts in the printed state were analyzed for their densities using the Archimedes method, and the relative density of the part to that of bulk powder was determined as 98.5 $\pm 1 \%$. Figure A.3 shows the microstructure of Ti-6Al-4V L-PBF printed samples along build and scan directions from the build plate. The microstructure differs along the build direction (Z-Y plane) and scan direction (X-Y plane), where (Figure A.3 a and b) along Z-Y plane columnar grains are evident which are 500-1000 $\mu \mathrm{m}$ long and 50-150 $\mu \mathrm{m}$ in width and along X-Y plane fine equiaxed grains are visible following the laser scan pattern 
of +45 and -45 . It can be observed from Figure A.3 $\mathbf{c}$ and $\mathbf{d}$ that the microstructure consists of very fine acicular martensite which is expected due to the high temperature gradients that occur during the process. The microstructure is comparable to the literature for the gas and plasma atomized powders which exhibit similar characteristics along the build and scan direction $[5,10,15]$. From previous work it was reported that change of aspect ratio and amount of the martensitic needles present greatly influences the mechanical properties of parts produced during the printing process.

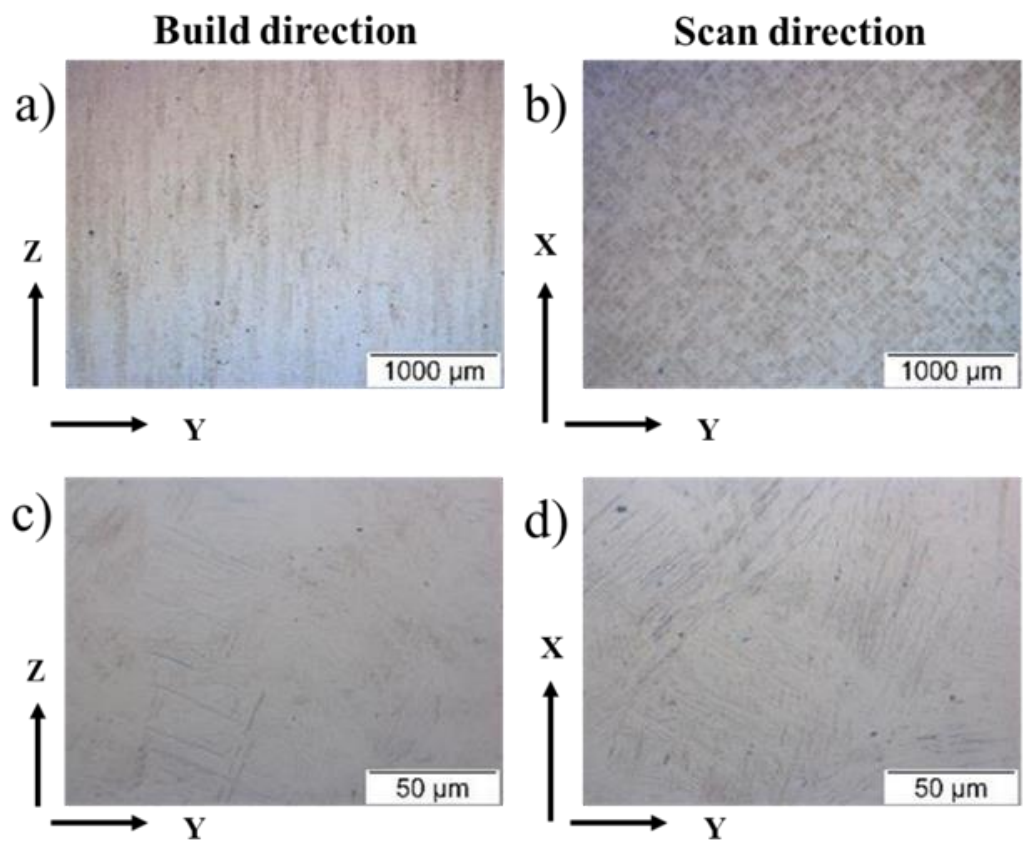

Figure A.3. Micrographs of L-PBF printed Ti-6Al-4V parts along the build and scan directions are two magnifications; (a,c) along build direction revealing columnar grains at low magnification and the acicular $\alpha$ martensite at higher magnification, $(b, d)$ along the scan direction showing equiaxed grains at low magnification. 


\section{A.3.3 MECHANICAL PROPERTIES}

The majority of the studies published on L-PBF of gas or plasma atomized Ti-6Al-4V powder have yielded higher tensile strength with low ductility in the as printed condition compared to the wrought and sintered parts [16]. The samples produced of the current powder in the as printed condition along the longitudinal orientation exhibited high strength of $1390 \pm 40 \mathrm{MPa}$ and good ductility with elongation of $7 \pm 0.5 \%$. Figure A.4 highlights the results from the current study and compares it with the available literature on Ti-6Al-4V processed by the L-PBF of gas or plasma atomized in longitudinal orientation, also compares metal injection molding (MIM), and wrought properties of Ti6Al-4V [5, 13, 15-20]. The Rockwell hardness resulted in the HRC value of $40 \pm 0.5$ for the printed samples, which is comparable to reported literature values $[5,9,13,20]$. One reason for improved tensile properties can be attributed to the aspect ratio and amount of $\alpha$ martensitic needles present in the microstructure as observed in Figure A.3. It can be attributed that the $\alpha$ lath width and colony size in the microstructure, fine and small $\alpha$ phase colonies result in improved tensile strength. Some of the literature has been listed in Table

1, comparing the powder production method with mean particle size to the resulting mechanical properties by L-PBF, MIM and wrought for Ti-6Al-4V alloy. 


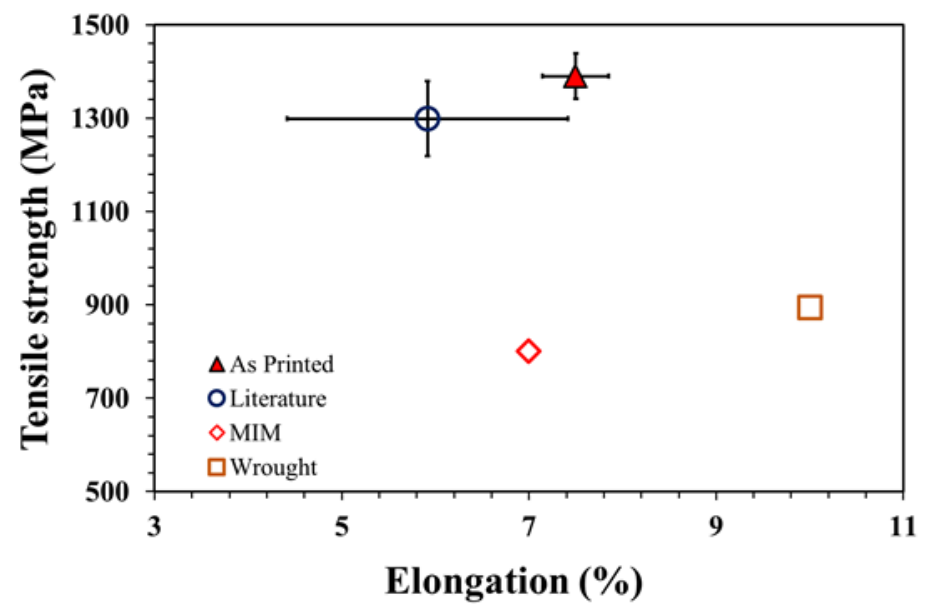

Figure A.4. Comparison of the mechanical properties of Ti-6Al-4V samples produced by textured powder in the current study, and literature on L-PBF of gas and plasma atomized powder, MIM and wrought properties.

\section{A.3.4 APPLICATION TO DENTAL IMPLANTS}

Over the last decade AM has become a key process in the production of industry acknowledged products including porous medical implants, these allowed realizing physical objects from 3D data involving minimal steps thus saving time and money. The elastic modulus of dense Ti-6Al-4V is $105 \pm 2 \mathrm{GPa}$ which is very high compared to the natural bone (cancellous: 1.5-11.2 GPa and cortical: 7-20 GPa) and is prone to stress shielding causing implant failure. To evaluate that in the current study, dental implants with controlled pore size have been fabricated using L-PBF with Ti-6Al-4V powder, osseointegration of dental implant can be biologically improved by such open interconnected pore system [21]. In the current study, the feasibility to produce pores with 100 and $400 \mu \mathrm{m}$ in size was successfully implemented in printing Ti-6Al-4V dental implant prototypes (Figure 5). Figure A.5a show the L-PBF printed dental implants with 100 to 
$400 \mu \mathrm{m}$ circular pore structure printed to scale (front row parts) and $2 \mathrm{X}$ scale for back row parts. Figure A.5b shows threaded magnified image of the implants top section that provides ability to easily get drilled into the jaw and Figure A.5c show the designed pores within the implant. Further investigation of such application involves understanding the dependence of pore size on the modulus and strength, which would be the scope of future work.

a)

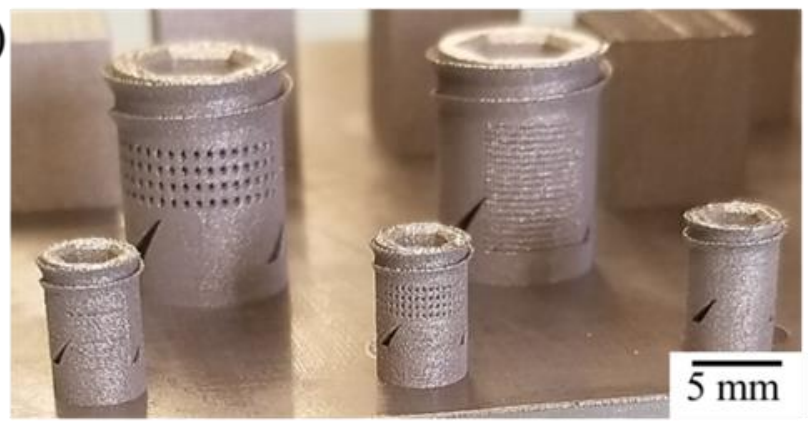

b)

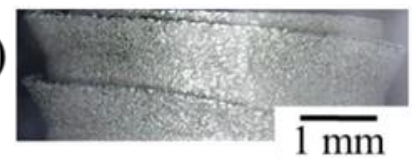

c)

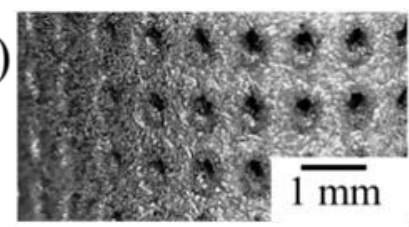

Figure A.5. Dental implant prototypes with pore size of 100 and $400 \mu \mathrm{m}$ printed with LPBF (a) printed parts in actual scale and two times scaled up version, (b) threaded geometry on the implant, (c) pores on the implant surface measuring $400 \mu \mathrm{m}$.

\section{A.4 CONCLUSIONS}

The ability to print Ti-6Al-4V parts using powder with textured surface by L-PBF has been demonstrated to achieve comparable properties to that of the traditionally used powder systems in AM. It was concluded that the tensile strength of the printed parts exceeded wrought values due to presence of colonies of $\alpha$ martensitic needles however more involved microstructural characterization is needed to evaluate the obtained grain size to correlate with the improvement in tensile properties while decrement in \% elongation of 
the L-PBF parts when compared to wrought. With the L-PBF approach it opens the ability to explore Ti-6Al-4V powders which are available at a low cost compared to gas and plasma atomized powders and thereby further strengthening the scope for AM of Ti-6Al$4 \mathrm{~V}$ alloys for innovative product development. As an extension this worked demonstrated that Ti-6Al-4V dental implant with incorporation of macro and micro pores into the design will enable us to tailor material properties specific to the actual requirements for medical implants.

\section{A.5 ACKNOWLEDGEMENTS}

The authors acknowledge funding from the Minority Business Development Agency. The authors are thankful to Caleb Combs, Sean Osborne, Ellery Payne, and Sarah Ziegler for their assistance in dental implant designs.

\section{A.6 REFERENCES}

[1] Wohlers, T., Wohlers report 2016. 2016: Wohlers Associates, Inc.

[2] Vartanian, K. and T. McDonald, Accelerating industrial adoption of metal additive manufacturing technology. JOM, 2016. 68(3): p. 806-810.

[3] Irrinki, H., et al., Effects of powder attributes and laser powder bed fusion (L-PBF) process conditions on the densification and mechanical properties of 17-4 PH stainless steel. JOM, 2016. 68(3): p. 860-868. 
[4] Gorsse, S., et al., Additive manufacturing of metals: a brief review of the characteristic microstructures and properties of steels, Ti-6Al-4V and high-entropy alloys. Science and Technology of Advanced Materials, 2017. 18(1): p. 584-610.

[5] Qiu, C., N.J.E. Adkins, and M.M. Attallah, Microstructure and tensile properties of selectively laser-melted and of HIPed laser-melted Ti-6Al-4V. Materials Science and Engineering: A, 2013. 578: p. 230-239.

[6] Song, B., et al., Effects of processing parameters on microstructure and mechanical property of selective laser melted Ti6Al4V. Materials \& Design, 2012. 35: p. 120-125.

[7] Rafi, H., et al., Microstructures and mechanical properties of Ti6Al4V parts fabricated by selective laser melting and electron beam melting. Journal of Materials Engineering And Performance, 2013. 22(12): p. 3872-3883.

[8] Xu, W., et al., Additive manufacturing of strong and ductile Ti-6Al-4V by selective laser melting via in situ martensite decomposition. Acta Materialia, 2015. 85: p. 74-84.

[9] Murr, L., et al., Microstructure and mechanical behavior of Ti-6Al-4V produced by rapid-layer manufacturing, for biomedical applications. Journal of the Mechanical Behavior Of Biomedical Materials, 2009. 2(1): p. 20-32.

[10] Vrancken, B., et al., Heat treatment of Ti6A14V produced by Selective Laser Melting: Microstructure and mechanical properties. Journal of Alloys and Compounds, 2012. 541: p. $177-185$.

[11] Vandenbroucke, B. and J.-P. Kruth, Selective laser melting of biocompatible metals for rapid manufacturing of medical parts. Rapid Prototyping Journal, 2007. 13(4): p. 196203. 
[12] Mezzetta, J., Process-property relationships of Ti6Al4V fabricated through selective laser melting. 2017, McGill University Libraries.

[13] Ergül, E., H. Özkan Gülsoy, and V. Günay, Effect of sintering parameters on mechanical properties of injection moulded Ti-6Al-4V alloys. Powder Metallurgy, 2009. 52(1): p. 65-71.

[14] Niinomi, M., Mechanical properties of biomedical titanium alloys. Materials Science and Engineering: A, 1998. 243(1-2): p. 231-236.

[15] Thijs, L., et al., A study of the microstructural evolution during selective laser melting of Ti-6Al-4V. Acta Materialia, 2010. 58(9): p. 3303-3312.

[16] Beese, A.M. and B.E. Carroll, Review of mechanical properties of Ti-6Al-4V made by laser-based additive manufacturing using powder feedstock. JOM, 2016. 68(3): p. 724734.

[17] Leuders, S., et al., On the mechanical behaviour of titanium alloy TiAl6V4 manufactured by selective laser melting: Fatigue resistance and crack growth performance. International Journal of Fatigue, 2013. 48: p. 300-307.

[18] Dehghan-Manshadi, A., et al., Metal injection moulding of titanium and titanium alloys: Challenges and recent development. Powder Technology, 2017. 319: p. 289-301. [19] Agius, D., K. Kourousis, and C. Wallbrink, A Review of the As-Built SLM Ti-6Al4V Mechanical Properties towards Achieving Fatigue Resistant Designs. Metals, 2018. $8(1)$.

[20] Ezugwu, E. and Z. Wang, Titanium alloys and their machinability — a review. Journal of Materials Processing Technology, 1997. 68(3): p. 262-274. 
[21] Tunchel, S., et al., 3D printing/additive manufacturing single titanium dental implants: a prospective multicenter study with 3 years of follow-up. International Journal of Dentistry, 2016. 2016. 


\section{APPENDIX B}

\section{ESTIMATION OF EXTRUSION-BASED 3D PRINTING PROCESS WITH VISCOSITY-SHEAR-RATE MEASUREMENTS FOR POWDER-FILLED POLYMERS}

\section{B.1 INTRODUCTION}

Fused Filament Fabrication (FFF) has been around for a long time now and one of the oldest Additive Manufacturing (AM) processes [1,2]. The FFF processes is also referred as the Fused Deposition Modeling (FDM), or the Solid Freeform Manufacturing process. The FFF 3D printing process has successfully demonstrated the ability to print with various thermoplastic materials and with recent advancements in the process improvement and rising competition has made it viable to produce metal parts using metal-powder filled polymers $[3,4]$. The current AM technologies capable of producing metals include laser melting, electron beam melting, binder jetting, which are heavily expensive and involve complicated setup and part processing after 3D printing. FFF offers the unique advantage of being cost-effective and having the flexibility to operate in minimalist space with lower energy usage and environmental impacts [1, 2].

The polymeric binder system is the most essential part in FFF process development. The composition of the binder has been studied in the past where effects have been shown in developing the binder chemistry and tailoring the metal powder surface properties [5]. The 
material properties of a filament being ideal for FFF 3D printing are described to have, low viscosity, high stiffness, and good adhesive behavior for bonding between the adjacent layers [6]. To print a part with FFF, the polymer filament is fed through the pinch rollers that drive it into the heated nozzle and the filament acts as a plunger to extrude the molten feedstock through the nozzle [7]. The diameter and material of the filament should be consistent to avoid problem like nozzle blocking, buckling, and slippage on the roller where it has been discussed it results from the varying diameter of the filament [8]. Additionally, challenges are observed when working with powder-filled polymer filament for FFF since there is an increase in viscosity with the addition of powders into the polymer matrix. Furthermore, in metal FFF 3D printing, high solids loading (>80 wt. \%) of powders in a polymer matrix is required since the printed part is subjected through subsequent process steps of debinding and sintering where the part may crumble due to less powder content and high shrinkage can occur. Therefore, understanding the rheological behavior (viscosity-shear rate-temperature) of the filled feedstock in the form of round filament as it enters the heated extruder nozzle is an important consideration in FFF process design which has not yet received much attention. This work focuses on demonstrating the shearrate and temperature dependence of viscosities for 70 and $80 \mathrm{wt} . \%$ bronze powder-filled polymer binder when compared with unfilled polylactic acid (PLA) for extrusion FFF 3D printing. It is anticipated that this work will provide new insights in material design for high powder filled polymers in metal FFF and reduce the trial and error experiments. 


\section{B.2 MATERIALS}

In the current process with FFF of polymer unfilled and filled systems, polylactic acid (PLA-3001D) was sourced from Natureworks (referred as the unfilled system). To create the filled polymer filaments, spherical bronze powder produced by gas atomization (Acupowder International LLC) with particle size distribution of $10 \mu \mathrm{m}-45 \mu \mathrm{m}$ was used in conjunction with a multicomponent binder developed by our research group referred as MIG binder 1. The MIG binder1 is a specialized binder developed at the Material Innovation Guild which effectively can be produced into continuous round flexible filaments to be used for FFF 3D printing. The binder constitutes a backbone, compatibilizer, surfactant, and the filler phase, with the important consideration that the binder should be easy to remove during the debinding stage, and at the same time able to provide necessary strength in holding particles together when sintered. Table B.1 lists density and melting points of the material systems used in the current work.

Table B.1. Material properties

\begin{tabular}{|c|c|c|}
\hline Material & Density $\left(\mathrm{g} / \mathrm{cm}^{3}\right)$ & Melting Point $\left({ }^{0} \mathrm{C}\right)$ \\
\hline PLA & 1.24 & 190 \\
\hline Bronze & 8.92 & $800-900$ \\
\hline MIG Binder1 & 1.01 & $90-190$ \\
\hline
\end{tabular}




\section{B.3 METHODOLOGY}

The feedstock preparation is a crucial step to disperse powder homogeneously and avoid powder binder separation or particle segregation [9]. An improper rheological behavior of the feedstock can cause defects in the printed parts like cracks, voids, and non-uniform shrinkage during the densification process. The binder and the metal powder were compounded using a torque rheometer. Mixing experiments were conducted for the bronze filled system (70 wt.\% \& 80 wt.\%) with a Brabender Intelli-Torque rheometer at a temperature of $200{ }^{\circ} \mathrm{C}$ and torque of $50 \mathrm{rpm}$, for 30 minutes of mixing time. The filament extrusion was conducted on a Rheograph 20 Gottfert capillary rheometer. The mixing was performed until the torque stabilizes and the curve follows a uniform trend. The mixing and extrusion process temperature was selected based on the Differential Scanning calorimetry (DSC) and Thermogravimetry (TGA) data for the PLA and the multicomponent MIG binder1, for PLA extrusion was done at $150{ }^{\circ} \mathrm{C}$, and for the MIG binder1 the extrusion was performed at $170^{\circ} \mathrm{C}$.

\section{B.4 VISCOSITY MEASUREMENTS}

The viscosity measurement is critical in determining the flow behavior of the molten feedstock when printing, where most of the polymer filled systems will show shear thinning behavior [10]. For the current study the solids loading or the volume concentration of the powder into the binder was restricted to $70 \mathrm{wt} . \%$ and $80 \mathrm{wt} . \%$, since the focus of current work is to capture the shear-rate and temperature dependence on the viscosity and its dependence in FFF 3D printing. Though higher solids loading is of much importance in 
developing polymer filled feedstock systems where the part properties after densification are of the major concern, the focus of which is the later part of our ongoing research work. In the present work we demonstrate how viscosity of a filled system can be tailored by varying the shear action and the temperature of operating printing system. The viscosity measurements were performed for PLA and the bronze filled system (70 wt.\% \& 80 wt.\%) at their corresponding printing temperatures $210^{\circ} \mathrm{C}$ and $250{ }^{\circ} \mathrm{C}$ respectively. The viscosity measurements were performed on Rheograph 20 Gottfert capillary rheometer using a capillary die with a length by diameter ratio of $30 / 1 \mathrm{~mm}$.

\section{B.5 FFF PROCESS MODELING}

The FFF 3D printing experiments were performed on a Printrbot simple metal with a nozzle diameter of $0.5 \mathrm{~mm}$, temperature was adjusted to maintain a constant volumetric flow $\operatorname{rate}(\mathrm{Q})$ of the printing material, the feed rate, track deposition width(W), and the layer height $(\mathrm{H})$ were set to fixed values with other common parameters governing the printing process in FFF. Provided in the Table B.2 are the input parameters, and the volumetric flow rate was determined measuring the extrudate mass during the printing time (using Equation B.1). A hollow square $(30 \mathrm{~mm} \times 30 \mathrm{~mm})$ with a thickness of $0.5 \mathrm{~mm}$ shown in Figure B.1, was selected as the basis for design to be used in the present study, irrespective of the feedstock material. To measure the shear effects two different flow rates were used at $100 \%$ and $75 \%$, this parameter can be directly controlled in the printing program (currently used was the repetier host). For in process shear rate estimations the Haggen Poiseuille relation was used (assumption: the flow through the tube is laminar). 
Table B.2. Input parameters for 3D printing

\begin{tabular}{|l|l|l|}
\hline Serial No. & Input Parameters & Selected Values \\
\hline 1 & Layer Height & $0.25 \mathrm{~mm}$ \\
\hline 2 & Fill Density & $100 \%$ \\
\hline 3 & Fill Angle & $45^{\circ}$ \\
\hline 4 & Speed for all print moves & $7.5 \mathrm{~mm} / \mathrm{s}$ \\
\hline 5 & Extrusion Width & $0.5 \mathrm{~mm}$ \\
\hline 6 & Filament Diameter & $1.6 \mathrm{~mm}$ \\
\hline 7 & Bed Temperature & $65^{\circ} \mathrm{C}$ \\
\hline
\end{tabular}

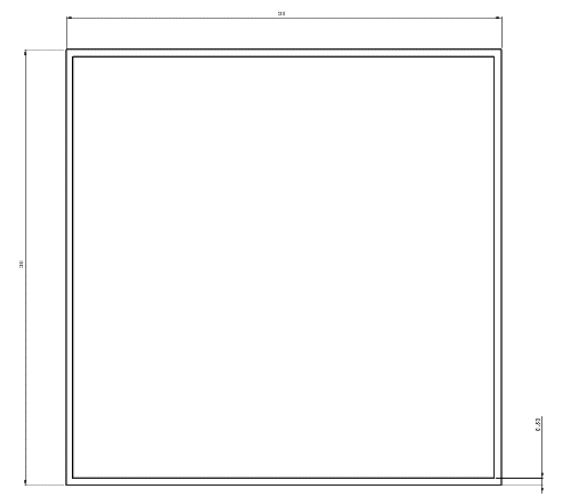

Figure B.1. Hollow square $(30 \mathrm{~mm} \times 30 \mathrm{~mm})$ with $0.5 \mathrm{~mm}$ thickness

Volume flow was determined using,

$$
Q=\frac{\text { mass flow per second }}{\text { density of the extrudate material }}
$$

To determine the shear rate at which the feedstock material is being extruded. The shear rate can be determined using the Hagen Poiseuille (Equation B.2), which can be further computer using the Equation B.3, \& B.4 to find the shear rate (Equation B.5), 


$$
\begin{gathered}
\Delta P=\frac{8 \mu L Q}{\pi R^{4}} \\
\mu=\frac{\tau}{\dot{\gamma}} \\
\tau=\frac{\Delta P R}{2 L} \\
\dot{\gamma}=\frac{4 Q}{\pi R^{3}}
\end{gathered}
$$

Where, $\Delta \mathrm{P}$ is the pressure drop, $\mathrm{L}=$ length of the tube, $\mathrm{R}$ is the nozzle radius $(0.25 \mathrm{~mm}), \tau$ is the shear stress, $\dot{\gamma}$ is the shear rate, $\mu$ is the viscosity of the considered fluid. Once the shear rate was determined, the viscosity measurements were conducted at the given printing temperature and calculated shear rate, for the PLA at $210^{\circ} \mathrm{C}$ and the bronze filled system at $70 \mathrm{wt} . \% \& 80 \mathrm{wt} . \%$ at $210{ }^{\circ} \mathrm{C} \& 250{ }^{\circ} \mathrm{C}$.

\section{B.6 RESULTS AND DISCUSSION}

\section{B.6.1 HOMOGENEOUS MIXING AND THERMAL ANALYSIS}

The homogeneity of the feedstock with different concentration of the bronze powder was determined using Thermogravimetric Analysis (TGA). As shown in Figure B.2, it can be

clearly seen that the binder can be completely removed thermally by heating to $600{ }^{\circ} \mathrm{C}$ leaving behind the bronze powder in their initial concentrations of $70 \mathrm{wt} . \%$ and $80 \mathrm{wt} . \%$. 
Though major part of the binder constituent can be easily removed by the solvent which will be addressed in the later part of the work.

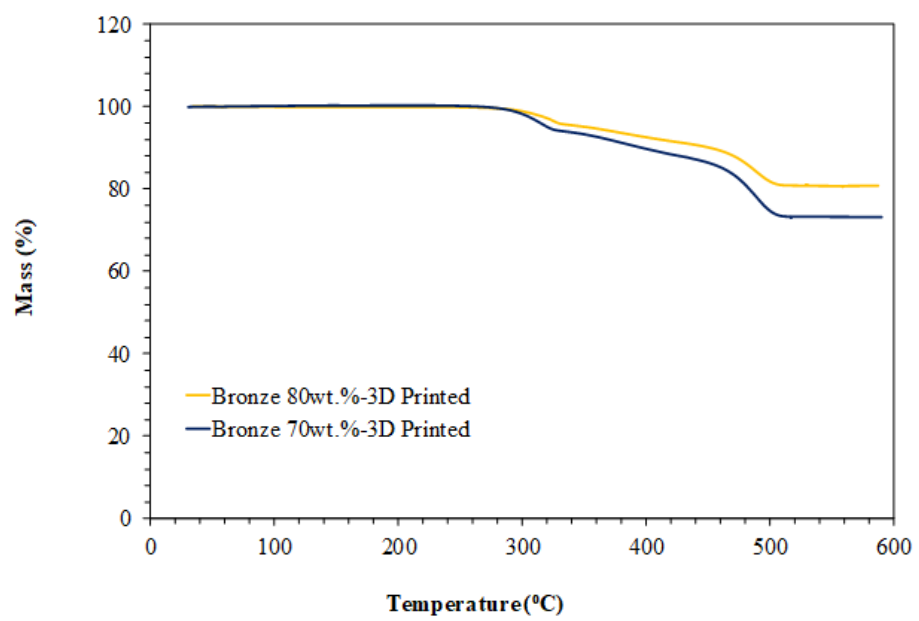

Figure B.2. Thermogravimetric Analysis to determine the homogeneous powder-binder distribution.

\section{B.6.2 3D PRINTING}

The developed feedstock material was turned into round filament of $1.6 \mathrm{~mm}$ diameter using a capillary rheometer. And the filament was fed into FFF device (Printrbot simple metal). Figure B.3, (a) illustrates the size and sphericity of the bronze powder used, (b) filament with consistent diameter of $1.6 \mathrm{~mm}$ produced having necessary flexibility and the stiffness required for the FFF process, (c) printing operation in the process of printing a cube $(10 \mathrm{~mm} \times 10 \mathrm{~mm} \times 10 \mathrm{~mm}),(\mathbf{d})$ some of the $3 \mathrm{D}$ printed parts including a cube, and ASTM tensile bar. 
(a)

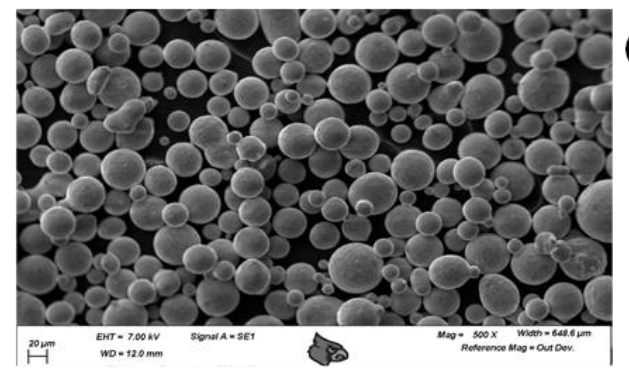

(c)

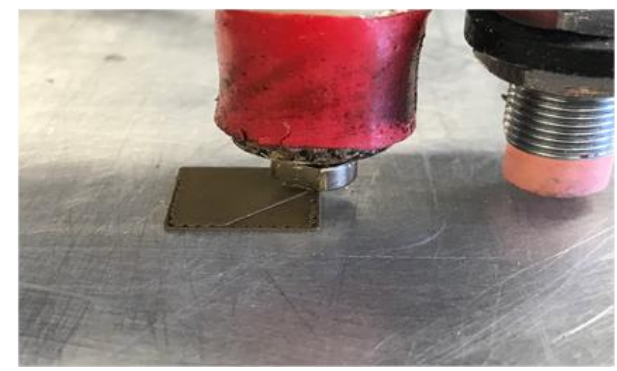

(b)

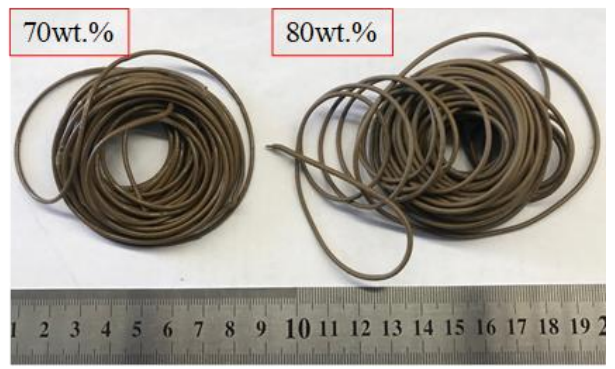

(d)

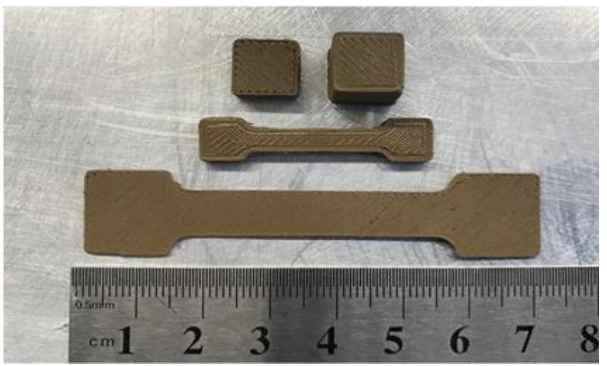

Figure B.3. (a) Electron microscopy image for the bronze powder, (b) filaments with 70 wt. $\%$ \& 80 wt.\% bronze in the binder, (c) FFF process with metal filament 3D printing, (d) printed parts with $80 \mathrm{wt} \%$ bronze.

Based on the process model discussed in the Section B.3.3, the shear rate was determined and presented in the Table B.3. Once the shear rate was determined for each condition of temperature and mass flow rate variations, the viscosity measurements were conducted to get the viscosity of the feedstock material including PLA and the bronze filled systems. 
Table B.3. Process modeling for FFF of unfilled and metal filled systems.

\begin{tabular}{|c|c|c|c|c|c|c|c|}
\hline & Mass & & Mass & Density & Volume & Shear & Viscosity \\
Material & flow & Temperature & $\left({ }^{\circ} \mathrm{C}\right)$ & extruded & $(\mathrm{g})$ & rate & $($ Pa.s $)$ \\
& $(\%)$ & & $\left(\frac{\mathrm{cm}^{3}}{s}\right)$ & $\left(s^{-1}\right)$ & measured \\
\hline PLA & 100 & 210 & 0.015 & 1.24 & 0.0008 & 64 & 11.9 \\
\hline PLA & 75 & 210 & 0.012 & 1.24 & 0.0006 & 52 & 13.5 \\
\hline Bz 70wt.\% & 100 & 250 & 0.034 & 2.29 & 0.0009 & 78 & 22.8 \\
\hline Bz 70wt.\% & 75 & 250 & 0.024 & 2.29 & 0.0007 & 55 & 30.8 \\
\hline Bz 80wt.\% & 100 & 250 & 0.047 & 3.3 & 0.001 & 76 & 41.7 \\
\hline Bz 80wt.\% & 75 & 250 & 0.033 & 3.3 & 0.0007 & 55 & 52.6 \\
\hline
\end{tabular}

PLA was chosen as the reference material which can be effectively printed at $210{ }^{\circ} \mathrm{C}$, and the viscosity measurement was performed at $210^{\circ} \mathrm{C}$ with two different flow rate conditions to account for the effects of the shear rate. The viscosity was found in the range of 11.913.5 Pa.s, which determined the optimum condition for printing PLA. Similarly, with trial and error the printing temperature for bronze filled systems was found to be $250{ }^{\circ} \mathrm{C}$, where the material extruded without any obstruction to its flow. The viscosity measurements were performed over the range of temperature from $210^{\circ} \mathrm{C}$ to $250{ }^{\circ} \mathrm{C}$, to analyze the effects of the feedstock viscosity when flowing. Referring to Figure 4, it was found that the viscosity for $80 \mathrm{wt} . \%$ bronze filled feedstock at $210^{\circ} \mathrm{C}$ with shear rate $76 \mathrm{~s}-1 \mathrm{was} 130 \mathrm{~Pa} . \mathrm{s}$, and when the temperature increased to $250{ }^{\circ} \mathrm{C}$, the viscosity decreased to $41.7 \mathrm{~Pa} . \mathrm{s}$ at the same shear rate. The viscosity of the $70 \mathrm{wt} \%$ bronze filled feedstock showed a similar trend, at 210 
${ }^{\circ} \mathrm{C}$ with shear rate 78 s- 1 viscosity was 76 Pa.s, and when the temperature increased to 250 ${ }^{\circ} \mathrm{C}$, the viscosity decreased to 22.8 Pa.s at the same shear rate. Represented in figure 4 , all the polymer systems showed a shear thinning behavior at increasing shear rate.

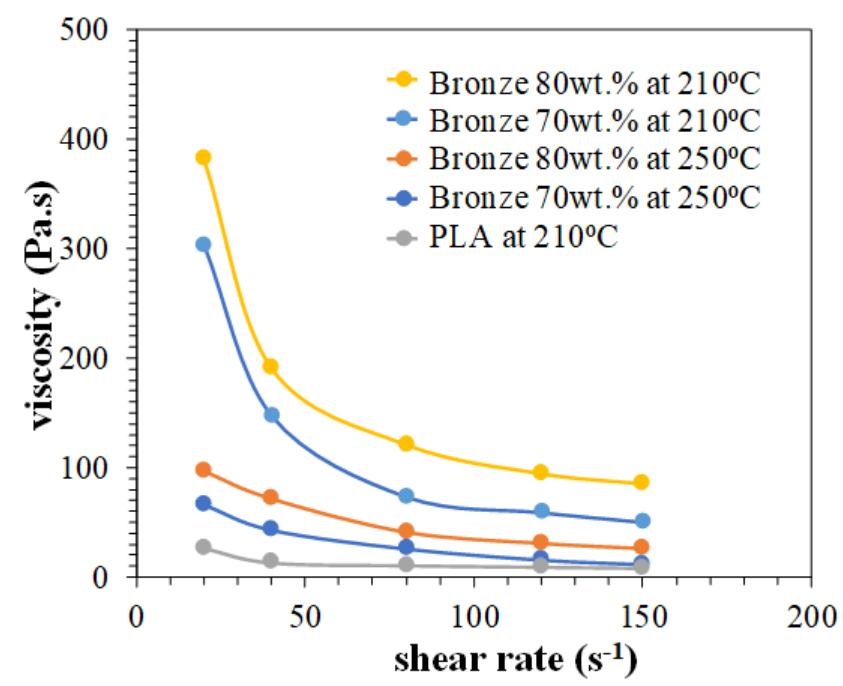

Figure B.4. Viscosity measurements at varying shear rate for PLA, at $210^{\circ} \mathrm{C}$, and Bronze filled system at $210^{\circ} \mathrm{C} \& 250{ }^{\circ} \mathrm{C}$.

\section{B.6.3 EFFECT OF EXTRUSION MASS FLOW RATE}

It has been observed from Figure B.4 and Table B.3 that with decreasing the mass flow rate from 100 to $75 \%$ during the printing process directly affects the shear rate to increase which in turn increases the viscosity of feedstock. A careful selection of mass flow rate can help in lowering feedstock viscosity for the effective continuous flow of the material. 


\section{B.6.4 EFFECT OF 3D PRINTING PROCESS TEMPERATURE}

Temperature is one of the major parameters that influence the feedstock viscosity, typical viscosity plotted as a function of temperature for polymer feedstock for the bronze filled polymer shows an increase in viscosity with a decrease in temperature from $250{ }^{\circ} \mathrm{C}$ to 210 ${ }^{\circ}$ C. From Figure B.4, we understand how the fluid viscosity drops down when the temperature of the bronze feedstock was changed from $210{ }^{\circ} \mathrm{C}$ to $250{ }^{\circ} \mathrm{C}$ and is in the same order (below 50 Pa.s) when compared to PLA at $210{ }^{\circ} \mathrm{C}$.

\section{B.7 CONCLUSIONS}

3D printing of unfilled PLA and 70 and 80 wt.\% bronze filled polymer binder was successfully demonstrated using the extrusion based FFF process. When FFF 3D printing with unfilled PLA the printing can be easily be performed at $210{ }^{\circ} \mathrm{C}$ however when printing with 70 and 80 wt.\% filled bronze polymer filament 3D printing cannot be achieved at $210^{\circ} \mathrm{C}$. A careful look at the feedstock viscosity of unfilled PLA at $210^{\circ} \mathrm{C}$ indicated that its viscosities range between 11-13 Pa.s for an extrusion 3D printing flow rate of 100 and $75 \%$ while that of 70 and 80 wt.\% bronze filled polymer filaments were all above $50 \mathrm{~Pa}$.s. To achieve 3D printing with the 70 and $80 \mathrm{wt} . \%$ bronze filled polymer filaments 3D printing process temperatures were increased to $250^{\circ} \mathrm{C}$ that allowed their viscosities to reach the necessary viscosity range. The current work demonstrates that in material designs for high powder filled polymer systems for metal FFF it is necessary to have a better control on the rheology of the material for successful 3D printing. 


\section{B.8 REFERENCES}

[1] Ashby, M.F. and D. Cebon, Materials selection in mechanical design. Le Journal de Physique IV, 1993. 3(C7): p. C7-1-C7-9.

[2] Edupack, C. Materials Design. 2018; Available from:

http://www.grantadesign.com/education/edupack/.

[3] DesktopMetal. Metal 3D printing. 2018; Available from: https://www.desktopmetal.com/.

[4] Markforged. Metal 3D printing. 2018; Available from: https://markforged.com/.

[5] Agarwala, M., et al. Fused deposition of ceramics and metals: an overview. in Proceedings of the Solid Freeform Fabrication Symposium, Austin, Texas. 1996.

[6] Agarwala, M.K., et al., Structural quality of parts processed by fused deposition. Rapid Prototyping Journal, 1996. 2(4): p. 4-19.

[7] Valkenaers, H., et al. A novel approach to additive manufacturing: screw extrusion 3D-printing. in Proceedings of the 10th International Conference on Multi-Material Micro Manufacture. 2013. Research Publishing.

[8] Bellini, A., S. Guceri, and M. Bertoldi, Liquefier dynamics in fused deposition. Journal of Manufacturing Science and Engineering, 2004. 126(2): p. 237-246.

[9] Supati, R., et al., Mixing and characterization of feedstock for powder injection molding. Materials Letters, 2000. 46(2-3): p. 109-114.

[10] Shenoy, A.V., Rheology of filled polymer systems. 2013: Springer Science. 


\section{APPENDIX C}

\section{NASA FABLAB REPORTS}

\section{C.1 INTRODUCTION}

This work was funded by NASA FABLAB project and during the course of the work various Ti-6Al-4V powder-binder combinations were investigated. For $\mathrm{MF}^{3}$ processability, different data sets were generated related to Ti-6Al-4V feedstock properties including physical, rheological, thermal, and mechanical. These properties serve a major pathway in understanding material printability and related issues. Some of the experimental designs to improve the part green density and further its effect of sintered density have been presented. Direct effect of process parameter on the print density and sintered density has been found. The effect of post processing cycle with hot iso-static pressing on the $\mathrm{MF}^{3}$ part properties has been shown. The results can form as a database to understand the process and material capabilities which can form a research subject for future work.
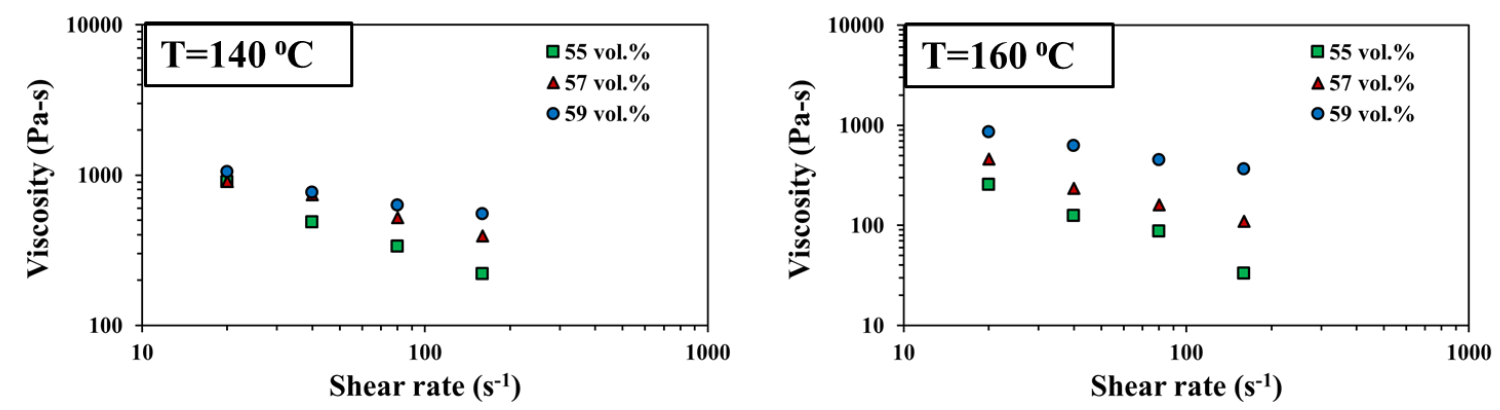

Figure C.1. Viscosity measured at $140{ }^{\circ} \mathrm{C} \& 160{ }^{\circ} \mathrm{C}$ with a shear rate of $20-160 \mathrm{~s}^{-1}$ for Ti6Al-4V coarse powder at different loadings. 


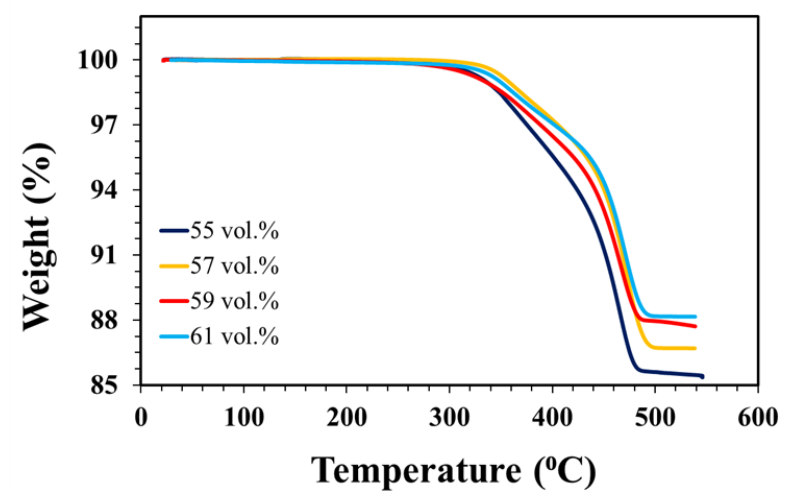

\begin{tabular}{|c|c|c|}
\hline $\begin{array}{c}\text { Actual wt.\% of } \\
\text { added Ti-6Al- } \\
\text { 4V powder }\end{array}$ & $\begin{array}{c}\text { Remaining Ti- } \\
\text { 6Al-4V powder } \\
\text { after TGA }\end{array}$ & $\begin{array}{c}\text { Percent } \\
\text { difference (\%) }\end{array}$ \\
\hline 85.10 & 85.36 & 0.30 \\
\hline 86.10 & 86.70 & 0.70 \\
\hline 87.00 & 87.71 & 0.80 \\
\hline 88.00 & 88.15 & 0.20 \\
\hline
\end{tabular}

Figure C.2. Results from TGA relate the residual weight to the initial powder added to the binder.

Table C.1. Pycnometer measured Ti-6Al-4V feedstock density compared to estimated density from inverse rule of mixtures.

\begin{tabular}{|c|c|c|c|}
\hline $\begin{array}{l}\text { Ti-6Al-4V } \\
\text { Feedstock }\end{array}$ & $\begin{array}{c}\text { Estimated density from } \\
\text { inverse rule of mixtures } \\
\left(\mathrm{g} / \mathrm{cm}^{3}\right)\end{array}$ & $\begin{array}{c}\text { Density determined by } \\
\text { pycnometer }\left(\mathrm{g} / \mathrm{cm}^{3}\right)\end{array}$ & $\begin{array}{c}\text { Percent } \\
\text { difference }(\%)\end{array}$ \\
\hline $\begin{array}{c}\text { Ti-6Al-4V } \\
(55 \mathrm{vol} \%)\end{array}$ & 2.88 & $2.90 \pm 0.003$ & 0.70 \\
\hline $\begin{array}{l}\text { Ti-6Al-4V } \\
(57 \text { vol.\% })\end{array}$ & 2.95 & $2.96 \pm 0.004$ & 0.30 \\
\hline $\begin{array}{l}\text { Ti-6Al-4V } \\
(59 \text { vol.\% })\end{array}$ & 3.01 & $2.99 \pm 0.002$ & 0.60 \\
\hline $\begin{array}{l}\text { Ti-6Al-4V } \\
(61 \text { vol.\% })\end{array}$ & 3.09 & $3.10 \pm 0.005$ & 0.30 \\
\hline
\end{tabular}




\begin{tabular}{|c|c|c|c|c|c|c|}
\hline Tablet & & Cube & & & sile bar & \\
\hline \multirow[b]{2}{*}{ Direction } & \multicolumn{2}{|c|}{ Tablet } & \multicolumn{2}{|c|}{ Cube } & \multicolumn{2}{|c|}{ Tensile bar * } \\
\hline & $\begin{array}{c}\text { STL } \\
\text { dimensions } \\
(\mathrm{mm})\end{array}$ & $\begin{array}{c}\text { Printed } \\
\text { dimensions } \\
(\mathrm{mm})\end{array}$ & $\begin{array}{c}\text { STL } \\
\text { dimensions } \\
(\mathrm{mm})\end{array}$ & $\begin{array}{l}\text { Printed } \\
\text { dimensions } \\
(\mathrm{mm})\end{array}$ & $\begin{array}{c}\text { STL } \\
\text { dimensio } \\
\text { ns (mm) }\end{array}$ & $\begin{array}{l}\text { Printed } \\
\text { dimensions } \\
(\mathrm{mm})\end{array}$ \\
\hline $\mathrm{X}$ & 10 & $10.08 \pm 0.07$ & 10 & $9.98 \pm 0.06$ & 68 & $67.9 \pm 0.10$ \\
\hline Y & 10 & $10.05 \pm 0.06$ & 10 & $9.92 \pm 0.02$ & 6.6 & $6.70 \pm 0.10$ \\
\hline $\mathrm{Z}$ & 5 & $4.85 \pm 0.02$ & 10 & $10.1 \pm 0.01$ & 3.2 & $3.15 \pm 0.05$ \\
\hline
\end{tabular}

Figure C.3. $\mathrm{MF}^{3}$ printed geometries and their dimensional analysis.

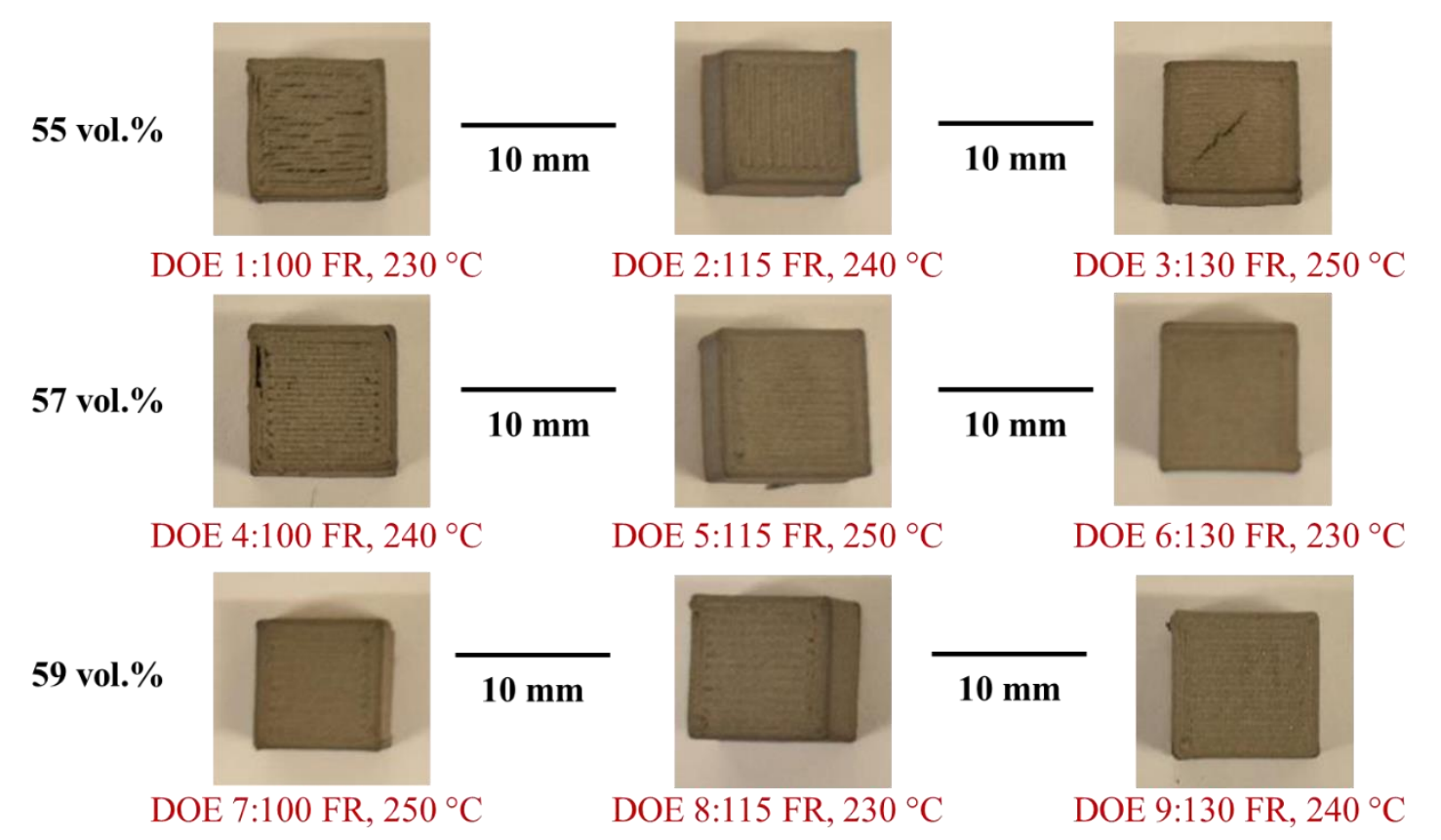

Figure C.4. Taguchi design of experiments (DOE) to find the effect of solids loading (vol.\%), extrusion multiplier (FR\%), and melt temperature $\left({ }^{\circ} \mathrm{C}\right)$ on $\mathrm{MF}^{3}$ parts sintered at $1300^{\circ} \mathrm{C}$ for 3 hours. 


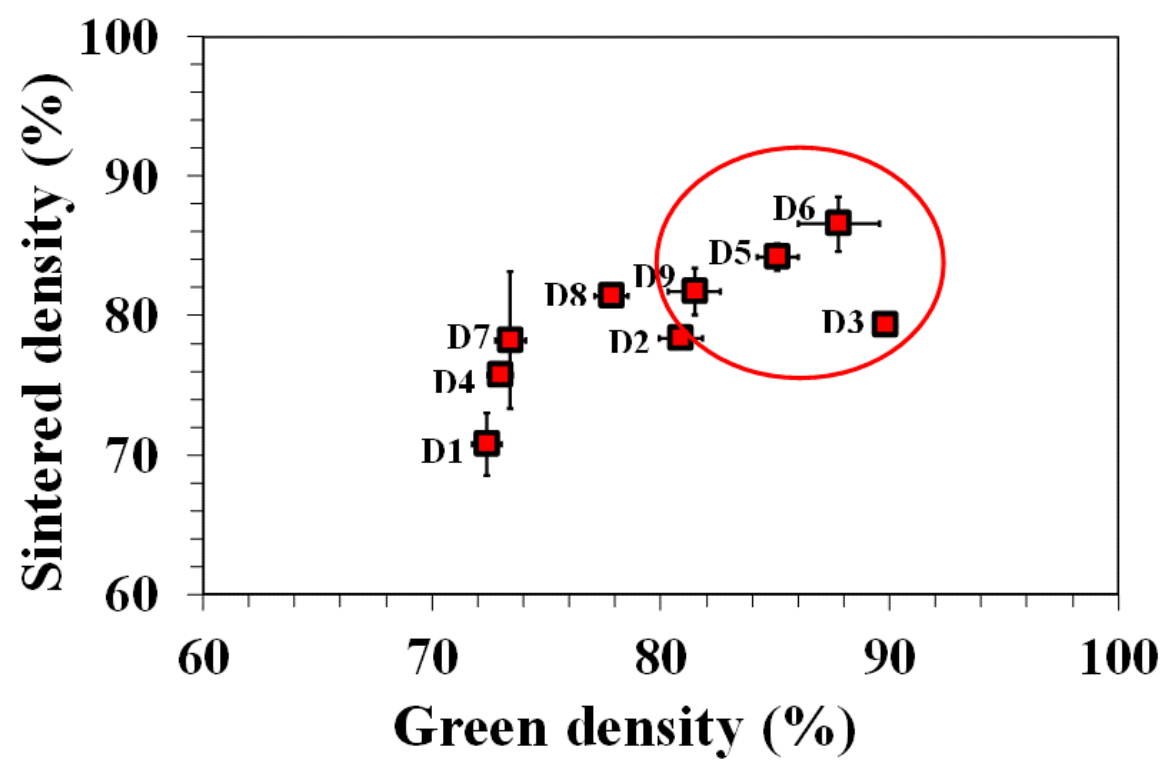

Figure C.5. Green density and sintered density of the $\mathrm{MF}^{3}$ parts, with "D" signifying the experiment DOE number (reference Figure C.4).

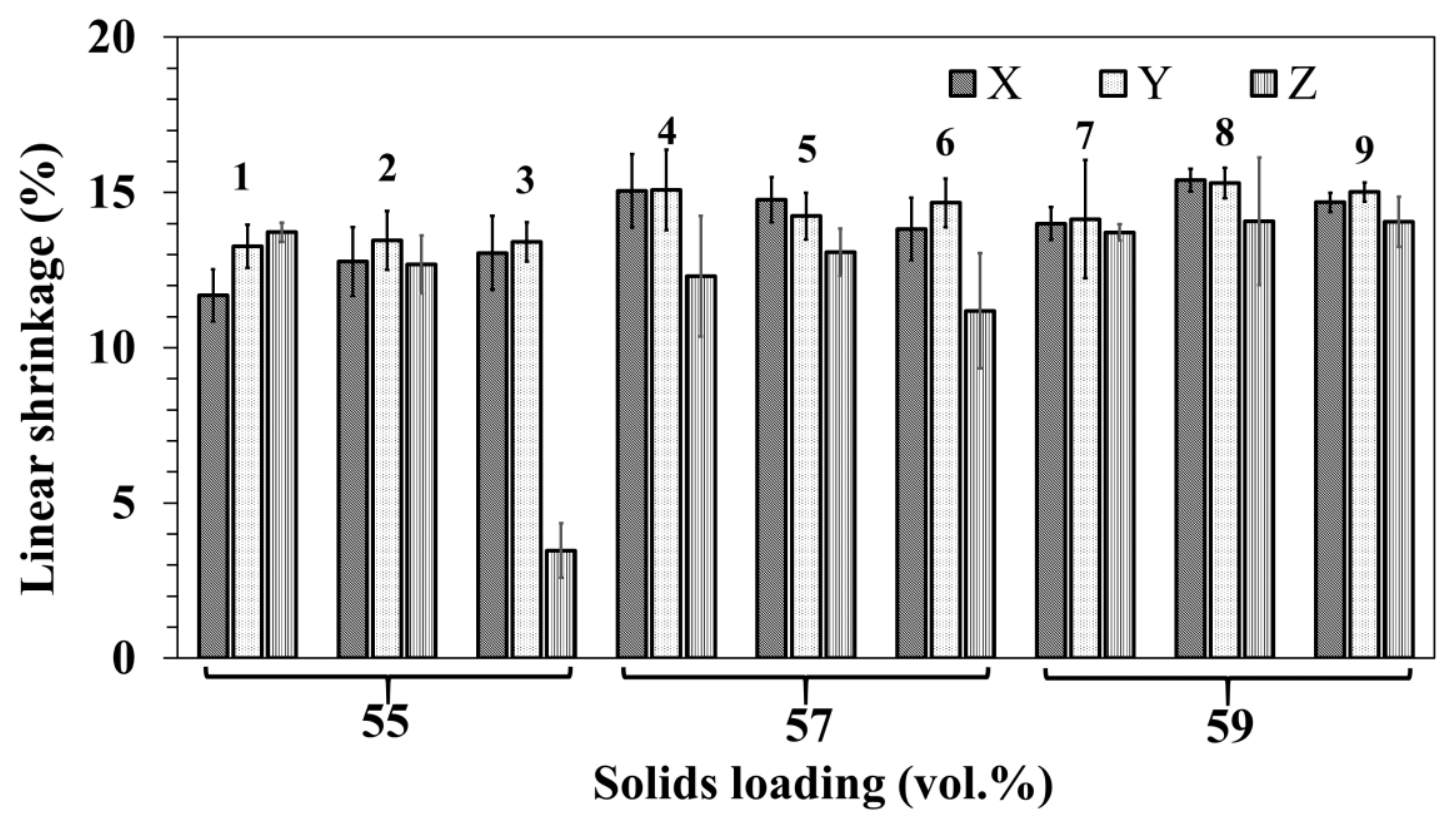

Figure C.6. Linear shrinkage along $\mathrm{X}, \mathrm{Y}$, and $\mathrm{Z}$ axis for $\mathrm{MF}^{3}$ parts with numbers indicating the DOE condition. 


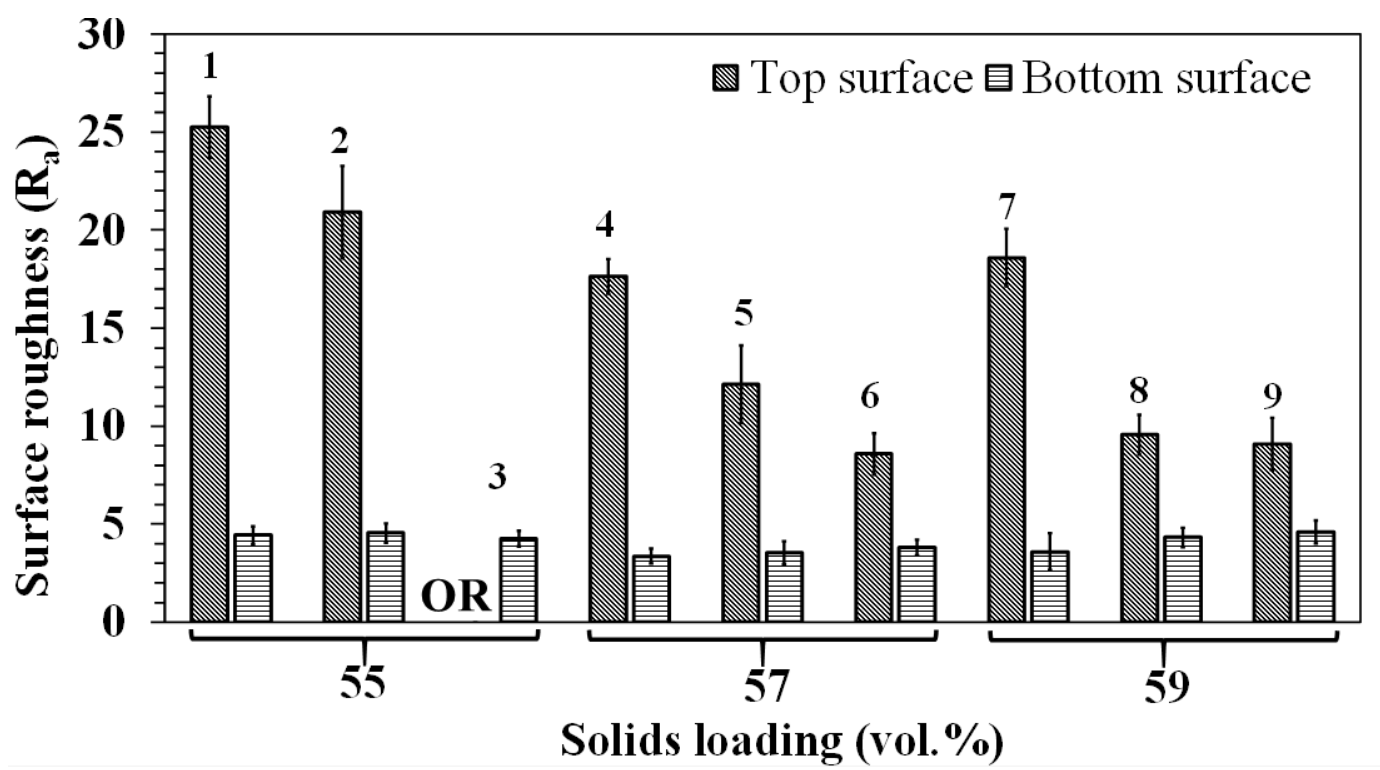

Figure C.7. Surface roughness for $\mathrm{MF}^{3}$ sintered parts with numbers indicating the DOE condition.

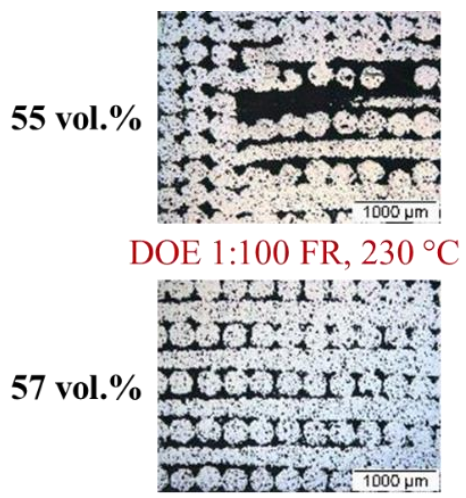

DOE 4:100 FR, $240{ }^{\circ} \mathrm{C}$

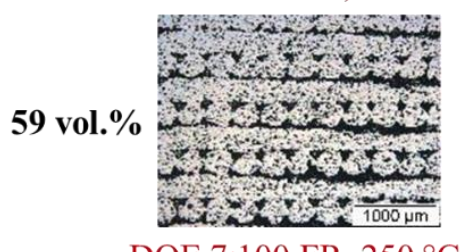

DOE 7:100 FR, $250^{\circ} \mathrm{C}$
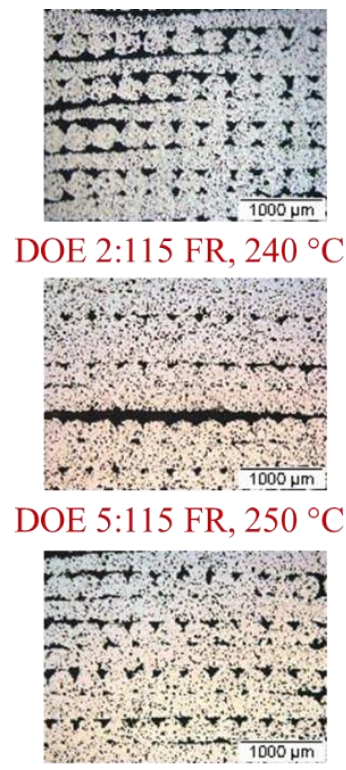

DOE 8:115 FR, $230{ }^{\circ} \mathrm{C}$

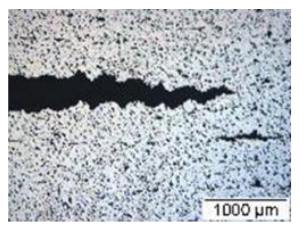

DOE 3:130 FR, $250^{\circ} \mathrm{C}$

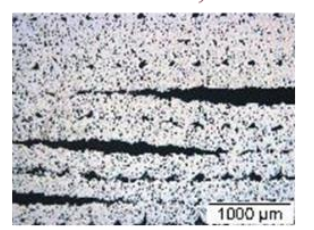

DOE 6:130 FR, $230{ }^{\circ} \mathrm{C}$

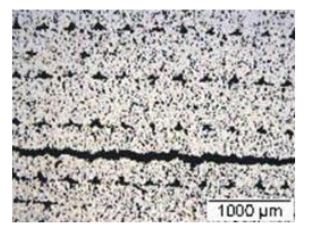

DOE 9:130 FR, $240{ }^{\circ} \mathrm{C}$

Figure C.8. Sintered defects in $\mathrm{MF}^{3}$ parts along the $\mathrm{Z}$ plane (perpendicular to the build direction). 


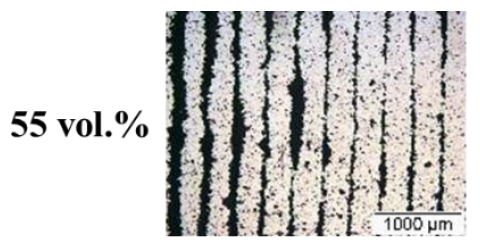

DOE 1:100 FR, $230^{\circ} \mathrm{C}$

57 vol. $\%$

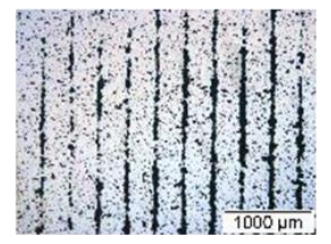

DOE 4:100 FR, $240{ }^{\circ} \mathrm{C}$

59 vol. \%

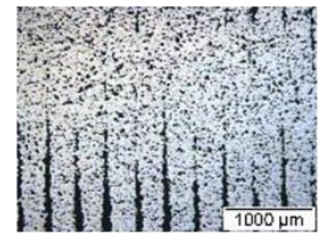

DOE 7:100 FR, $250^{\circ} \mathrm{C}$

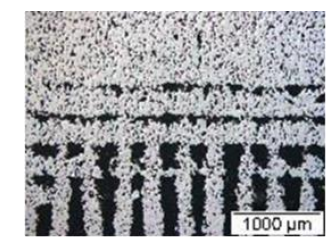

DOE 2:115 FR, $240{ }^{\circ} \mathrm{C}$

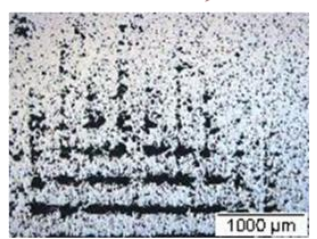

DOE 5:115 FR, $250^{\circ} \mathrm{C}$

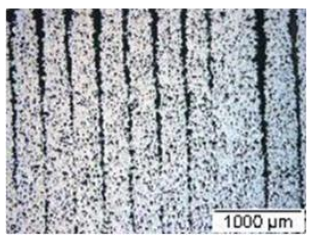

DOE 8:115 FR, $230{ }^{\circ} \mathrm{C}$

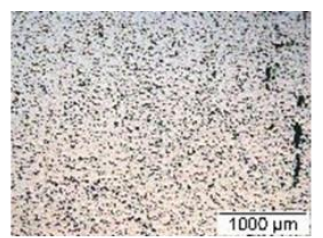

DOE 3:130 FR, $250{ }^{\circ} \mathrm{C}$

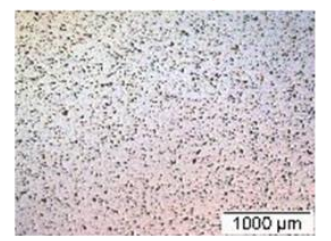

DOE 6:130 FR, $230{ }^{\circ} \mathrm{C}$

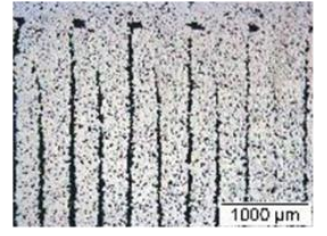

DOE 9:130 FR, $240{ }^{\circ} \mathrm{C}$

Figure C.9. Sintered defects in MF3 parts along the X-Y plane (parallel to the build direction).
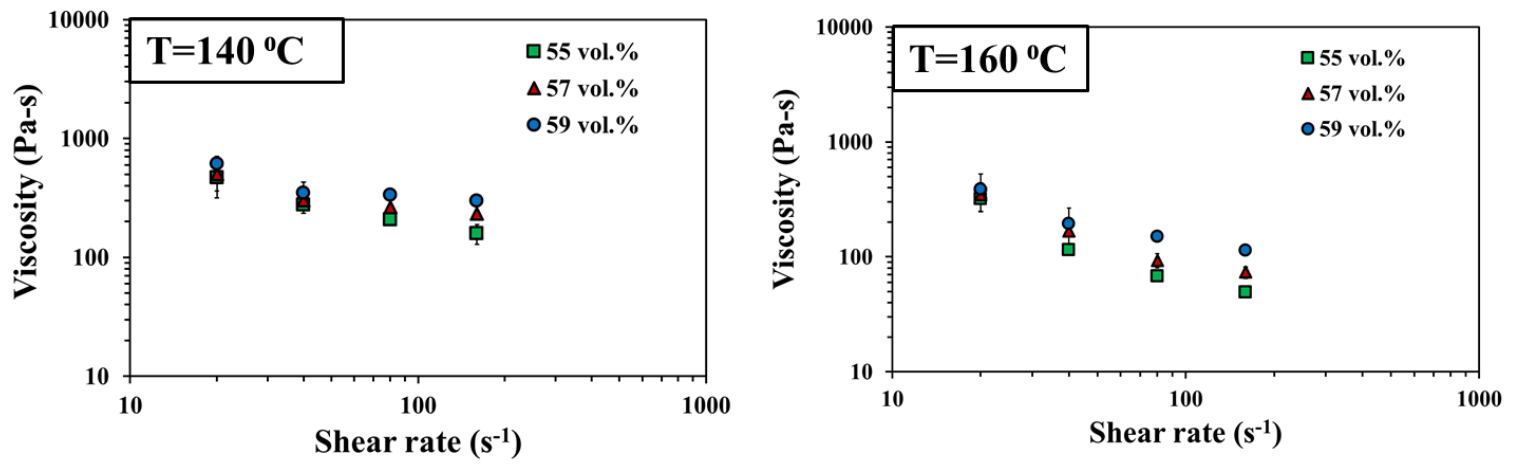

Figure C.10. Viscosity measured at $140{ }^{\circ} \mathrm{C} \& 160{ }^{\circ} \mathrm{C}$ with a shear rate of $20-160 \mathrm{~s}^{-1}$ for Ti-6Al-4V coarse powder with a different binder composition (B1). 


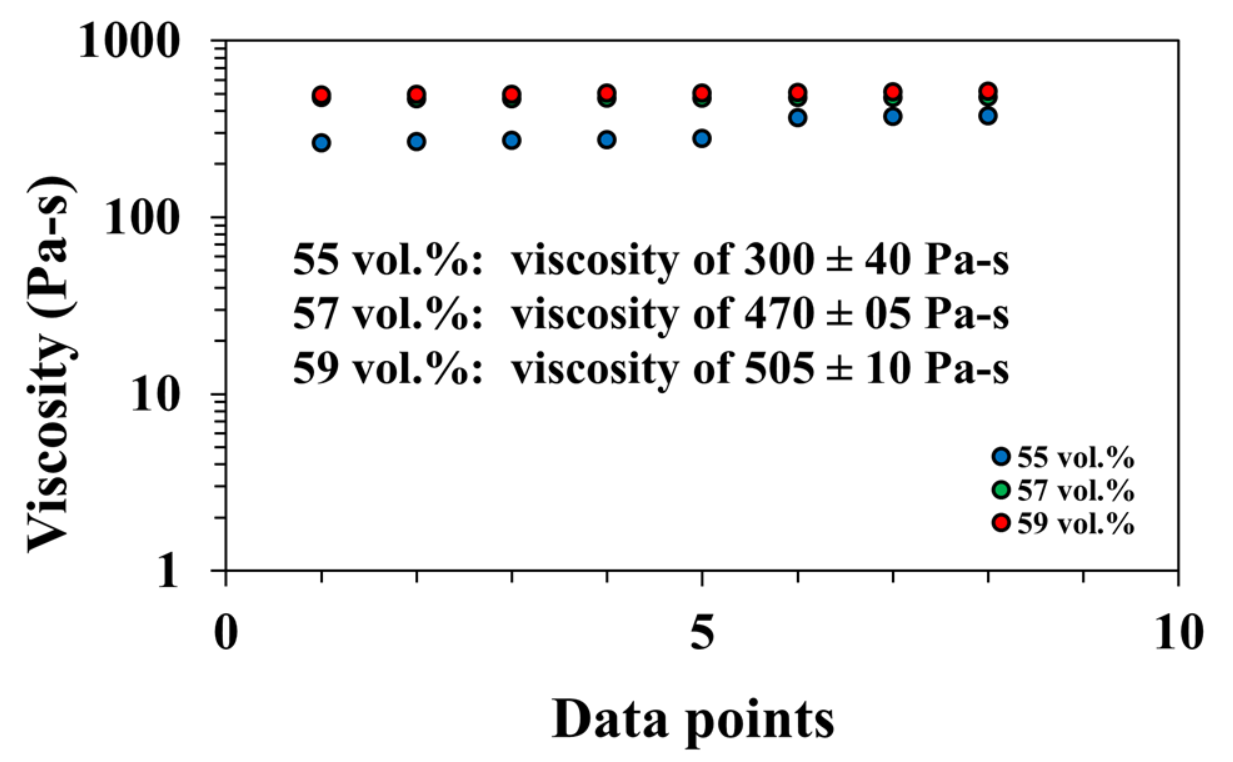

Figure C.11. Ti-6Al-4V MF ${ }^{3}$ feedstock viscosity at a constant shear rate of $50 \mathrm{~s}^{-1}$ at 140 ${ }^{\circ} \mathrm{C}$, to enable homogeneity assessments.

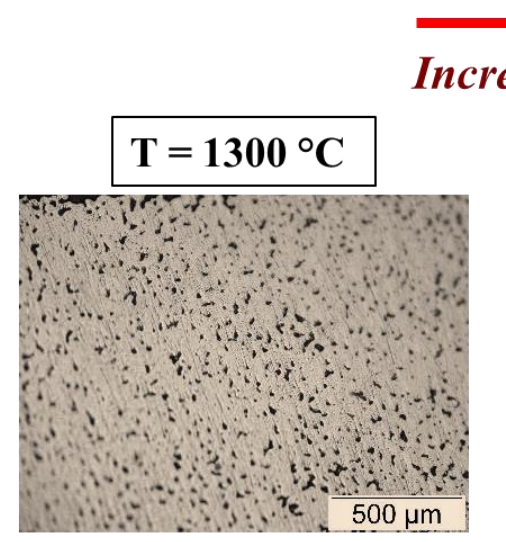

Relative density: $90 \%$

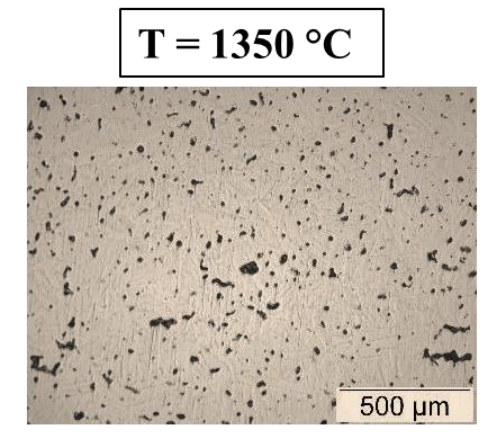

Relative density: $\mathbf{9 2 . 4 \%}$

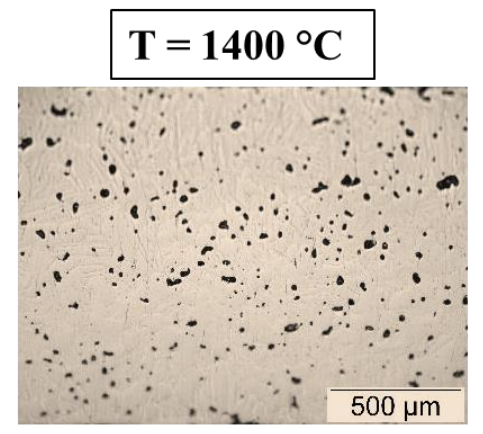

Relative density: $94.4 \%$

Figure C.12. Sintering of filament samples at different temperatures. 


\section{$2 \mathrm{~cm}$}

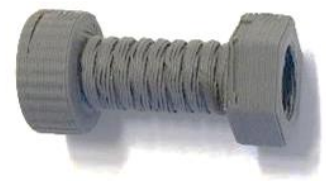

Nut \& bolt

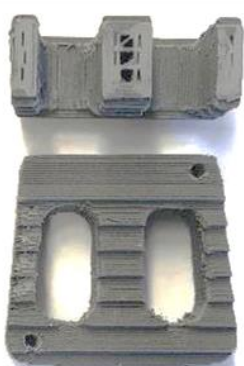

Porous spinal implant

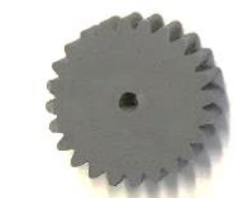

Pinion gear

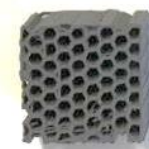

$40 \%$

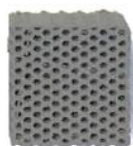

$60 \%$

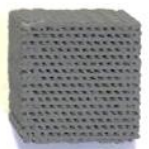

$80 \%$

Porous honeycomb structures

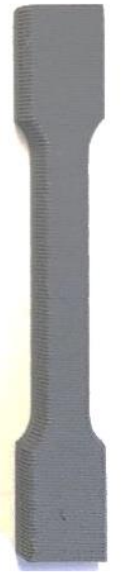

T bar printed along Z-axis

Figure C.13. Complex geometries printed with $\mathrm{MF}^{3}$ using 59 vol.\% Ti-6Al-4V filament.
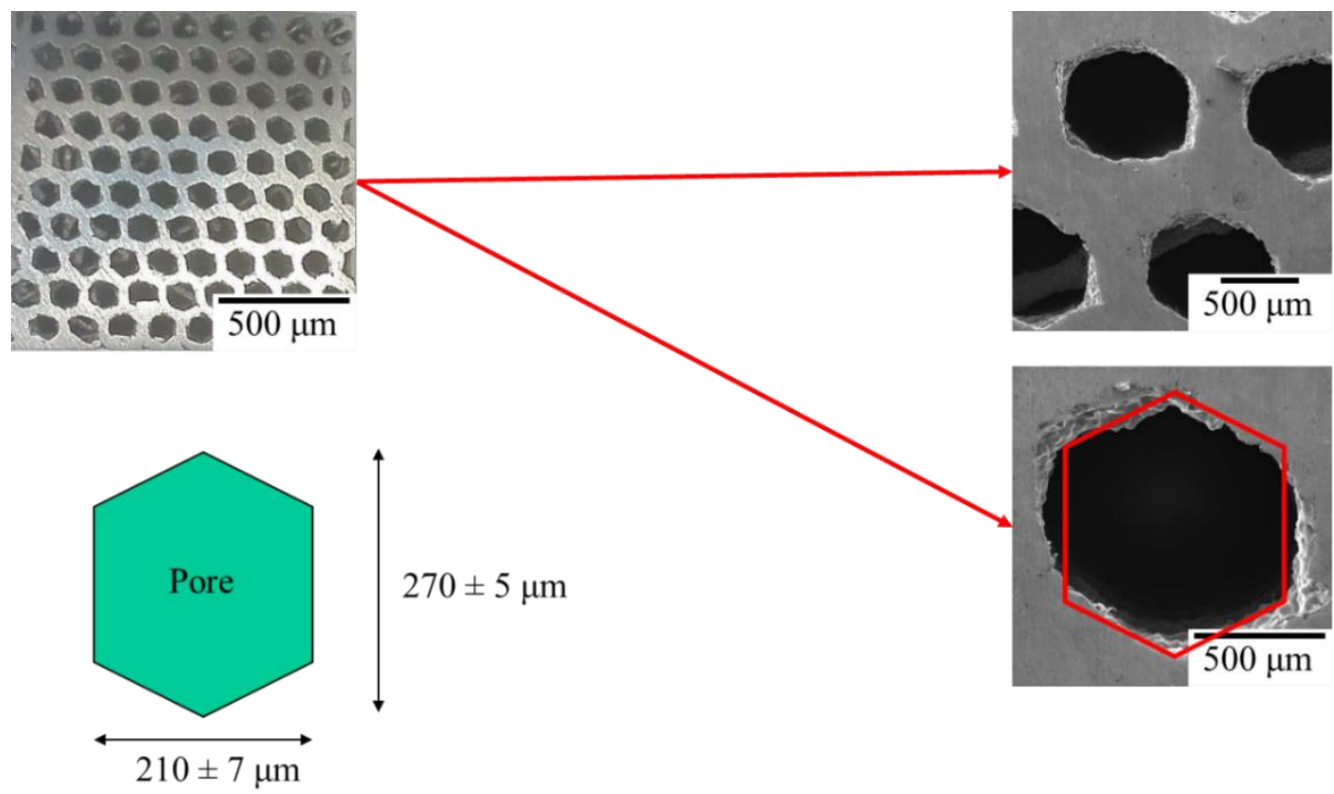

Figure C.14. $\mathrm{MF}^{3}$ sintered honeycomb structure. 


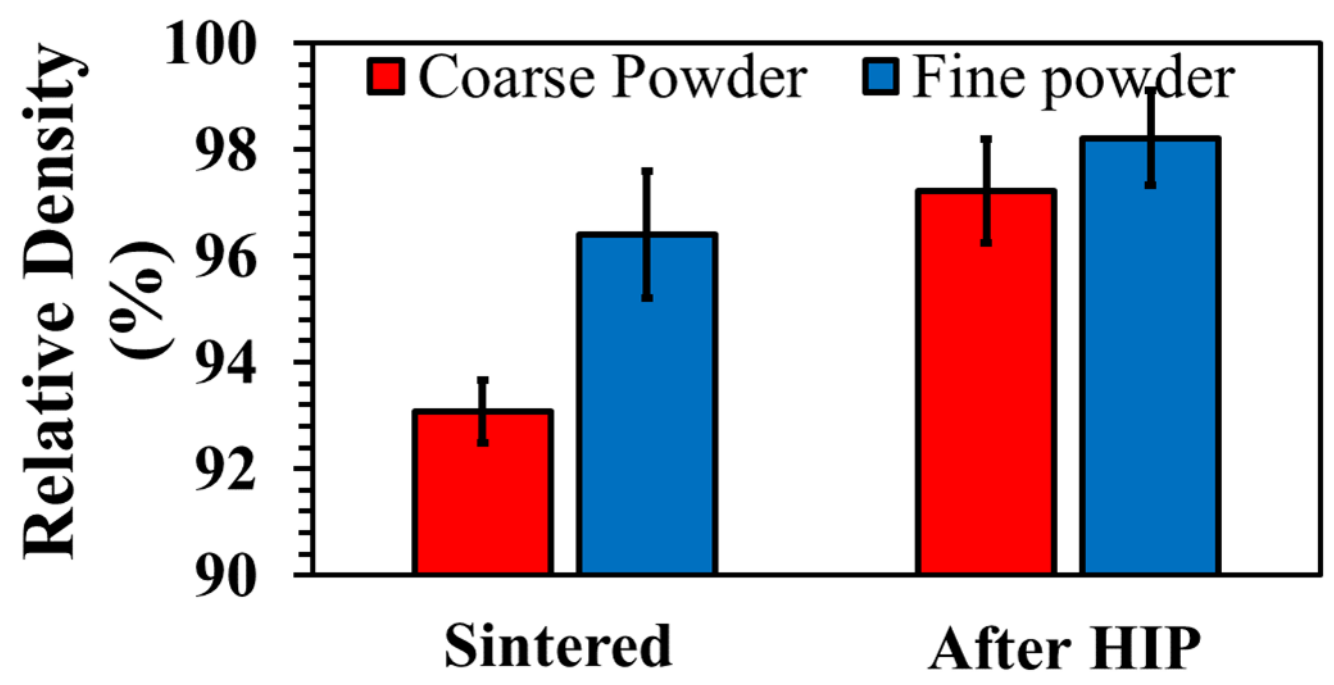

Figure C.15. Effect of hot iso-static pressing (HIP) on $\mathrm{MF}^{3}$ part density for Ti-6Al-4V coarse and fine powder.

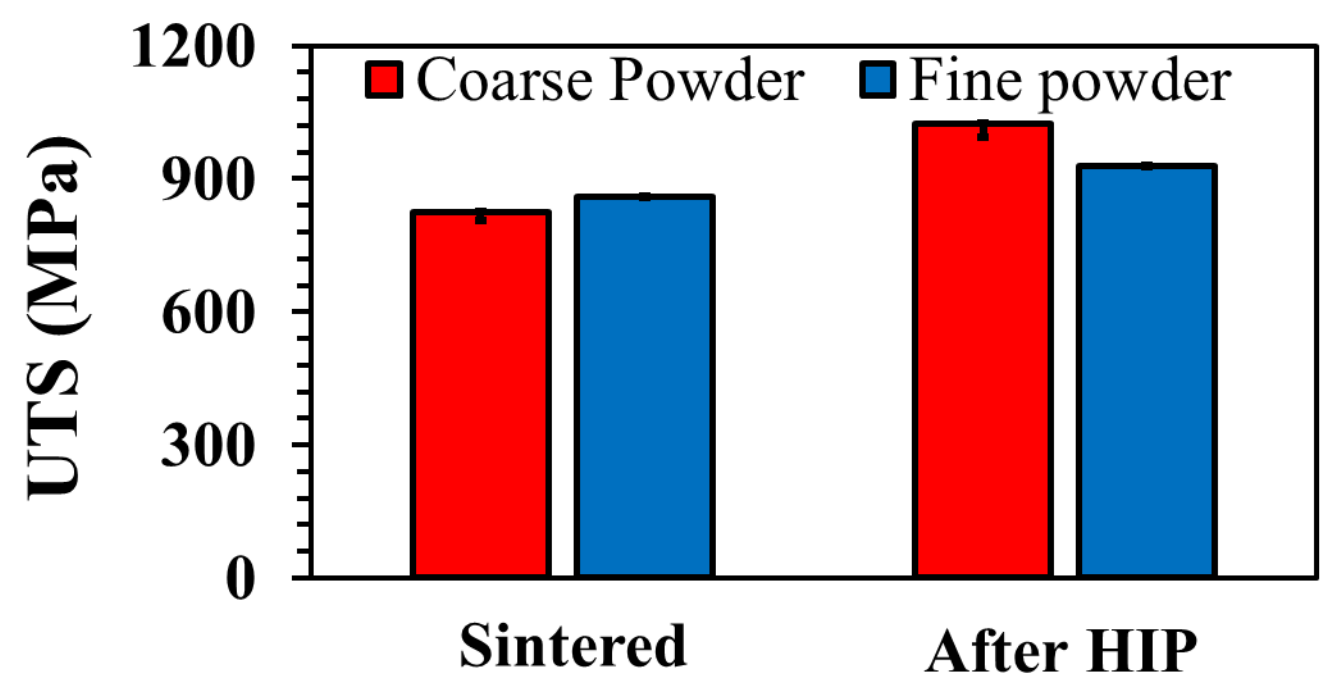

Figure C.16. Effect of hot iso-static pressing (HIP) on $\mathrm{MF}^{3}$ sample UTS for Ti-6Al-4V coarse and fine powder. 


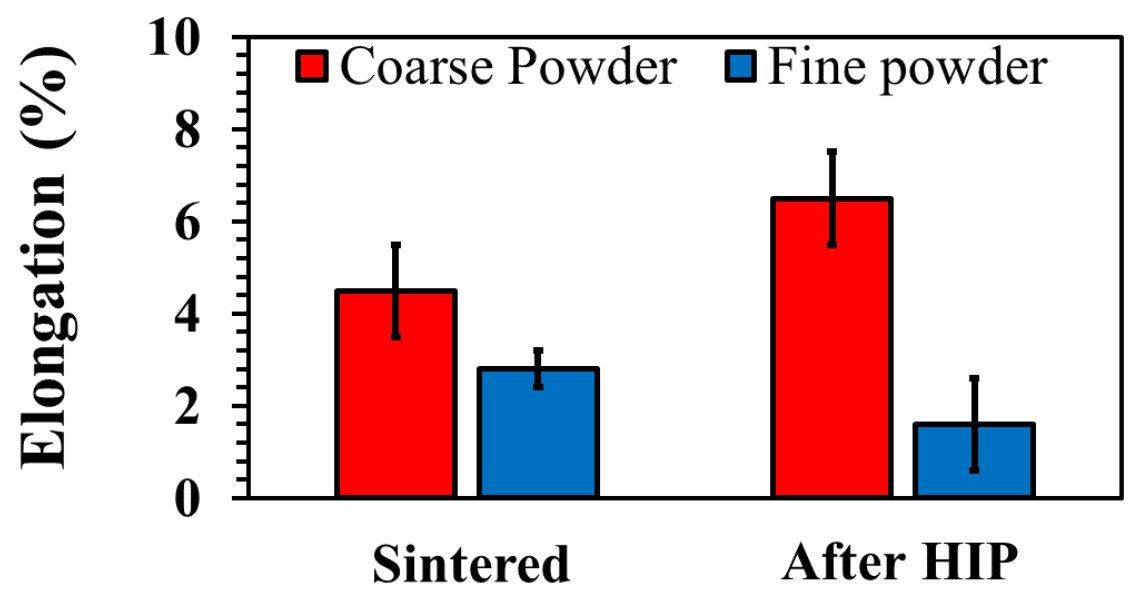

Figure C.17. Effect of hot iso-static pressing (HIP) on $\mathrm{MF}^{3}$ sample elongation for Ti-6Al$4 \mathrm{~V}$ coarse and fine powder. 


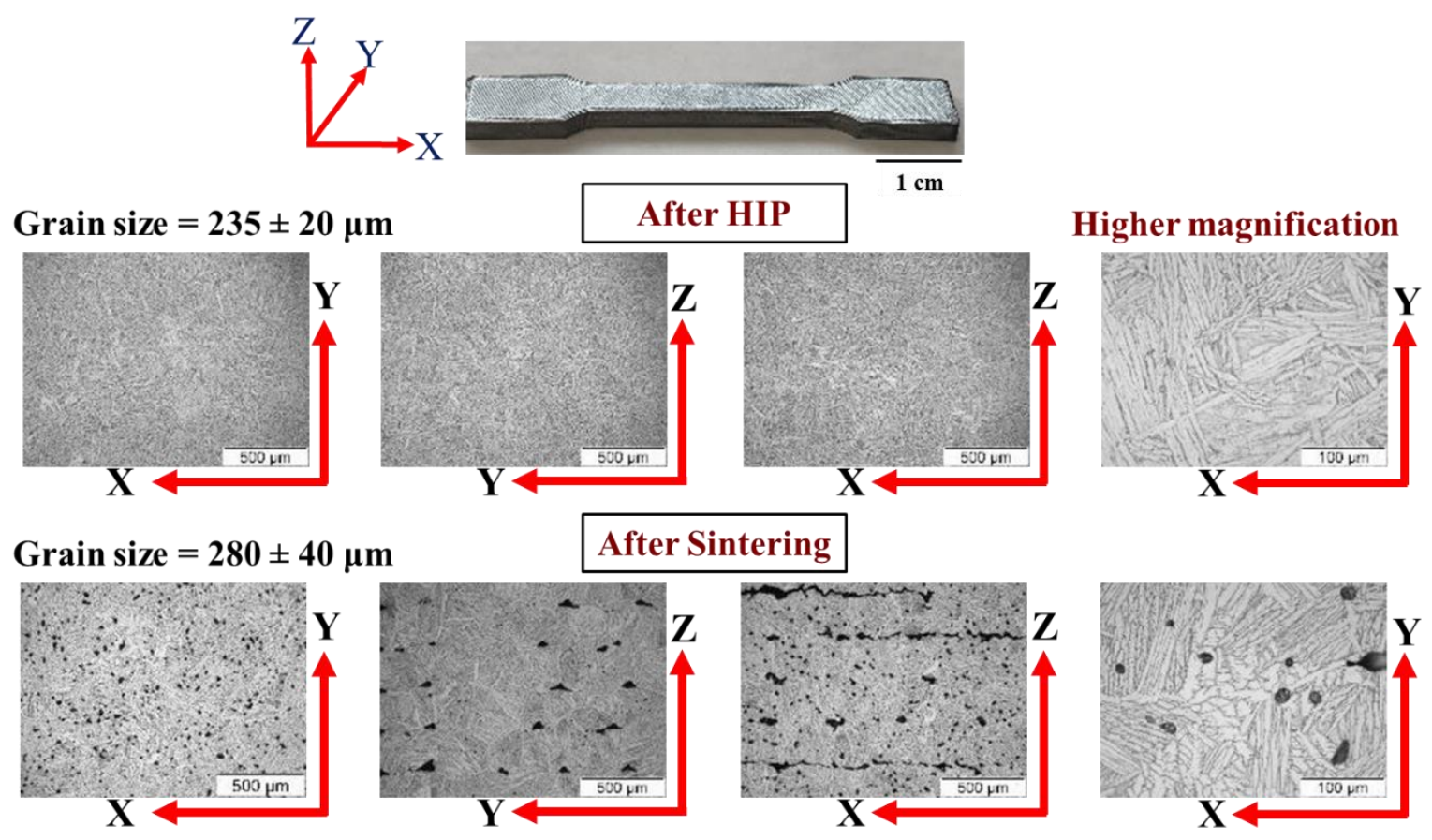

Figure C.18. Effect of hot iso-static pressing (HIP) on the coarse Ti-6Al-4V MF ${ }^{3}$ sample microstructure. 


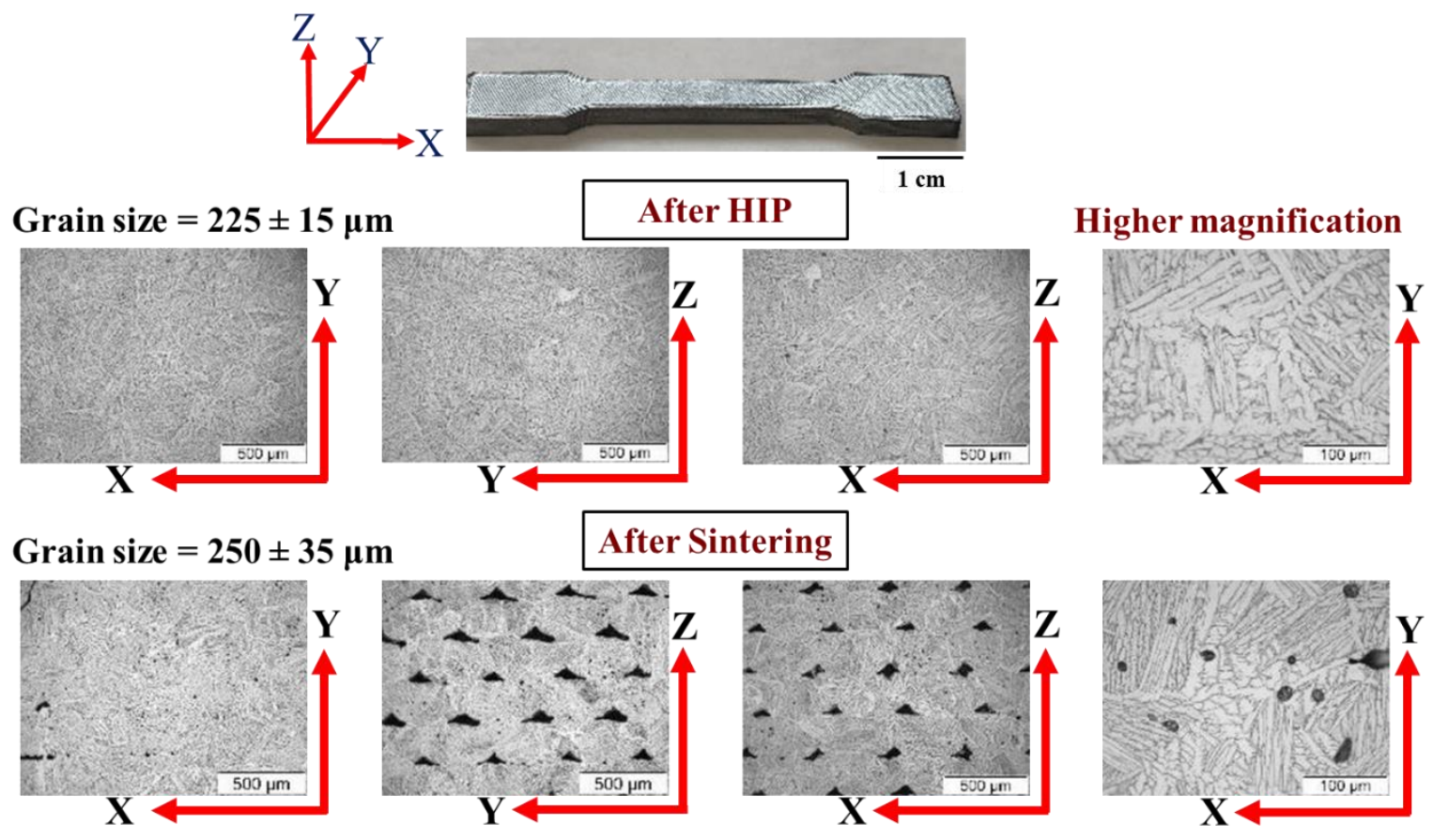

Figure C.19. Effect of hot iso-static pressing (HIP) on the fine Ti-6Al-4V MF $\mathrm{MF}^{3}$ sample microstructure 


\title{
CURRICULUM VITAE
}

\author{
Paramjot Singh
}

Email: paramjot.singh@ louisville.edu, Cell: (619)-335-6221

Address: 2204 James Pirtle Ct, Apt. 3, Louisville, KY- 40217

\section{EDUCATION}

University of Louisville, Louisville, KY

Doctor of Philosophy (Ph.D.), Mechanical Engineering

May 2020

San Diego State University, San Diego, CA

May 2017

Master of Science (M.S.), Mechanical Engineering

West Bengal University of Technology, Kolkata, India

May 2014

Bachelor of Technology (B.Tech.), Mechanical Engineering

\section{JOURNAL PUBLICATIONS}

- Singh, P., Balla, V. K., Tofangchi, A., Atre, S. V., \& Kate, K. H. (2020). Printability studies of Ti-6Al-4V by metal fused filament fabrication $\left(\mathrm{MF}^{3}\right)$. Special issues in the AM of Titanium alloys. International Journal of Refractory Metals and Hard Materials, 105249.

- Singh, P., Shaikh, Q., Balla, V. K., Atre, S. V., \& Kate, K. H. (2020). Estimating PowderPolymer Material Properties Used in Design for Metal Fused Filament Fabrication $\left(\mathrm{DfMF}^{3}\right)$. JOM, 72(1), 485-495.

- Singh, P., Balla, V. K., Gokce, A., Atre, S. V., \& Kate, K. H "Metal fused filament fabrication $\left(\mathrm{MF}^{3}\right)$ of Ti-6Al-4V alloy: microstructure and properties", Materials Today, under review.

- Singh, P., Balla, V. K., Gokce, A., Atre, S. V., \& Kate, K. H "Factors affecting density and related properties of Ti-6Al-4V alloy parts made using metal fused filament fabrication $\left(\mathrm{MF}^{3}\right)^{\prime}$, in process of submission.

- Singh, P., Balla, V. K., Atre, S. V., \& Kate, K. H "Metal fused filament fabrication $\left(\mathrm{MF}^{3}\right)$ of copper alloy $(\mathrm{Cu}-10 \mathrm{Sn})$ : microstructure and properties", under preparation.

- Balla, V. K., Kate, K. H., Satyavolu, J., Singh, P., \& Tadimeti, J. G. D., "Additive manufacturing of natural fiber reinforced polymer composites: Processing and prospects". Composites Part B: Engineering, 106956,

- Campbell, M., Singh, P., Kate, K., \& Harnett, C. K. (2019). Controlling Thermoplastic Elastomer Optical Properties by Mechanical Processing. MRS Advances, 4(23), 13411347. 
- Thilakaratne R., Singh P., Livchak M., Kate K., and Satyavolu J., Impact of Chemical Treatment on Thermal Properties of Kenaf Fiber-Polymer Composites for 3D Printing, submitted to Polymer composites (under review).

\section{CONFERENCE PROCEEDINGS AND PRESENTATIONS}

- Singh, P., Atre, S.V., Kate, K.H., "Influence of powder characteristics on properties of laser-powder bed fusion processed Ti-6Al-4V". Additive Manufacturing with Powder Metallurgy (AMPM), June 2019.

- Singh, P., Atre, S.V., Kate, K.H., "Metal fused filament fabrication of Cu-10Sn alloy: feedstock preparation, 3d printing, and thermal processing". Materials Science \& Technology (MS\&T), 2018

- Singh, P., Atre, S.V., Kate, K.H., "Estimation of extrusion-based 3D printing process with viscosity-shear-rate measurements for powder-filled polymers". Additive Manufacturing with Powder Metallurgy (AMPM), June 2018.

- Singh, P., Atre, S.V., Kate, K.H., "Mathematical models to predict viscosity behavior for new feedstock development in powder injection molding to perform mold flow simulations". Metal Injection Molding (MIM), February 2018.

\section{ACADEMIC EXPERIENCE}

Teaching Assistant at University of Louisville

Fall 2017-Summer 2018

- Measurements Lab

- Solid Mechanics Lab

- Fluid Mechanics Lab

Teaching Assistant at San Diego State University

Fall 2015-Fall 2016

- Metal Injection Molding

- Mechanics of Materials

- Engineering Design I \& II

INDUSTRY COLLABORATIONS

Project: In-space 3D printing with Metals

July 2018-May 2020

\section{NASA Marshal Space Flight Center, AL, and Techshot Inc., IN}

- Led development of novel process and material formulations for NASA FABLAB project, to facilitate in-space 3D printing of metals.

- Developed a scientific process physics model to predict material printability and failure rate limits.

- Evaluated printing variables through the design of experiments (DOE) and analyzed results using statistical tools to optimize part microstructure, physical, and mechanical properties.

- Data-driven decisions to identify appropriate post-processing operations and process environment conditions to optimize final part properties. 
- Fostered mutual growth for participating teams in project development by providing consistent updates through NASA review meetings in order to track the challenges and implementing strategies to achieve stability.

\section{Project: Process-Property Optimization for New Material Developments with Laser Powder}

\section{Bed Fusion}

January 2018-August 2018

\section{University of Utah, UT}

- Process optimization for non-traditional powders with L-PBF process on Concept Laser machine: evaluated parameters, characterized printed parts for physical, mechanical and microstructural properties.

- Mentored a team of 4 senior graduate students to design and develop a dental implant prototype, collaborated with the dental school to evaluate customer cases, developed a minimal viable product with 3D printing, and presented the case for a business model.

\section{AWARDS}

- National Science Foundation (NSF) grant to attend MS\&T conference, 2018

- National Science Foundation (NSF) grant to attend AMPM conference, 2018

- Metal Injection Molding Association (MIMA) grant to attend MIM conference, 2018

\section{CERTIFICATIONS}

- Certified training: Launching a Lean Startup, 2019 (LaunchIt, UofL School of Business, Louisville, KY).

- Certified in CAD product design: Pro Engineer, ANSYS, 2014 (CAD Center Services, Kolkata, India).

- Certified in advanced training on heat-treatment and material testing, 2012 (Advanced Training Institute, Govt. of India, Kolkata, India).

\section{SKILLS}

- Material Processing: Additive Manufacturing (FFF, L-PBF), Powder Metallurgy, Sintering, High-Temperature Furnaces, Dilatometry

- Material Characterizations: Microscopy (Optical, SEM, EDS), Polymer Rheology (Capillary and Torque Rheometry), TGA, DSC, X-ray Diffraction, Mechanical Testing, Metallography, Microstructure Analysis

- Software Skills: Solidworks, PTC Creo, Digimat-AM Simulations, Minitab, MicrosoftOffice 